\title{
ADVANCED RESERVOIR CHARACTERIZATION IN THE ANTELOPE SHALE TO ESTABLISH THE VIABILITY OF CO2 ENHANCED OIL RECOVERY IN CALIFORNIA'S MONTEREY FORMATION SILICEOUS SHALES
}

Annual Report

February 7, 1997 - February 6, 1998

By

Michael F. Morea

$$
\begin{aligned}
& \text { DEOENGEO } \\
& \text { JUL } 211988 \\
& \text { OSTI }
\end{aligned}
$$

June 1998

Performed Under Contract No. DE-FC22-95BC14938

Chevron USA Production Company Bakersfield, California

\section{National Petroleum Technology Office U. S. DEPARTMENT OF ENERGY Tulsa, Oklahoma}




\section{DISCLAIMER}

This report was prepared as an account of work sponsored by an agency of the United States Govemment. Neither the United States Government nor any agency thereof, nor any of their employees, makes any warranty, expressed or implied, or assumes any legal liability or responsibility for the accuracy, completeness, or usefuiness of any information, apparatus, product, or process disclosed, or represents that its use would not infringe privately owned rights. Reference herein to any specific commercial product, process, or service by trade name, trademark, manufacturer, or otherwise does not necessarily constitute or imply its endorsement, recommendation, or favoring by the United States Govemment or any agency thereof. The views and opinions of authors expressed herein do not necessarily state or reflect those of the United States Government.

This report has been reproduced directly from the best available copy.

Available to DOE and DOE contractors from the Office of Scientific and Technical Information, P.O. Box 62, Oak Ridge, TN 37831; prices available from (615) 5768401 .

Available to the public from the National Technical Information Service, U.S. Department of Commerce, 5285 Port Royal Rd., Springfield VA 22161 


\section{DISCLAIMER}

Portions of this document may be illegible electronic image products. Images are produced from the best available original document. 
$\mathrm{DOE} / \mathrm{BC} / 14938-8$

Distribution Category UC-122

Advanced Reservoir Characterization In The Antelope Shale To Establish The Viability Of CO2 Enhanced Oil Recovery In California's Monterey Formation Siliceous Shales

By

Michael F. Morea

June 1998

Work Performed Under Contract No. DE-FC22-95BC14938

Prepared for

U.S. Department of Energy

Assistant Secretary for Fossil Energy

Gary Walker, Project Manager

National Petroleum Technology Office

P.O. Box 3628

Tulsa, OK 74101

Prepared by:

Chevron USA Production Company

5001 California Avenue

Bakersfield, California 93309 



\section{Table of Contents}

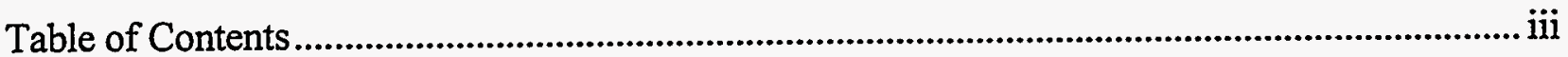

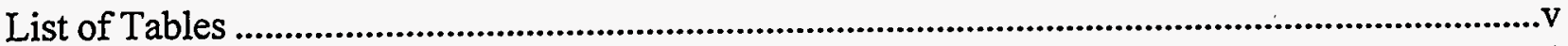

List of Figures ......................................................................................................................... vi

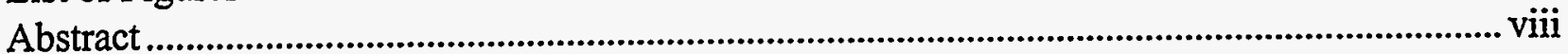

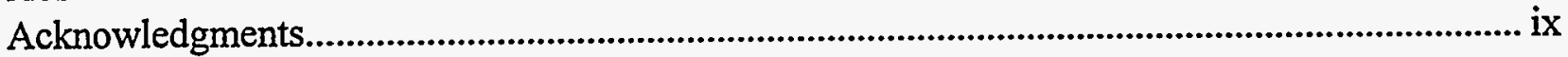

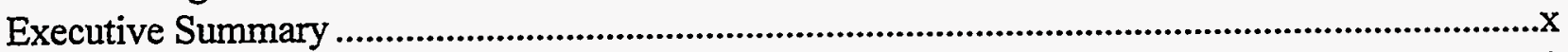

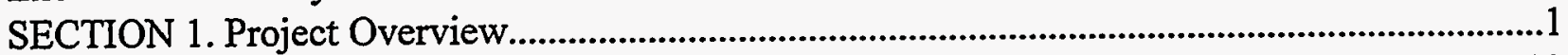

SECTION 2. Discussion of Selected Tasks....................................................................................13

Regional Tectonic Synthesis of the Southern San Joaquin Basin..................................................14

Part I. Synopsis of Previous Investigations.................................................................................14

Part II. Structural Analysis and Natural Fracture Detection .......................................................38

Crosswell Imaging in the Buena Vista Hills..............................................................................55

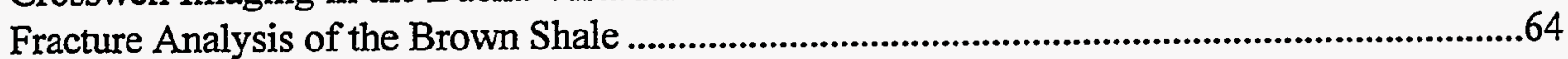

Natural Fractures in the Brown and Antelope Shales ...............................................................74

Petrographic and Confocal Analyses .......................................................................................83

A Mineral Model and Inorganic Geochemistry of the Brown and Antelope Shales ....................93

Complex Lithologic Analysis ................................................................................................111

3D Earth Model...................................................................................................................117

CO2 Coreflood Experiments.................................................................................................126

SECTION 3. Summary of Technical Progress ..............................................................................131

Characterize the Brown Shale and Antelope Shale ....................................................................132

Collect and Analyze Reservoir Data from Existing Wells ........................................................132

New and Old Tech. Production Logging ...............................................................................132

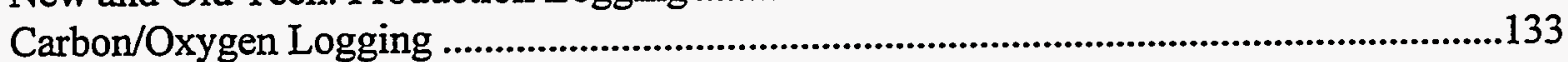

Perform Core Analysis..................................................................................................134

Wettability Testing - Laboratory ......................................................................................134

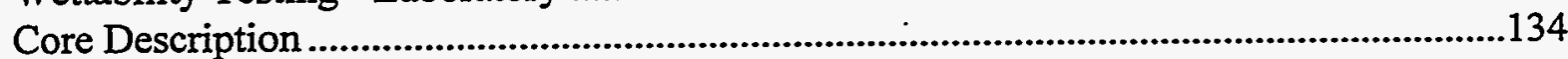

Produced and Extracted Oil Geochemical Fingerprinting ......................................................134

Mineralogical Analysis ..............................................................................................135

Mercury Porosimetry .................................................................................................136

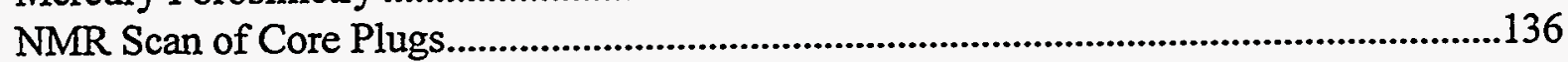

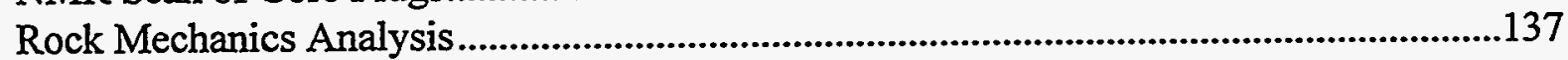

Specific Liquid Permeability ................................................................................................137

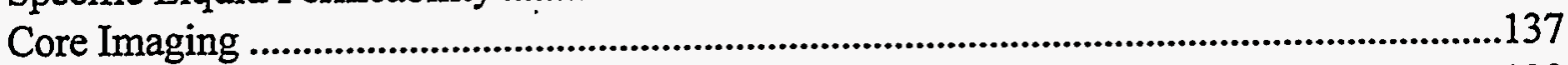

Fracture Characterization...............................................................................................138

Shear-Wave Birefringence VSP ........................................................................................138

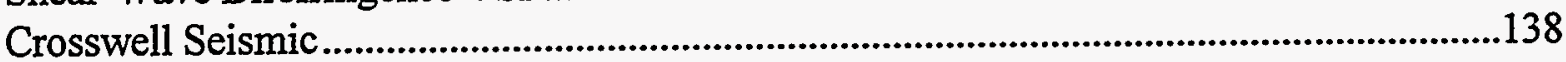

High Resolution Structural Mapping .............................................................................138

Core Fracture Analysis .....................................................................................................138 


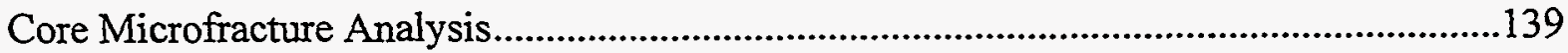

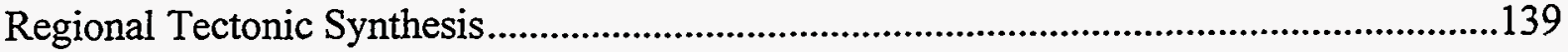

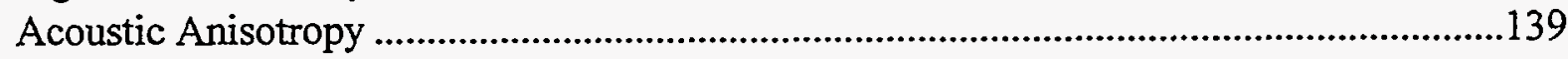

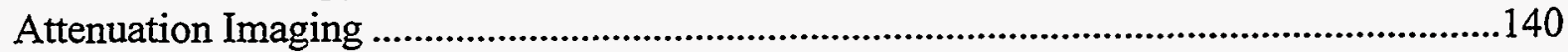

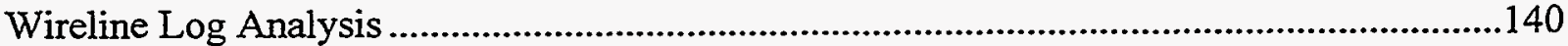

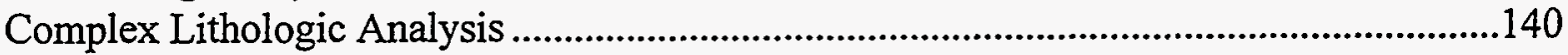

Characterize Flow Units .........................................................................................140

Define Hydraulic Flow Units...............................................................................140

Develop Flow Unit Transforms ................................................................................140

Develop 3D Earth Model ................................................................................................141

Geostatistically Populate Model ..............................................................................141

Visualize Reservoir Property Distribution.................................................................141

Preliminary Preparation for CO2 Injection.......................................................................141

Re-evaluate Pre-1994 Production Performance .....................................................................141

Analyze Recovery, Pressure and Saturation Data......................................................141

Initiate Fluid Characterization and Lab Displacement Tests .............................................141

Phase Behavior on CO2 - Oil Systems ..................................................................141

Perform CO2 Corefloods at Reservoir Conditions ..........................................................142

Pre-injection Evaluation of the Target Drive Zone.............................................................142

Perforate and Evaluate Drive Interval..............................................................142

Technology Transfer .....................................................................................................142

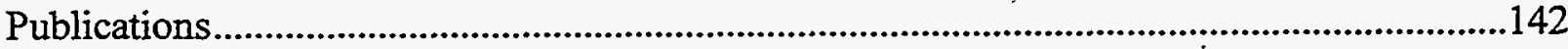

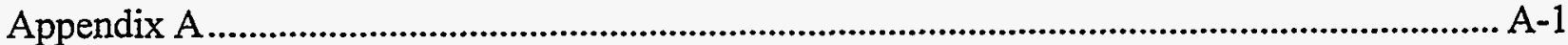

Graphical Core Description, 653Z-26B Buena Vista Hills.............................................. A-1 


\section{List of Tables}

Table 2e.1. Summary of fracture-derived parameters.......................................................................76

Table 2e2. Fracture collection spreadsheet ....................................................................................77

Table 2f.1. Thin section sample summary ...................................................................................89

Table 2f2. Thin section microfracture characterization .................................................................90

Table 2f.3. Porosity characterization by confocal microscopy ......................................................91

Table 2g.1. Chemical compositions of significant minerals.......................................................100

Table 2g.2. Log parameters ("Mineral Endpoints") for significant minerals ..............................101

Table 2g.3. ESTMIN mineralogy of a selected interval in the Antelope Shale...........................102

Table 2i.1. List of Buena Vista Hills cored wells .........................................................................121

Table 3.1. Wettability analyses on core plugs ............................................................................147

Table 3.2. Mineralogy determined by Mineralog method ............................................................148

Table 3.3. Mercury injection data summary for siliceous Brown Shale........................................151

Table 3.4. Mercury injection data summary for siliceous Antelope Shale ..................................152

Table 3.5. Mercury injection data summary for Antelope Shale sand........................................153

Table 3.6. Results of NMR core plug analyses..........................................................................154

Table 3.7. Ultrasonic velocity and dynamic moduli summary .....................................................154

Table 3.8. Summary of specific liquid permeability....................................................................155

Table 3.9. Lithology determinations from Imagelog analysis ......................................................156

Table 3.10. Results of the relative permeability tests ......................................................................157 


\section{List of Figures}

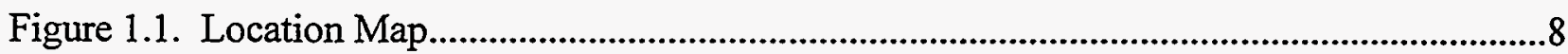

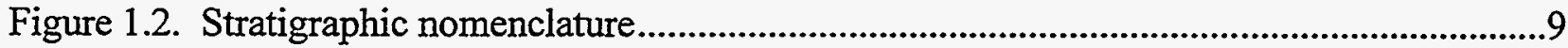

Figure 1.3. Structure contour map on the top of the Antelope Shale............................................10

Figure 1.4. Structure contour map on the top of the Antelope Shale, Section 26B-T31S/R23E, Buena Vista Hills Field ....................................................11

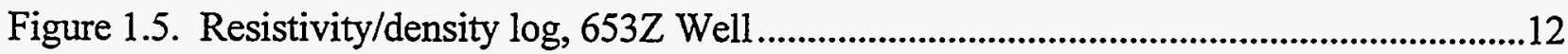

Figure 2a.1. Regional map of southern San Joaquin Valley, California........................................36

Figure 2a.2. Index map of central California showing structural regions of the San Joaquin Valley ...........................................................................................37

Figure 2b.1. Map of structural compartments, Buena Vista Hills anticline...................................54

Figure 2c.1. Structure contours on top of Antelope Shale, West Dome .........................................60

Figure 2c.2. Combined velocity-reflection images along dip..........................................................61

Figure 2c.3. Combined velocity-reflection images along strike ...............................................62

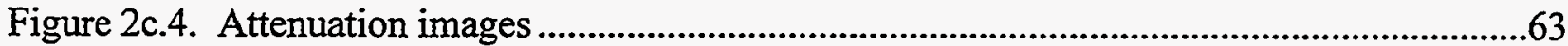

Figure 2d.1. Location of the Chico Martinez Creek outcrop .......................................................69

Figure 2d.2. Zone of en echelon fractures, 653Z Well ..................................................................70

Figure 2d.3. Strike of bedding and orientation of individual veins within en echelon zones, 653Z Well ......................................................................70

Figure 2d.4. Results of permeability test on a sigmoidal vein zone, $653 \mathrm{Z}$ Well ...........................71

Figure 2d.5. Sigmoidal vein, 653Z Well...............................................................................72

Figure 2d.6. Sample from the Belridge Member of the Chico Martinez Creek outcrop ...............73

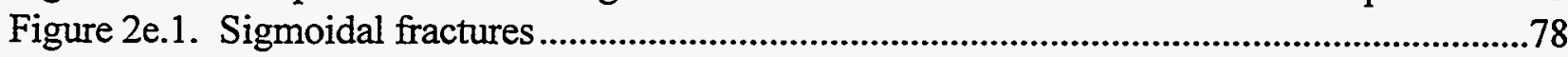

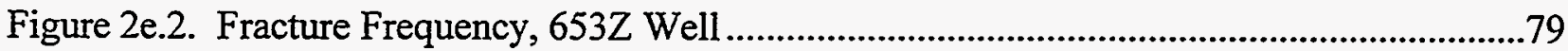

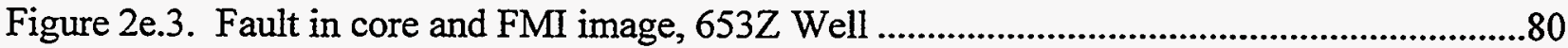

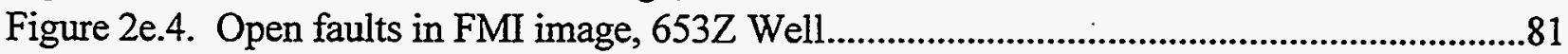

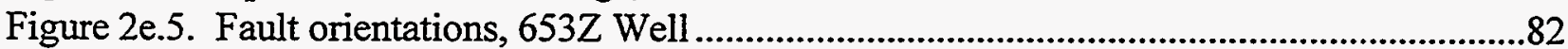

Figure 2f.1. Photomicrograph, Brown Shale, 4041.65 feet, $653 Z$ Well .......................................92

Figure 2g.1. Chemical composition of feldspar grains, 653Z Well ............................................103

Figure 2g.2. Histograms of plagioclase feldspar compositions, 653Z Well ...............................104

Figure 2g.3. Cross plots of predicted versus observed uranium, 653Z Well ...............................105

Figure 2g.4. Abundances of selected minerals vs depth, 653Z Well.........................................106

Figure 2g.5. Classification of siliceous shale lithologies.........................................................107

Figure 2g.6. Lithology of siliceous shale samples from $4100-4180$ feet, $653 Z$ Well.................108

Figure 2g.7. Lithology of siliceous shale samples from 4225-4305 feet, 653Z Well..................109

Figure 2g.8. Lithology of siliceous shale samples from $4480-4560$ feet, $653 Z$ Well..................110

Figure 2h.1. Schlumberger ELAN mineral model from 653Z Well logs ...................................113

Figure 2h.2. Cross plot of volume of quartz+feldspar, ELAN versus ESTMIN, 653Z Well 
Figure 2h.3. Cross plot of volume of clay+pyritetorganic matter, ELAN versus ESTMIN, 653Z Well....................................................................115

Figure 2h.4. Cross plot of volume of Opal-CT, ELAN versus ESTMIN, 653Z Well .................116

Figure 2i.1. Cross plot of core porosity versus Vshale, 653Z Well .............................................122

Figure 2i.2. Cross plot of drill stem test permeability versus Vshale, $653 \mathrm{Z}$ Well.......................122

Figure 2i.3. Cross plot of initial oil saturation versus porosity, $653 \mathrm{Z}$ Well ..................................123

Figure 2i.4. ID neural net analysis using FaciesFinder .............................................................124

Figure 2i.5. Reservoir characterization workflows .....................................................................125

Figure 2j.1. A schematic of the mixed lithology core elements ..............................................128

Figure 2j.2. A flow diagram of the $\mathrm{CO} 2$ displacement apparatus...............................................128

Figure 2j.3. Pressure in the produced gas tank as a function of time...........................................129

Figure 2j.4. Pressure drop across the mixed lithology core as a function of time .......................129

Figure 2j.5. Oil production from $\mathrm{CO} 2$ injection .............................................................130

Figure 2j.6. Total oil production from the high pressure (2500 psi) $\mathrm{CO} 2$ flood..........................130

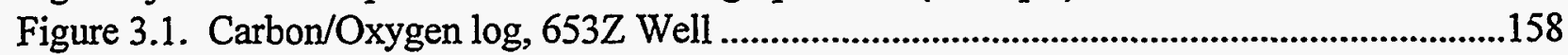

Figure 3.2. Antelope Shale core photograph, 653Z Well ...............................................................159

Figure 3.3. Antelope Shale core photograph, 4689 feet, $653 Z$ Well ............................................160

Figure3.4. Graph showing mercury injection curve data from a typical siliceous shale from the Brown Shale, $653 Z$ Well.......................................161

Figure 3.5. Pore size histogram of a typical siliceous from the Brown Shale, $653 \mathrm{Z}$ Well ..........162

Figure 3.6. Graph showing mercury injection curve data from a typical siliceous shale from the Antelope Shale, 653Z Well...................................163

Figure 3.7. Pore size histogram of a typical siliceous from the Antelope Shale, $653 Z$ Well .....164

Figure 3.8. Graph showing mercury injection curve data from a typical sand from the Antelope Shale, $653 Z$ Well

Figure 3.9. Pore size histogram of a typical sand from the Antelope Shale, $653 Z$ Well .............166

Figure 3.10. Results of the acoustic anisotropy measurements, $653 \mathrm{Z}$ Well 


\section{Abstract}

The Buena Vista Hills Field is located about 25 miles southwest of Bakersfield, in the San Joaquin Valley (SJV), California. The Antelope Shale zone was discovered at the Buena Vista Hills in 1952, and has since been under primary production. Little research was done to improve the completion techniques during the development phase in the 1950s, so most of the wells are completed with about 1000 feet of slotted liner.

The primary objective of this research is to conduct advanced reservoir characterization and modeling studies in the Antelope Shale reservoir. Characterization studies will be used to determine the technical feasibility of implementing a $\mathrm{CO} 2$ enhanced oil recovery project in the Antelope Shale in Buena Vista Hills Field. The proposed pilot consists of four existing producers on 20 acre spacing with a new 10 acre infill well (653Z) drilled as the pilot $\mathrm{CO}_{2}$ injector. Most of the reservoir characterization during Phase I of the project will be performed using data collected in the pilot pattern wells.

This is the second annual report of the project. It covers the period February 7, 1997 to February 6,1998 . During this period the following tasks have been completed: laboratory wettability; specific permeability; mercury porosimetry; acoustic anisotropy; rock mechanics analysis; core description; fracture analysis; digital image analysis; mineralogical analysis; hydraulic flow unit analysis; petrographic and confocal thin section analysis; oil geochemical fingerprinting; production logging; carbon/oxygen logging; complex lithologic log analysis; NMR T2 processing; dipole shear wave anisotropy logging; shear wave vertical seismic profile processing; structural mapping, and regional tectonic synthesis.

Crosswell seismic was run in the pilot wells and attenuation imaging is proceeding. Both the $3 \mathrm{D}$ earth model and $\mathrm{CO} 2$ coreflooding are close to completion. Lastly a potential target interval has been identified and plans are underway to hydraulically fracture and complete the $653 \mathrm{Z}$ well.

Noteworthy technological successes for this reporting period include: 1) First (ever) high resolution, crosswell reflection images of SJV sediments; 2) first successful application of the TomoSeis acquisition system in siliceous shales; 3 ) first detailed reservoir characterization of SJV siliceous shales; 4) first mineral based saturation algorithm for SJV siliceous shales, and 5) first $\mathrm{CO} 2$ coreflood experiments for siliceous shale.

Preliminary results from the $\mathrm{CO} 2$ coreflood experiments (2500 psi) suggest that significant oil is being produced from the siliceous shale. This stage of the experiment is in its $5^{\text {th }}$ week, and oil recovery continues. 


\section{Acknowledgments}

I would like to thank the following individuals for their help and participation on this project: Greg Bender, Mark Emanuele, Kent Gailey, Charles Horsch, Rong Hwang, Dale Julander, Aleks Marasigan, Rick Mollenkopf, Pat Perri, Deborah Piceno, Steve Smith, and Tom Zalan of Chevron USA; Angela Barker, Dave Baskin, Dale Beeson, Alden Carpenter, Bob Langan, Karen De Louraille, Ed Dezabala, Chuck Magnani, Sharon Puckett, Ray Tang, Julian Thorne, Don Winterstein, and Dengen Zhou of Chevron Petroleum Technology Company; Bruce Bilodeau of Chevron Overseas Petroleum Company; Allen Britton, Frank Ene, Dan Fargo, Mike Long, and Jeff Smith of Core Laboratories; Stan Denoo, Chris Presnyk, and Bill Scanlan, of Schlumberger Wireline Services; Atilla Aydin, Sneha Dholakia, Jerry Harris, and Jud Jacobs of Stanford University; Bob Bereskin and Barbara Marin of TerraTek; David Campagna, Ned Mamula, and Vello Kuuskraa of Advanced Resources International; David Decker of Basin Energy Development; Theresa Knox and Mike McKee. 


\section{Executive Summary}

The Monterey Formation siliceous shale in California represents a major but largely underdeveloped domestic oil resource. The Monterey Formation in the San Joaquin Valley (SJV), locally called the Antelope Shale, contains an estimated 7 billion barrels of oil in place (OIP). Whereas the Monterey Formation siliceous shales that underlie much of California's coastal area and offshore hold nearly 3 billion barrels. Thus, the focus of this project is the 10 billion barrel (OIP) siliceous shale resource.

Siliceous shale is an unusual reservoir, both because it is found in only a few hydrocarbon basins in the world and because its production characteristics are unlike any other type of reservoir rock. It is composed primarily of diagenetically altered diatomaceous (biogenic silica) mudstone. It has relatively high porosity but very low permeability and it must be naturally or artificially fractured to produce oil at economic rates.

Buena Vista Hills Field was picked as the location for this project. The Antelope Shale reservoir, discovered in 1952, has produced only 9 million bbl of oil representing $6.5 \%$ of the estimated 130 million bbl of original-oil-in-place. The current status of the reservoir indicates that it is producing at $40 \%$ of its original reservoir energy. In addition, production from wells in this field, and in the Antelope Shale in general, has been declining, and the wells are in danger of being abandoned. Several methods have been tried to improve the reservoir productivity. Technologies such as waterflooding, acid treatments, and induced fractures were implemented and, although some were proven successful, the overall oil recovery from the Antelope Shale still remains low at $6.5 \%$.

This project represents the first comprehensive characterization of siliceous shale in the San Joaquin basin in the public domain using advanced coring, logging, fracture characterization and modeling. It is also potentially the first $\mathrm{CO} 2 \mathrm{EOR}$ flood conducted in the siliceous shale, and it is the first project to integrate advanced seismic and other injection profiling tools to monitor fluid flow through this fractured reservoir.

The primary objective of this project is to increase oil recovery from the Monterey/Antelope siliceous shale. The project goals are to 1) fully characterize the reservoir storage, flow paths and other key properties of the Antelope Shale zone, 2) design and pilot test the optimum $\mathrm{CO} 2$ EOR flood for the Antelope Shale to achieve good sweep efficiency, and 3) transfer the reservoir characterization and EOR technology to other Antelope Shale zone producers.

The research consists of four primary work processes: Reservoir Matrix and Fluid Characterization; Fracture Characterization; Reservoir Modeling and Simulation; and CO2 Pilot Flood and Evaluation. The first phase of the project will focus on the application of a variety of advanced reservoir characterization techniques to determine the production characteristics of the Antelope Shale reservoir. Reservoir models based on the results of the characterization work will be used to evaluate how the reservoir will respond to secondary recovery and EOR 
processes. The second phase of the project will focus on implementation and evaluation of an advanced enhanced oil recovery (EOR) pilot.

During the first reporting period the Chevron $653 \mathrm{Z}$ well was drilled in Section 26B-T31S/R23E in the Buena Vista Hills field, Kern County, California during July, 1996. . The Monterey Formation equivalent Brown and Antelope Shales were continuously cored, the zone was logged with a comprehensive suite of wireline logs, and the well was cased to a total depth of $4907 \mathrm{ft}$. Core recovery was $99.5 \%$. Core analyses that were performed included: Dean Stark porosity, permeability and fluid saturations, field wettability, anelastic strain recovery, spectral core gamma, profile permeametry, and photographic imaging.

This is the second annual report of the project. It covers the period February 7, 1997 to February 6,1998 . During this period the following analyses have been completed: laboratory wettability, specific gas, oil and water permeability, mercury porosimetry, acoustic anisotropy, rock mechanics analysis, core description/fracture analysis, Imagelog analysis, mineralogical analysis, hydraulic flow unit analysis, petrographic and confocal thin section analysis, oil geochemical fingerprinting, production logging, carbon/oxygen logging, mineral-based error minimization modeling (ELAN), NMR T2 processing, dipole shear wave anisotropy logging, shear wave vertical seismic profile processing, structural mapping, and regional tectonic synthesis.

To date, the project has had a number of technological successes: 1) first (ever) high resolution, crosswell reflection images of SJV sediments; 2) first successful application of the TomoSeis acquisition system in siliceous shales; 3 ) first detailed reservoir characterization of SJV siliceous shales; 4) first mineral based saturation algorithm for SJV siliceous shales; 5) first $\mathrm{CO} 2$ coreflood experiments for siliceous shale; and 6) improved core handling procedures. Preliminary results from the $\mathrm{CO} 2$ coreflood experiments $(2500 \mathrm{psi})$ suggest that significant oil is being produced from the siliceous shale. This stage of the experiment is in its $5^{\text {th }}$ week, and oil recovery continues.

With regards to current work, the reservoir characterization of the Brown and Antelope siliceous shales is nearing completion. New core, well log, seismic and engineering data are being analyzed and incorporated into a comprehensive 3D geologic model. A potential drive zone in the $653 Z$ well has been identified and will be hydraulically fractured in the First Quarter, 1998. Also laboratory $\mathrm{CO} 2$ corefloods are nearing completion, and the data, along with the geologic model, will form the input to the reservoir simulation. Work is under way for technology transfer at the following: AAPG Annual Convention in Salt Lake City, UT, SPWLA Annual Convention in Keystone CO, SPE Archie Conference, Kerrville, TX, and SPE Western Regional Meeting in Bakersfield, CA. A booth also will be set up at the AAPG Pacific Section Meeting in Ventura, CA displaying various technologies used in the study. Lastly, the project continues to be on schedule and within budget. 
SECTION 1.

Project Overview 


\section{PROJECT OVERVIEW}

\section{Introduction}

Siliceous shale is an unusual reservoir for hydrocarbons, both because it is found in only a few hydrocarbon basins in the world and its production characteristics are unlike any other type of reservoir rock. It is composed of the diagenetically altered silica shells of ancient diatoms, a planktonic plant that thrived in the coastal waters of western North America in the Miocene epoch. Siliceous shale has relatively high porosity but very low permeability so that must be naturally or artificially fractured to produce oil at economic rates.

The Monterey Formation siliceous shale in California represents a major but largely underdeveloped domestic oil resource. The part of the Monterey Formation in the San Joaquin Valley, locally called the Antelope Shale, contains an estimated 7 billion barrels of oil in place (Chevron, 1994). The Monterey Shale that underlies much of California's coastal area and offshore holds nearly 3 billion barrels. Monterey Formation diatomite (i.e., Belridge Diatomite), a geologically and depositionally related siliceous sedimentary rock is not included in these resource estimates because it presents distinctly different production challenges. Thus, the focus of this project is the 10 billion barrel (OOIP) siliceous shale resource. Particular emphasis is placed on the lower permeability, larger resource located in the San Joaquin Valley, specifically in the Buena Vista Hills, Elk Hills, Lost Hills, Asphalto, Midway Sunset, Railroad Gap, and other smaller fields (Figure 1.1).

The operation of a Class III research and field demonstration project on the Antelope Shale is most timely. The wells in the Antelope Shale in many fields in the southern San Joaquin Valley have been declining for decades and are in danger of being abandoned. The recent well stimulation efforts by Chevron at Buena Vista Hills have "bought some time" for the Antelope Shale to be shown as a candidate for improved recovery and future commercial development.

This project represents the first comprehensive characterization of siliceous shale in the San Joaquin basin in the public domain using advanced coring, logging, fracture characterization and modeling. It is also potentially the first $\mathrm{CO} 2$ enhanced oil recovery (EOR) flood to be conducted in the siliceous shale, and it will be the first project to integrate advanced seismic and other injection profiling tools to monitor fluid flow through this fractured reservoir. Equally as important, should the project demonstrate commercial viability, it may open up California light oils to $\mathrm{CO} 2$ based EOR. Currently, sufficient $\mathrm{CO} 2$ can be obtained from Chevron's gas plants for 5 MMCFGD of $\mathrm{CO} 2$ supply. While additional $\mathrm{CO} 2$ may be obtained from other gas plants and from additional industrial sources, the large scale application of this process will call for pipeline based CO2 from the Rockies, the San Juan Basin or Arizona. While these sources are nearly as close as California as they are to West Texas oil fields currently being flooded with $\mathrm{CO} 2$, the major hurdle is to demonstrate a sufficiently large, economic use for $\mathrm{CO} 2$ in the California basins to justify the building of a new pipeline, or dedication of a current pipeline for low cost transmission of $\mathrm{CO} 2$. 
The overall scope of the project is to use advanced reservoir characterization on the Antelope Shale (including the overlying, locally siliceous Brown Shale) in one newly drilled and cored well in the West Dome area of the Buena Vista Hills Field. After characterizing the formation and determining the most appropriate enhanced oil recovery technique, a pilot demonstration enhanced oil recovery project will be installed using the four surrounding wells as producers and the newly drilled well as an injector.

The first step is to apply a variety of advanced reservoir characterization techniques to determine the reservoir and production characteristics of the Brown and Antelope shales. These characteristics will be determined by innovative core and log analyses, laboratory core floods, and well tests, which will be used to build a reservoir model to simulate how the reservoir will respond to the application of $\mathrm{CO} 2$ EOR processes. The second step will be to design and implement an advanced CO2 EOR pilot demonstration in the West Dome part of the field to evaluate how effective the process is in increasing the recovery of oil.

The West Dome area of the Buena Vista Hills Field is an excellent site for this reservoir characterization and EOR pilot project. The field has many features common not only to California siliceous shale reservoirs but many slope basin clastic reservoirs. It has been under primary production (slotted liner completions) for a long time, the reservoir pressure is low, there is a long interval of pay, and oil recovery has been low.

\section{Project Objectives}

Despite Chevron's numerous attempts to diagnose the Brown and Antelope shales in Buena Vista Hills in the 1960s, little is known about the production characteristics of siliceous shale. Siliceous shale is not a typical clastic reservoir: it is thinly laminated, has tiny pore throats, low permeability, and may or not be fractured. Little modern reservoir characterization information is available in West Dome because only 3 new wells have been drilled there since 1966. Advanced reservoir characterization tools need to be applied to understand the reservoir rock, its storage and flow paths, and its production mechanisms.

The reservoir characterization proposed here will be the first truly comprehensive modern reservoir characterization in the public domain performed on siliceous shale in the San Joaquin Valley. Each analytical tool has a purpose and will answer one or more questions about how the reservoir produces oil and gas and how it would react to enhanced recovery processes. The advanced reservoir characterization techniques planned will be coordinated within the four main work processes: reservoir matrix and fluid characterization; fracture characterization; reservoir modeling and simulation, and $\mathrm{CO}_{2}$ pilot flood and evaluation.

The objectives of this project for increasing oil recovery from the Monterey/Antelope siliceous shale are threefold: 
1. To fully characterize the reservoir storage, flow paths and other key properties of the Brown and Antelope shales that control current oil recovery and that impact the success of the proposed EOR technique.

2. To design and pilot test the optimum EOR recovery process for the Antelope Shale to achieve good sweep efficiency and favorable oil displacement from small pore throat rock.

3. To transfer the reservoir characterization and EOR technology to other Antelope Shale producers.

\section{Reservoir History}

The Antelope Shale zone was discovered at the Buena Vista Hills field in 1952, and has been under primary production for the last 45 years. Since discovery, 161 wells have been drilled through the Antelope Shale. The Brown and Antelope shales (Antelope Shale Zone) was unitized in the East Dome area in 1954 and is currently operated by Texaco. Of the 52 wells in the West Dome part of the field, 20 are currently producing, 31 are shut-in, and 1 is abandoned. Average per well production is about $20 \mathrm{BOEPD}$, boosted recently from a low of 6 BOEPD. Average reservoir pressure is about $650 \mathrm{psi}\left(-3400 \mathrm{ft}\right.$ VSS datum). Oil gravity ranges from $25^{\circ}$ to $40^{\circ} \mathrm{API}$, but averages about $30^{\circ} \mathrm{API}$ in the pilot area. The gross pay interval averages about $800 \mathrm{ft}$. Recovery to date has been about 9 MMBO. With the estimated $130 \mathrm{MMB}$ of original oil in place, $93 \%$ of the oil in West Dome is still trapped in the reservoir.

The Antelope siliceous shale at the Buena Vista Hills field suffers from three primary problems that cause low recovery, current low production, and hamper any secondary recovery attempts. These producibility problems are common to all other siliceous shale reservoirs, with the exception of problem \#1 (low pressure), since undeveloped siliceous shale reservoirs usually have high initial reservoir pressure. The three producibility problems are listed below:

1. The reservoir has low pressure (650 psi), low permeability $(0.08 \mathrm{md})$, and the primary recovery mechanism is solution gas drive. At Buena Vista Hills, the reservoir pressure decreased rapidly until it was below bubble point after only 6 years of production. These factors combine to cause low recovery (currently $6.5 \%$ OOIP). We need to be able to displace oil from small pores and add energy to the reservoir to increase recovery.

2. Siliceous shale is a poorly understood reservoir because of complex lithology, unknown fracture patterns, low permeability matrix, interbedded sand laminae, and unknown formation damage. It is unknown how to determine "sweet spots" from log or core data for limited interval completion. It is also unknown how fractures or formation damage affect current production, although acid stimulation can improve productivity. The technology challenge is to develop a working reservoir model that will enable producers to drill, complete, and stimulate wells to maximize production at the lowest cost. 
3. Inadequate reservoir characterization has led to limited ability to manage the siliceous shale reservoir, as a result, many mature siliceous shale fields are considered "stripper" properties, ready for abandonment. Because the siliceous shale is still so poorly understood, the current depletion strategy is often only a variation of "harvest the investment" strategy, where operators stop spending any money on siliceous shale wells. In addition, operators of properties that have siliceous shale are often hesitant to fully develop this asset because of geologic and technical uncertainties resulting from inadequate reservoir characterization.

\section{Stratigraphic Nomenclature}

Chevron's common usage for Upper Miocene stratigraphy (Figure 1.2) distinguishes the interval between Tmc (or N Point) and P Point as the Brown Shale, and the interval between P Point and P4 Point as the Antelope Shale. Brown Shale is equivalent to the "N Shales" at Elk Hills. We find that the term Brown Shale is useful to distinguish the production characteristics of the intervals above and below P Point so it will be used throughout this report. Upper Antelope refers to the interval from P Point to P2a Point, and lower Antelope the interval from P2a Point to P4 Point. The term "Antelope Shale Zone" refers to the Brown Shale and Antelope Shale.

\section{Depositional Model}

In the late Miocene epoch, submarine channels were common on the southwest side of the Maricopa depocenter (Webb, 1981). Many of the channels were fed with sand derived from Gabilan Range granitic rock on the southwest side of the San Andreas Fault. At that time, the Gabilan Range was about 150 miles south of its present location near the town of Salinas. The submarine channels were the path that turbidity currents followed to carry material from the coastal shelf to the basin floor. The coarsest material was deposited in channels on submarine fans, which formed the Stevens turbidite sands. The channels were located primarily in the low spots between submarine highs present at the time. The submarine highs were the surface expression of anticlines actively forming in the basin due to tectonic stress localized along the San Andreas Fault. The anticlines continued to grow throughout the Pliocene, later becoming anticlinal oil fields like the Buena Vista Hills and the 29R and Main structures at Elk Hills.

The basin was restricted, so tidal and storm currents were at a minimum, and much of the detritus from surrounding land areas was trapped on nearshore shelves (Graham and Williams, 1985). The water apparently was nutrient-rich, providing an ideal environment for diatom growth, so siliceous diatoms tests were constantly being deposited throughout the southwest part of the basin.

Turbidity currents periodically swept down the channels, depositing sand in the submarine fans. The fine material in the turbidity current consisting of diatoms, very fine sand, silt, and clay was injected into the water column above the current. This fine detritus eventually settled out of suspension in the basin near the channels, forming siliceous graded beds. Subsequent turbidity currents eroded the siliceous graded beds that were deposited in the channels, leaving them preserved primarily on the submarine highs. Only very infrequently was sand deposited on the 
submarine highs when a channel formed near their base or an exceptionally large turbidity current occurred. The Antelope Shale built up over time as a thick sequence of these thin graded siliceous distal turbidite beds interbedded with hemipelagic siliceous deposits. Most of the anticlinal submarine highs were within the oxygen-minimum zone, which discouraged bioturbation and preserved the bedding and organic material (Graham and Williams, 1985).

\section{Structure, Stratigraphy, and Lithology}

The Buena Vista Hills structure (Figure 1.3) is an elongated doubly-plunging anticline with a northwest-southeast trend containing two structural culminations, referred to as East Dome (Honolulu Anticline) and West Dome (United Anticline). The crests of the two domes are 3.5 miles apart, with East Dome 240 feet structurally higher than West Dome. The pilot area is located just north of the crest of the anticline in Section 26B (Figure 1.4). The Antelope Shale Zone, as defined by the Antelope Shale Zone Unit, extends from the Tmc marker to P4 Point. The reservoir consists primarily of upper Miocene siliceous shale belonging to the Monterey Formation, locally known as the Brown Shale, and Antelope Shale. Thin $(1 / 2$ to $25 \mathrm{~cm})$ interbedded turbidite sands are common in the Antelope Shale, representing up to $4 \%$ of the reservoir volume. The lateral stratigraphic continuity across the Buena Vista Hills field is legendary where channel turbidite sands are not present.

The reservoir consists of up to 1325 feet of hard, brownish gray to gray siliceous shale Figure 1.5 shows a $\log$ from the 653Z-26B well and stratigraphic markers. The Brown Shale extends from the Top Miocene Cherts (TMC) marker to P Point. This 350-500 foot interval is essentially gas productive. Below the Brown Shale, is the Antelope Shale interval (P Point to P4). The best oil production comes from the $\mathrm{Pa}$ to $\mathrm{P} 2 \mathrm{a}$ zone. Below $\mathrm{P}$ Point, there are many thin sand laminae. Sand thickness usually ranges from $1 \mathrm{~mm}$ to $25 \mathrm{~cm}$. Sand represents about $4 \%$ of the reservoir thickness from TMC to $\mathrm{P} 2$ and about $6 \%$ from $\mathrm{P}$ to $\mathrm{P} 2$.

Examination of the $653 \mathrm{Z}-26 \mathrm{~B}, 522 \mathrm{~A}-26 \mathrm{~B}$, and $621-25 \mathrm{~B}$ core has revealed that the Antelope Shale reservoir consists primarily of thin $(1-5 \mathrm{~cm})$ graded beds of siliceous shale intercalated with discrete turbidite sand beds and hemipelagic beds of very finely laminated siliceous shale. Each siliceous shale bed grades upward from either sand, silt, or silty siliceous shale at the base to porcelanite at the top. The basal contact of each graded bed is commonly eroded.

\section{Fracture System}

The fracture system is not believed to be pervasive because of the low average permeability of $0.64 \mathrm{md}$ calculated from pressure build-up analyses, small drainage radii of 76 to 554 feet calculated from the pressure build-ups, and the unfractured nature of the bulk of the core. Core recoveries in Buena Vista Hills are typically over $95 \%$, the core in this study recovered $99.5 \%$ of the cored interval. In contrast, core recoveries in the Point Arguello Field in Monterey Formation offshore California were less than $5 \%$ in the highly fractured part of the reservoir. However, there is ample evidence of significant fracture permeability in Buena Vista Hills Field. 
For example, well 555-6D was acidized in 1957 and subsequently wells 505-5D, 551-7D, and 501-8D showed an abrupt increase in oil production. Well 544-26B was drilled in 1957 and lost circulation in the Antelope Shale. Six days later, drilling mud was produced in wells 523-26B (2150 feet away), 543-26B (800 feet away), 553-26B (1130 feet away), 564-26B (1600 feet away), 566-26B (2400 feet away), and 556-26B (1900 feet away), skipping wells 554-26B and 555-26B. Fracturing occurs at all scales from coffee-ground-like fractured rock, to rubble, to fractures spaced about every six feet. Most of the fractures observed in core and microresistivity images are concentrated in dolomite beds.

Small scale "fractures" related to diagenesis are evident in core throughout the Brown and Antelope Shales. Williams (1982) described similar features as fluid escape fractures, which were formed when the sediment was compacting. They are typically 1 to $2 \mathrm{~cm}$ long, less than $1 / 2 \mathrm{~mm}$ thick, filled with material from adjacent beds, and parallel to each other. Core analysis in well $621-25 \mathrm{~B}$ has found that the rock matrix is 10 times more permeable parallel to these fractures than perpendicular to them (Chevron, 1994).

\section{References}

Chevron, 1994, Advanced reservoir characterization the Antelope Shale to establish the viability of $\mathrm{CO} 2$ enhanced oil recovery in California's Monterey siliceous shales, Volume IIA, U. S. Department of Energy, Class III Oil Program Proposal.

Graham, S. A., and Williams, L. A., 1985, Tectonic, depositional, and diagenetic history of Monterey Formation (Miocene), central San Joaquin basin, California: American Association of Petroleum Geologists Bulletin, v. 69, p. 385-411.

Snyder, W. S., 1987, Structure of the Monterey Formation, stratigraphic diagenetic, and tectonic influences on style and timing, in R. V. Ingersoll and W. G. Ernst, eds., Cenozoic basin development of coastal California, Rubey Volume VI: Prentice-Hall, Inc., Englewood Cliffs, New Jersey, p. 496.

Webb, G. W., 1981, Stevens and earlier Miocene turbidite sandstones, southern San Joaquin Valley, California: American Association of Petroleum Geologists Bulletin, v. 69, p. 385-411.

Williams, L. A., 1982, Lithology of the Monterey Formation (Miocene) in the San Joaquin Valley, California, in L. A. Williams and S. A. Graham, eds., Monterey Formation and associated coarse clastic rocks, central San Joaquin basin, California: Pacific Section Society of Economic Paleontologists and Mineralogists Annual Field Trip Guidebook, p. 17-36. 


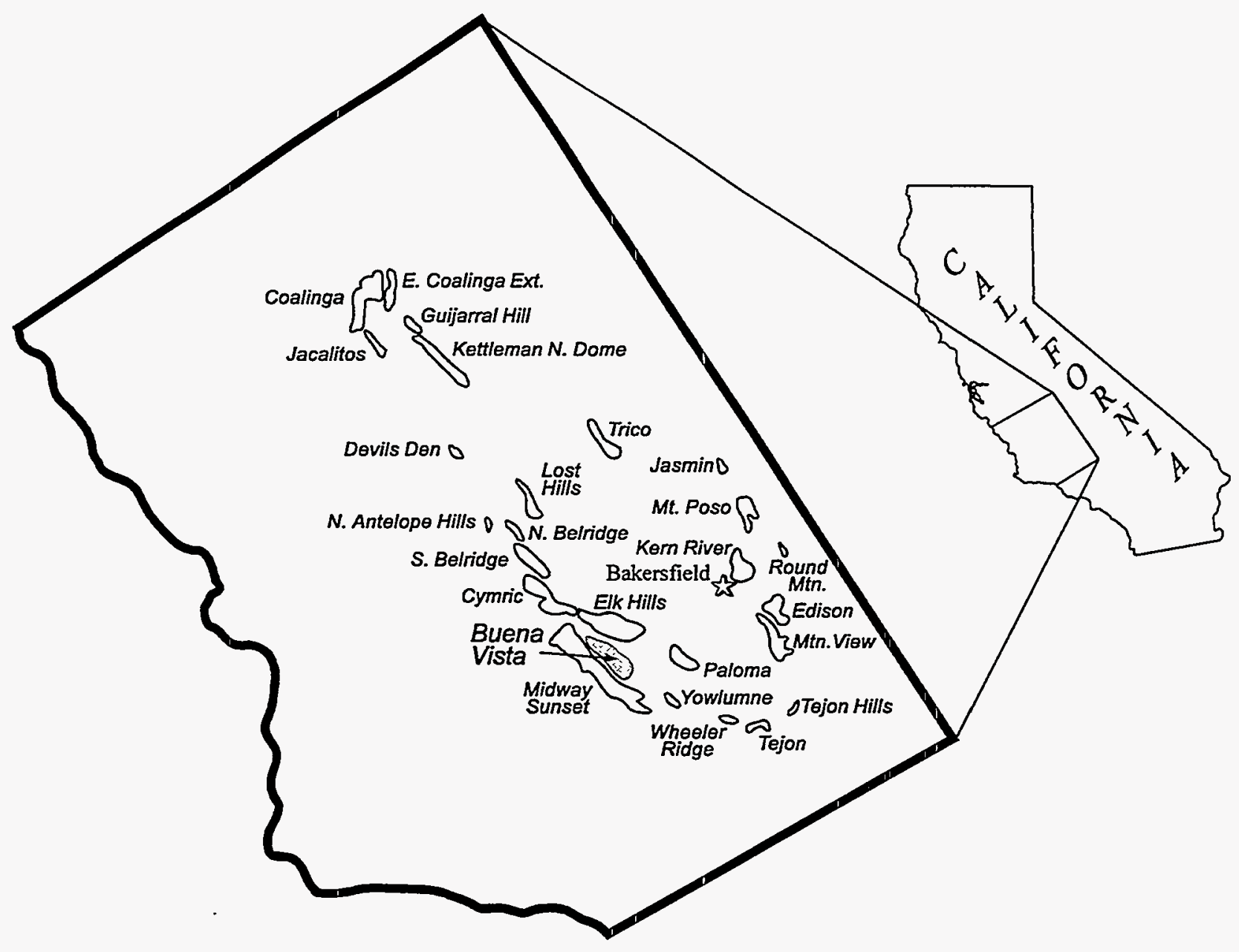

Figure 1.1. Location Map showing Buena Vista Hills and other major oil fields in the southern San Joaquin Valley, California. 


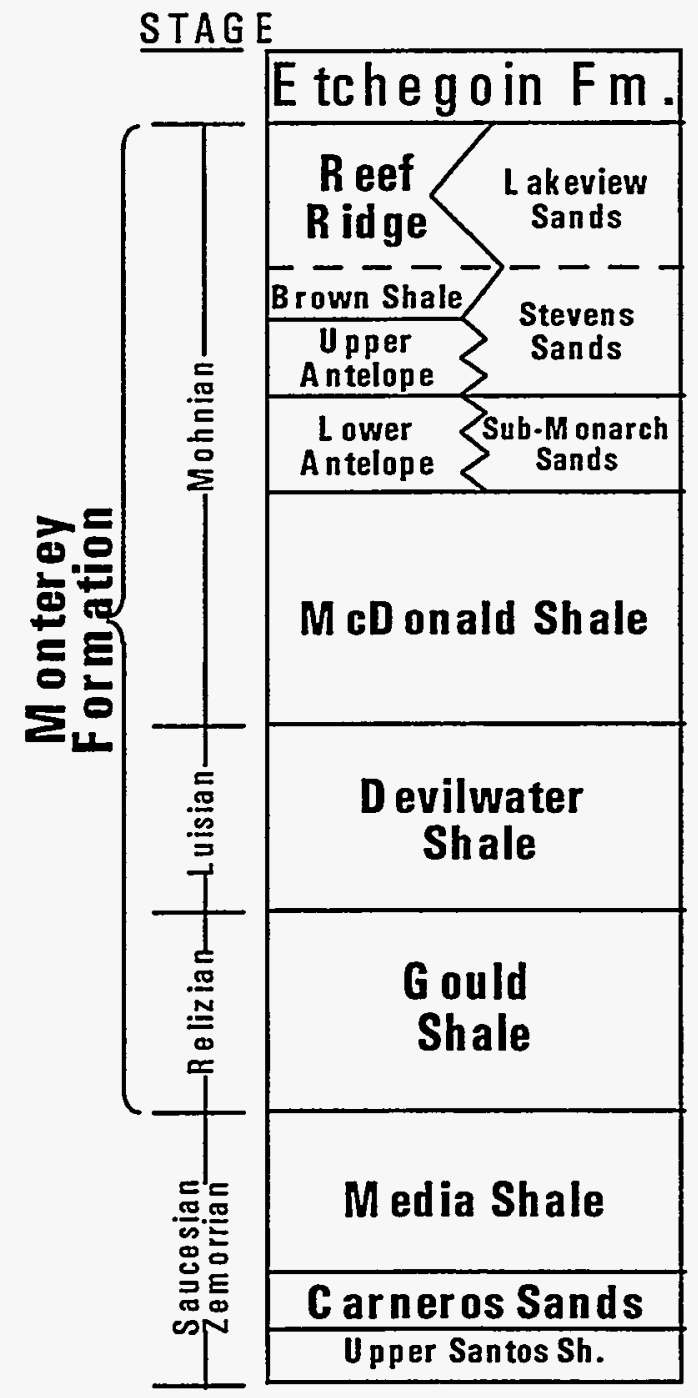

Figure 1.2. Stratigraphic nomenclature used in this report. 


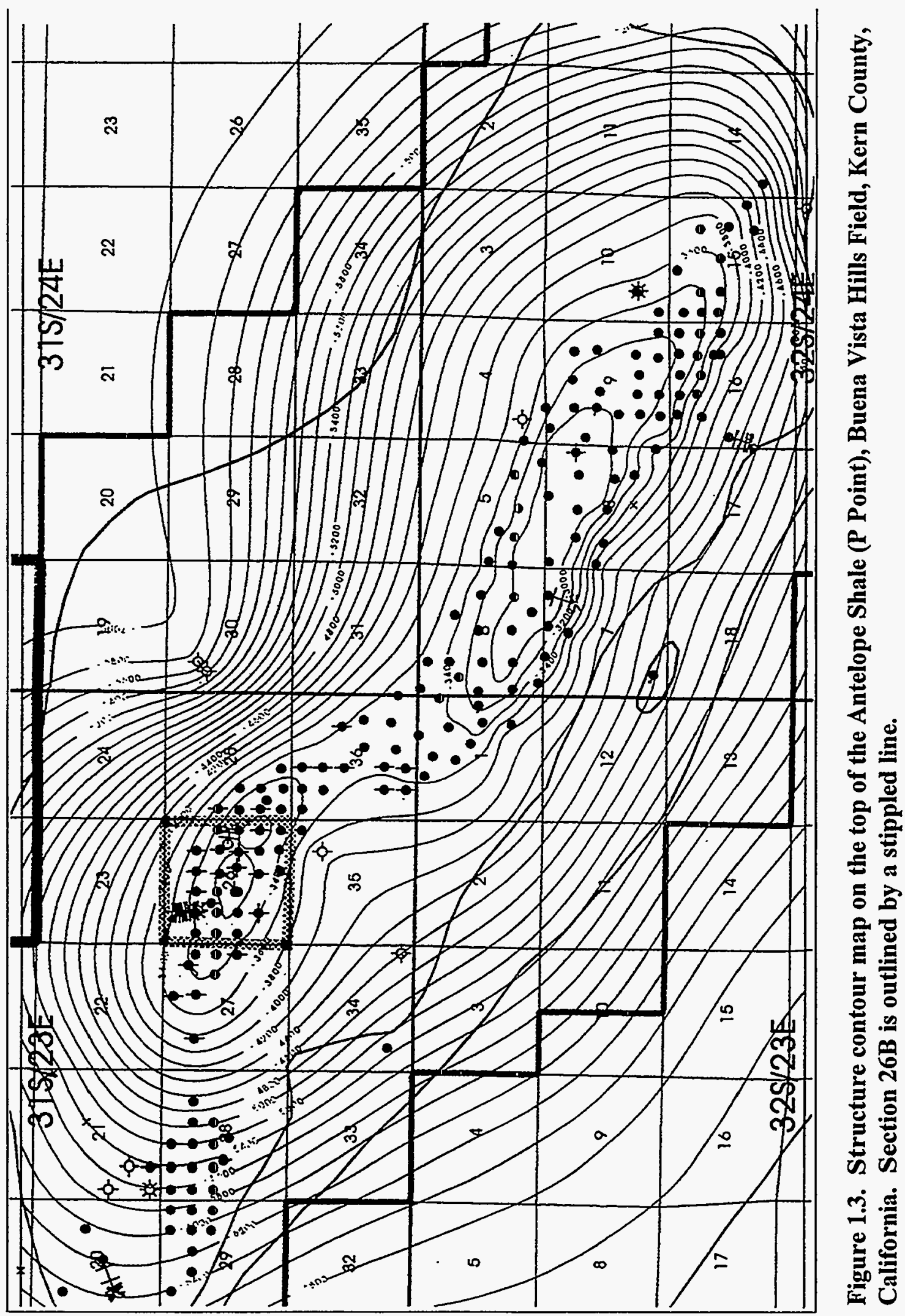




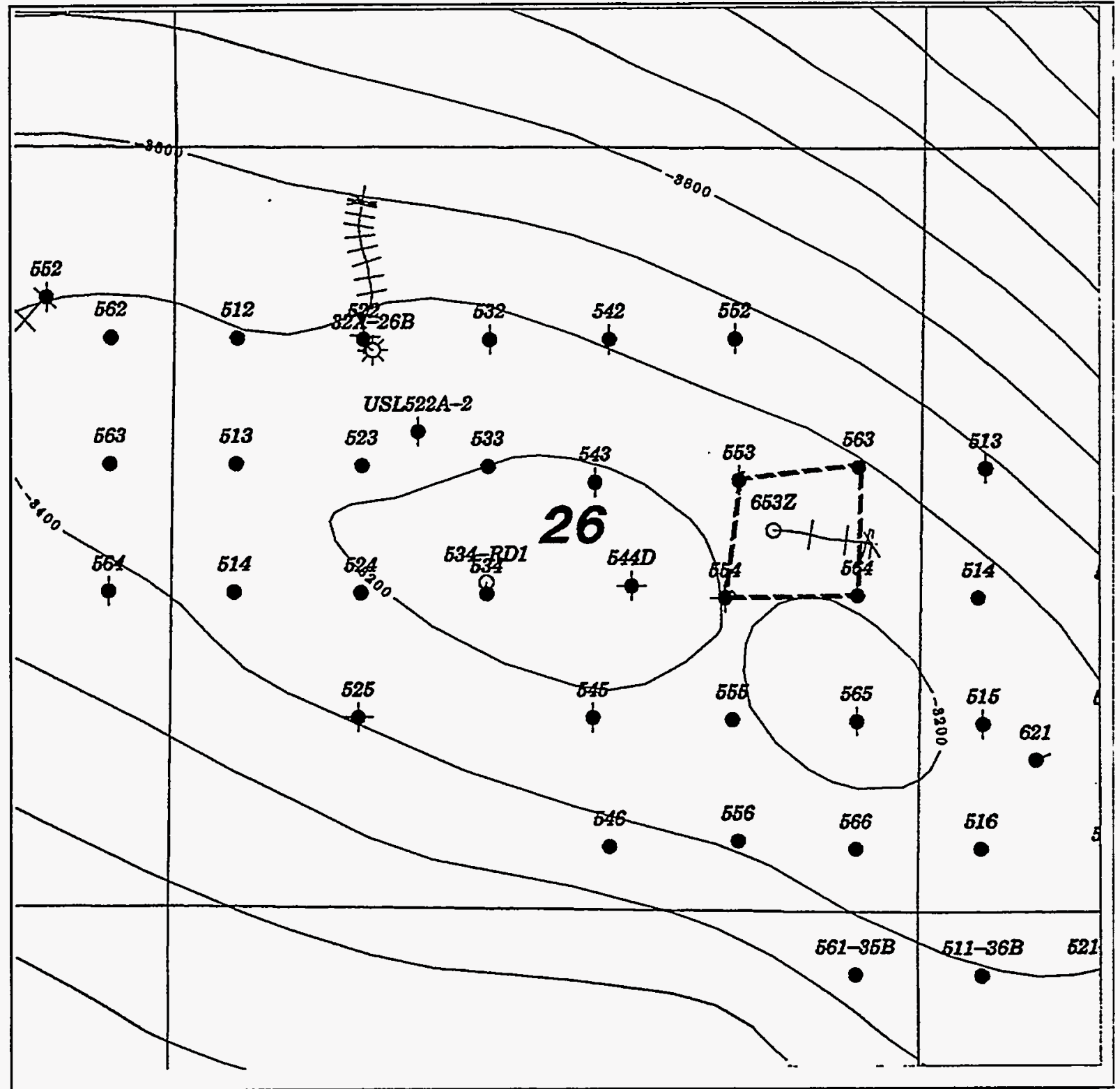

Figure 1.4. Structure contour map on the top of the Antelope Shale (P Point), Section 26B-T31S/R23E, Buena Vista Hills Field, Kern County, California. Pilot area outlined by dashed line. 


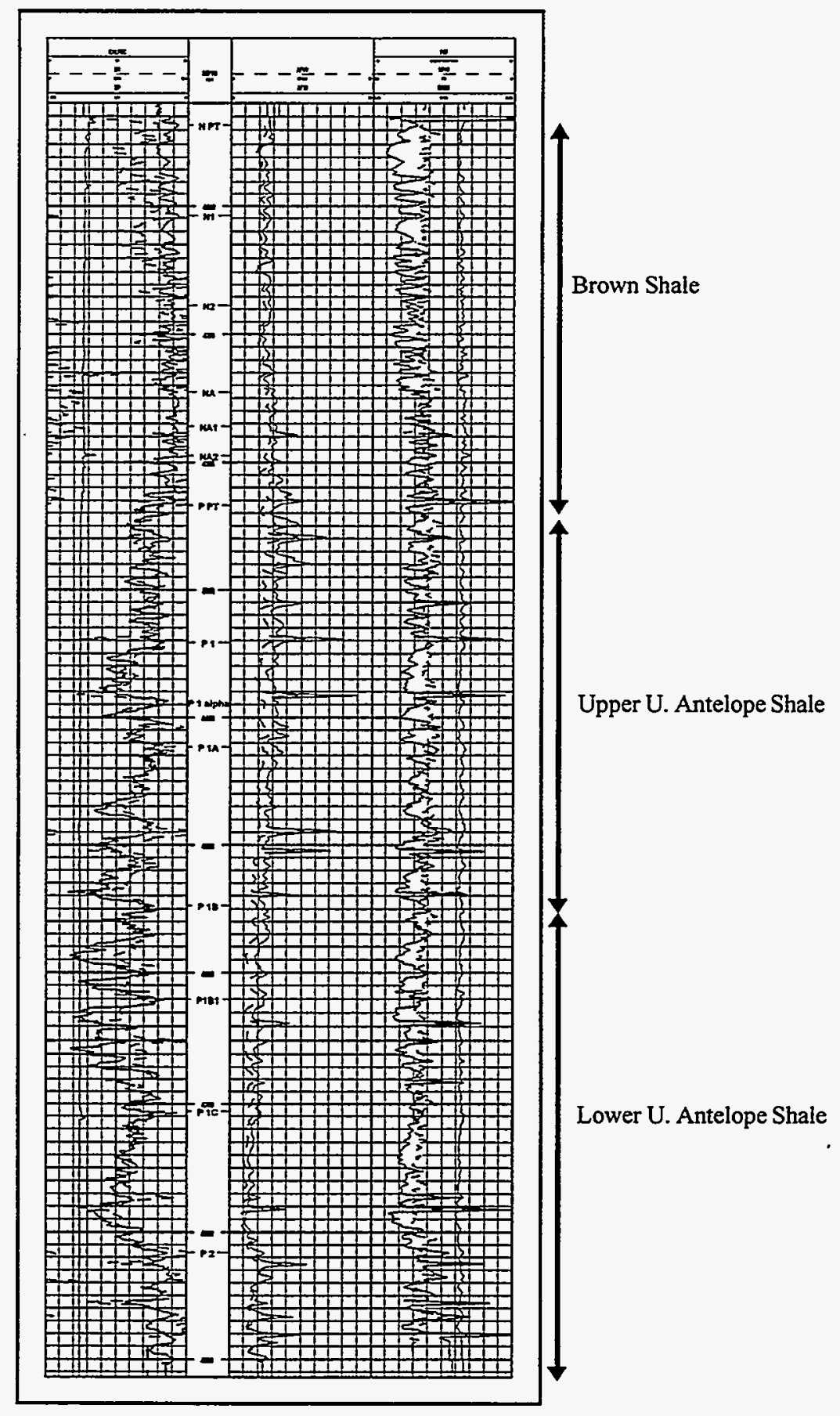

Figure 2.5. Resistivity/density log of 653Z Well, Section 26-T31S/R23E. 


\section{SECTION 2.}

\section{Discussion of Selected Tasks}

Regional Tectonic Synthesis of the Southern San Joaquin Basin (2a. \& b.)

Part I. Synopsis of Previous Investigations (2a.)

Part II. Structural Analysis and Natural Fracture Detection (2b.)

Crosswell Imaging in the Buena Vista Hills (2c.)

Fracture Analysis of the Brown Shale (2d.)

Natural Fractures in the Brown and Antelope Shales (2e.)

Petrographic and Confocal Analyses (2f.)

A Mineral Model and Inorganic Geochemistry of the Brown and Antelope Shales (2g.)

Complex Lithologic Analysis (2h.)

3D Earth Model (2i.)

CO2 Coreflood Experiments $(2 \mathbf{j}$.) 


\section{Section 2a. \\ Regional Tectonic Synthesis of the Southern San Joaquin Basin \\ Part I. Synopsis of Previous Investigations \\ David Campagna and Ned Mamula \\ Advanced Resources International, Inc.}

\section{SUMMARY}

As part of the "Fracture Characterization" task within the Chevron/DOE Class III investigation, we have completed a tectonic synthesis of the southern San Joaquin basin, including the Buena Vista Hills oil field. The study area extends from near Wheeler field (south of Buena Vista Hills) northward to the Lost Hills field, and covers much of western Kern County. The report on this work, Regional Tectonic Synthesis of the Southern San Joaquin Basin, is presented in two parts. Part I: Synopsis of Previous Investigations provides a summary of geologic knowledge pertinent to this study. Part II: Structural Analysis and Natural Fracture Detection describes original work by Advanced Resources to characterize natural fracturing and develop a structural framework of the Buena Vista Hills area, using remote imagery, potential field measurements, published geologic information, and well production data.

Part I provides the geologic foundation for the analysis in Part II. We reviewed the most relevant literature identified by our search, and compiled a list of the essential maps and illustrations to be incorporated in the synthesis. This document includes a discussion of: 1) the scope of our literature review, 2) a broad geologic overview of the San Joaquin basin, 3) tectonics and structural deformation of the southern and western San Joaquin basin, and 4) structural and reservoir characteristics of the Buena Vista Hills oil field.

Our literature review is not intended to be comprehensive with respect to the geology of the San Joaquin basin. Rather, the review focuses on work that provides a geologic and tectonic overview of the southern San Joaquin basin, including relevant associated investigations of the Monterey Formation; and specific information regarding the types and history of structural deformation within the southern and western San Joaquin basin, and structural and reservoir characteristics of the Buena Vista Hills oil field. During this review we realized that relatively little published information exists for the Buena Vista Hills field. Valuable, unpublished information regarding the structure, reservoir and production were made available by Chevron.

Studies published between 1900-1950 largely concentrated on stratigraphy and biostratigraphy, as well as general outcrop observations and field mapping. During this time, the U.S. Geological Survey (USGS) published maps and several classic monographs still in use, including the treatises on the Monterey Formation and on the geology and oil resources of the southern San Joaquin basin. After the 1950's, the geological emphasis on the San Joaquin basin shifted to subsurface studies by petroleum companies and much of this work remains unpublished. 
Between 1960 and 1990, the published literature consists mainly of university dissertations and geological society guidebooks including the American Association of Petroleum Geologists (AAPG), the Society of Economic Paleontologists and Mineralogists (SEPM), and the San Joaquin Geological Society. The USGS published other important investigations between 1970 and the early 1990 's, including the comprehensive work on the Elk Hills field and the Cenozoic evolution of the San Joaquin Valley. Entire sections devoted to the geology of the San Joaquin basin appeared in the Geological Society of America (GSA) Decade of North American Geology monographs published between 1988 and 1992. Other major sources of published information on the San Joaquin basin are the GSA Bulletin and the AAPG Bulletin.

The literature review of the tectonics and modern stress state adjacent to the San Andreas fault demonstrates a quick transition of structural concepts from pure shear models to a special case of transpression. It is now purported that the "weak" (i.e. zone of low friction) San Andreas fault system accommodates all of the strike-slip displacement and the folds near the system are a result of the regional state of compression. For example, folded anticlines such as those of the major oil fields in the San Joaquin basin were considered related to early simple shear displacements along the San Andreas fault. About 20 years ago, it was inferred that the periods of fold growth described in the subsurface along the west side of the San Joaquin basin correspond to known and postulated episodes of strike-slip displacement along the San Andreas fault. Within the past ten years, however, stress state studies have shown that the direction of maximum horizontal compression is perpendicular to the San Andreas fault. With some fold axes oriented almost parallel to the San Andreas fault, it is now considered that fault-fold relationships consistent with thrust-fold belts are more appropriate in understanding the folds along the San Andreas fault system.

Another finding we made based upon our review and critique has to do with fault-fracture relationships within the Monterey Formation. Despite all the information gathered on Monterey rocks in the San Joaquin basin and elsewhere in central California, there is still not a clear or consistent understanding on the character of the fractures and their relationship to faulting. Relatively few areas of surface-exposed faulting and associated fractures are available for detailed examination within the San Joaquin basin. Some investigators have observed that highly fractured areas and intervals are not genetically related to folding or faulting, citing that some wells drilled into anticlines or close to faults frequently fail to find adequate fracture permeability and porosity in the Monterey Formation. Also, fracture porosity and permeability in the Monterey are often erratically distributed on productive anticlines, and not present in the hinge line of folds or in the vicinity of faults. Many fractures in Monterey rocks, however, display systematic orientations implying that the fractures did not develop in a hydrostatic stress field, and are more likely associated with faulting than with diagenesis. For example, it has been postulated that early-formed, oriented fractures may have developed at shallow depth due to dewatering, coupled with faulting and gravity-induced down-slope extension. However, recent 
work on fault/fracture relationships has shown evidence for fault-related fractures, and that these types of fractures are possibly related to bedding slip during folding.

It can be argued that faulting controls hydrocarbon migration, accumulation and production in the Buena Vista Hills and surrounding fields, especially where the faults evolve from a preexisting discontinuity, forming a highly fractured or brecciated zone along which fluid migration occurs. These types of bed-parallel (and bed-perpendicular) faults have been observed and well documented throughout the Monterey Formation. The key to their existence is undoubtedly the tectonic deformation that occurred in this region from latest Miocene to Recent time, when the southwestern San Joaquin basin experienced uplift and crustal shortening due to thrusting and folding. The regional pattern of folds and faults in the Monterey indicates extensive N35E-directed compression, producing crustal shortening between 12 and 17 percent.

The importance of diagenesis cannot be overlooked in this case, because diagenetic overprinting of fractured rocks may "heal" fractures, as observed in chert and porcelanite horizons (Snyder, 1987), suggesting that the timing of deformation and diagenesis has a great deal to do with hydrocarbon production. Another scenario thought to occur in Monterey rocks is that localized tectonic fracturing, superimposed on preexisting diagenetic structures, creates a maximum of interconnected fracture permeability with an increased level of tectonic control.

Undoubtedly the control of Monterey Formation production is affected by all of these processes. It would appear that the occurrence and post-diagenetic timing of tectonic deformation would have the most influence on economic production, and would be the most favorable model in terms of future exploration in the Buena Vista Hills and elsewhere in the San Joaquin basin.

\section{INTRODUCTION}

Advanced Resources International has completed a tectonic synthesis of the southern San Joaquin basin (SJB), including the Buena Vista Hills (BVH) oil field. The study area extends from near Wheeler field (south of BVH) northward to the Lost Hills field, and covers much of western Kern County (Figure 2a.1). The report on this work, Regional Tectonic Synthesis of the Southern San Joaquin Basin, is presented in two parts. Part I: Synopsis of Previous Investigations provides a summary of geologic knowledge pertinent to this study. Part II: Structural Analysis and Natural Fracture Detection describes original work by Advanced Resources to characterize natural fracturing and develop a structural framework of the BVH area, using remote imagery, potential field measurements, published geologic information, and well production data. The primary goal of Part I (this document) is to provide the geologic foundation for the analysis in Part II.

\section{Scope of Literature Review}

Our literature review is not intended to be comprehensive with respect to the geology of the SJB. Rather, the review focuses on work that provides a geologic and tectonic overview of the southern SJB, including relevant associated investigations of the Monterey Formation; and 
specific information regarding the types and history of structural deformation within the southern and western SJB, and structural and reservoir characteristics of the BVH oil field. Valuable unpublished information regarding the structure, reservoir and production were made available by Chevron.

During our efforts to complete the literature review, we realized that little published information exist for the BVH oil field. There are four published investigations on the BVH thrust fault, but not much else was discovered.

We began by compiling a comprehensive geological data base search and identifying the most important literature in terms of the overall objective: a regional tectonic synthesis of the southern (and western) SJB. There is bias toward our selection of published papers from the geological literature because our selection of a study area was keyed to the availability of other regional data sets that are to be used in Part II of our analysis. Copies of the publications, essential published maps and illustrations were obtained largely from the USGS Library in Reston, Virginia. Most of the literature selected for review was published within the past 25 years.

\section{Previous Work}

Despite the voluminous amount of published geological literature, there appears to be a lack of consensus on the structural nature of this major petroleum-producing basin. Studies published between 1900-1950 were largely about stratigraphy and biostratigraphy, as well as general outcrop observations and field mapping. During this time the USGS published maps and several classic monographs still in use, including the treatises by Bramlette (1946) on the Monterey Formation, and that of Hoots (1930) on the geology and oil resources of the southern SJB.

After the 1950's, geological investigations of the SJB shifted to subsurface studies by petroleum companies and much of this work remains unpublished. Between 1960 and 1990, the published literature consists mainly of university dissertations, and geological society guidebooks including the AAPG, the SEPM and the San Joaquin Geological Society.

The USGS published other important investigations between 1970 and the early 1990's, including the comprehensive work on the Elk Hills field (Maher and others, 1975) and the Cenozoic evolution of the San Joaquin Valley (Bartow, 1991). Entire sections devoted to the geology of the SJB appeared in the GSA's Decade of North American Geology (DNAG) monographs published between 1988 and 1992. Other major published sources of information on the geology of the SJB are the GSA Bulletin and AAPG Bulletin. All the above mentioned works and other prominent articles and monographs on the geology of the SJB are listed in the References Cited section. 


\section{GEOLOGIC OVERVIEW}

\section{Regional Setting}

In the vicinity of the southern SJB, the central part of California consists of three major physiographic provinces: the Sierra Nevada, the Central or Great Valley, and the Coast Ranges. These are elongate features more than 400 miles long and subparallel to the Pacific coastline. The Sierra Nevada is a granitic mass that has been faulted upward along its eastern edge and tilted slightly toward the west. The Coast Ranges, the westernmost province, are an anticlinorium in which Mesozoic and Cenozoic sedimentary rocks are complexly folded and faulted (Maher and others, 1975). Between the Sierra Nevada and the Coast Ranges lies a broad topographic and structural basin, the Great Valley.

The northwest-trending SJB is approximately $380 \mathrm{~km}$ long and $65-80 \mathrm{~km}$ wide, encompassing the entire southern half of the Great Valley. The SJB is bounded on the north by the Stockton arch fault, on the east by the Sierra Nevada Range, on the south by the Tehachapi and San Emigdio Mountains, and on the west by the Temblor Range, San Andreas fault and Diablo Range. The basin is further subdivided into five structural regions. The two structural regions covered by this study are the western fold belt and the Maricopa-Tejon sub-basin (Figure 2a.2).

The SJB is an asymmetrical structural trough with a gently inclined, broad and relatively undeformed east flank. The west flank is actually a steeply dipping homocline in the northern basin, and a narrow belt of folds and faults, referred to as the "mobile west flank," in the southern part of the basin (Harding, 1976). The western SJB consists of a tightly folded and complexly faulted anticlinorium resulting from active shearing along the San Andreas fault.

The basin-filling sediments rest on a westward titled block of crystalline basement composed of Jurassic-Cretaceous Sierra Nevada plutonic and metamorphic rocks under the eastern valley, and mafic and ultramafic rocks of a presumed Jurassic ophiolite under the western and central valley. Overlying Mesozoic strata also thin toward the southeast and are absent south of the Bakersfield arch.

Cenozoic strata in the SJB thicken toward the southeast from approximately $800 \mathrm{~m}$ over the Stockton arch to more than $9,000 \mathrm{~m}$ in the Maricopa-Tejon sub-basin in the south (Bartow, 1991). Neogene strata in the northern SJB are entirely nonmarine, while marine sediments have been deposited in the thicker, southern part of the basin. Nonmarine Cenozoic deposits, both Paleogene and Neogene, are more common along the eastern edge of the basin adjacent to the Sierra Nevada, which has been the principal sediment source throughout the Cenozoic (Bartow, 1991).

Developed as a marine forearc basin during the late Mesozoic and early Cenozoic, the SJB was initially situated between the volcanic arc and the shelf break in a convergent plate boundary environment. As such, the basin was parallel to the encroaching arc and closer to it than to the trench-slope basin and the trench. During the late Cenozoic, subduction along the continental 
margin was replace by right-lateral transform shear along the San Andreas fault, which isolated the basin from the ocean to the west (Callaway and Rennie, 1991).

\section{San Joaquin Basin}

The San Joaquin Valley is contained within the SJB, which developed during late Mesozoic and early Cenozoic time as a marine forearc basin. The Paleocene central California coast was a site of active subduction until about $29 \mathrm{Ma}$, during the Oligocene, when the Pacific and North American plates first made contact (Atwater, 1970). During the late Cenozoic, subduction along the continental margin was replaced by right lateral transform shear along the San Andreas fault zone, which isolated the SJB from the ocean to the west, and forms the present day western tectonic boundary (Figure 2a.2).

From the first plate interaction in the Oligocene, subsequent northern migration of the Mendocino triple junction and southern migration of the Rivera triple junction initiated the evolution of the San Andreas fault system. Transform motion brought about the wrench fault regime that has dominated the tectonic development of central California up to the present time (Dickinson and Snyder, 1979).

The northern tectonic boundary of the SJB is the Stockton arch. Bounded on the north by the Stockton fault, the Stockton arch is a broad transverse ridge of Cretaceous rocks caused by structural and sedimentary thickening of the Cretaceous section. Well data indicate that the basement is higher north of the Stockton fault than south of the fault, which is beneath the regional arch (Figure 2a.2). The arch may represent up-tilted basement that has moved along the Stockton fault, which is a high-angle reverse fault with $500 \mathrm{~m}$ of lateral displacement. The Stockton fault is dated as post-Eocene, but Paleocene and younger deformation south of the fault is postulated (Bartow, 1991). The Stockton arch appears to be a relatively old feature that has persisted as a positive structural element throughout the entire Cenozoic.

- Movement and uplift of the Sierran basement has dominated the structural style of the eastern SJB and serves as the eastern seismo-tectonic boundary of basin. Late Miocene tension in the Basin and Range province (about $10 \mathrm{Ma}$ ) and associated left-lateral movement on the Garlock fault appears to have resulted in the westward movement of the Sierra Nevada block, including the SJB. The last major uplift of the Sierra Nevada is believed to have begun after $10 \mathrm{Ma}$, but the uplift and western movement of the Sierra Nevada may not have been related.

The Maricopa-Tejon sub-basin and the south margin deformed belt of the SJB are structurally distinct areas but are probably genetically related (Bartow, 1991). The Maricopa-Tejon sub-basin is located at the extreme southern end of the SJB between the Bakersfield arch and the deformed belt on the north flank of the San Emigdio Mountains to the south. This region is bounded on the east by the Tehachapi Mountains of the southernmost Sierra Nevada and merges westward with the southeast end of the west side fold belt. Collectively, these structures comprise the complex southern tectonic boundary of the SJB (Figure 2a.2). 
The SJB has two basic structural styles; extensional deformation and high-angle normal faulting characterize the east whereas contractional and shear deformation characterize the west. In the latter case, thrust faults and related asymmetric anticlines form near the basin edge and highangle reverse and normal faults occur basinward. The location and styles of deformation in the $\mathrm{SJB}$ are related to the tectonic boundaries of the basin.

Some tens of thousands of wells drilled in the SJB demonstrate that the Neogene section alone is up to 21,000 feet thick, and that the total sedimentary package may be as much as twice that thick. Stratigraphically, there is a great diversity of sediments, ranging from biogenic ooze to turbidites to redbeds. Sedimentary rocks crop out everywhere around the basin and, given the large number of drill holes, there now exists a relatively complete description of the Cenozoic stratigraphic section.

\section{Basement}

The enormously thick sedimentary section of the eastern basin is floored by pre-Upper Cretaceous Sierran granite, with some meta-sedimentary and meta-igneous schist. Beneath the western basin the basement is chiefly Franciscan subduction (ophiolite) complex and a melange of Jurassic and Cretaceous sandstone, shale and chert (Callaway and Rennie, 1991).

Sediments in the extreme southern end of the basin are underlain by the Tehachapi Gneiss Complex, which is regarded as the exposed floor of the southern Sierra Nevada batholith. These basement rocks consist of heterogeneous mafic to felsic igneous and meta-igneous Cretaceous rocks, which appear to have been emplaced and metamorphosed at considerable depth in the continental crust (Goodman and Malin, 1992). North of the Tehachapi Gneiss, outcrops south of Bakersfield indicate that basement consists mainly of mafic Mesozoic and Paleozoic rocks of transitional or oceanic crustal affinity.

\section{Depositional History}

The SJB figures prominently in the late Cenozoic history of central California because it is the largest sedimentary basin in the region, and because it persisted as a depocenter during the change from a convergent plate margin to a transform margin. Beginning in the Oligocene, manifestations of this transformation include a change in sediment composition from volcanic detritus to granitic detritus with recycled sedimentary and metasedimentary materials. Also, a cycle of relatively rapid uplift, followed by rapid subsidence, migrated north through the basin synchronously with the passage of the northward-migrating Mendocino triple junction (Graham and Williams, 1985).

There is a close correspondence in time and space between 1) the passage of the triple junction, 2) volcanism and 3) initial subsidence of the various basins of central California (Dickinson and Snyder, 1979). The SJB began to evolve with rapid late Oligocene and early Miocene subsidence (25-15 Ma) and achieved maximum water depths in about mid-Miocene, just after the 
passage of the Mendocino triple junction. Basin filling and wrench folding during mid-Miocene time (15-10 Ma) was followed by renewed late Miocene and Pliocene subsidence (7.5-2.5 Ma).

Three main factors contribute to the extremely complex stratigraphic composition of the SJB: 1) the basin configuration, with a tectonically active west flank and a shallow dipping east flank, 2) four distinct and separate source areas that simultaneously contributed shelf and basinal sediments, and 3) sporadic uplift and erosion contemporaneous with downwarp (Callaway and Rennie, 1991).

The center of the basin preserves the most complete record of sedimentation. The Eocene to early Miocene tectonic history of the SJB is divisible into three contrasting periods. Regional uplift of Sierran basement during the Paleocene to early Eocene was followed by an episode of rapid subsidence during the middle Eocene. A tectonic load associated with the emplacement of the Salinian block at the southwestern corner of the SJB may have driven this subsidence. The second period of tectonic activity occurred during the late Eocene to early Oligocene and involved two major episodes of uplift and subsidence in the southern SJB. This tectonic activity may have been caused by reactivation of structures originally produced by the emplacement of the Salinian block. The final period of tectonism in the late Oligocene to early Miocene involved faulting, volcanism, and major uplift and erosion within the southern SJB, as the Mendocino triple junction migrated northwestward past the southern SJB (DeCelles, 1988).

Continuous deep-marine sedimentation persisted from late Eocene through late Miocene (Bandy and Arnal, 1969). During the Oligocene through Miocene, the SJB was in communication with the Pacific Ocean via passages through the Salinian block along the western margins of the basin (Graham, 1991). Deep-marine shales, siliceous shales and porcelanites of the overlying Monterey Formation, the most important petroleum source rocks of the region, reflect the basinwide change in response to the initiation of a transform fault setting, probably during the Oligocene (Graham, 1987). Finally, the Neogene stratigraphy is characterized by rapid vertical and horizontal facies changes and numerous unconformities that record the removal of thick sections of strata along the basin margins.

During the Pliocene, the SJB was the site of a large shallow-marine embayment in the California coastline, bounded on one side by the Coast Ranges which were rising along the San Emigdio and Temblor Range thrust belts adjacent to the San Andreas fault (Davis and Lagoe, 1988). Thick accumulations of highly fossiliferous shallow-marine clastics are overlain by a complex of alluvial-fluvial-lacustrine sequences, of Pliocene to Holocene age, that record eventual isolation of the SJB from the Pacific Ocean (Barlow, 1991). The SJB persists through the Quaternary as a structural and topographic low, characterized mainly by longitudinal drainage to the northwest with local areas of internal drainage, and was heavily influenced by Pleistocene glaciation in the adjacent Sierra Nevada (Lettis, 1988). 


\section{Deformation History}

From the inception of the San Andreas fault system through the Miocene, any structural deformation that occurred is severely complicated by later deformation during the PlioPleistocene. Plio-Pleistocene fold axes on the west side of the SJB trend northwest, and those folds nearest the basin edge are en-echelon, more E-W oriented, and impinge on the San Andreas fault zone. Basinward anticlines are oriented parallel to the long axis of the basin. Harding (1976) considered this structural style to be caused by right-lateral strike slip movement of the San Andreas fault, because the observed relations suggest that folds and wrench faults are essentially independent structural responses to a common, diffuse coupling, originating in the deeper crust. In Harding's scenario, structural deformation on the west side of the basin is older near the basin edge and younger toward the basin center. The same pattern of structural growth on basinward fields and repeated growth on previously affected, more westward fields continued in late Miocene, Pliocene, and into the Pleistocene (Callaway and Rennie, 1991).

Recent structural analyses of these folds, however, suggest that they are part of an actively developing fold and thrust belt, rather than part of the generally-cited wrench tectonics model of Harding (1976). Using tectonostratigraphic sequences and kinematic analysis of regional cross sections, a fold and thrust belt model is offered for the western and southern SJB structures (Davis and Lagoe, 1988; Namson and Davis, 1988). Evidence shows that these structures are two-phased and compressional. In this model, mid-Tertiary development of a west-verging foldthrust belt resulted in the transition of the basin from west-facing continental slope to an asymmetric, semi-closed basin, and Pliocene-Pleistocene-Recent development of an east-verging fold-thrust belt is coincident with a change in Pacific/North American plate motion (Namson and Davis, 1988). The southern end of the SJB contains a combination of structural styles observed in the west and east sides of the basin. Davis and Lagoe (1988) have proposed six deformational pulses for this region: 1) a south-verging Oligocene thrusting and folding event, 2) a late Oligocene to early Miocene volcanism and normal faulting event, 3) three Miocene and Pliocene pulses of down-to-the-north normal faulting, and 4) localized north-vergent thrusting and folding that began in late Miocene and continued until late Pliocene to Recent.

\section{Monterey Formation}

The Miocene Monterey Formation is a succession of siliceous sedimentary rock that was deposited in a series of continental borderland basins associated with the development of the San Andreas fault system (Blake and others, 1978; Snyder, 1987). The enormous volume of these sediments, both onshore and offshore, is on the order of 100,000 cubic kilometers. Since the 1950 's, detailed exploration in the basin has uncovered various subtleties of the Monterey Formation. The siliceous shales of the Monterey are the key to its hydrocarbon potential because they serve as both the source and reservoir rocks. Intense fracturing of the shale reservoir rocks is necessary for economic production.

Naturally fractured reservoirs, and the causes thereof, are the focus of present-day exploration in the Monterey, especially in light of the extremely low permeability of Monterey shales and 
diatomites, and the recent tendency toward using horizontal drilling for production from naturally fractured reservoir rocks. Without a doubt, the most obvious target for horizontal drilling in the SJB is the Monterey Formation. Prior to the early 1990's, it does not appear that any horizontal well had been drilled in the Monterey. Recently, horizontal drilling has been used in the BVH field to obtain oriented core samples to investigate the possible occurrence of vertically fractured reservoirs.

\section{Distribution of Sediments}

Monterey rocks are distributed in the Coast Ranges and borderland basins from north of San Francisco to south of Los Angeles. In many areas the rocks are several thousand feet thick, sometimes exceeding a mile in thickness and many square miles in extent. The complete vertical sequence is not present everywhere in California, nor are the specific lithofacies always the same age (Pisciotto and Garrison, 1981). In the southwestern SJB east of the San Andreas fault, the lower Monterey Formation consists almost entirely of bathyal marine sedimentary rocks (Bandy and Arnal, 1969). Continental deposits do comprise the lower Monterey Formation in specific areas in central California. Despite these inconsistencies, the general succession of lithofacies, representing a major Neogene cycle of basin formation and filling, is recognizable throughout central and southern California.

\section{Lithology}

The Monterey Formation reflects the three major sedimentary processes: biogenic, detrital, and diagenetic. Variations in input of those components during sedimentation, due to Miocene tectonic and climatic effects, have resulted in a highly heterogeneous stratigraphic unit. Depositional and diagenetic effects added further complexity, which in some cases led to present-day mixed fracture- and matrix-porosity reservoirs, and in other cases to reservoirs of altered beds with poor fracture potential intercalated with beds having good fracture potential (Williams, 1988).

There are nine lithotypes in the Monterey Formation: 1) diatomite and diatomaceous shale, 2) shale, 3) siltstone and sandstone, 4) siliceous shale, 5) mat-laminated siliceous rocks, 6) calcareous siliceous rocks, 7) chert, 8) dolomite, and 9) porcelanite. Of these lithologies, the Monterey is best known for its combined biogenic/diagenetic components, particularly the siliceous lithologic suite of diatomite, porcelanite and chert. Most Monterey biogenic sediments have been mixed to some extent with terrigenous components. In the SJB there was probably more terrigenous sediment influx from the nearby Sierra Nevada than in other borderland basin areas (Graham and Williams, 1985).

The siliceous facies of the Monterey Formation is the thickest, most widespread, and most economically important of the three basinal facies (the other two facies being the phosphatic and calcareous). The diatomite and diatomaceous mudrocks and their diagenetic equivalents, chert, porcelanite, and siliceous mudrocks, are the principal rock types of the siliceous facies. Biogenic and diagenetic silica and clay are the main components of these rocks (Pisciotto and Garrison, 
1981). The classic description of Monterey siliceous facies by Bramlette (1946) is still probably the best work on the subject to date, wherein the lithology and genesis of each of the diatomaceous, porcelaneous, chert and cherty shale facies have been described.

More recent studies of these lithologies using X-ray diffraction, scanning and transmission microscopy and isotopic analysis have provided details and refinements to Bramlette's original work, but have not changed the original premise of how the Monterey rocks were formed (Pisciotto and Garrison, 1981). Some of these newer studies (Williams, 1982; Kruge and Williams, 1982; Isaacs, 1982) demonstrate the general progression of lithologic and mineralogic changes related to burial diagenesis and source materials. For example, diatom skeletons characterize diatomites and diatomaceous shales, with diatomites being more siliceous than diatomaceous shales. Cherts, porcelanites and siliceous shales, in order of decreasing purity, are diagenetic equivalents of opal-A (diatomaceous) rocks in either opal-CT or quartz phase (Graham and Williams, 1985).

\section{Paleoenvironment}

Despite the regional variability, the overall age and stratigraphic sequence of the Monterey Formation rocks attest to the first order control exerted by tectonic, climatic and biologic events. The change from a convergent to a transform plate boundary imposed a different structural style upon the California borderlands and affected sedimentation patterns. Structural segmentation caused basins to be largely isolated from clastic influx, and the general depositional model for the Monterey Formation emphasizes the importance of tectonically active offshore areas protected from clastic input by differential uplift and subsidence (Williams, 1988). These phenomena determined the gross change from a calcareous lower facies to a siliceous upper facies throughout the Monterey Formation. Aside from the regional pattern of deposition, there were numerous local depositional environments for the Monterey rocks in the California borderland basins. There are four that are repeated throughout the Monterey Formation, each having distinguishing sedimentological and paleontological characteristics: 1) outer shelf-upper slope, 2) isolated bank-top, 3) aerated basin and 4) anoxic basin. The details of these depositional paleoenvironments have been well summarized by Pisciotto and Garrison (1981).

\section{Relationship to Tectonics}

The passage of the Mendocino triple junction significantly affected deposition in the SJB, although wrench tectonism associated with the San Andreas fault appears not to have had much effect on early sedimentation patterns of Monterey rocks in the basin for several million years (Graham and Williams, 1985). As the slip rate of the San Andreas increased in the late Miocene, however, regional tectonics exerted more of an influence on Monterey deposition. Concurrently, as sea level rose in the late Miocene, the deposition of Monterey rocks extended eastward toward the Sierra block, as the entire SJB began to fill. Sedimentary loading began to play an important part in the tectonics of the basin. 
Eventually, deep marine conditions that prevailed during late Miocene began to abate with the continued filling of the basin. As Graham and Williams (1985) have pointed out, it is difficult to gauge the relative importance of tectonism, falling sea level or increased sediment supply in the termination of deep marine conditions. They speculate that the tectonic controls on sedimentation may have been both regional and local, as the Monterey deposition began to slow in various places within the basin.

\section{STRUCTURE AND TECTONIC HISTORY \\ San Andreas Fault}

The term "San Andreas" has multiple meanings, depending upon the scale of observation and other geologic factors. Dibblee (1977) has proposed a precise nomenclature, which we use here: 1) the San Andreas "fault system," referring to a set of NW-trending high-angle faults subparallel to and similar to the San Andreas fault, within the region extending westward from the San Andreas fault beyond the coast, and eastward to the Great Valley and the western edge of the SJB region; 2) the San Andreas "fault zone," or the set of subparallel faults that splay from and rejoin the San Andreas fault within a $10 \mathrm{~km}$ wide band; and 3) the San Andreas "fault," which is the principal rupture of right-lateral slip traceable for about $1000 \mathrm{~km}$ through California, and is in large part seismically active.

The San Andreas fault system originated in mid-Oligocene when the ancestral East Pacific rise first encountered the subduction zone and created a transform plate boundary (Dickinson and Snyder 1979). Regionally, the entire orogenic mobile borderland belt is experiencing right-lateral deformation. Movement is distributed along individual NW-trending right-slip transcurrent faults of the overall fault system, as folding or clockwise rotation of strips between faults of the system, or as right-slip along the singular San Andreas fault plane.

In central California, the Hayward and Calaveras fault strands bifurcate from the main San Andreas fault, thereby creating a complex linear belt of NW-trending serpentine faults: the San Andreas fault zone. The multiple faults within the zone each have significant components of dip displacement in addition to strike displacement. Unique to the fault zone are long, attenuated blocks of terrain which lie between the faults. The blocks are themselves internally deformed by other lesser faults and folds that trend subparallel to the major faults, or trend into them at an oblique angle, suggesting a scenario of simple shear deformation, much of which has been dated as Pliocene and Quaternary (Stewart and Crowell, 1992).

The San Andreas fault is a well-defined structural and geomorphic feature that transects the Coast Ranges of central California, and has had a profound effect on the entire region due to the displacement and associated wrench tectonism. In central Califormia, the San Andreas has experienced a total right-slip of approximately $330 \mathrm{~km}$, acquired since the present main onshore strand originated in Miocene time. Late Miocene strata are offset by about $240 \mathrm{~km}$, while early to mid-Miocene strata are thought to be offset approximately $90 \mathrm{~km}$ (Huffman, 1972). Recent studies of the sedimentology and petrology of Oligocene and Miocene strata in the Temblor 
Range (southwest SJB) indicate that the SJB and La Honda basin to the west were once contiguous and are now separated along the San Andreas. Although these types of investigations are useful for constraining the movement of the San Andreas, the time of slip initiation is not well known everywhere, and the geologic data collected thus far do not permit discrimination between continuous slip or episodic slip (Graham and others, 1989).

\section{Modern Stress State}

Investigations over the past 25 years have collectively explained the observed stress field adjacent to the San Andreas fault as a consequence of several superposed effects. These include: 1) current relative plate motions resulting in a component of convergence across the San Andreas, 2) extension in the Basin and Range province to the east, and 3) a shear strength for the San Andreas fault that is considerably lower than the level of far-field stresses in the crust (Zoback and Zoback, 1989). The observed fault-normal compression in central California and the western side of the SJB is proposed to result from the extremely low shear strength of the San Andreas and the slightly convergent relative motion between the Pacific and North American plates.

Recent studies regarding the state of stress in central California, including the SJB, has relied upon stress-induced well bore breakout and earthquake focal plane mechanisms to provide data with which to plot the crustal stress field. These contemporary in-situ tectonic stress indicators gathered along the San Andreas fault system suggest a regional NE-directed horizontal compression, nearly perpendicular to the strike of the fault (Zoback and others, 1987). This compression is probably related to the recent uplift of the Coast Ranges (including the Diablo and the Temblor ranges adjacent to the southern SJB) and the numerous active reverse faults and folds, including those in SJB that trend nearly parallel to the San Andreas fault.

More detailed analyses of stress-induced well-bore breakouts, from wells scattered over 10 production fields in the southern SJB, indicate spatial variations in the NE-directed maximum horizontal stress occurring at three different scales (Castillo and Zoback, 1994). First, the regional NE-directed compressional stress field along the western margin of the SJB in the Elk Hills and Kettleman Hills gradually changes to approximately N-S compression over a distance of 10-20 km. Second, the stress field shows ENE-oriented maximum horizontal compression over a distance of several kilometers in the extreme southern SJB, based on measurements gathered at some of the producing wells near the White Wolf reverse fault.

In addition, there are also localized perturbations in the stress field on the order of a few meters between individual wells. These small-scale perturbations have been observed where wells appear to intersect tectonically active faults (Castillo and Zoback, 1994). For example, in 1932 it had become evident that wells were being sheared off by an active thrust fault in the BVH field (Koch, 1933). Geodetic monuments were installed in 1933 and subsequent monitoring has shown variable N-S movement (contraction) along the E-trending north-dipping Buena Vista thrust fault. Field observations, compatible with the analysis of geodetic displacement data, include 
sheared well casings, bent piping, broken pavement where roads cross the trace of the fault, a recent fault scarp and evidence of faulting at locations predicted by the analyses (Wilt, 1958; Howard, 1968).

\section{Fault/Fold Relationships}

Folds are common features within the Monterey Formation, and are typically related to faulting. Relatively minor warping of the Monterey Formation occurred in the late Miocene and early Pliocene, followed by major faulting and folding beginning in the latest Pliocene and continuing to present day. Normal and reverse faults with small displacements usually tend to parallel fold hinges. Folds related to the regional structural fabric are largely Pliocene and Pleistocene age, nucleate above reverse faults, are slightly asymmetric with concentric to chevron profiles, and are accompanied by flexural slip.

Folds in the southern and western SJB were believed to be related to shear displacements along the San Andreas fault, due in part to their proximity and subparallel orientation to the fault (Stewart and Crowell, 1992). According to Harding (1976) the periods of fold growth described in the subsurface along the west side of the SJB correspond to the known and postulated Cenozoic episodes of strike-slip displacement on the San Andreas fault. Further supporting the idea of folding in a pure strike-slip environment, Dibblee (1977) asserted that the San Andreas fault system is accompanied by contractional deformation in the Coast Ranges. He based this conclusion upon: 1) the uplift of individual mountain ranges and hills adjacent to or near segments of almost all the transcurrent faults, 2) thrust faults occurring internal to or bounding these individual mountain ranges and 3) tightly compressed folding of sedimentary rocks adjacent to or near the transcurrent faults, such as in the western fold belt of the SJB.

It is now purported that the "weak" (i.e. low shear strength) San Andreas fault system creates a special case in the transpressive motion of the North American and Pacific plates. The strain is resolved into strike-slip displacement along the San Andreas fault system and normal contractional displacement accommodated by thrust faulting and related folding. As discussed above, stress state studies show that the direction of maximum horizontal compression

is nearly perpendicular to the San Andreas fault. With some fold axes oriented almost parallel to the San Andreas fault, it is now considered that fault-fold relationships consistent with thrustfold belts are more appropriate in understanding the folds along the San Andreas fault system. Using 2D seismic profiles and well data as guides, anticlines in the western half of the SJB are interpreted as fault-bend and fault-propagation folds (Namson and Davis, 1988).

\section{Fractures}

Fractures in the Monterey are commonly related to lithology, but in a gross sense are produced through both folding and faulting. Most of the fractures in Monterey rocks are fold-related and these are sometimes overprinted by fractures which are fault-related (Snyder, 1987). However, it was noted that fold-related fracture sets are not always observed in Monterey exposures, nor do 
the fractures always occur with predicted orientations. On the other hand, the orientation of fault-related fractures can be more readily predicted because they reflect the same stress conditions that are responsible for the faulting. Their importance in terms of reservoir porosity and permeability is uncertain, due to insufficient field data on fault-related fractures in the Monterey.

Snyder and others (1983) observed that many fractures in Monterey rocks display systematic fracture orientations, implying that the fractures developed in a non-hydrostatic stress field, and are more likely associated with faulting. For example, early-formed, oriented fractures may develop at shallow depth due to dewatering, coupled with faulting and gravity-induced downslope extension. Recent work on fault/fracture relationships has found evidence for fault-related fractures in exposures of Monterey rocks at Chico Martinez Creek and along the California coast (Dholakia, 1996). A multi-disciplinary approach using field studies and borehole data identified a relationship between shearing along brittle fault zones in the Monterey (both bed-parallel and bed-perpendicular) and brecciated networks of connected fractures along which hydrocarbons can migrate.

Despite all the information gathered on Monterey rocks in the SJB and elsewhere in central California, there is not a clear understanding of the character of rock fractures and their relationship to faulting. There are few areas of well-exposed faulting available for detailed examination within the SJB or elsewhere. Some investigators (Redwine, 1981) have observed that highly fractured areas and intervals are not genetically related to folding or faulting, citing the fact that wells drilled on well-developed anticlines, or close to faults, often fail to encounter adequate fracture permeability and porosity in, for example, the productive Monterey Shale. Even on productive anticlines of Monterey, suitable fracture porosity and permeability are often erratically distributed and not present in the hinge line of folds or in the vicinity of faults. Instead, these studies favor the diagenetic origin of fractures.

\section{Diagenetic Structures}

Diagenetic influences in the Monterey Formation have recently been investigated in considerable detail (Snyder, 1987; Snyder and others, 1983; Isaacs, 1981; Garrison and Douglas, 1981). Within Monterey rocks, on a scale of hundreds of meters or less, the structural style is a function of the lithology and diagenetic state of the rock during deformation. The rheology of these siliceous rocks changes from relatively ductile to brittle and the solubility decreases as the siliceous sediments diagenetically progress from biogenic opal-A to opal-CT to quartz. The intensity of fracturing in the Monterey Formation depends on the lithology; as a general rule the most fractures are observed in cherts, fewer fractures in porcelanite and fewer still in diatomite (Snyder, 1987). Careful evaluation of fracture intensity, relative to lithology and the state of diagenesis, is required prior to using fracture intensity as a guide to exploration for fractured reservoirs in the Monterey Formation. 
Other common diagenetic structures that occur in the Monterey include stylolites and solution cleavage. Pressure solution features commonly occur as bedding-parallel stylolites and as solution cleavage at high angles to bedding (Pisciotto, 1978). These structures probably formed early in the silica diagenetic sequence (opal-A or opal-CT phases) because of the progressive decrease in solubility with advancing diagenesis (Snyder, 1987). Pressure solution has played a role in both vertical compaction and horizontal shortening of the siliceous sediments of the Monterey Formation, and is responsible for reduction in porosity. Bedding-plane-parallel stylolites may provide surfaces for movement between layers during flexural-slip folding.

\section{BUENA VISTA HILLS OIL FIELD}

\section{Structure}

The Buena Vista Hills stand within the southwestern SJB, and are part of the southern Taft oil district along with the Elk Hills and Midway-Sunset oil fields. The primary structure is a NWoriented, doubly-plunging anticline, subparallel to the thrust faults of the Temblor Range and San Andreas fault. The fold is composed of two offset domes which are referred to as the United anticline, or West Dome, and the Honolulu anticline, or East Dome. The domes are approximately 3 to 4 miles apart and the East Dome is 240 feet structurally higher than the West Dome.

Little is known regarding subsurface structures at BVH. According to Chevron (1994), only 40 miles of 2D seismic data have been gathered over the entire field in the 1970's and 1980's, with about one fourth of that from the West Dome. Drillhole pressure tests made by Chevron do not indicate pervasive fracturing at depth. However, in one instance, drilling fluids in one well were abruptly lost, and were recovered one week later from six neighboring wells. In another incident, acids used to stimulate one well actually increased production in three neighboring wells. Both events strongly indicate the presence of a fracture network.

Most of the subsurface structural information regarding fracturing has been gathered through analysis of recovered core, which indicates approximately 30 percent of the Monterey reservoir rocks are fractured. According to work compiled by Chevron (1994) fracturing occurs at all scales, from crushed or brecciated material, to rock rubble, to six-foot spacing between fractures. Most of the fracturing appears to be in the latter category; these fractures are vertical and parallel to the N65W structural axis. Recovered core contains small-scale (mesoscopic) fractures that have been described as diagenetic, similar to those described as fluid-escape features formed prior to sediment lithification (Williams, 1982). Chevron core analysts have determined that the formation is ten times more permeable parallel to observed fracturing than perpendicular to fracturing.

In the previous discussion on stress state, we mentioned the active NW-trending thrust fault that underlies part of the northwest BVH. The thrust is directed out-of-the-basin toward the Temblor Range and has manifested itself at the surface in sections 7 and 8 south of the United anticline (West Dome) as a recent scarp. The orientation of the thrust fault is approximately E-W; 
however, nearby linear features which trend roughly N60-70W, possibly associated with the fault, have been accurately mapped from low-altitude aerial photography (Howard, 1968). These linear features may be the surface expression of other faults in the BVH, and they are oriented parallel to fractures described from the core analysis.

\section{Antelope Shale Reservoir}

The Antelope Shale (Monterey Formation) reservoir in the BVH field was discovered in 1952 and developed during the 1950's and 1960's. Chevron put considerable effort into characterizing the reservoir. The Monterey, in its brittle quartz facies, is productive as a fractured reservoir in a number of oil fields including Elk Hills, Midway-Sunset and Lost Hills (Callaway and Rennie, 1992). The late Miocene Antelope Shale consists of 1325 feet of hard brownish gray to gray siliceous fractured shale, with sand or silt laminae (between 0.04 to 8.0 inches thick) common in the lower section. The upper 350 to 500 feet is shale and is nonproductive. The lithology of the East Dome and West Dome are the same and both indicate that the reservoir is tight (Chevron, 1994).

The best data available to date on the Antelope Shale reservoir are from modern core extraction and analysis. According to Chevron (1994) the older core data are superseded by modern data, because of the newer, more reliable fluid extraction and porosity measurement techniques. Average porosity in cores of Antelope Shale ranges from 20 to 31 percent, and the fracture porosity ranges between 2.4 and 4.3 percent for the West Dome and East Dome, respectively. The reservoir characteristics of the Antelope Shale do compare well with other major fractured reservoirs (e.g. Spraberry field, east Texas) where the rocks of both have high porosity, low permeability, and recoveries are relatively very low. As far as is known the fracture network in the Antelope Shale is not very extensive. Recent core retrieval at West Dome using horizontal drilling and modern analysis techniques may provide much-needed information.

\section{Production}

Much of the oil produced and reserves added since the 1960's have been yielded by improved production technology (Callaway and Rennie, 1992). Further investigation into the possibility of fault-related, interconnecting fracture patterns continues. Recent field and core analysis work has made some progress toward finding intensely fractured or brecciated zones which appear to be shear-related, including studies of core photographs collected at a well, recently drilled in the $\mathrm{BVH}$, which may show evidence of bed-parallel shearing. Increased fluid flow associated with shearing within Antelope Shale has been demonstrated in the Cymric field located northwest of BVH. The photogeologic work by Howard (1968) which indicates a series of NW-trending enechelon lineaments across the BVH may correlate with production records from nearby wells, which could indicate increased fracture permeability associated with those lineaments.

\section{SUMMARY}

The west side of the San Joaquin basin, deformed by compressional shear, is characterized by large asymmetric anticlines and faults that range from thrusts near the basin edge, changing to 
high angle reverse to high angle normal faults basinward. Fold axes on the west edge of the basin trend northwest; those nearest the basin margin, as at Buena Vista Hills, are en-echelon, more westerly-oriented, and impinge upon the San Andreas fault zone (Callaway and Rennie, 1992). The northwest-oriented folds and faults of the western San Joaquin basin are thought to exert considerable tectonic control on production as they provide important structural traps for migrating hydrocarbons. Many of these structures are classified as major fields, including Buena Vista Hills, Kettleman Hills, Elk Hills and others in the western San Joaquin basin.

It can be argued that faulting controls hydrocarbon migration and production in the Buena Vista Hills and surrounding fields, especially where faults have evolved from a preexisting discontinuity to form a highly fractured or brecciated zone, along which migration occurs. These bed-parallel (and bed-perpendicular) faults are well-documented throughout the Monterey Formation. The key to their existence is undoubtedly the tectonism that occurred in this region since late Miocene time, when the southwestern San Joaquin basin experienced uplift and crustal shortening due to thrust faulting and folding. The overall configuration of folds and faults in the Monterey indicates crustal shortening of between 12 and 17 percent in a N30-40E direction.

The importance of diagenesis cannot be overlooked. Diagenetic overprinting of fractured rocks may "heal" fractures, as observed in chert and porcelanite horizons (Snyder, 1987), suggesting that the timing of tectonism and diagenesis has a great deal to do with hydrocarbon production. Maximum interconnected fracture permeability may occur in Monterey rocks where local tectonic fracturing is superimposed on preexisting diagenetic structures.

\section{REFERENCES}

AAPG-SEPM, 1968, Geology and oil fields, west side southern San Joaquin Valley--43rd Ann. Mtg. 1968, Guidebook: Society of Economic Paleontologists and Mineralogists, Pacific Section, Map 1:125,000 scale.

-Atwater, T. M., 1970, Implications of plate tectonics for the Cenozoic tectonic evolution of western North America: Geological Society of America Bulletin, v. 81, p. 3513-3536.

Bandy, O. L., and Arnal, R. E., 1969, Middle Tertiary basin development, San Joaquin Valley, California: Geological Society of America Bulletin, v. 80, p. 783-820.

Bartow, J. A., 1987, The Cenozoic evolution of the San Joaquin Valley, California: U.S. Geological Survey, Open-File Report no. 87-58, p. 74.

Bartow, J. A., 1991, The Cenozoic evolution of the San Joaquin Valley, California: U.S. Geological Survey, Professional Paper no. 1501, p. 40.

Blake, M. C., Jr., Campbell, R. H., Dibblee, T. W., Jr., Howell, D. G., Nilsen, T. H., Normark, W. R., Vedder, J. C., and Silver, E. A., 1978, Neogene basin formation in relation to plate- 
tectonic evolution of San Andreas fault system, California: American Association of Petroleum Geologists Bulletin, v. 62, no. 3, p. 344-372.

Bramlette, M. N., 1946, The Monterey Formation of California and the origin of its siliceous rocks: U.S. Geological Survey, Professional Paper no. 212, p. 57.

Callaway, D. C., and Rennie, E. W., Jr., 1991, San Joaquin basin, California, in Gluskoter, H.J., Rice, D. D., and Taylor, R.B., eds., Economic Geology, U.S.: Geological Society of America, The Geology of North America, v. P-2.

Castillo, D. A., and Zoback, M. D., 1994, Systematic variations in stress state in the southern San Joaquin Valley; inferences based on well-bore data and contemporary seismicity: American Association of Petroleum Geologists Bulletin, v. 78, no. 8, p. 1257-1275.

Cowan, D. S., and Bruhn, R. L., 1991, Late Jurassic to early Late Cretaceous geology of the U.S. Cordillera, in Burchfiel, B. C., Lipman, P.W., and Zoback, M. L., 1991, The Cordilleran orogen: Conterminous U.S.: Geological Society of America, The Geology of North America, v. G-3, p. 169-204.

Davis, T. L. and Lagoe, M. B., 1988, A structural interpretation of major tectonic events affecting the western and southern margins of the San Joaquin Valley, California, in Graham, S.A., ed., Studies of the geology of the San Joaquin basin: SEPM Book no. 60, Society of Economic Paleontologists and Mineralogists, Pacific Section, Los Angeles, p. 65-87.

DeCelles, P. G., 1988, Middle Cenozoic depositional, tectonic, and sea level history of southern San Joaquin basin, California: American Association of Petroleum Geologists Bulletin, v. 72, no. 11, p. 1297-1322.

Dibblee, T. W., Jr., 1959, Geologic map of California: San Luis Obispo sheet: U.S. Geological Survey, scale 1:250,000.

Dibblee, T. W., Jr., 1977, Strike-slip tectonics of the San Andreas fault and its role in Cenozoic basin evolvement: Late Mesozoic and Cenozoic sedimentation and tectonics in California: San Joaquin Geological Society, p. 26-38.

Dickinson, W. R., and Seely, D. R., 1979, Structure and stratigraphy of forearc regions: American Association of Petroleum Geologists Bulletin, v. 63, no. 1, p. 2-31.

Dickinson, W. R., and Snyder, W., 1979, Geometry of triple junctions related to San Andreas transform: Journal of Geophysical Research, v. 84, p. 561-572. 
Goodman, E. D., 1989, The tectonics of transition along an evolving plate margin--Cenozoic evolution of the southern San Joaquin basin, California: Ph.D. Dissertation, University of California, Santa Barbara, 255 p.

Goodman, E. D., and Malin, P., 1992, Evolution of the southern San Joaquin basin and midTertiary transitional tectonics, central California: Tectonics, v. 11, p. 478-498.

Graham, S. A., and Williams, L. A., 1985, Tectonic, depositional and diagenetic history of Monterey Formation (Miocene), central San Joaquin basin, California: American Association of Petroleum Geologists Bulletin, v. 69, no. 3, p. 385-411.

Graham, S. A., Stanley, R. G., Bent, J. V, and Carter, J. B., 1989, Oligocene and Miocene paleogeography of central California and displacement along San Andreas fault: Geological Society of America Bulletin, v. 101, no. 5, p. 711-730.

Harding, T. P., 1976, Tectonic significance and hydrocarbon trapping consequences of sequential folding synchronous with San Andreas faulting, San Joaquin Valley, California: American Association of Petroleum Geologists Bulletin, v. 60, no. 3, p. 356-378.

Hoots, H. W., 1930, Geology and oil resources along the southern border of San Joaquin Valley, California: U.S. Geological Survey Bulletin, v. 812, p. 243-332.

Howard, J. H., 1968, Recent deformation at Buena Vista Hills, California: American Journal of Science, v. 266, p. 737-757.

Huffman, O. F., 1972, Lateral displacement of upper Miocene rocks and Neogene history of offset along the San Andreas fault in central California: Geological Society of America Bulletin, v. 83 , no. 10, p. 2913-2946.

Isaacs, C. M., 1981, Porosity reduction during diagenesis of the Monterey Formation, Santa Barbara coastal area, California, in Garrison, R. E., and Douglas, R.G., eds., Monterey Formation and related siliceous rocks of California: Society of Economic Paleontogists and Mineralogists, Pacific Section, Los Angeles, 327 p.

Isaacs, C. M., 1982, Influence of rock composition on kinetics of silica phase changes in the Monterey Formation, Santa Barbara area, California: Geology, v. 10, p. 304-308.

Koch, T. W., 1933, Analysis and effects of current movement on an active fault in Buena Vista Hills oil field, Kern County, California: American Association of Petroleum Geologists Bulletin, v. 17 , no. 3, p. 694-712. 
Kruge, M. A., and Williams, L. A., 1982, Silica diagenesis in the Monterey Formation (Miocene) in the Lost Hills oil field, San Joaquin Valley, California, in Williams, L. A. and Graham, S.A., eds., Monterey Formation and associated coarse clastic rocks, central San Joaquin basin, California: Society of Economic Paleontologists and Mineralogists, Pacific Section, p. 95.

Lettis, W. R., 1985, Late Cenozoic stratigraphy and structure of the west margin of the central San Joaquin Valley, California, in Weide, D. L., ed., Soils and Quaternary geology of the southwestern United States: Geological Society of America Special Paper no. 203, p. 97-114.

Maher, J. C., Carter, R. D., and Lantz, R. J., 1975, Petroleum geology of Naval Petroleum Reserve No. 1, Elk Hills, Kern County, California: U.S. Geological Survey, Professional Paper no. 912,109 p.

Namson, J. S., and Davis, T. L., 1988, Seismically active fold and thrust belt in the San Joaquin Valley, California: Geological Society of America Bulletin, v. 100, no. 2, p. 257-273.

Nason, R. D., Cooper, A. K., and Tocher, D., 1968, Slippage of the Buena Vista thrust fault: in Karp, S., ed., Geology and oil fields, west side southern San Joaquin Valley: AAPG, SEG, SEPM Pacific Sections, 43rd Annual Meeting Guidebook, p. 141.

Nilsen, T.H., 1996, Regional geology of the southwestern San Joaquin basin, California: in Nilsen, T.H., Wylie, A. S., Jr., and Gregory, G.J., eds., Geology of the Midway-Sunset oil field: AAPG Field Trip Guidebook, p. 7-38.

Pisciotto, K. A., and Garrison, R. E., 1981, Lithofacies and depositional environments of the Monterey Formation, California, in Garrison, R. E. and Douglas, R.G., eds., Monterey Formation and related siliceous rocks of California: Society of Economic Paleontologists and Mineralogists, Pacific Section, Los Angeles, 327 p.

Redwine, L., 1981, Hypothesis combining dilation, natural hydraulic fracturing, and dolomitization to explain petroleum reservoirs in Monterey Shale, Santa Maria area, California, in Garrison, R. E., and Douglas, R.G., eds., Monterey Formation and related siliceous rocks of California: Society of Economic Paleontologists and Mineralogists, Pacific Section, Los Angeles, $327 \mathrm{p}$.

Stewart, J. H., and Crowell, J. C., 1992, Strike-slip tectonics in the Cordilleran region, western United States, in Burchfiel, B. C., Lipman, P.W., and Zoback, M. L., eds., The Cordilleran orogen: Conterminous U.S.: Geological Society of America, The Geology of North America, v. G-3.

Snyder, W. S., 1987, Structure of the Monterey Formation: Stratigraphic, diagenetic, and tectonic influences on style and timing, in Ingersoll, R. V., and Ernst, W.G., eds., Cenozoic basin 
development of coastal California, Rubey Volume VI: Prentice-Hall, Inc., Englewood Cliffs, New Jersey, p. 496.

Snyder, W. S., Brueckner, H.K., and Schweickert, R.A., 1983, Deformational styles in the Monterey Formation and other siliceous sedimentary rocks, in Isaacs, C. M., and Garrison, R. E., eds., Petroleum generation and occurrence in the Miocene Monterey Formation, California: Society Of Economic Paleontologists and Mineralogists, Pacific Section, p. 228.

Williams, L. A., 1982, Lithology of the Monterey Formation (Miocene) in the San Joaquin Valley of California, in Williams, L. A., and Graham, S.A., eds., Monterey Formation and associated coarse clastic rocks, central San Joaquin basin, California: Society of Economic Paleontologists and Mineralogists, Pacific Section, p. 95.

Williams, L. A., 1988, Origins of reservoir complexity in Miocene Monterey Formation of California, in Graham, S.A., ed., Studies of the geology of the San Joaquin basin: Book no. 60, Society of Economic Paleontologists and Mineralogists, Pacific Section, Los Angeles, p. 65-87.

Williams, L. A., 1990, Description of the Monterey Formation: Chico Martinez Creek Area, Western Kern County, California, in Kuespert, J.G., and Reid, S.A., eds., Structure, stratigraphy and hydrocarbon occurrences of the San Joaquin basin, California: SEPM and AAPG, Pacific Sections, Bakersfield, California, p. 347-355.

Witt, J. W., 1958, Measured movement along the surface trace of an active thrust fault in the Buena Vista Hills, Kern County, California: Seismological Society of America Bulletin, v. 48, p. 169-176.

Zoback, M. D., Zoback, M. L., Mount, V. S., Suppe, J., Eaton, J. P., Healy, J. .H., Oppenheimer, D., Resenberg, P., Jones, L., Raleigh, C. B., Wong, I.G., Scotti, O., and Wentworth, C. M., 1987, New evidence on the state of stress of the San Andreas fault system: Science, v. 238, p. 11051111.

Zoback, M. L., and Zoback, M. D., 1989, Tectonic stress field in North America and relative plate motions, in Slemmons, B., et al., eds., Neotectonics of North America, The Geology of North America: Geological Society. 


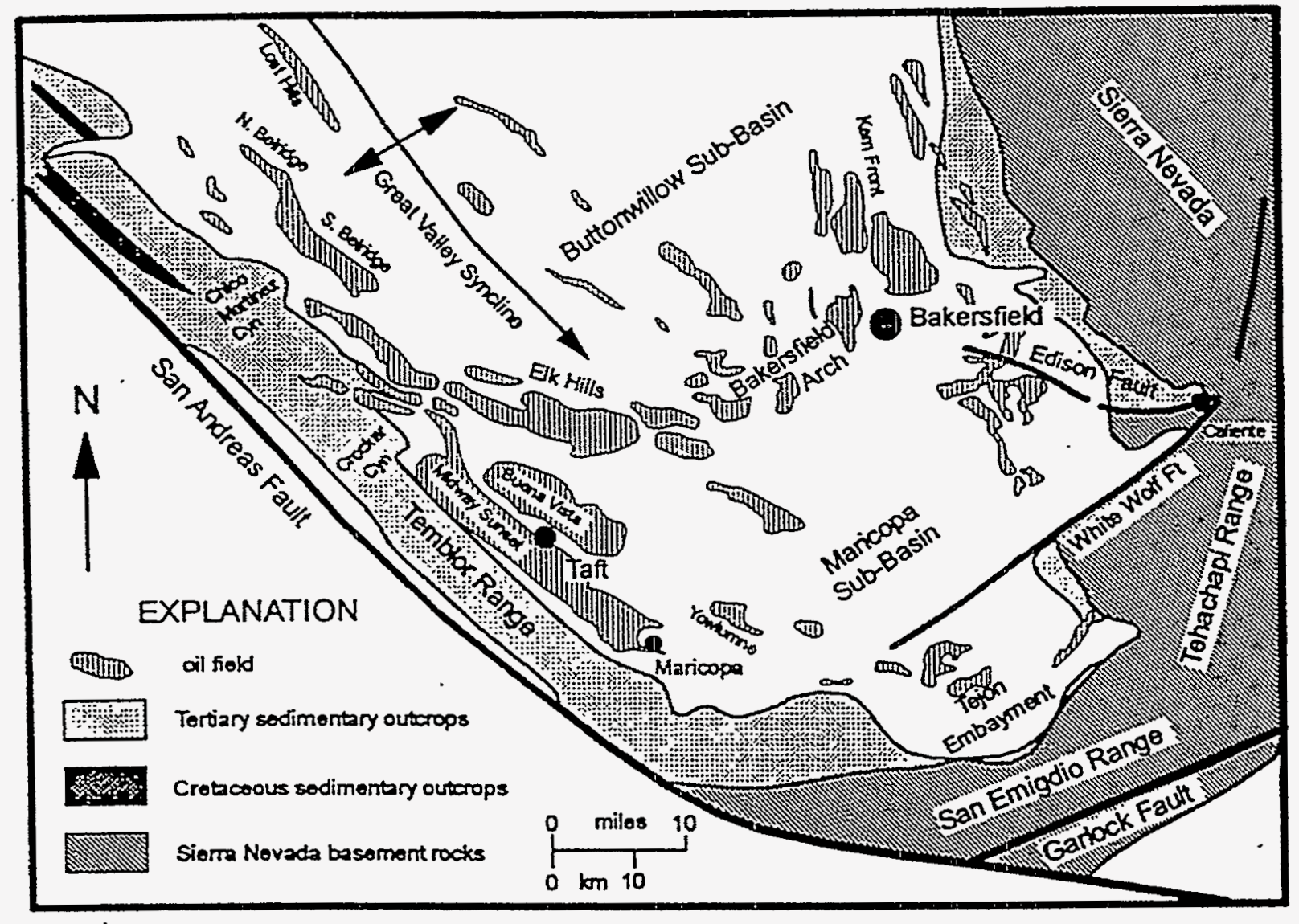

Figure 2a.1. Regional map of southern San Joaquin Valley, California (from Nilsen, 1996). 


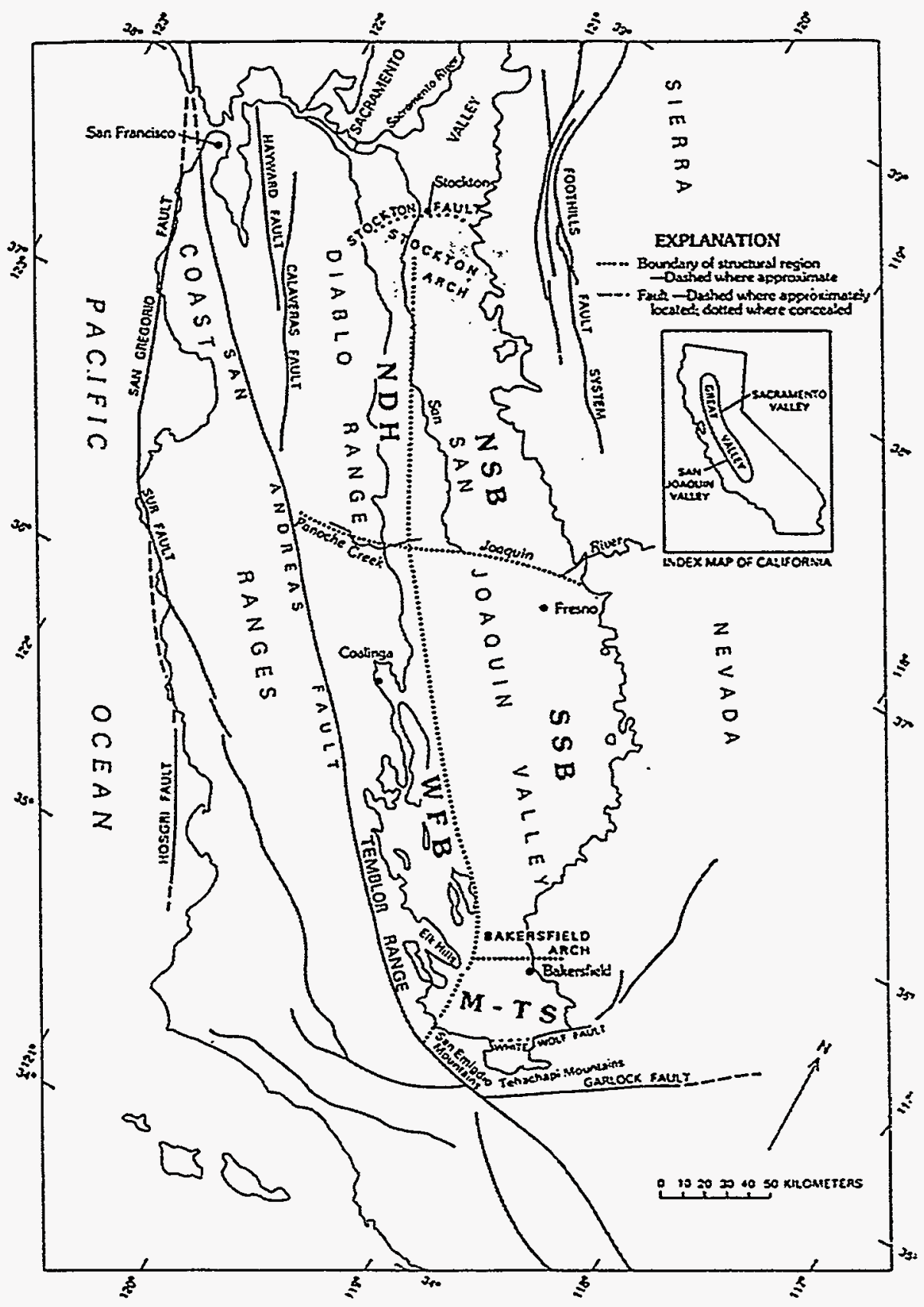

Figure 2a.2. Index map of central California showing the five structural regions of the San Joaquin Valley in relation to principal geographic and structural features. NSB, northern Sierran block; SSB, southern Sierran block; NDH, northern Diablo homocline; WFB, westside fold belt; M-TS, Maricopa-Tejon sub-basin and south-margin deformed belt (from Bartow, 1991). 
Section $2 b$.

\author{
Regional Tectonic Synthesis of the Southern San Joaquin Basin \\ Part II. Structural Analysis and Natural Fracture Detection \\ David Campagna and Ned Mamula \\ Advanced Resources International, Inc.
}

\title{
SUMMARY
}

This investigation is part of the Chevron/DOE Class III investigation of enhanced oil production within tight, siliceous shales of the Monterey Formation in the Buena Vista Hills oil field of southern California. The work presented here represents the second part of the Regional Tectonic Synthesis of the Southern San Joaquin Basin conducted by Advanced Resources International (see Part I, Synopsis of Previous Investigations).

The study area focuses on the Buena Vista Hills oil field but encompasses much of the western fold belt of the southern San Joaquin basin. The objective of this analysis is to provide fieldscale reservoir structural analysis from meso- to macro-scale data. The primary data for this investigation are digital imagery, remotely sensed from satellite and aircraft platforms. We present a methodology that integrates image-based geomorphic and photogeologic mapping with potential field data, published surface geology, and well production data.

Regional geomorphic features were analyzed from Landsat Thematic Mapper satellite imagery across the southern San Joaquin basin, resulting in the identification of major ENE-trending structures. These structures transect a series of NW-trending folds and related thrust faults, including the Buena Vista Hills anticline. Existence of pervasive, ENE-trending, linear geomorphic features represents new structural information. We propose that with the inception of thrust-related folding, the ENE-trending fractures developed into lateral ramps, possibly with oblique components of displacement. The locations and orientations of surface fractures were mapped using high-resolution ATLAS aircraft image data over the Buena Vista Hills and a portion of the adjacent Elk Hills. It appears that folding has influenced the formation and distribution of fractures. We suggest that flexural slip during folding is the primary mechanism for the development of open fractures in the anticline.

Structural analysis suggests that the ENE-trending structures, together with the thrust faults, represent compartment-bounding faults. Structural compartments were identified over the Buena Vista Hills oil field by integrating image analyses performed at regional scale (satellite imagery) and local scale (aircraft imagery) with previous geologic mapping and gravity data. The distance between compartment-bounding faults ranges between about one to four kilometers. The distance between adjacent fold axes and aligned scarps is less than two kilometers. Cumulative production data from the Antelope Shale reservoir in the Buena Vista Hills show that the structural compartments have impermeable boundaries that partition the productive areas. 
The production data and structural analysis yield indications that gas production occurs in the Monterey Formation due to desorption. The potential for producing desorbed gas in the Monterey Formation could be enormous; wells in the west dome of the Buena Vista Hills field have produced in excess of $7000 \mathrm{MMcf}$. The key to finding and exploiting adsorbed gas may lie in identifying small reservoir compartments that can be effectively and economically dewatered.

\section{INTRODUCTION}

Industry and government estimate that significant quantities of oil and gas still exist within the productive units of the Monterey Formation of the southern San Joaquin basin, California. The reservoir rock, typically consisting of tight, siliceous shales and thin, discontinuous sands, requires fracture permeability for efficient production. It is postulated that fractures in the Monterey Formation may have developed at shallow depth due to sediment desiccation, coupled with gravity-induced down-slope extension (Williams, 1988). Many fractures in the Monterey rocks, however, display systematic orientations (Johnson and others, 1997) and recent work provides evidence for tectonic-related fractures, possibly due to bedding slip during folding (Dholakia, 1996). For this investigation, we build upon the concept that tectonic forces create and add to the natural fracture pattern. Given the existence of tectonic fractures, the limits and orientation of the connected fracture network are predictable once the structural nature of a local region is known.

This investigation is part of the Chevron/DOE Class III investigation of enhanced oil production within the tight, siliceous shales of the Monterey Formation in the Buena Vista Hills oil field, southern San Joaquin basin. The work presented here represents the second part of the Regional Tectonic Synthesis of the Southern San Joaquin Basin conducted by Advanced Resources International. For a summary of the published geological and structural works of the oilproducing folds of the western fold belt, the reader is referred to Part I: Synopsis of Previous Investigations. Part II: Structural Analysis and Natural Fracture Detection, builds upon Part I and uses satellite and aircraft imagery over the southern San Joaquin basin as its primary data source.

\section{Investigative Scope and Methodology}

It is often valuable to "step back" and observe the structural fabric of an entire region before focusing on a local area of interest. Such is the case here, where the structural analysis ultimately focuses on the Buena Vista Hills oil field. The initial study area encompasses much of the western fold belt of the southern San Joaquin basin and covers approximately 500 square miles. The San Andreas fault system and the Garlock fault system define the western and southern boundaries, respectively, of the study area and the basin. The study area's eastern boundary approximately marks the center of the basin and the northern boundary was arbitrarily drawn just north of the Lost Hills anticline. The Buena Vista Hills structure is a NW-WNW-trending, doubly-plunging anticline that is oriented obliquely to the Temblor Range and the San Andreas fault. There are two producing areas situated along the Buena Vista Hills axis: the west dome (or 
"United dome") to the northwest, and the east dome (or "Honolulu dome") to the southeast. These structural culminations are approximately three to four miles apart.

Analyzing satellite and aircraft imagery is an efficient way to evaluate both the regional and local character of natural fractures. Image interpretation provides new and important structural information, and can be used to detect local surface fractures. The objective of this analysis is to provide field-scale reservoir structural analysis from meso- to macro-scale data. The products of this structural analysis include 1) regional fault and local fracture maps, 2) delineated structural compartments within the Buena Vista Hills anticline, 3) fracture azimuths within these structural compartments, and 4) production characteristics for Antelope Shale wells within the structural compartments of the Buena Vista Hills. Based on the results outlined above, we offer recommendations for additional work.

The primary data for this investigation are digital images, remotely sensed from satellite and aircraft platforms. We present a methodology here that integrates geomorphic and photogeologic mapping with potential field data, published surface geology, and well production data. Surface geology and geophysical data provide important information to the structural analysis and help validate the image interpretation. These data sets, therefore, constrain the regional structural framework as well as indicate any significant depth-extent of surface faulting identified in the imagery. Analyzing the imagery together with geology and geophysical data in an integrated fashion, allows for a more complete structural interpretation of the area. Photogeologic techniques, coupled with standard geomorphic mapping at field-scale, should improve the success of fracture detection, and of future exploration and exploitation efforts, in the Antelope Shale of the Monterey Formation.

We conducted image analysis at two scales of investigation: a regional level at 1:100,000 scale, and a local field-level at 1:25,000 scale. Regional structure identification requires geomorphic mapping; Landsat Thematic Mapper (TM) satellite image data were chosen for this task. The results of the geomorphic mapping are then compared with published geology and gravity data for verification and determination of regional significance. Detailed mapping of geomorphic features at a mesoscopic scale (field level) is best accomplished with high-resolution image data. NASA's airborne multispectral scanner, ATLAS, was chosen for this study. This experimental instrument can be flown at a spatial resolution comparable to that of several new satellites planned for launch in the next two years. Because the resolution of ATLAS data approaches that of aerial photographs, a standard photogeologic interpretation of the image was performed. This information further strengthens the regional structural interpretation over the Buena Vista Hills. In addition, this scale of investigation includes mapping of linear geomorphic features using a procedure similar to the regional TM analysis. Due to the difference in resolution, the linear geomorphic features mapped from the ATLAS data are more likely related to individual surface fractures rather than regional structures. 
The results of the image analyses are used to help define structural compartments in the Buena Vista Hills anticline. The regional structural interpretation of the TM data is checked against the ATLAS photogeologic mapping. Where regional TM-based alignments appear to affect the structural nature of the anticline, a structural boundary is identified. Orientations of the detailed linear features, identified from the high-resolution ATLAS image data, are then grouped by structural compartment. In most cases the orientations of linear features differ significantly from one compartment to another, providing important local structural information.

The study concludes with a test of the structural mapping by comparing production data for the Buena Vista field with the newly identified compartments. The intent of this test is to relate the image-derived structural information to subsurface permeability, approximated by the cumulative production of all fluids (gas, oil, and water). The influence of compartments on production is noted, and implications for further production in the Buena Vista Hills, as well as the entire study area, are offered.

\section{IMAGE ANALYSIS}

Several types of imagery have been collected over the oil-producing structures of the western fold belt. Commercially available satellite image data from the Landsat Thematic Mapper sensor were selected as the primary data for regional structural analysis. Aircraft image data from NASA's ATLAS sensor were selected for detailed structural analysis of the Buena Vista Hills area.

\section{Regional Analysis}

Thematic Mapper Imagery

TM images, collected by the Landsat 4 and 5 satellites, provide excellent spectral, spatial and geometric performance at a 1:100,000 scale of investigation. Barker (1985) and Salomonson (1985) describe the TM system in detail. The TM instrument senses three spectral bands in the visible, one band in the short-wavelength infrared, two bands in the mid-infrared, and one band in the far-infrared (thermal) region of the electromagnetic spectrum. Images cover an area of about $180 \mathrm{~km} \times 180 \mathrm{~km}$ with a nominal spatial resolution of 28.5 meters. The data used in this investigation comprise part of a TM image of central California that was acquired on December 14, 1984. The data were obtained in digital format by ARI from the U.S. Geological Survey's EROS Data Center. Spatial filtering was used for improving the appearance of the imagery prior to analysis of linear geomorphic features. We applied a standard $3 \times 3$ spatial filter to "sharpen" terrain detail.

\section{Procedure}

Following a preliminary examination of the TM imagery, we decided to select and map only those geomorphic features that might be related to the regional structure of the San Joaquin basin, and that can be readily and consistently identified in the image. The primary geomorphic criteria we selected are straight drainage features and straight topographic scarps. We define "straight drainage feature" as a straight segment of a stream channel, approximately 1000 feet or 
more in length; the channel may lie in either a depositional or erosional setting. We define "straight topographic scarp" as a cliff or escarpment, probably created by the action of faulting, folding, slumping, or some other offset of the ground surface. Hundreds of these primary geomorphic features were identified and mapped during on-screen analysis of the TM imagery.

We then selected secondary geomorphic criteria to identify regionally significant linear geomorphic features. We assume that when geomorphic features appear aligned for distances greater than a mile, they likely represent some structural feature, whether a fault segment or the surface expression of a subsurface fault or flexure. When three or more segments of linear geomorphic features align in the imagery, or when a linear feature exceeds one mile, they are designated "aligned straight drainage features" and "aligned straight topographic scarps," depending on their composition. This step was performed to determine whether or not there are regional spatial alignments among the hundreds of linear features mapped from the TM image.

\section{Results}

The linear geomorphic features mapped on the TM image range in length between 1000-2000 feet. These can be divided into two groups based on orientation: NW-trending features, primarily straight scarps; and ENE-trending features, primarily consisting of straight drainages. The NW-trending features are pervasive along the San Andreas fault and within the adjacent Temblor Range. The ENE-trending features appear mostly on the eastern slopes of the Temblor Range and into the western fold belt.

The aligned features were identified and plotted with the primary linear features. Interestingly, the ENE-trending aligned drainage features are more extensive than are the aligned NW-trending escarpments. The ENE-trending aligned drainage features are organized into approximately 10to 30-mile-long geomorphic features, many of which are concave to the northwest. Almost all of the ENE-trending geomorphic features occur in the region between the Kettleman Hills to the north and Maricopa to the southeast. These features extend many miles northeastward across the major oil-producing anticlines of the western fold belt.

The orientations of these alignments suggest that they might be manifestations of secondary faults related to movement along the San Andreas fault. Many of the alignments appear to splay off the San Andreas fault system before curving back to the ENE trend. Seven of the ENEtrending alignments transect all or part of the NW-trending Midway-Sunset and Buena Vista anticlines, and several extend northeast into the Elk Hills anticline. These alignments may represent lateral ramps or some similar structural complication in the development of the folds.

\section{Integration of Published Geological and Geophysical Data}

Published geologic maps and gravity data are used to help verify results of the regional image analysis. They also provide a subsurface component of information that adds structural

relevance to the interpretation. For this work, we compare the image interpretation to previously mapped surface structure. If any features need further verification, or if a group of significant 
linear features has not been mapped, we check the validity of the interpretation with regional gravity data to ascertain any subsurface relevance.

The alignments derived from the TM image analysis were compared with the structural information available on published geologic maps. The sources of field maps include Bartow (1991) and Dibblee (1973). We digitized structural information from these maps, including: 1) anticlinal axes, 2) normal and reverse faults, 3) thrust faults, and 4) structures comprising the San Andreas fault system. Both the straight and aligned geomorphic features derived from the TM imagery relate to the regional structural trends in the southwestern San Joaquin basin. The most interesting relationship among these features occurs in the area surrounding the Midway-Sunset and Buena Vista anticlines. Apparent offset of anticlinal axes and straight scarps trending perpendicular to, and located between, adjacent pairs of the ENE-trending features are evident. The offset of fold axes raises the possibility that the ENE-trending alignments represent regional faults, which have transversely segmented the major oil-producing structures in the western fold belt. In the area east of the Temblor Range, near the center of the image, the NE-trending curvilinear features appear to intersect and offset many of the NW-trending anticlinal axes in a right-lateral sense. Further to the west, the NW-tending mapped faults within the Temblor Range do not appear to be offset along the ENE-trending features.

The gravity data used in this investigation are from Langenheim and Plescia (1991) and include digital gravity station data obtained directly from the USGS. The isostatic gravity data appear to contain more useful information regarding structural anomalies of the southern San Joaquin basin than do the Bouguer gravity data. Isostatic correction removes the long-wavelength effect of deep crustal masses that compensate the regional topography. Therefore, isostatic gravity data are more likely to reflect density variations in mid- to shallow-crustal levels of the San Joaquin basin.

Aligned features from the TM image analysis and digitized structures from the published geologic maps were registered with, and plotted on top of, the gravity anomaly map to examine possible relationships among the data sets. Prominent gravity anomalies include: 1) the NWtrending structures in the Temblor Range, 2) the NE-trending Bakersfield Arch that covers the Elk Hills and Buena Vista Hills anticlines, and 3). the deep San Joaquin basin sedimentary sequence. Anomalies in the gravity data also appear to correspond to thrust-related folds in the western fold belt. A series of NE-trending gravity anomalies apparently correspond with the ENE-oriented regional structures.

The existence of pervasive, ENE-trending linear geomorphic features represents new structural information. There are far fewer NE-trending structures on the published maps, and none are of the magnitude indicated from our study. A reason for this discrepancy might be that the scale of the published fieldwork, with its emphasis on regional tectonics and complicated stratigraphy, was not appropriate for mapping these features. In addition, many of the seismic surveys conducted in the San Joaquin basin have been oriented nearly perpendicular to the NW-trending 
fold axes, and, therefore, are not likely to provide subsurface information on ENE-trending structures.

\section{Buena Vista Hills Analysis}

ATLAS Imagery

ATLAS (Airborne Terrestrial Applications Sensor) is a 15-band multispectral scanning instrument operated by NASA at the Stennis Space Center. Georeferenced digital data were obtained directly from NASA. ATLAS bands 1 through 6 cover the visible through near-infrared part of the spectrum; bands 7 through 15 occur in the far-infrared (thermal). The data were acquired during a flight on October 5 . The footprint of the ATLAS image is relatively small, extending from Maricopa to the northwest, through the Taft and Ford City areas to the northern part of the Elk Hills anticline (see Figure 3). A false-color infrared composite was made by displaying bands 4, 6 and 2 as red, green and blue, respectively. This composite rendered the best terrain detail in the Buena Vista and Elk Hills. Extensive areas of recent grass fires (dark purple to black) cover a significant part of the image, particularly in the Buena Vista Hills, somewhat hindering the identification of linear geomorphic features in those areas.

\section{Procedure}

The analysis of the ATLAS data was conducted on-screen at a scale of 1:18,000. Photogeologic mapping focused specifically on structural features seen in the imagery, including fault traces and relative motion (where observable), fold axes, and dip directions. Lithologic boundaries were not mapped due to limitations of the image data. Linear geomorphic features were also identified, similar to the regional analysis performed on the TM imagery. In this case, drainagerelated features were divided into two criteria: erosional channels, as represented by arroyos, and depositional channels, as represented by flowing drainage systems. The minimum mapping length was 500 feet.

\section{Results}

Most of the mapped faults trend NE; a few trend NW or E. The majority of fold axes are NWtrending, with some oriented WNW. In the vicinity of the Buena Vista Hills-Elk Hills area some of the major NW-trending fold axes, particularly the Buena Vista Hills anticline, appear to be offset by NE- and ENE-trending faults. In other instances, NW-trending fold axes appear to be truncated by or terminated against NE-, ENE- and E-trending faults. Many of the mapped folds have a sinuous axial trace, particularly the Buena Vista Hills anticline. The fold axis on the southwest flank of the Elk Hills anticline is locally offset by three or more NE- and ENEtrending faults. In this case, the NE-trending fault cuts the fold axis into discrete sections. Other folds are not obviously offset, but are bounded by faults along which the fold axes either abruptly terminate or change direction.

The ATLAS imagery was also analyzed using geomorphic criteria similar to that used for the TM data: straight escarpments, straight arroyos and straight drainages. Most of these features trend NE; a few trend E and fewer still trend NW. Straight drainages appear to be more 
randomly orientated (i.e. trending NW, NE and $\mathrm{E}$ ), and are far fewer in number than the other types of linear features mentioned. Alignments of these features were not interpreted in the ATLAS imagery; we believe the local scale of observation makes it inappropriate to extract regional information from data at this scale.

\section{STRUCTURAL INTERPRETATION}

\section{Regional Structures in the Western Fold Belt}

The western fold belt is noted for its NW- to E-trending, thrust-related folds. Collectively, the folds of the western fold belt indicate N-S to NE-SW compression throughout the Cenozoic (Bartow, 1991). Initial N-S directed principal horizontal stress might have formed $\mathrm{E}-\mathrm{W}$-oriented thrusts in association with right-lateral movement along the San Andreas fault (Simonson, 1991; Sylvester, 1988; Harding, 1988). Abundant paleomagnetic evidence gathered in central and southern California confirms significant clockwise rotation of large blocks of the crust, associated with ongoing right-lateral displacement along the San Andreas fault (Sylvester, 1988). Other conceptual frameworks, however, have redefined the role of the San Andreas fault system in the formation of thrust-related folds. It is now thought that the San Andreas fault system is a "weak" fault, unable to transmit stress across its boundary (Mount and Suppe, 1987). In this scenario, the strike-slip fault accommodates all of the lateral strain while thrust-related folding accommodates all the constrictional strain.

The geometry and history of displacement between the San Andreas and Garlock fault systems complicate the regional stress pattern (Castillo and Zoback, 1994). The Garlock fault is an intraplate, left-lateral strike-slip fault with vertical displacement reaching a maximum at its western extremity, near the intersection with the San Andreas fault. The spatial relationship between these faults changes the orientation of the stress field in the southern San Joaquin basin. The principal stress orientation changes from NE in the northern extent of the study area to nearly ENE in the vicinity of Buena Vista Hills. South of the study area, in the locus of the intersection between the San Andreas and Garlock fault systems, the principal stress orientation . is essentially NS.

Image analysis reveals two conspicuous indictions that the strike-slip fault systems influence the structural nature of the western fold belt. First, in the southern third of the study area, reverse faults and folds are at an oblique angle to the San Andreas fault system. This obliquity dissipates eastward from the fault system until the thrusts and folds are oriented nearly parallel to the San Andreas fault (e.g., the Lost Hills anticline). Structures do parallel the strike-slip system, however, in the Temblor Range due to their close proximity. This structural pattern could be explained by strike-slip kinematics where the secondary structures occur in the compressional quadrant of the strike-slip fault system. Second, the ENE geomorphic features mostly parallel the measured present-day stress field, even where the stress directions deviate in the region near the intersection of the two major fault systems. 
The aligned linear drainage features appear to represent a series of discrete NE-ENE-trending fractures/faults that transect the southern San Joaquin basin. The discovery of pervasive ENEtrending linear geomorphic features represents new structural information. We have found little published information regarding the existence of regional ENE-trending structures in the southern San Joaquin basin in general, or in the Buena Vista Hills- Elk Hills area in particular. NE-trending faults identified in the northeastern Elk Hills, based on surface mapping (e.g. Maher and others, 1975; Dibblee, 1973) and subsurface data (Nicholson, 1990), can be identified in the TM imagery (ATLAS imagery did not cover the specific area). No similar NE-trending faults have been field-mapped in the Buena Vista Hills. The location of some depositional features in the form of a series of NE-trending submarine canyons may have been tectonically controlled along the NE-trending structures (Nilsen, 1997).

The origin and timing of the ENE-trending regional structures, however, are not well constrained. The structures do parallel present-day stress orientations, however, and this suggests that they may have originated as fractures - possibly joints. The thrust-related folds are influenced by these structures, as evidenced by the termination of folds and by marked changes in structural styles across the ENE-trending structures. These are common characteristics across lateral ramps in thrust-fold systems. We postulate that, with the inception of thrust-related folding, ENE-trending joints or fractures developed into lateral ramps, possibly with oblique components of slip.

In summary, thrust-related folding near the Buena Vista Hills appears to be structurally influenced by the San Andreas fault system. Eastward from the Temblor Range this influence wanes, and the structures become more simple and coherent. The transverse ENE-trending faults may have initiated as joints or fractures parallel to the direction of principal compressive stress. With increasing strain, they evolved into lateral ramps with oblique slip that may include leftlateral and reverse components. As lateral ramps, these structures developed relatively impermeable surfaces that partition the folds into discrete structural compartments.

\section{Structural Compartments}

The concept of compartmentalization may provide an important structural/exploration model in the western fold belt. Faults transverse to the regional structural trend can act as relatively impermeable barriers or structural traps where they intersect fold axes. They also must be considered in determining regional balance of structures and/or for explaining simple offset of local structural trends. The observed characteristics of transverse faults in other oil-producing basins include abrupt changes in structural asymmetry on opposite sides of the faults, but with structural balance maintained from one compartment to another. These characteristics are applicable to areas where transverse faults often serve as "regional zones of displacement transfer" between neighboring thrust faults (e.g. Brown, 1984). Therefore, together with the thrust-fold geometry, the transverse faults create structural compartments that may, in turn, relate to pressure compartments and production variation within the reservoir. 
Conditions similar to those described above are particularly evident in the Buena Vista Hills anticline. Three characteristics suggest that the ENE-trending structures, together with the NWtrending thrusts, represent compartment-bounding faults. First, the length of many of the NWoriented folds in the western fold belt appears to be controlled by the spacing between adjacent ENE-trending structures. Second, many of these smaller NW-trending folds appear to be truncated against or terminated by NE-trending curvilinear structures. Third, there appears to be a pattern of right-lateral offset of major and minor fold axes (and scarps) across the ENEtrending structures.

We delineated structural compartments using the geomorphic alignments derived from the TM imagery, integrated with the gravity data and published geologic information. The initial interpretation was then checked against detailed photogeology as mapped from the ATLAS data (therefore limiting the area of our structural analysis to the extents of the ATLAS imagery). Key indicators of compartment boundaries include direct correlation with a photogeologic fault, abrupt changes in fold style, and fold termination or offset. Where alignments in the regional structural interpretation appear to complicate the folds in the Buena Vista region, potential compartment boundaries were marked. As many as six distinct NE- to ENE-trending structures transect the Buena Vista Hills-Elk Hills area. Together with the northwest-trending fault scarps, ten structural compartments were identified: three in the Elk Hills and seven in the Buena Vista Hills (Figure 2b.1). The distance between adjacent compartmental faults ranges generally from one to four kilometers. The distance between adjacent fold axes and aligned scarps is less than one to two kilometers.

The timing and relative motion across the compartment-bounding faults in the Buena Vista Hills must have had a complex history. SW-directed thrusting along the Buena Vista Thrust (Wilt, 1958; Nason and others, 1968; Howard, 1968) is currently occurring between two ENE-oriented faults. The western end of the thrust is truncated against one ENE fault and the other end of the thrust merges into an escarpment that terminates at an ENE fault to. the east. The apparent rightlateral offset of the Buena Vista Hills anticlinal axis might also be explained by some component of oblique-slip along the same compartmental fault. For example, the longest ENE-trending compartmental fault is located between the east dome and west dome directly north of Ford City. The east dome is structurally 240 feet higher than the west dome, according to Chevron drill hole data. The vertical relief between the domes results from a component of dip-slip along the ENEtrending fault; apparent right-lateral offset of the anticlinal axis implies a component of rightlateral slip. Therefore, oblique-slip displacement must have occurred across the ENE-trending fault.

The paradigm that development wells are best located as step-outs from a producing structure should be tempered by the realization that significant differences in structure can occur on opposite sides of a compartmental fault. Important compartmental fault trends are transverse to the strike of regional structures. One exploration approach would be to acquire seismic reconnaissance lines parallel to the regional structures. In plan view, these reconnaissance lines 
would be at a relatively high angle to the compartmental fault(s), in the optimum orientation for resolving the structural geometry with seismic reflection data. Subsequent seismic lines could be arrayed parallel to regional dip on each side of the compartmental fault, thereby obtaining maximum control of anticipated changes in structural continuity across the fault.

\section{Fracture Orientations within Defined Compartments}

Most of the structural data regarding fractures in the Buena Vista Hills anticline has been gathered through analyses of recovered core. Previous analyses indicate that approximately 30 percent of the Monterey reservoir rocks are fractured, and suggest that fractures occur at all scales (Chevron, 1994). Most of the measured subsurface fractures are oriented N60-70 $\mathrm{W}$. Fracture detection in this study involves the mapping of surface fractures. The existence of structural compartments within the region limits fracture analysis to an individual compartment or group of contiguous compartments. Regionally aggregated data would have uncertain value in a compartmentalized setting.

Surface fractures, as represented by linear geomorphic features, were mapped from the ATLAS data, and their orientations were analyzed within each structural compartment. Two interesting observations can be made regarding the changes in fracture orientation from one compartment to another. First, as one travels from west to east, the fracture orientations tend to change from nearly EW to NE. This is especially noticeable in the Elk Hills, and may reflect the influence that the San Andreas fault system and related structures in the Temblor Range have in either perturbing the regional stress field, or in rotating the fractures. Thus, the further one's position is from the regional strike-slip system, the more likely that the fracture system will be aligned with the NE-trending principal compressive stress direction for the region.

The second observation is that fracture trends appear to change systematically, depending on where a compartment is located within an individual fold. Across the NW-trending compartmental boundaries, defined by the thrust faults, fracture orientations change by $90^{\circ}$ from NE outside the fold to WNW in the fold, nearly parallel to the fold axes. It appears that folding has influenced the genesis and orientations of fractures. Fracturing associated with beddingplane slip has been documented at the Chico Martinez outcrop in the Temblor Range (Dholakia, 1996). Fractures formed as splays to bedding-plane slip should be oriented perpendicular to the direction of slip (Cotterell and Rice, 1980), typically parallel to the fold axis. Thus, the orientations of fractures in the Buena Vista Hills suggest that flexural slip during folding is the primary mechanism for the development of open fractures in the anticline.

\section{STRUCTURAL COMPARTMENTS AND PRODUCTION}

Production data for wells in the Buena Vista Hills help demonstrate whether structural compartments effect the Antelope Shale reservoir. We obtained production information for the Buena Vista Hills field from Chevron (M. Morea, personal comm., 1997), including total production of gas, oil, and water since 1952. We examine the cumulative production of all fluids as a way to average out variations imposed by completion and production practices, and thus 
reveal the most permeable zones within the reservoir. Our method is simple and straightforward; we determine the influence of structural compartments by overlaying the compartmental boundaries with contours showing the total production of each fluid. We then qualitatively describe any coincidence between reservoir permeability and the structural framework.

The two structural culminations divide the Buena Vista Hills anticline into the east and west domes. On the surface, a transverse ENE-trending fault that marks the major compartmental boundary between the two domes also separates the production of fluids. There appears to be no hydraulic connectivity across this boundary. The southwest boundary of each structural compartment appears to delimit production as well, with most fluids being produced from wells adjacent to the boundary. This effect may be due entirely to structural position, as the southwest boundaries nearly coincide with the crest of the Buena Vista Hills anticline, but the asymmetrical nature of fluid production relative to the fold axis does argue for some structural influence on the southwest side.

The east dome is transected by an ENE-trending structure that divides the fold into separate compartments. Unlike the major boundary between the domes, this compartment boundary is not readily evident in the subsurface structure contour maps. A northeast-trending fault is mapped in the subsurface, however, and is probably related to the ENE-trending structure mapped in the image analysis. Along this boundary there is a distinct separation between producing wells. In the oil production data there is a pattern that parallels the ENE-trending structure in section 9 of T32S-R24E. The other fluids (water and gas) show high production restricted to the southeast of this boundary as well. This is good evidence that the ENE-trending transverse structures act as hydraulic barriers within the reservoir system.

As relatively impermeable boundaries, the ENE-trending structures may influence the amount of gas production due to desorption. Production data from the wells in sections 8 and 9, just south and east of the compartment boundary, reveal an interesting relationship between the amount of gas and the amount of water produced. Greater gas production generally occurs where less water is produced, in wells located near a compartmental boundary. Assuming that the relatively impermeable compartment boundary impedes the migration of fluid, water removal creates a localized draw-down of reservoir pressure within the compartment that promotes gas desorption within that cone of depression. Where wells are not confined by a boundary, as in section 15 , high water production does not promote high gas production.

\section{CONCLUSIONS}

Linear geomorphic features were analyzed on satellite imagery of the southern San Joaquin basin, resulting in the identification of previously unrecognized, regional, ENE-trending structures. These features transect a series of NW-trending folds and related thrust faults, including the Buena Vista Hills anticline. Two conspicuous observations from the image analysis indicate that the San Andreas and Garlock strike-slip fault systems effect the structural style of the western fold belt. First, in the southern part of the study area, reverse faults and folds 
are oriented obliquely to the San Andreas fault system, typical of secondary structures located in the compressional quadrant of a strike-slip fault. Second, the ENE-trending geomorphic features mapped are almost everywhere aligned with the measured present-day stress field, even where the stress directions deviate near the intersection of the two major fault systems.

The existence of pervasive ENE-trending linear geomorphic features represents new structural information. These features parallel the present-day principal compressive stress direction, and may have originated as joints or open fractures. These features, however, influence the thrustfold structures in the Buena Vista-Elk Hills area: they terminate folds and bound regions of differing structural complexity. These are typical characteristics of lateral ramps in thrust-fold systems. We postulate that, with the inception of thrust-related folding, the ENE-trending fractures developed into lateral ramps with oblique components of slip.

Several structural compartments were defined in the Buena Vista Hills oil field by integrating image analyses, performed at regional and local scales, with previous structural mapping, gravity data, and well production data. Three characteristics suggest that the ENE-trending structures, together with the NW-trending thrusts, represent compartment-bounding faults: 1) the length of many of the NW-oriented folds in the western fold belt appears to be controlled by the spacing between adjacent ENE-trending structures; 2) many of the smaller NW-trending folds appear to terminate against ENE-trending structures; 3) fold axes and scarps show right-lateral offset across the ENE-trending structures.

Geomorphic indicators of surface fractures were mapped using high-resolution airborne scanner imagery, and were spatially analyzed for each structural compartment. Two patterns emerge from the fracture analysis: 1) overall, moving from west to east across the study area, the dominant fracture orientation changes from $\mathrm{E}$ to $\mathrm{NE}$; this effect is especially noticeable in the Elk Hills; 2) locally, fracture orientation depends on structural position, relative to the axis of the Buena Vista anticline. In compartments outside the axial region, the dominant fracture orientation is NE. Within axial compartments the trend is WNW, nearly parallel to the fold axis. This suggests that surface fractures in the Buena Vista Hills formed as splay fractures, due to interlayer flexural slip during folding.

There is good evidence that the ENE-trending structures, together with the thrust faults, act as pressure and permeability barriers within the reservoir system. Cumulative production data from the Buena Vista Hills Antelope Shale reservoir confirm the influence of structural compartments, which partition the productive areas. On the surface, an ENE-trending fault between the west and east domes corresponds with a definite break in the production of all fluids; there appears to be no hydraulic connectivity across this boundary. The east dome is traversed by another ENEtrending structure that further subdivides the dome into compartments with distinct separation between producing wells. Unlike the major boundary between the domes, this structure is not apparent in the subsurface structure contour maps. 
There are strong indications that gas production due to desorption occurs in the Monterey Formation. The potential for producing desorbed gas in the Monterey Formation could be enormous; wells in the west dome have produced in excess of $7000 \mathrm{MMcf}$. The key to exploiting this potential may be to find small reservoir compartments that can be effectively dewatered to lower the compartment pressure. The smaller, more complex structural compartments in the study area occur near the Temblor Range. It is possible that the western portions of the Buena Vista Hills - Elk Hills region would be another promising area for gas desorption, due to the many small and structurally complicated folds.

\section{RECOMMENDATIONS}

Three recommendations are listed below that concern additional data collection and fracture studies, and a new gas play in the Monterey Formation. These recommendations emerge from the conclusions discussed above: ENE-trending transverse structures compartmentalize the reservoir at Buena Vista Hills; fractures within the anticline formed as splays to interlayer slip during folding; and gas desorption may hold excellent potential for new production in the Monterey Formation.

1) Seismic acquisition parameters. Future seismic surveys conducted in the San Joaquin basin should be designed to provide more subsurface information on ENE-trending structures. The existence of pervasive, ENE-trending structural features that form compartment boundaries represents new structural information that should be verified by seismic interpretation.

2) Field- and core-based fracture study. WNW-trending fractures mapped using the highresolution image data should be verified by fieldwork. These features could be examined in the field to confirm whether they are splay fractures, as postulated here. A core-based study would help corroborate whether these features occur in the subsurface.

3) Desorbed gas play. The relationship between compartment boundaries and trends in gas/water production strongly suggests potential for a desorbed gas play in the Monterey Formation. A more detailed examination of production history and practices may better illuminate our contention that gas production in certain areas of the Buena Vista Hills is related to gas desorption. The potential for gas desorption is probably related to compartment size; smaller compartments are better suited for the necessary pressure draw-down to induce gas desorption. Other areas in the southern San Joaquin basin could be identified where these smaller compartments exist, using the methodology that we developed here for the Buena Vista Hills.

\section{REFERENCES}

Barker, J. L., editor, 1985, Landsat-4 science characterization early results: NASA Conference Publication 2355, $2114 \mathrm{p}$.

Bartow, J. A., 1991, The Cenozoic evolution of the San Joaquin Valley, California: U.S. Geological Survey Professional Paper 1501, 40 p. 
Brown, W. G., 1984, Basement-involved tectonics: Foreland areas: American Association of Petroleum Geologists, Continuing Education Course Note Series n. 26, 92 p.

Castillo, D. A., and Zoback, M. D., 1994, Systematic variations in stress state in the southern San Joaquin Valley: Inferences based on well-bore data and contemporary seismicity: American Association of Petroleum Geologists Bulletin, v. 78, n. 8, p. 1257-1275.

Cotterell, B., and Rice, J. R., 1980, Slightly curved or kinked cracks: International Journal of Fracture, v. 16, n. 2, p. 155-169.

Dibblee, T. W., 1973, Regional geologic map of San Andreas and related faults in Carrizo Plain, Temblor, Caliente and La Panza Ranges and vicinity, California: U. S. Geological Survey Miscellaneous Map Investigation, I-757.

Dholakia, S. A., Lore, J., Brankman, C. M., and Roznovsky, R., 1996, Fault control on hydrocarbon migration in the Monterey Formation, California: Proceedings of the Stanford Rock Fracture Project Field Workshop, 112 p.

Howard, J. H., 1968, Recent deformation at Buena Vista Hills, California: American Journal of Science, v. 266, p. 737.

Harding, T. P., 1988, Comments on the "State of stress near the San Andreas fault: Implications for wrench tectonics": Geology, v. 16, p. 1151-1152.

Johnson, S. J., De, G. S., and Winterstein, D. F., 1997, Natural fracturing impacts siliceous shale reservoir development: Cymric field, California, U.S.A. (abstract): American Association of Petroleum Geologists Bulletin, v. 81, n. 4, p. 688.

Langenheim, V. E., and Plescia, J. B., 1991, Complete Bouguer gravity anomaly and isostatic residual gravity maps of the Bakersfield 1 degree by 2 degree quadrangle, California: U. S. Geological Survey Open File Report 91-554.

Maher, J. C., Carter, R. D., and Lantz, R. J., 1975, Petroleum geology of Naval Petroleum Reserve No. 1, Elk Hills, Kern County, California: U. S. Geological Survey Professional Paper 912,109 p.

Mount, V. S., and Suppe, J., 1987, State of stress near the San Andreas fault: Implications for wrench tectonics: Geology, v. 15, p. 1143-1146.

Namson, J. S., and Davis, T. L., 1988, Seismically active fold and thrust belt in the San Joaquin Valley, central California: Geological Society of America Bulletin, v. 100, p. 257-273. 
Nason, R. D., Cooper, A. K., and Tocher, D., 1968, Slippage of the Buena Vista thrust fault: Geology and oil fields, west side southern San Joaquin Valley: in Karp, S., editor, AAPG, SEG and SEPM Pacific Sections, 43rd Annual Meeting Guidebook, p. 141.

Nicholson, G. E., 1990, Structural overview of Elk Hills, in Kuespert, J.G., and Reid, S.A., editors, Structure, stratigraphy and hydrocarbon occurrences of the San Joaquin basin, California: Society of Economic Paleontologists and Mineralogists and the American Association of Petroleum Geologists, Pacific Sections, p. 133-140.

Nilsen, T. H., 1997, Geology of the east-central Temblor Range, California: in Nilsen, T. H., Wylie, A. S., and Gregory, G. J., editors, Geology of the Midway-Sunset oil field and adjacent Temblor Range, San Joaquin basin, California: American Association of Petroleum Geologists and the Society of Economic Paleontologists and Mineralogists, Guidebook GB-75, p. 89-95.

Salomonson, V. V., Smith, P. L., Park, A. B., Webb, W. C., and Lynch, T. J., 1985, An overview of progress in the design and implementation of Landsat-D systems: IEEE Transactions, Geosciences and Remote Sensing, v. GE-18, p.137-145.

Simonson, R. R., 1991, Large accumulations of oil likely beneath thrust faults in east Temblor Range area: Oil and Gas Journal, April 29, 1991, p. 69-72.

Sylvester, A. G., 1988, Strike-slip faults: Geological Society of America Bulletin, v. 100, p. 1666-1703.

Wilt, J.W., 1958, Measured movement along the surface trace of an active thrust fault in the Buena Vista Hills, Kern County, California: Seismological Society of America Bulletin, v. 48, p. 169-176. 


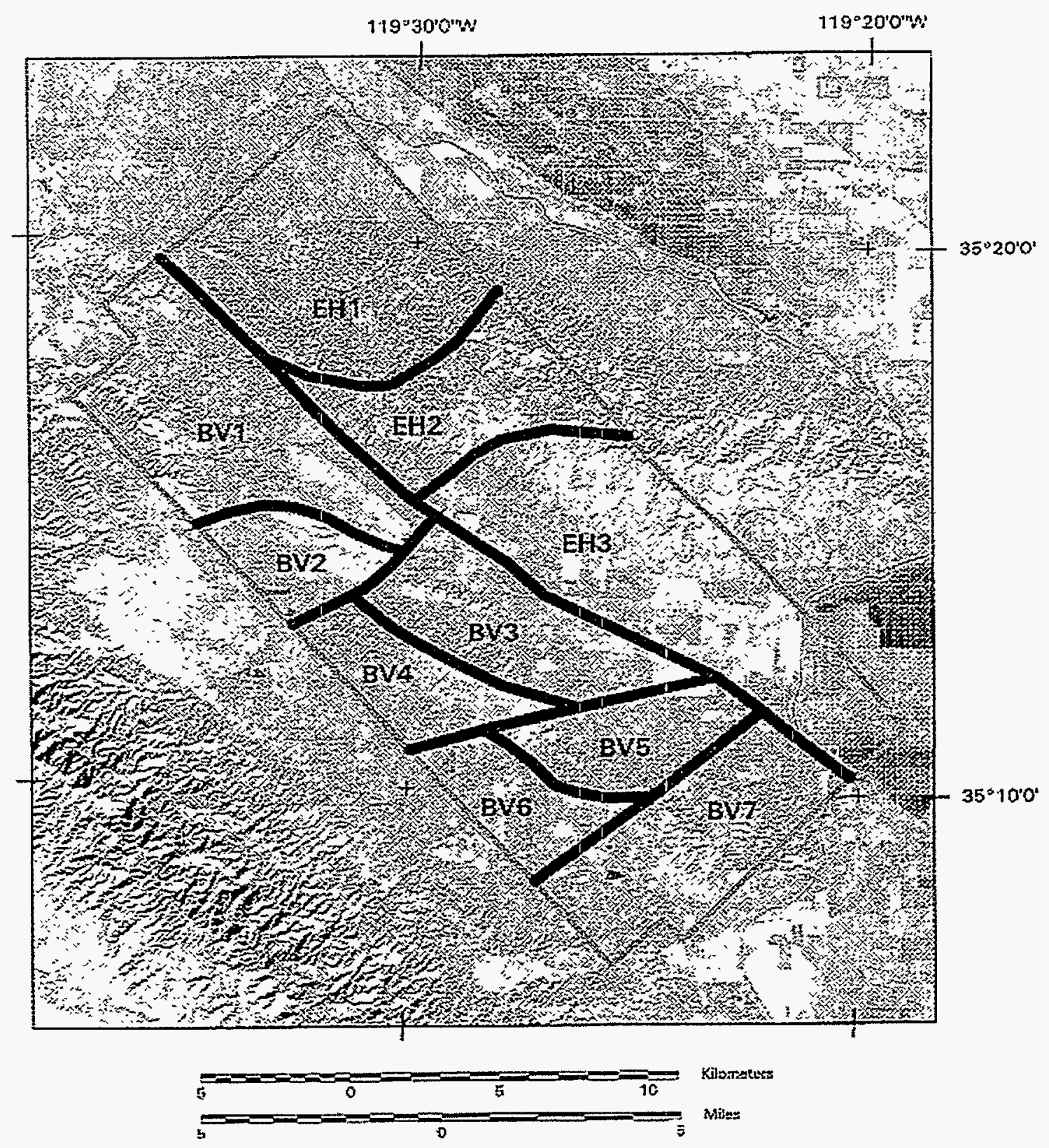

Figure 2b.1. Map of structural compartments in the vicinity of the Buena Vista Hills anticline, resulting from the intersection of NE-trending compartmental faults with NWtrending fold axes and escarpments. 


\author{
Section 2c. \\ Crosswell Imaging in the Buena Vista Hills \\ Bob Langan \\ Chevron Petroleum Technology Company \\ Jerry Harris \\ Seismic Tomography Project \\ Stanford University
}

\begin{abstract}
SUMMARY
In March 1997 we successfully completed the acquisition of four crosswell profiles in the Buena Vista (BV) Hills pilot study area using the TomoSeis acquisition system. One motivation for collecting this data was that surface seismic data acquisition has been historically unsuccessful at obtaining images over San Joaquin Valley (SJV) anticlines, and BV Hills is no exception. We also needed a basis for characterizing the interwell region of the study area for evaluation as an EOR pilot, and we wanted to establish baselines for potential time-lapse monitoring of the pilot area should the EOR program proceed.
\end{abstract}

The size of the profiles ranged from about 40,000 traces to 70,000 traces. On average it took about 3.5 days to acquire each profile, but had the source been about $5 \mathrm{~dB}$ more powerful, or had we known in advance what the optimal acquisition strategy would be in this new environment, the average acquisition time might have been cut to 2 days per profile.

The data were acquired with the idea of obtaining three different types of crosswell images: velocity, reflection, and attenuation. This required us to re-shoot many of the source-receiver combinations with different sweep and stacking parameters because different imaging technologies place different constraints on the acquisition parameters. Velocity images have been routinely obtained from crosswell data in the San Joaquin Valley in the past, but we are aware of only one other instance where a crosswell reflection image has been obtained (Tura et al., 1994, Geophysics), and its frequency content was on the order of $100 \mathrm{~Hz}$. Attenuation images are a totally new area of academic research and we have only a general feeling as to what to expect with their application.

Based upon field observation of the raw data, we felt that all four profiles were suitable for velocity imaging, that two of the profiles (563-653 and 564-653) were suitable for reflection imaging, and that the outcome of attenuation imaging was unknown. In practice we were able to obtain all three types of images for all four profiles, but two of the reflection image profiles are of somewhat poor quality at this time.

The velocity and reflection images confirm the structure of the anticline as inferred from the well data alone. The reflection images also suggest the presence of one or two major fractures in the 
interwell region, depending on whether one concludes we have imaged the same fracture with two different profiles, or we have imaged two separate fractures. The relatively low resolution attenuation images suggest that there are "soft spots" near the center of the five-spot pattern, but they are hard to correlate with the other images at this time.

\section{DATA ACQIUSITION}

The five wells in the pilot study area form a traditional "five-spot" pattern (an " $X$ " in plan view) along the northeast flank of the United Anticline (Figure 2c.1). The central well (653Z) will be used as an injection well if the decision is made to proceed with $\mathrm{CO} 2$ injection while the four surrounding wells $(553,554,563$, and 564$)$ will be producers. Well $653 Z$ crosses the Brown Shale and upper Antelope Shale (the zones of interest) at about a 15 degree angle to the vertical while the four producers are vertical. The deviation of the central well is such that the plane of the deviation is at about a 45 degree angle to all the profiles (in plan view). Because of the deviation in $653 \mathrm{Z}$, well spacings varied from $440 \mathrm{ft}$ to $850 \mathrm{ft}$.

Four crosswell profiles were shot, with the source being placed in each of the four corner wells and the receiver always being placed in the central well. Two of the profiles are approximately on strike with geologic structure and two are $90^{\circ}$ to strike. One factor that contributed to the success of the surveys was that $653 Z$ was not open to the reservoir. Thus, $653 Z$ provided a quiet environment in which to place the receivers.

The four corner wells are all producing wells that produce gas out of solution through slotted liners over a several hundred foot interval. The slotted liners end at about the top of the Brown Shale. The coupling characteristics of the source were dependent on whether the source was "firing" in slotted liner, standard casing, or zones of overlap of slotted liner and casing. As a result, we shot major portions of the surveys twice using different acquisition parameters because we were unsure what parameters would be optimum for the various image types we would attempt to obtain in this new environment.

We utilized the TomoSeis acquisition system, which is relatively low cost. It employs a 5-level hydrophone string and a patented piezoelectric swept source which is based upon resonant cavity technology. All devices are fluid coupled to the borehole wall. The source can be fired while it is moving in a manner equivalent to a traditional logging run, and it is this "logging on the fly" that results in low cost and rapid data acquisition rates. Our application of this technology is the first successful one in the SJV, because conventional wisdom was that this system did not have sufficient energy to work in these highly attenuative rocks.

In general, we swept the source from $300 \mathrm{~Hz}$ to $2000 \mathrm{~Hz}$ over $1.2 \mathrm{sec}$ and stacked either 4 or 8 sweeps for each source point. In some areas where we felt we were losing too much signal, we reduced the sweep to a $450 \mathrm{~Hz}$ to $1600 \mathrm{~Hz}$ band and re-shot much of the profile. Attenuation imaging assumes that consistent frequency characteristics are maintained by the source over the whole survey, while velocity imaging requires adequate signal-to-noise $(\mathrm{S} / \mathrm{N})$ ratios on 
transmitted energy only. Reflection imaging is best if the reflected energy is broad-banded and has adequate $\mathrm{S} / \mathrm{N}$ ratios. The result of our strategy was that although about 70,000 traces of data were acquired for each profile, only 35,000 to 40,000 of these traces are unique shot-receiver location combinations.

\section{DATA PROCESSING AND IMAGING RESULTS Velocity Imaging}

Velocity imaging ("traveltime tomography") was relatively straightforward in that the picking of firstbreak traveltimes was not especially difficult. The more difficult part has been in getting uniform convergence of the algorithm during attempts to solve for velocity. This is in part due to a need for stability improvements in the imaging algorithm, but may also be an expression of the assumptions we made to handle the out-of-plane dip of the central well (653Z), which is common to all four profiles. A second factor is likely to be the presence of anisotropy, which is not accommodated in our current isotropic models.

In Figures 2c.2-3 we present the velocity models obtained from this imaging step. They are characterized by rather constant velocity backgrounds, with thin, higher velocity "strips". There is a very poor well tie for some of the velocity profiles, which we currently attribute to poor convergence in the tomography in at least one of the profiles, improperly handled well-deviation effects, and anisotropy.

\section{Reflection Imaging}

Obtaining coherent reflection images is inherently more difficult than velocity imaging in that it is critically dependent on accurate velocity models and precise wavefield separation. Wavefield separation refers to the need to filter or remove an abundance of unwanted events in the raw data before one can focus on using the upgoing $P$-to- $P$ (compressional wave) arrivals to obtain an image much like one seen with surface seismic data, except for the frequency content. We are aware of only one prior success in obtaining a crosswell reflection imaging from SJV data, and that is the work of Tura et al. (1994) using a low frequency prototype source. Their data were confined to frequencies below $100 \mathrm{~Hz}$. Our raw data have reflection energy extending to 1500 $\mathrm{Hz}$, and our reflection imaging requires a correspondingly more accurate velocity model in order to obtain a coherent image.

In Figures 2c.2-3 we also present the reflection images obtained using an imaging algorithm based upon the VSP-CDP transform. These reflection images have better well ties than the velocity images (tomograms) used to obtain them. However, the reflection images needed to be low pass filtered at a cutoff of $900 \mathrm{~Hz}$ because the reflection energy that extended to $1500 \mathrm{~Hz}$ would not stack coherently. This is probably due to the fact that the underlying velocity models are not accurate enough and the well deviation has not been properly treated in the imaging.

The anticlinal structure in the pilot area is confirmed by both the strike and dip lines. We have interpreted specific reflection events in the images and tied them to standard SJV markers in the 
well logs. There are far more reflection events in the upper Antelope Shale $\left(\mathrm{P}_{1 c}\right.$ through $\left.\mathrm{P}_{\text {Poin }}\right)$ and lower Brown Shale $\left(\mathrm{P}_{\text {Point }}\right.$ through $\left.\mathrm{N}_{2}\right)$, than in shallower portions of the Brown Shale (above $\mathrm{N}_{2}$ ). One interesting aspect of this reflection imaging is that the reflected energy is missing some of the low-frequency energy contained in the direct arrivals used for the velocity imaging. We presently have no explanation for this phenomena.

Another interesting aspect of these images is the presence of a major disruption in the reflection continuity in two of the profiles (labeled). These disruptions may be attributable to a single major fracture or to separate fractures. If these images are sustained by refinements in the processing of the data, it would have major implications for the EOR processes being considered in this pilot area.

\section{Attenuation Imaging}

Attenuation imaging makes use of the frequency content or amplitude variation of the same direct arrivals that are used in the velocity imaging (traveltime tomography). Attenuation imaging, therefore, is dependent on first obtaining accurate velocity models. Using amplitudes to subsequently estimate $Q$ is quite challenging because of the difficulty in determining such things as coupling effects and radiation/sensitivity patterns of source and receivers used in the data collection. A more robust approach is to use the change in the frequency content of the direct arrival as a basis for obtaining a measure of the absorption or attenuation of the interwell region. One standard measure of attenuation is $Q$ (quality factor). Images of crosswell attenuation only yield a relative $Q$ and must be tied to laboratory measurements in order to obtain absolute values that can be compared to estimates of $Q$ obtained at other locations.

Attenuation calculations based upon frequency content depend on a model which says that the center frequency (centroid) of the direct arrival decreases with increased path length and increased absorption. Since $Q$ is a quality factor, small $Q$ represents high attenuation or absorption of energy. Higher frequencies are absorbed more readily than lower frequencies in general, and this relative effect is more pronounced in low $Q$ rocks than in high $Q$ rocks. The result is that for a given path length, a low $Q$ rock will cause a greater downward frequency shift than a high $Q$ rock.

The hope for attenuation imaging in the SJV is that areas of high attenuation ("soft spots") will correlate with fractured zones. In carbonates there is a suggestion that attenuation measured at crosswell frequencies correlates with permeability, but this possibility has not been explored for clastics. Attenuation imaging is so new and experimental that its resolution is likely to be poor for some time, until all the variables have been explored more thoroughly and refinements developed.

For our project, researchers at the Seismic Tomography Project at Stanford University (under Professor Jerry Harris) have developed a modification of their original centroid frequency shift scheme which now includes the rise time of the direct arrival as a way of improving the estimate 
of the degree of frequency shift in the waveform. The results of their attenuation imaging efforts are shown in Figure 2c.4.

The region of highest attenuation in these images is near the central well 653Z. Our current reflection images have no clear expression of fracturing in this zone, but future refinements may. There is also an interesting zone of low attenuation near Well 554 which seems to show up in the SP logs.

\section{CURRENT/FUTURE ACTIVITIES}

It is obvious that there is great potential for obtaining improved results from the data because of the shortcomings already cited. We are currently working on improved velocity imaging algorithms which will properly handle well deviations and will estimate small amounts of elastic anisotropy. We expect to apply these algorithms to the BV Hills data during Spring 1998 and will then reprocess the data for reflections. We expect to see immediate improvement in the reflection images following these steps.

We are also developing improved reflection imaging algorithms which can handle well deviations, elastic anisotropy, and complex structure. We anticipate completing these algorithms by Summer 1998 and will then test them on the BV Hills data as well.

\section{CONCLUSIONS}

Using crosswell velocity and reflection images, we have confirmed the interwell bed geometry and stratigraphy obtained from well logs in the EOR Pilot Area and have identified one to two major fracture systems which would impact any EOR process. We have also established baseline velocity, reflection, and attenuation images for time-lapse imaging of EOR processes at this location in the future. We were able to collect these data using the TomoSeis system at a relatively low cost. This is the first successful application of this system in the SJV. We also believe that our crosswell reflection images are the first high frequency images of this type obtained in the SJV. We have identified ways of reducing the cost of subsequent crosswell surveys of this type and have identified needed improvements in both the acquisition and imaging technology. We are currently working on imaging improvements while TomoSeis focuses on the acquisition improvements. 


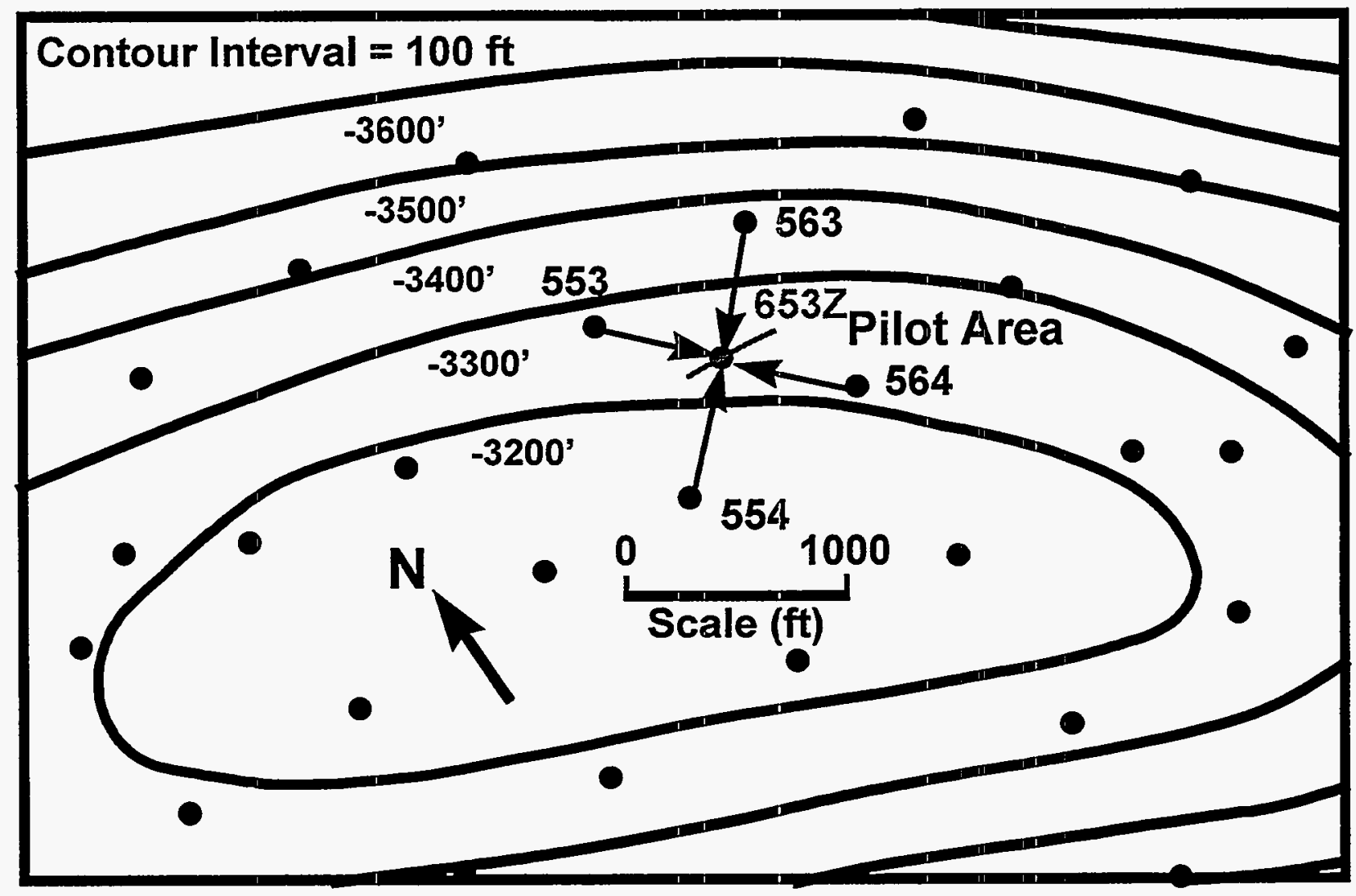

Figure 2c.1. Structure contours on P Point (top of upper Antelope Shale) in West Dome Buena Vista Hills, based on well data. Crosswell profiles are shown by arrows in pilot area and the track of Well $653 \mathrm{Z}$ at the reservoir level is shown in gray. 


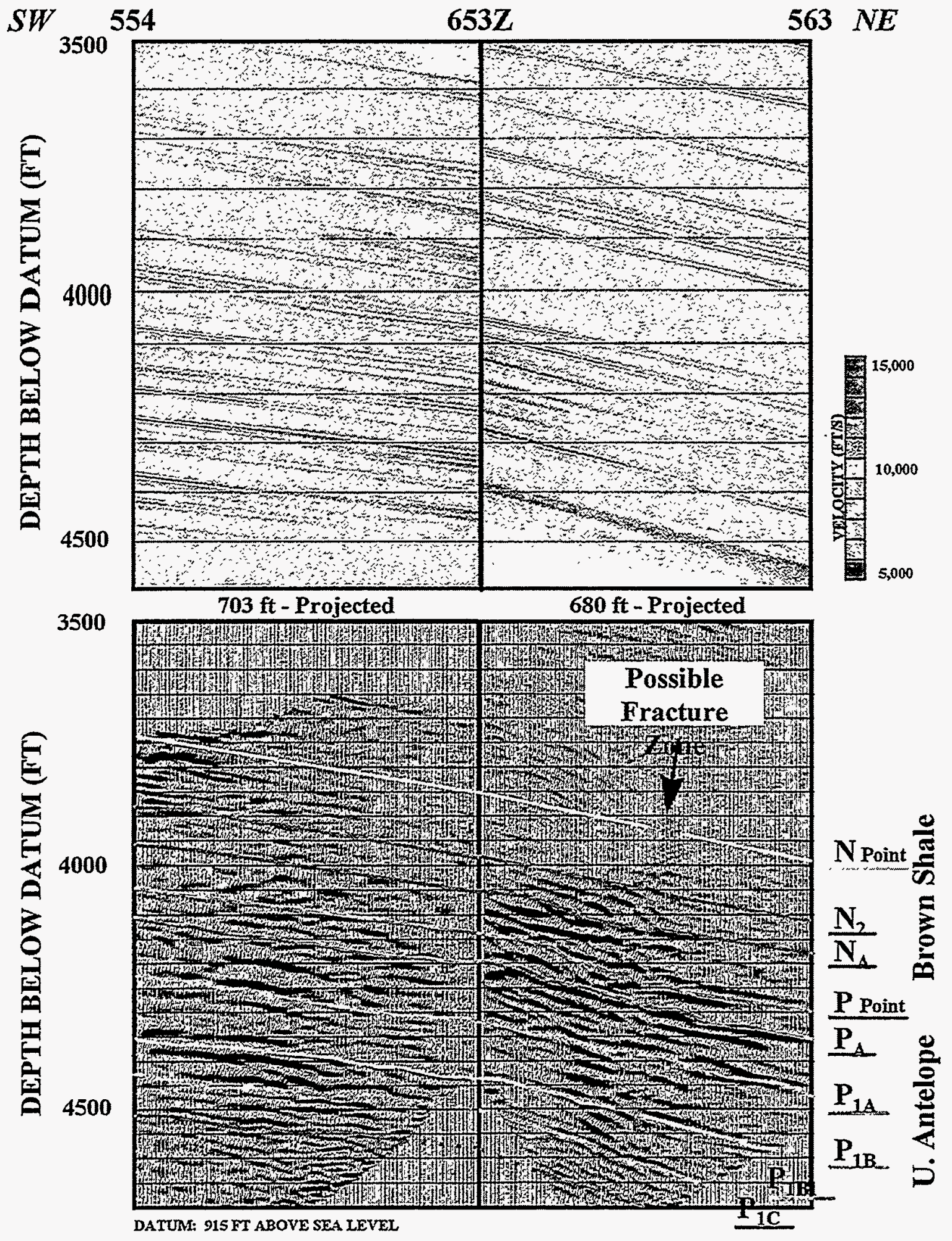

Figure 2c.2. Combined velocity-reflection images along dip in study area. 


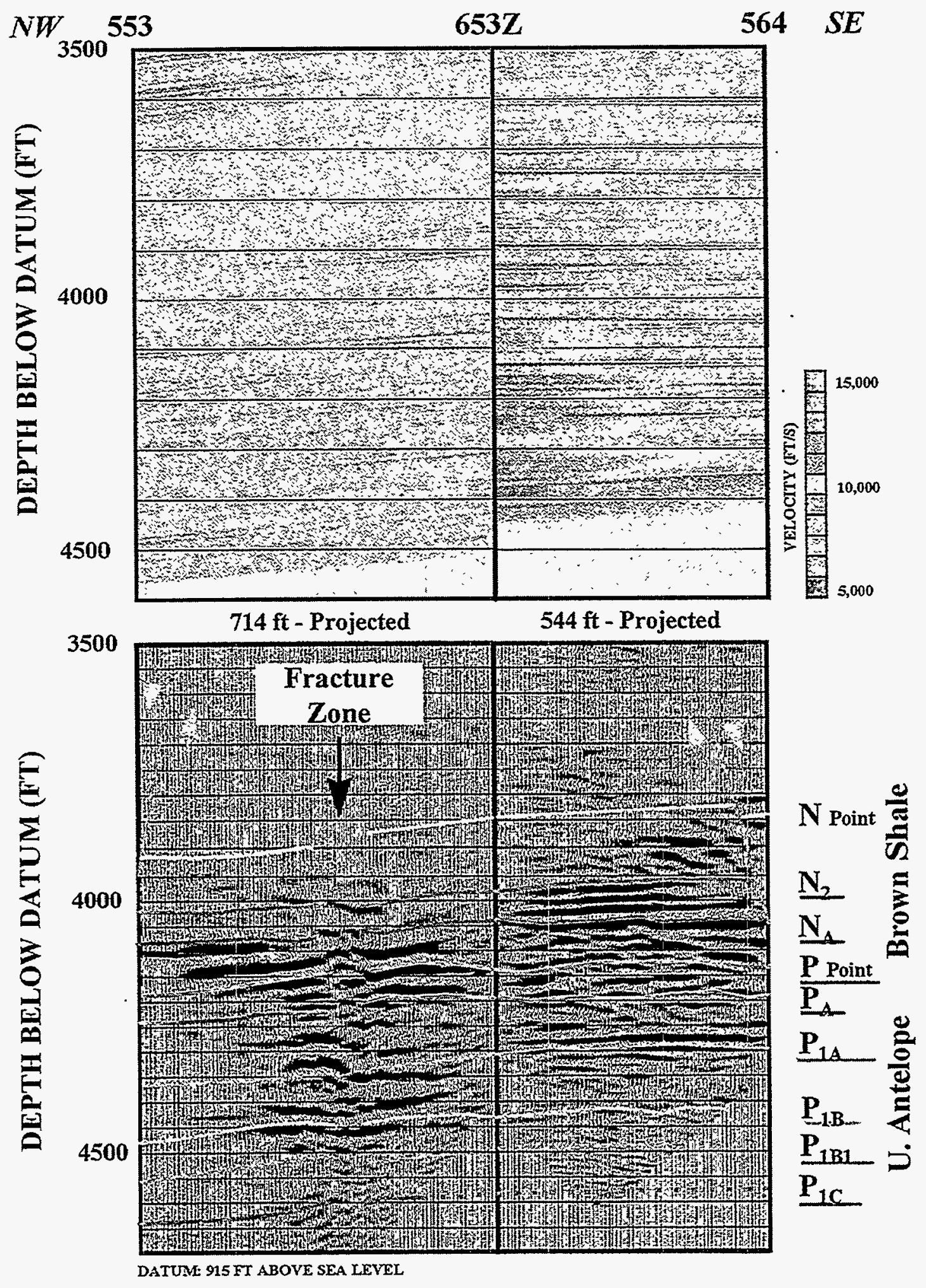

Figure 2c.3. Combined velocity-reflection images along strike in study area. 

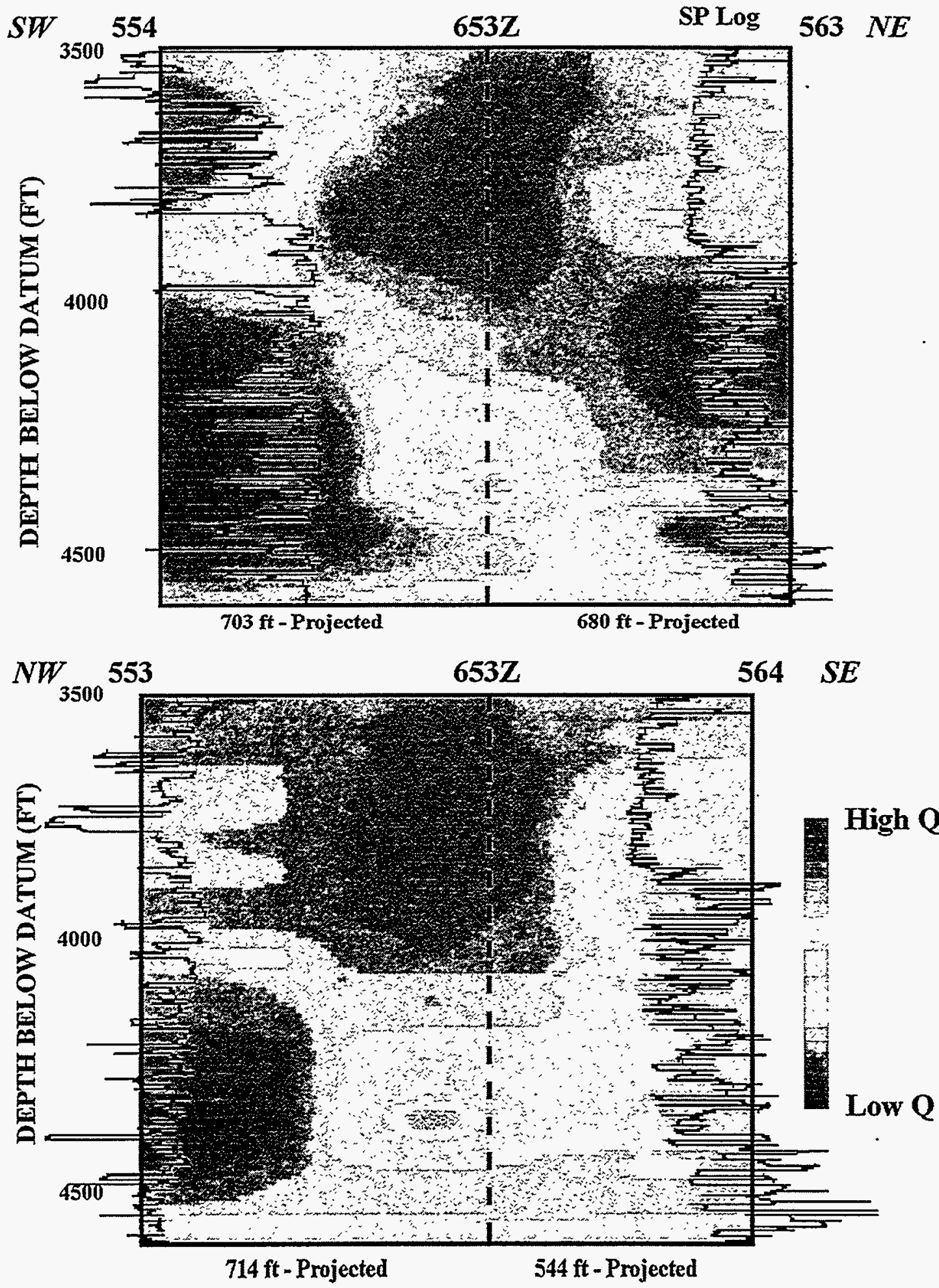

Figure 2c.4. Attenuation images in study area. The location of deviated Well $653 \mathrm{Z}$ is not accurately depicted. 


\title{
Section $2 d$. \\ Fracture Analysis of the Brown Shale \\ Buena Vista Hills, 653Z-26B \\ Atilla Aydin and Judson Jacobs \\ Department of Geological and Environmental Sciences \\ Stanford University
}

\begin{abstract}
INTRODUCTION
Over the past year we have examined the core from Chevron's 653Z-26B well to determine what, if any, effect fractures may have on production over this interval. The most promising zone appears to be the interval of sigmoidal fractures located in the Brown Shale. Initial results indicate that these features are open in the sub-surface and may serve as conduits for hydrocarbons. We have integrated core analysis, petrographic studies and outcrop observations to determine the role that sigmoidal veins may play in hydrocarbon production from the Buena Vista Hills Field.
\end{abstract}

\section{CORE OBSERVATIONS AND INTERPRETATION}

During the past year we have had access to the core obtained from the $653 \mathrm{Z}-26 \mathrm{~B}$ well, drilled on the northwestern edge of the Buena Vista Hills (BVH) Field (Figure 2d.1). During the drilling process, Chevron extracted 952 feet of traditional core from a depth of 3955 to 4907 feet with an excellent recovery rate of $98 \%$. We were also able to examine the core obtained from the nearby $32 \mathrm{X}-26 \mathrm{~B}$ well. This core is approximately 300 feet thick, segmented among a number of depth zones. It was not slabbed and is in poor condition. Nonetheless, the core from the $32 \mathrm{X}-26 \mathrm{~B}$ well assisted in determining the lateral consistency of the features we observed in the sample from the $653 Z-26 \mathrm{~B}$ well.

Though fracturing occurs throughout the cored interval, our study has focused on the fractured zones within the Brown Shale from a depth of 4200 to 3990 feet. Each zone consists of a set of systematic, regularly-spaced en echelon fractures (Figure 2d.2). Individual fractures are predominantly sigmoidal-shaped, have opened to some extent ( 1 to $3 \mathrm{~mm}$ ), and are filled with a fine-grained dark brown material. Due to the nature of the opening and fill, we will henceforth refer to these fractures as sigmoidal veins. The zones of veins are bed-parallel and are contained within discrete lithologic layers which are lighter colored than adjacent siliceous shales. Lighter color implies a higher silica content (Williams, 1988), and thus a layer more brittle and susceptible to fracture. Cloos (1955) was one of the first to demonstrate experimentally the mechanism by which zones of en echelon veins form. By applying bed parallel shear to semiconsolidated sediment, he formed features which have the same characteristics of those that we observe in the Brown Shale. 
According to the model of Cloos (1955), en echelon sigmoidal veins form normal to the sense of bed parallel shear. Consequently, vein orientation relative to bedding and other deformational features may assist in determining formation mechanism. We were able to measure the true orientations of individual en echelon veins with the aid of a mechanical core goniometer (Figure 2d.3). Chevron obtained an oriented core sample from a depth of 4105 to $4015 \mathrm{ft}$. Within this interval are fourteen zones of sigmoidal veins that were appropriate for testing. The results indicate that vein orientation differs from bedding strike by approximately 45 degrees. Slickenside orientations measured from bedding planes across this interval are similar to bedding strike. Consequently, we can conclude that the veins did not form as a result of the deformation reflected by the slickensides. It is possible though, that the veins formed normal to the original dip direction, which was later rotated.

We also performed permeability tests on the fractured zones in order to determine the effect that sigmoidal veins may have on fluid flow within the Brown Shale. Measurements were made using the Profile Permeameter PDPK-200 (supplied by Core Laboratories) by moving the measuring nozzle across the zone, parallel to bedding, and testing each individual vein and host rock area between the veins. We performed tests on twenty zones. It was difficult to fully isolate a vein from the surrounding siliceous shale matrix and adjacent veins, but we found that zones with the largest spacing produced the best results. Our tests clearly show that measurements performed on the veins yield consistently higher permeabilities than those performed on the host rock matrix (Figure 2d.4). The increase in permeability for the veins is often as great as two orders of magnitude. As the veins have a significantly higher permeability than the siliceous shales and adjacent more detrital-rich shales, the zones of veins appear to enhance the permeability of the Brown Shale.

\section{THIN SECTION EXAMINATION}

Microscale examination of sigmoidal veins is crucial to understanding the possible formation mechanism responsible for vein growth. Such analysis may also provide insight to the source of the increased permeability that we measured for the fractures. We obtained core plugs from five separate zones of the sigmoidal features found in the $653 \mathrm{Z}-26 \mathrm{~B}$ well and prepared polished, covered thin-sections. Microscale observations of sigmoidal veins were performed using standard petrographic techniques. Our work was complemented by a similar study.performed by TerraTek Inc. of Salt Lake City.

Vein fill is comprised of three major components: clay particles, diatom frustules and terrigenous detritus. Minor amounts of pyrite and other biotic grains are also present. In addition, clasts of siliceous shale host sediment are commonly found in vein interiors. These clasts can often be matched to concavities along the vein margin, suggesting that stopping of host sediment particles occurs during vein formation. Vein fill components exhibit a massive texture with no apparent sedimentary fabric. The enrichment of the vein interior, as compared to the host rock, with clay minerals suggests that some form of clay transport accompanied vein formation. 
Petrographic studies reveal two fracture styles associated with sigmoidal veins. The first form of fracturing occurs within the clay fill of the vein interior. Fractures of this type generally form in two distinct sets, one sub-parallel and one normal to the vein margin. Offsets in one set due to slippage along the other set, as well as terminations of one set at the interface of the other set are common along the entire length of the veins. Both of these observations indicate that deformation within the vein interior occurred in at least two separate stages, subsequent to growth of the sigmoidal vein itself.

The second style of fracturing occurs along the vein margins (Figure 2d.5). These are opening mode fractures which generally form at the interface of the clay-rich vein fill and the surrounding host rock. They have often been attributed to desiccation of the core or sample handling when preparing thin-sections. However, there is strong evidence that they were open in the subsurface. Though fracture growth generally occurs directly along the vein margin, there are abundant examples of fracturing proceeding into the surrounding siliceous shale (Figure 2d.5). Desiccation alone cannot account for this form of crack growth. Axial shortening due to desiccation would have to be accommodated by similar opening mode fractures forming normal to the vein margin. We have not observed such fracture growth in our examination. As a result of these observations, desiccation does not appear to play a major role in fracture development. TerraTek's study, in fact, supports the supposition that these fractures were open in the subsurface. They found that pyrite tends to concentrate along fracture walls and there is evidence of crystal growth into the fracture void space.

Petrographic examination of the thin-sections also reveals an opaque material contained both within the fractures along the vein margins as well as for those in the vein interior. The material is consistently present in the fractures within the vein interior. However, the opaque substance is present infrequently in the void space of the fractures along the vein margins. The absence of the material in these fractures may be due to grain plucking involved in the polishing process or to the solution used in sample preparation. Initial examination indicates that this material is organic and is most likely a hydrocarbon. Further analysis is planned to determine its exact nature. The presence of organic material in the fracture void space clearly demonstrates that these fractures were open at some stage during sigmoidal vein development and may serve as conduits for hydrocarbons.

\section{OUTCROP OBSERVATIONS AND INTERPRETATION}

Finally, our study has examined sigmoidal veins extensively in outcrop. Core and thin-section studies have been crucial to understanding the microscale features of vein structure and composition. At the same time, outcrop investigations are instrumental in placing these characteristics into a regional context.

Detailed observations were made at the Chico Martinez Creek (CMC) outcrop of the Temblor Range (Figure 2d.1) and at Laguna Beach, located just north of Santa Cruz. Sigmoidal veins are associated with diatomaceous sediments (and their diagenetic equivalents of chert and 
porcelanite) at both locations. They exhibit many of the same characteristics that we observe in the 653Z-26B core: a sigmoidal shape, opening mode form and a rich clay fill. However, the zones of sigmoidal veins that we observe at CMC differ from those that we observe at Laguna Beach and in core, both in their complexity of interaction between adjacent zones as well as their occurrence rate.

The Laguna Beach site provides an excellent opportunity to study sigmoidal veins in-situ. Numerous outcrop faces along the beach expose complete cross-sectional views of the fractured zones, while the interaction of individual veins within in a zone can be studied in map view along extensive bedding surfaces. The 100 meter long section of Monterey Formation that we examined represents a portion of the western limb of a normal fold. While bedding strike varies along the limb of the fold, fracture orientation remains remarkably constant. Individual vein spacing and height is similar to what we observe in the 653Z-26B core. Spacing varies from 0.2 to $2.0 \mathrm{~cm}$ and height ranges from 2.0 to $6.0 \mathrm{~cm}$. Sigmoidal vein zones also occur in discrete and well-defined layers. Though the zones do not appear to be controlled by lithology, we have obtained a number of samples from both deformed and unaffected layers. We will XRD these samples to determine if there is a relationship between silica content and occurrence of fracturing. Finally, a map view perspective clearly demonstrates that individual veins do interact. Branching between sub-parallel veins is common, and may have a significant impact on fluid flow in affected layers.

Sigmoidal veins are present in a small northwestern portion of the CMC outcrop as well. The siliceous shale is extremely weathered at this location, making detailed observations of the features difficult. It is immediately apparent though that sigmoidal vein development progressed differently at $\mathrm{CMC}$ than it did at other locations we have examined. Sigmoidal vein zones do not appear in discrete layers. There is substantial interaction and overlap between adjacent zones (Figure 2d.6). The sigmoidal vein layers also appear to have been deformed by subsequent folding. Vein spacing and height vary significantly between the different zones. Spacings from 0.1 to $2.0 \mathrm{~cm}$ and heights ranging from 0.5 to $12.0 \mathrm{~cm}$ were observed. Weathering of the outcrop is too extensive to determine if lithology plays a role in controlling vein development.

We have chosen the Laguna Beach and Chico Martinez Creek outcrops, along with the 653Z26B core and a Jalama Beach outcrop, to be locations involved in a detailed study of sigmoidal veins. We are in the process of performing a quantitative analysis on zone complexity, interaction and occurrence rate for each site. Initial results indicate that increased regional deformation and bedding dip lead to increased complexity and occurrence of sigmoidal zones.

\section{References}

Cloos, E. 1955, Experimental Analysis of Fracture Patterns, Geol. Soc. Am. Bull. 66, 241-258. 
Dholakia, S. K. 1996, Outcrop to Reservoir: Importance of Faulting to Hydrocarbon Migration in the Monterey Formation, California, Proceedings of the Stanford Rock Fracture Project, Stanford University, v. VII, M1-M14.

Williams, L. A. 1988, Origins of Reservoir Complexity in the Miocene Monterey Formation of California, in: Studies of the Geology of the San Joaquin Basin, Graham, S. A., editor, Pacific Section SEPM, Los Angeles, 261-279. 


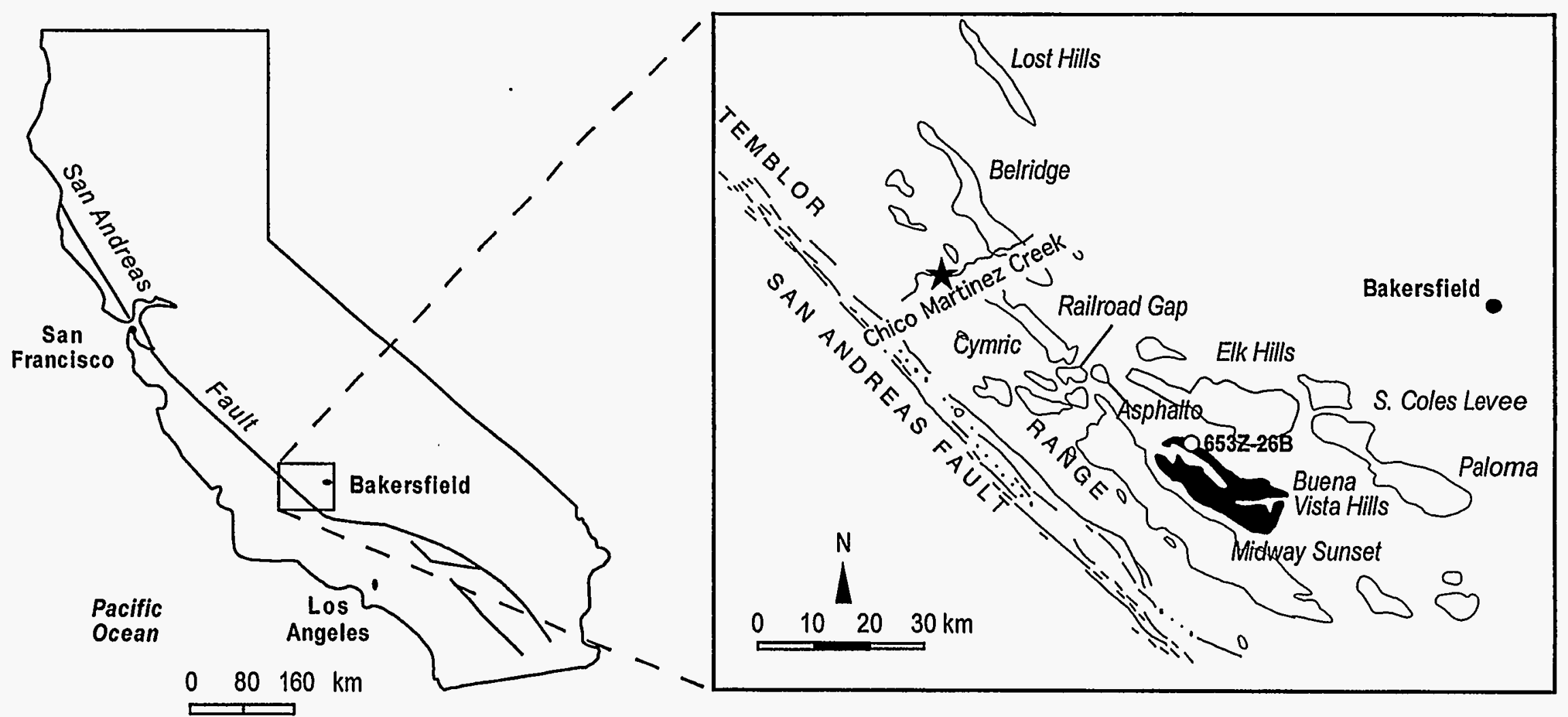

Figure 2d.1. Location of the Chico Martinez Creek outcrop (star), Buena Vista Hills field and the 653Z-26B Well in the southern San Joaquin Valley, California. Also displayed are major oil fields in the area. Modified from (Dholakia, 1996). 


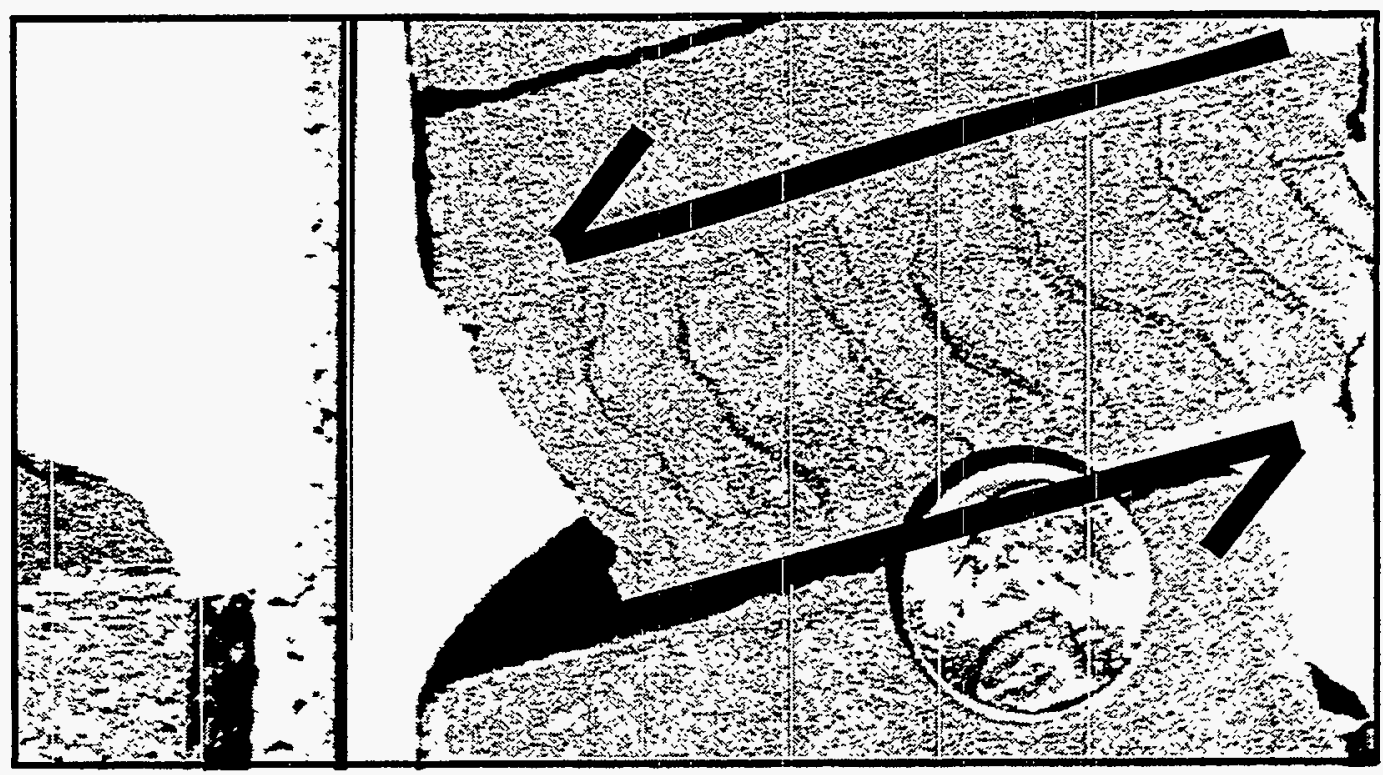

Figure 2d.2. Zone of en echelon fractures located at a depth of $4075 \mathrm{ft}$ in the Chevron 653Z-26B Well. Notice the sigmoidal shape of the fractures and the orientation of their tips. Interpreted sense of shear imposed on zone.

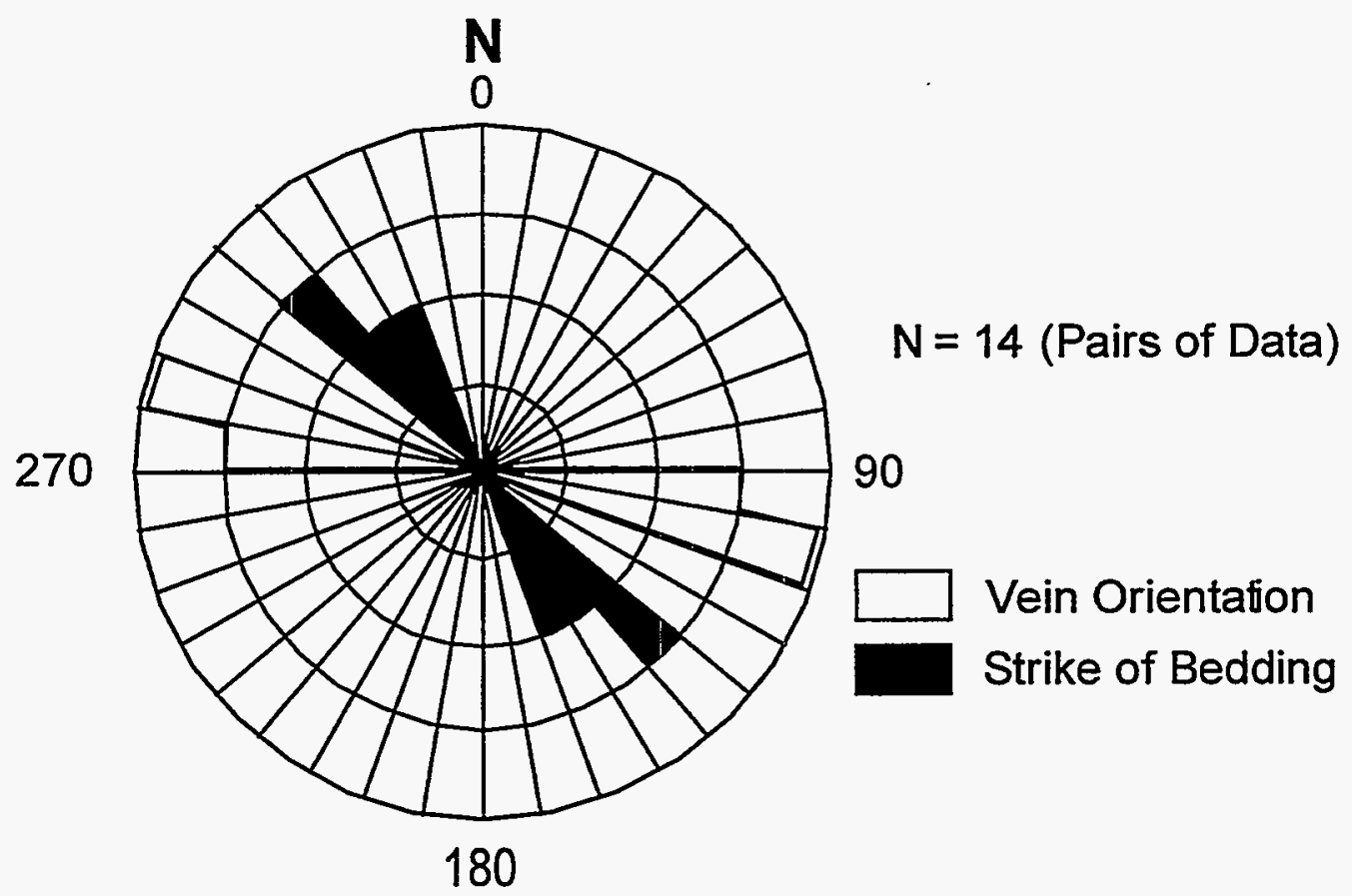

Figure 2d.3. Strike of bedding and orientation of individual veins within en echelon zones. Each vein orientation data point represents the average vein orientation in a single zone. Notice that the vein orientation differs from the bedding strike by approximately $\mathbf{4 0}$ degrees. All results obtained from the $90 \mathrm{ft}$ section of oriented core ( 4015 to $4105 \mathrm{ft}$ ) of the Chevron 653Z-26B Well. 


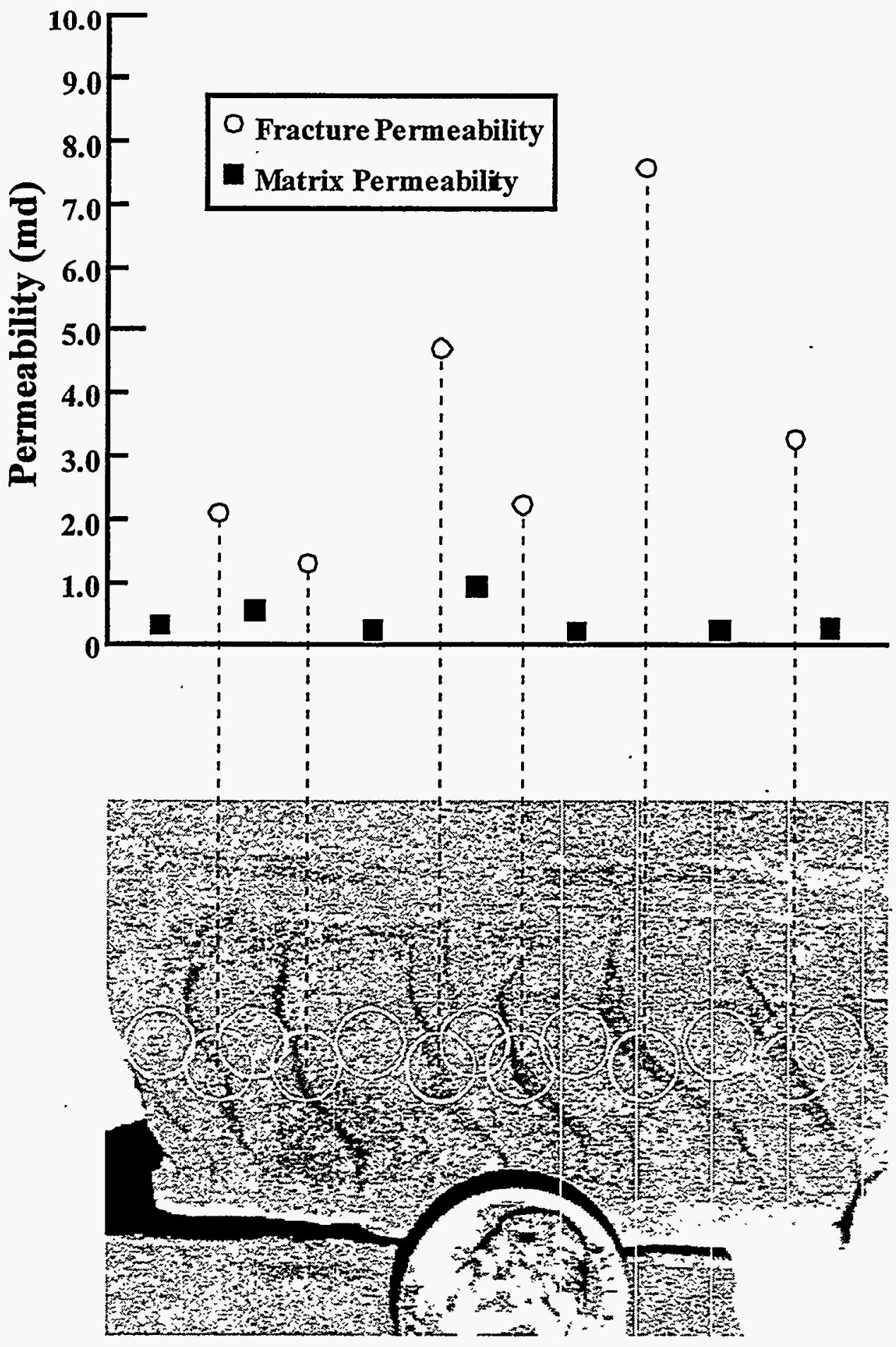

Figure 2d.4. Results of permeability test on a sigmoidal vein zone from a depth of $4075 \mathbf{f t}$ in the 653Z-26B well. White circles represent approximate location of measuring nozzle. All vein permeabilities are relative, as cannot fully isolate vein from host rock matrix when performing measurements. 


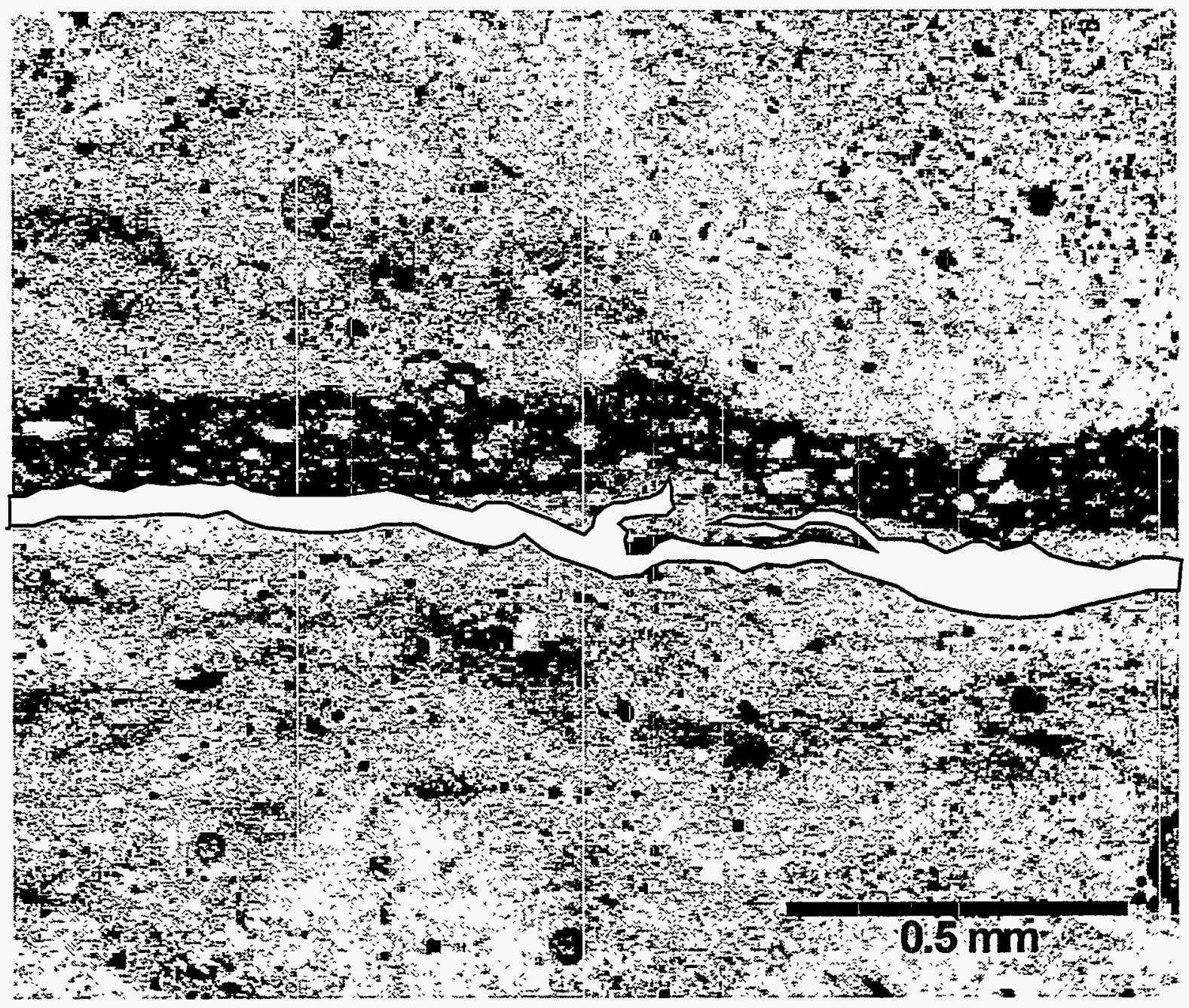

Figure 2d.5. Sigmoidal vein from a depth of $4127.95 \mathrm{ft}$ in the 653Z-26B well. Original filled vein appears directly above subsequent opening mode fracture. Notice pyrite concentrations along fracture walls and departure of fracture from vein margin. Modified from (TerraTek Petrographic and Confocal Analysis, 1997). 


\section{$5 \mathrm{~cm}$}

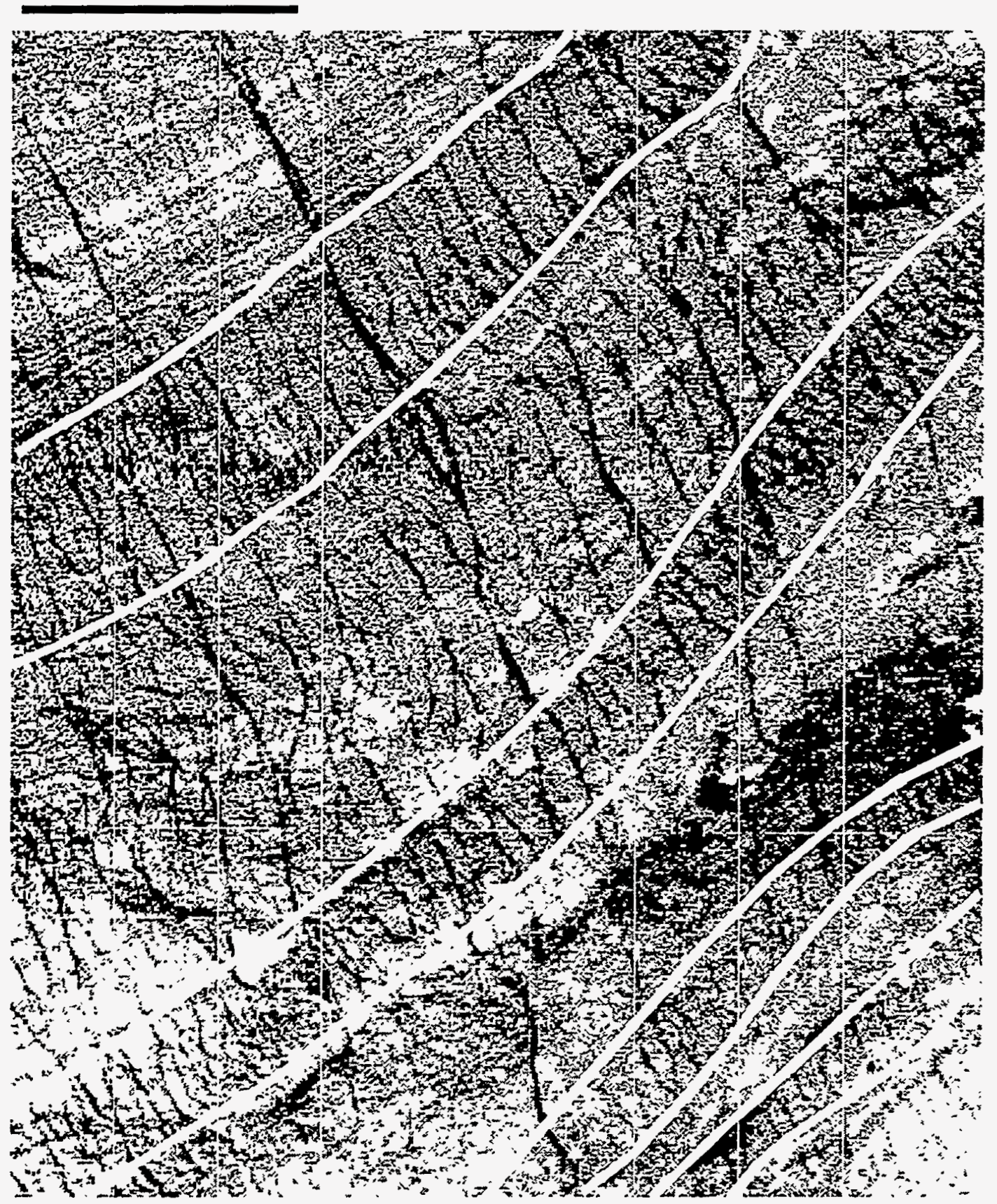

Figure 2d.6. Sample from the Belridge Member of the Chico Martinez Creek outcrop. Four distinct zones of en echelon fractures are present. Additional fractures have developed between the zones which have complicated the fracture geometry. Note that the originally linear zones have been deformed by regional folding. 


\author{
Section 2e. \\ Natural Fractures in the Brown and Antelope Shales \\ Buena Vista Hills, 653Z-26B \\ Wayne Narr and Haiqing $\mathrm{Wu}$ \\ Chevron Petroleum Technology Company
}

\title{
SUMMARY
}

The 653Z core (952 feet total) contains joint-like fractures, minor faults, and sigmoidal veins. Their density of occurrence varies through the core, with more faults near the top and more joints in the central portion of the core.

The joints in this core are extremely sparse and very small, hence their effect on well productivity is probably not great. Both open and sealed faults are present; their effect on productivity is much more difficult to estimate due to the possible large size of some of the faults. The faults are varied in their degree of openness, orientation, and type, hence no logical pattern to the faults is evident.

\section{OBSERVATIONS AND INTERPRETATIONS}

\section{Core Condition}

We examined the butt portions of the cores (larger splits of the sliced core) in order to have maximum size samples of potential fractures. We did not feel the need to examine the rocker pieces, as they would have contributed little additional information to the results reached from the larger core pieces. The core is well preserved, very nearly continuous, and induced mechanical breakage is minimal. An excellent FMI log was collected in this well, and it was examined for orienting some of the fractures seen in the core, but it was not thoroughly interpreted independent of the core.

Three types of natural fractures are common in this core: clay-filled sigmoidal fractures, minor faults, and joint-like fractures. Drilling-induced and handling-induced fractures are also present in the core. Distinguishing induced from natural fractures in this core is difficult at times. The basic fracture data Table 2e.2 at the end of this report includes a column "Certainty of fracture origin" that seeks to capture the uncertainty of this natural vs. induced fracture interpretation by ranking the interpretation of each fracture from 1 (best guess) to 3 (definite). Other fracture attributes - both qualitative and quantitative - are described in this log.

\section{Soft-sediment Deformation}

The Brown Shale portion of the core contains abundant sigmoidal fractures lined with black material, probably clay. These fractures (veins) are likely soft-sediment deformation features that formed within a few meters of the sea floor shortly after burial of the sediments. Their sigmoidal shape is likely due to simple shearing of the fractured interval due to down-slope 
movement of the near-surface, rheologically plastic strata (Figure 2e.1). Our initial supposition regarding the sigmoidal veins, based on their evident richness in clay filling, is that they are more likely to act as fluid baffles than as fluid conduits. However, Aydin and Jacobs (Stanford University) report that micropermeameter results indicate the veins show higher permeability than the host rock. These sigmoidal fractures are especially common in upper portion of core, above approximately 4500 feet. They were not measured explicitly during our study. The issue of whether the sigmoidal veins contribute to reservoir permeability could be established by running a series of whole-core permeability analyses on rock with the veins (being careful to measure parallel and perpendicular to the veins) and similar lithologies lacking veins.

Minor faults-Faults having little or no apparent offset are common, especially in the uppermost part of the cored interval (Figure 2e.2). Nineteen faults were observed. Maximum offset of faults is $17 \mathrm{~cm}$ (Figure 2e.3), although most show less offset. All of the faults appear to be open in core, although on the FMI log some appear resistive, hence closed at the borehole wall (Figure 2e.3). However, some of the minor faults do appear to be open on the FMI (Figure 2e.4). The orientations of fractures that can be correlated from core to FMI were measured. Seven of the eight correlated fractures are minor faults. Clearly, there is a wide variation in orientation of the minor faults relative to each other and to the axis of the Buena Vista anticline. In addition, the group of minor faults include members with strike-slip, normal, and reverse displacement. These different fundamental fault types do not show a consistent pattern with respect to orientation. From this wide spread in fracture orientation and sense of displacement there is little to conclude about their structural significance. This collection of faults probably formed at different times relative to the kinematic history of development of the Buena Vista anticline.

The faults tend to extend beyond the confines of the core, hence their areal extent is unknown. However, individual faults can have substantial extent, so have the potential to considerably enhance productivity of a well.

Joint-like fractures-- Joints are naturally occurring fractures showing no shearing offset. Joints occur with spaced, parallel fractures in extensive groups called "joint sets". In stratified rock, joints are usually at a high angle to layering. The joint-like fractures in this core fit the definition of joints, except we lack the ability to determine whether they occur in sets (only one was identified on the FMI log). Joint-like fractures are in greatest abundance in the central portion of the cored interval, from 4440 to 4540 feet (Figure 2e.2). Their dips are nearly vertical and their heights are relatively short (see attached data sheet). A total of 14 joint-like fractures are present in the core.

Flow-related characteristics of joints and faults-- The aperture of each fracture was estimated visually in hand specimen, by direct comparison with a fracture thickness gauge chart (similar to a grain-size chart). For open fractures these measurements are, at best, crude estimates. Nevertheless, they have been used to estimate fracture porosity of the Brown Shale and the Antelope Shale (Table 2e.1). It is clear that the fracture porosity is vanishingly small. We 
sometimes use fracture data to estimate fracture spacing and fracture permeability, but this core contains so few fractures that such estimates would make little real sense. Suffice it to say that this core is very sparsely fractured, especially with regard to joint-like fractures.

Despite a scarcity of fractures in this core, individual fractures could have impact on the producibility of the well. There are many instances where, in formations of relatively low matrix permeability, a single fracture can make a difference between a good well and an uneconomic well. This seems particularly true in the presence of faults, probably due to the often large surface area of some faults (unlike joints, which tend to be limited -- at least in height -- by mechanical bedding surfaces). One way to determine the actual effect of fractures on the productivity of wells is to collect open-hole production logs, and to compare these with direct data on fracture incidence (core or FMI logs).

\section{CONCLUSIONS}

The joint-like fractures probably contribute little to productivity of this well. Faults may enhance productivity of the well. The effect of sigmoidal veins on the well productivity has not been conclusively established, but could be resolved from whole-core permeability analysis.

Table 2e.1. Summary of fracture-derived parameters for BV Hills 653Z-26B.

\begin{tabular}{llccl} 
& \multicolumn{2}{l}{ Analyzed Interval (ft) } & Cumulative & Fracture \\
& Top & Base & core height (ft) & Porosity (\%) \\
Brown Shale & 3955 & 4233.7 & 278.7 & $0.00061 \%$ \\
Antelope Shale & 4233.7 & 4907.4 & 673.7 & $0.00091 \%$
\end{tabular}


Table 2e2. Data Collection spreadsheet.

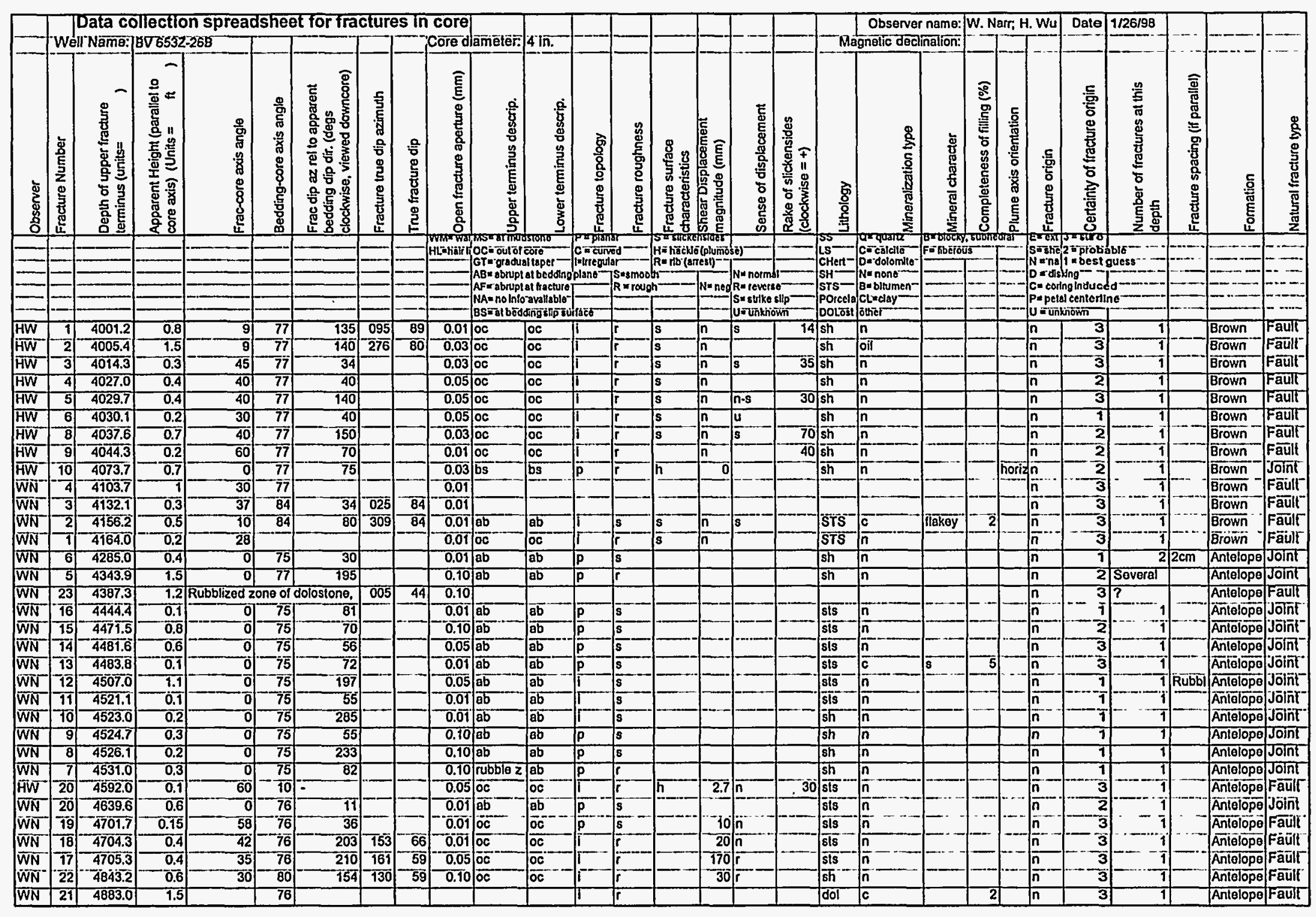




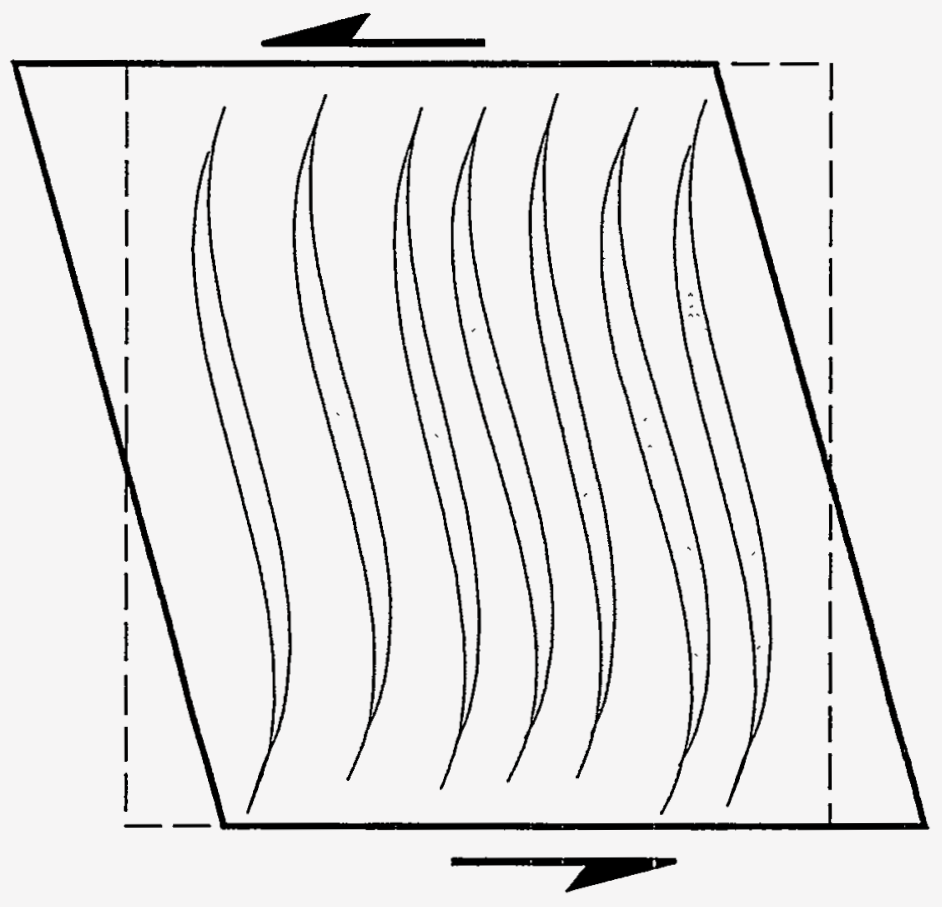

Figure 2e.1. Sigmoidal fractures or "tension gashes" probably form when a bulk simple shear occurs to the containing rock mass within an environment in which a significant bulk volume increase is able to occur. 


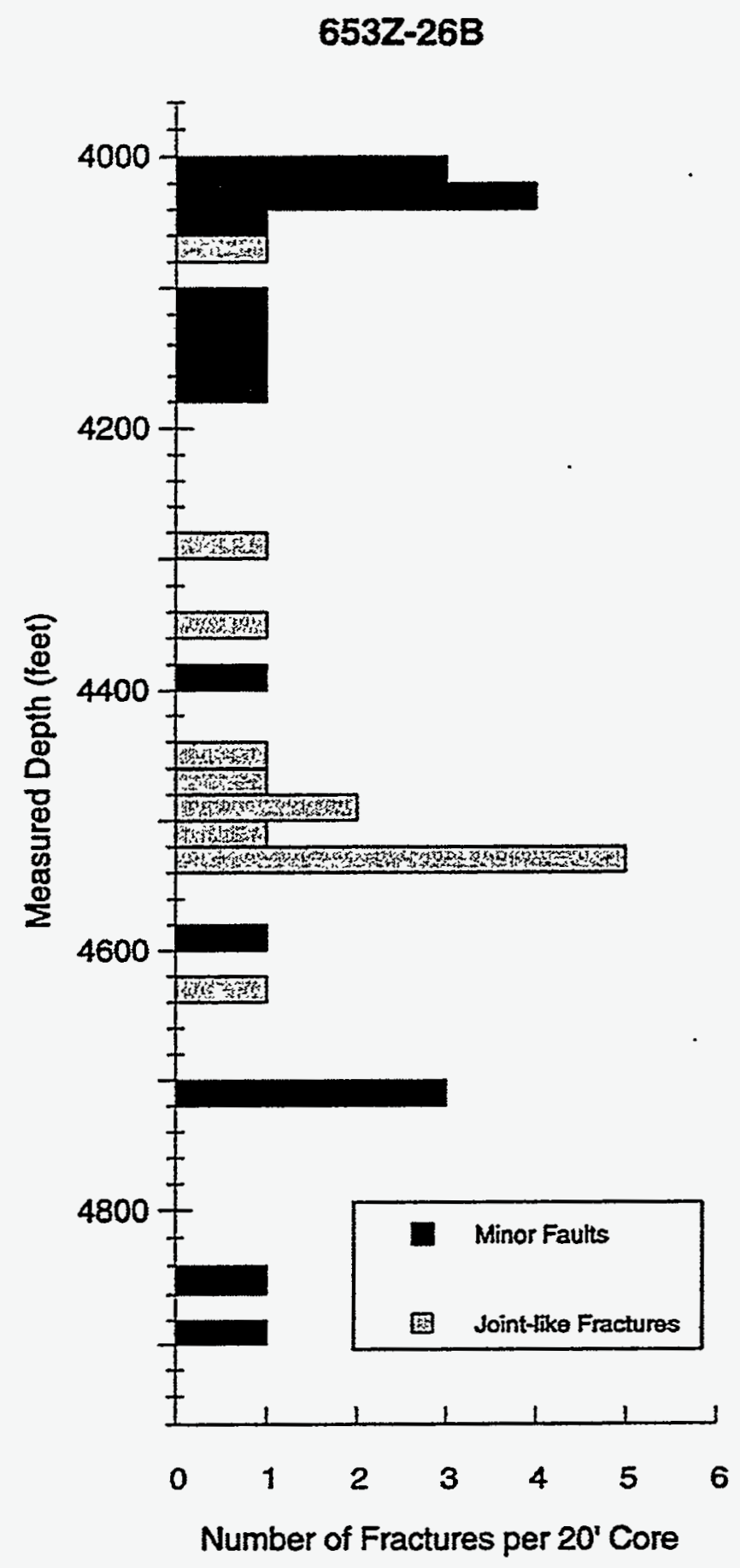

Figure 2e.2. Fracture Frequency in 653Z-26B. 


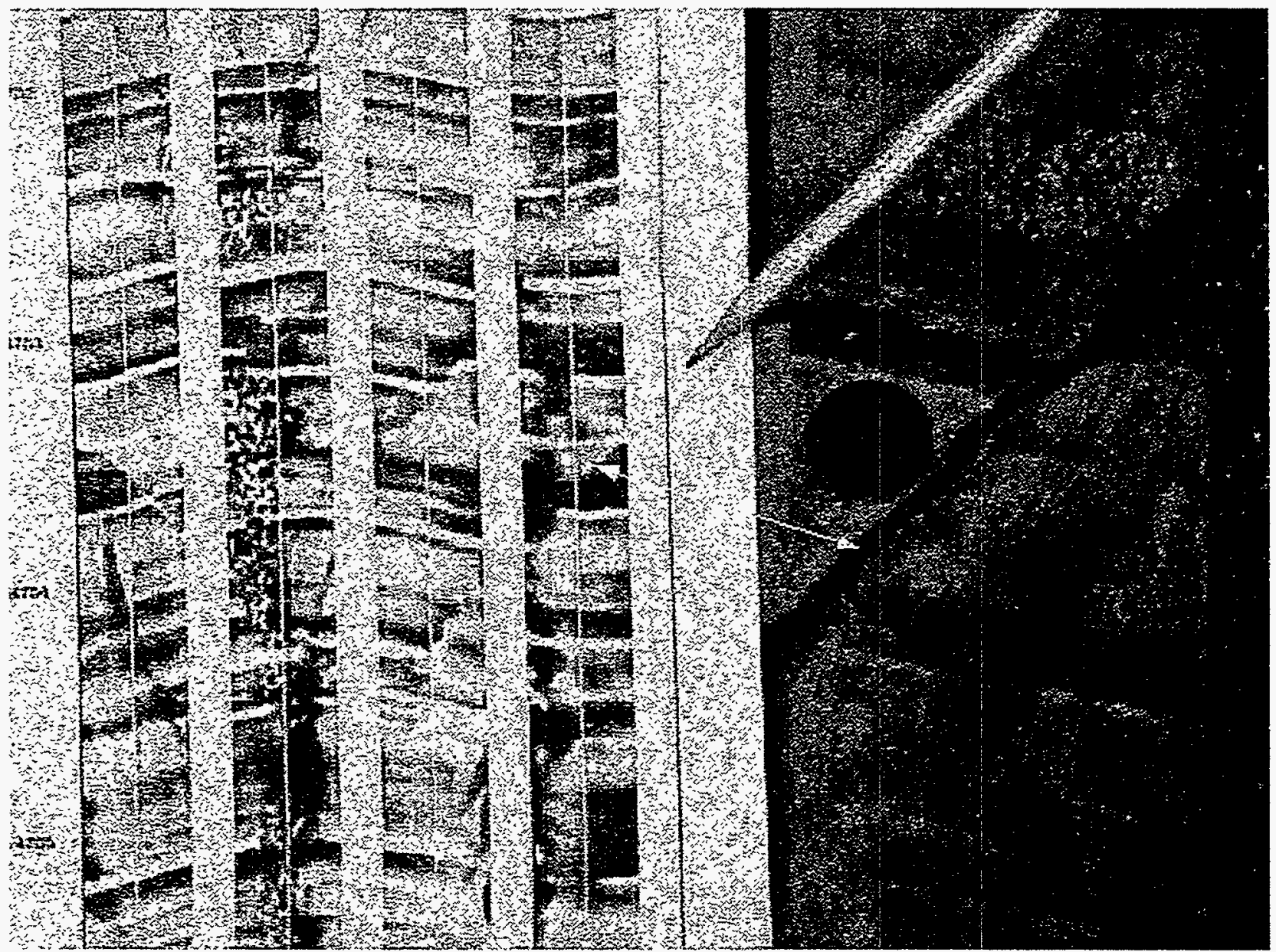

Figure 2e.3. Fault in $653 \mathrm{Z}$ core is distinct on FMI image. Where the fault appears as a light-colored trace, indicates that it is resistive, hence sealed, in the subsurface. 


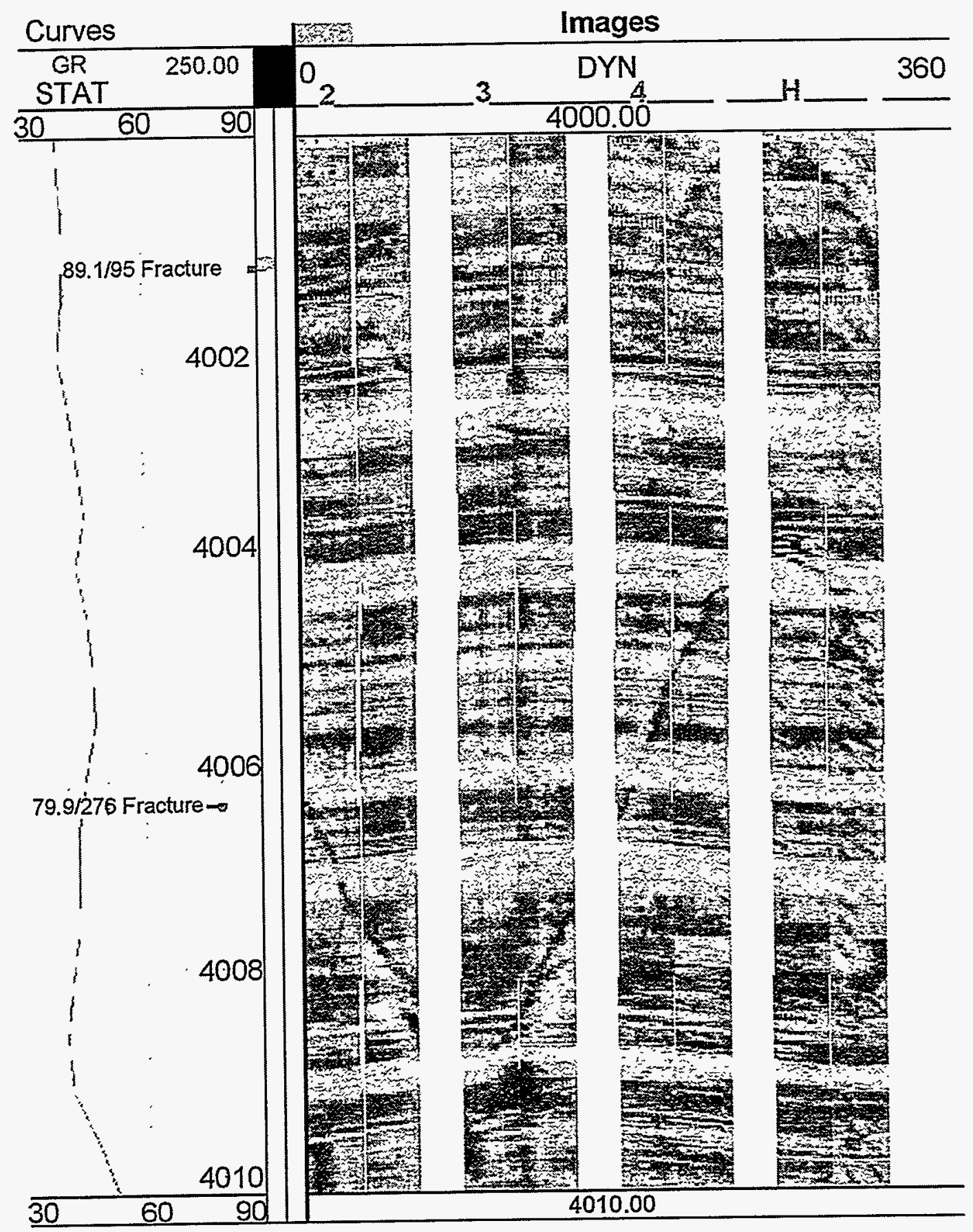

Figure 2e.4. Based on their high conductivity in this $653 \mathrm{Z}$ FMI image, these minor faults are open and transmissive of fluids in the subsurface. 


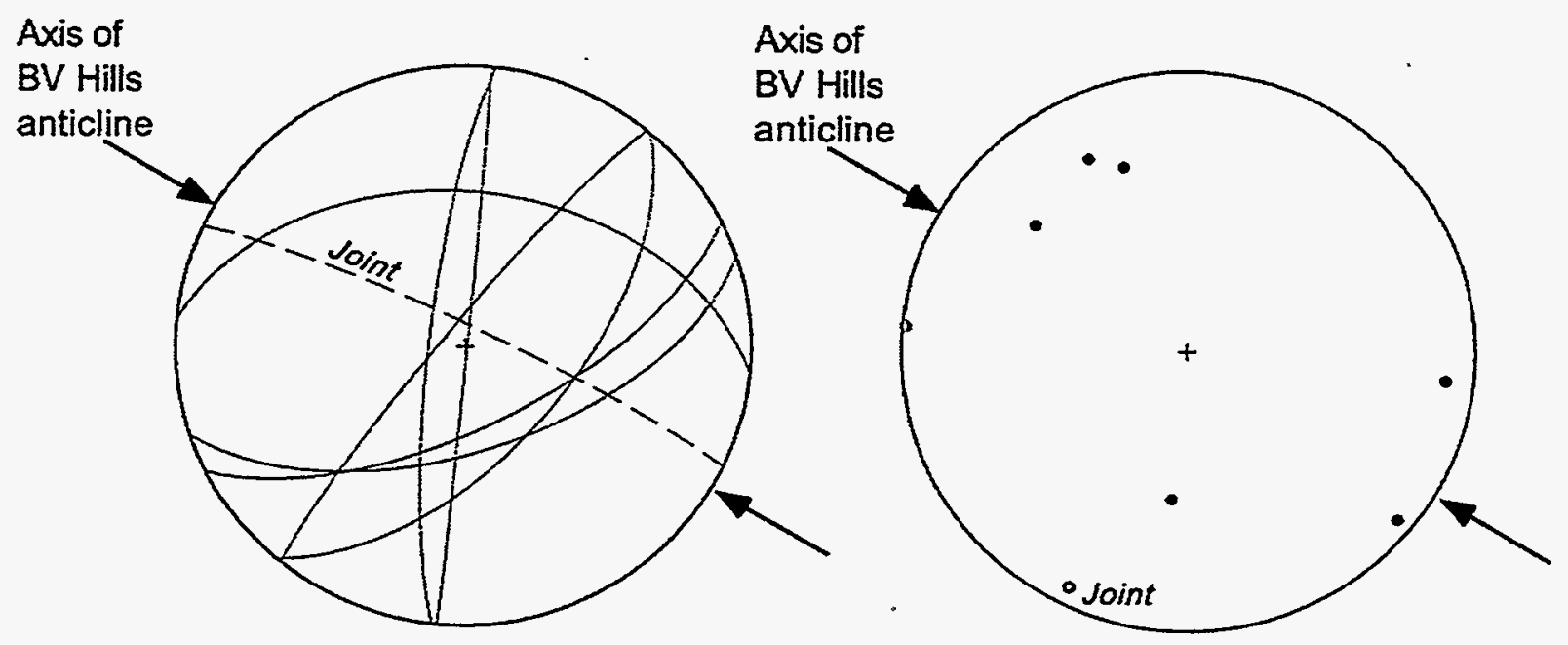

$$
\begin{gathered}
\text { Equal Area } \\
\text { Lower Hemisphere } \\
N=8
\end{gathered}
$$

Figure 2e.5. Great circles and poles to seven minor faults and one joint that are present in core and visible on an FMI from the well. Although the faults generally strike at a high angle to the axis of the anticline there is a lack of consistency to their orientation as well as their displacement vectors. 


\author{
Section $2 f$. \\ Petrographic and Confocal Analyses \\ 653Z-26B \\ Barbara Marin \\ TerraTek, Inc.
}

\title{
SUMMARY
}

Petrographic analysis was conducted on an interval of the Monterey Formation (Miocene) from Chevron's 653Z-26B well, Buena Vista Hills Field, Kern County, California. Twelve thin section samples representing the gross depth interval $4002-4763$ feet were analyzed using transmitted fight epifluorescent light, and confocal microscopy techniques. In addition, examination of microfractures was performed on all samples, and measurements of fracture orientations were obtained from three oriented thin sections.

All twelve samples are of similar lithology and can be characterized as silty, dolomitic, opaline mudstones. Matrix is composed of isotropic opal-CT with minor amounts of very finely crystalline dolomite dispersed throughout the sample. Detrital mineralogy is arkosic with minor carbonate rock fragments. Silt grains are angular and matrix supported, and coarser carbonate grains are predominantly composed of ferroan dolomite. Biotic grains are common in some intervals and likely include diatoms, sponge spicules, and various foraminifers.

Porosity exists in three generalized forms: 1) matrix microporosity, 2) molds, and 3) fractures. Minute micropores represent the greatest void volume, but exhibit highly restricted pore-to-pore connectivity. Slight dissolution of matrix enhances microporosity in localized areas. Moldic pores are volumetrically significant at some depths, and connectivity of isolated moldic pores is dependent upon (dissolution enhanced) porosity development in the enveloping matrix. Fractures appear critical to reservoir development, and effective fracture porosity is most commonly concentrated along older previously healed cracks. These fractures typically host minor amounts of silica cement and opaline gouge. A slight potential for reservoir damage could exist if migration of fine opal gouge material occurs, particularly in the vicinity of the wellbore.

\section{INTRODUCTION}

The following report summarizes results of petrographic analysis and confocal microscopy conducted on core material recovered from Chevron's 653Z-26B well, Buena Vista Hills Field, Kern County, CA. Samples representing the Miocene Monterey Formation (core depths 4002 4764 feet) were analyzed to determine general petrographic characteristics and the nature and distribution of porosity. Two examples of petrographic images (Figure 2f.1) are presented in the back of the report, and a summary of analyzed samples and depths is presented below in Table 2f.1. 


\section{ANALYTICAL PROCEDURES}

\section{Thin Section Preparation}

Petrographic samples were trimmed from full diameter core pieces cut transverse to the (vertical) core. These rectangular rock slabs were then vacuum-impregnated with a low-viscosity fluorescent red-dye epoxy resin, surfaced, mounted to oversized ( 2 inch $\times 3$ inch) thin section slides, and ground to a thickness of approximately 30 microns. A portion of each thin section was then stained with a combination of Alizarin Red "S" and potassium ferricyanide to facilitate identification of carbonate minerals. Transmitted plane-polarized and epifluorescent microscopy was conducted using a Nikon polarizing binocular microscope with camera and ultraviolet (UV) filter attachments. Photomicrographs were taken at a range of magnifications to document petrographic observations.

\section{Petrographic Description}

All twelve studied samples can be lithologically characterized as silty, dolomitic, opaline mudstones. Terrigenous silt and biotic grains are recognized in all samples, although their relative abundances and compositional varieties may vary.

Detrital grain composition is typically arkosic, with quartz and feldspars as the most abundant grain types. Plagioclase is more commonly encountered than potassium feldspar, although microcline is present in moderate amounts. Accessory grains include micas and a variety of opaque and heavy minerals. Glauconite grains are relatively rare but exist in most samples. Lithic grains include dolomitic rock fragments (ferroan) and rare volcanic rock fragments. Texturally, detrital grains exhibit good overall sorting, fine to coarse silt particle size, and angular to subangular grain shape. Grains are matrix supported except where concentrated in apparent burrows or other fabric heterogeneity.

Biotic grains vary in abundance from highly sparse to plentiful and include: diatoms, sponge spicules, phosphatic grains (fish scales), and assorted Foraminifera. Various types of benthic and planktonic forams include uniserial, biserial, triserial, rotalloid and agglutinated forms. Phosphatic grains of differing sizes and shapes likely include fossilized fish scales, bones, and teeth.

Pyrite is common in all samples and exists largely as pore filling and grain or matrix replacement. Pyrite may also be spatially associated with organic material, which is commonly dispersed throughout matrix. Chlorite is observed in some intervals as an alteration product of some heavy mineral grains.

Mudstone matrix is invariably composed of microcrystalline opal. In most cases, the transformation from opal-A to more stable opal-CT and quartz is in the early stages, given by the highly isotropic nature of the matrix under cross-polarized fight. Minor amounts of low-birefringence quartz are observed at 4763.1 feet, which is within the stratigraphically oldest interval in this study. Authigenic dolomite exists as very finely crystalline, subhedral- to- 
euhedral crystals uniformly dispersed throughout the microcrystalline matrix. Overall, dolomite represents only a minor compositional component, generally $<5 \%$ of the bulk mineralogy.

\section{Porosity}

Porosity exists as three generalized types: 1) matrix microporosity; 2) moldic (dissolution) porosity; and 3) microfractures. The relative abundance and distribution of each pore type varies by interval, as summarized in Table $2 \mathrm{f} .3$.

Microporosity inhabiting the microcrystalline matrix is clearly the most abundant pore type in all analyzed samples. For this study, microporosity is herein defined as void spaces less than 10 microns in maximum dimension (diameter). Although techniques employed here do not involve measurement of individual pores or pore throats, minute, nearly microscopically imperceptible pores (submicron size) are prevalent in most matrix areas. At even high magnifications under the confocal microscope, these submicron voids inhabiting the opaline matrix structure cannot be individually resolved. As an interpretive note, matrix microporosity development is perhaps inherently related to consolidation and/or lithification of silica rich "ooze' and early stage transformation of opal to more stable forms of silica. Patchy nonporous areas observed in the matrix in most samples may reflect localized pore filling by mobilized silica.

Evidence of porosity enhancement via matrix dissolution is clearly observed in some samples. Dissolution enhancement features are typically detected parallel to microfracture walls, proximal to burrows and other sedimentary structures, and adjacent to moldic pores. Pores are generally enlarged in "enhanced" areas, yet extensive matrix removal and vuggy porosity are not observed. Microporosity adjacent to microfracture walls is particularly obvious and curious: an outer "bleed off' zone of enhanced microporosity contains an inner zone exhibiting little void space. This phenomenon is elsewhere encountered in micritic limestones and dolostones, and in bedded cherts.

Moldic pores are defined here as void space spatially associated with biotic grains. This pore class includes inherent intraskeletal void space, as well as porosity created by the dissolution of skeletal tests or other structural components. Typically, molds represent vestiges of diatoms, various foraminifers, sponge spicules, and other nondescript biotic grains. Dissolution of terrigenous silt is not apparent. The distribution of moldic pores is simply related to the relative wealth of fossiliferous material: i.e., intervals containing biotic grains exhibit moldic pores, whereas barren intervals do not.

Microfractures are present in most intervals, particularly in the stratigraphically higher (younger) samples. Four categories of microfractures are envisioned: 1) early, highly sinuous fractures reminiscent of vertical stylolites; also tension gashes orthogonal to these structures which may or may not be healed by organic material or gouge; these fractures show evidence of rejuvenation in some cases; 2) early, healed fractures containing organic material and gouge; these fractures may exhibit discontinuous porosity remnants, "bleed off ' microporosity, and minor silica (opal or 
chalcedony) cement; 3) open microfractures formed by the secondary regeneration of previously healed fractures; these are the predominant fracture types and may exhibit minor opaline gouge, silica infill, and pronounced "bleed off' porosity; 4) open fractures in undisturbed matrix, similar to regenerated fractures but existing in stratigraphically lower samples where preexisting fabric anisotropies are not so common.

\section{Microfracture Analysis in Thin Section}

Nine of the twelve studied samples exhibit microfractured textures. In some cases, cross-cutting fractures are numerous (4002.75 feet, 4041.65 feet, 4127.95 feet, 4230.9 feet, 4333.0 feet), whereas in other samples ( 4370.7 feet, 4424.1 feet, 4538.1 feet, 4763.1 feet) fractures are sparse or more widely spaced. No fractures were observed at sample depths 4479.95 feet, 4633.6 feet, and 4713.1 feet. In most fractured samples, both open (or reopened) and healed fractures are present. Healed fractures invariably contain dark organic material with pyrite, but may locally contain silica cement in the form of opal or chalcedony. In open or reopened fractures, apertures are typically narrow and most commonly range from $<2 \mu \mathrm{m}$ to $40 \mu \mathrm{m}$. Three of the twelve thin section samples are oriented with respect to north, and close examination of these microfractures reveals no distinct or repeatable fracture patterns. Fracture orientation and characterization are summarized below in Table 2f.2.

\section{Confocal Microscopy}

Confocal microscopy is a relatively new observational technique which has been exploited extensively in the biological community during the past five years. Although the theoretical conception dates back over thirty years to Minski (U.S. Patent 3013467), routine application has only been made possible by recent advances in optical and electronic technology (Inoue, 1990). Three dimensional imaging is possible because the confocal microscope can be used to "slice" thin optical sections of thick specimens with remarkably high resolution.

This unique optical sectioning capability of confocal microscopy results from fundamental differences in image formation as compared to more conventional reflected light microscopy. Namely, illumination and detection are confined to a single thin plan - as thin as $1 \mu \mathrm{m}$ - within the specimen. Additionally, because each point in the focal image plane is examined individually (in the absence of scattered fight from neighboring points), in-plane (x-y) resolution is greatly enhanced. Conversely, in reflected light microscopy, fight from both above and below the focal plane is admitted for image formation, precluding the possibility of depth discrimination and resulting in significant image degradation. Furthermore, an object is viewed under uniform illumination, and point to point resolution is thus degraded by scattering.

Because each point in the field of view is imaged individually in confocal microscopy, the beam must be scanned over the entire field of view in order to build an image. Such a scan generally takes 5-10 seconds, and computerized image processing is thus required. The use of a laser fight source further enhances resolution. Lasers are ideal fight sources because they offer a high degree of monochromaticity, small divergence, high brightness, high degree of spatial and 
temporal coherence, and plane polarized emission (Gratton and vandeVen, 1990) The resultant resolution is extreme and approaches the theoretical limit set by diffraction: a point to point resolution of $200 \mathrm{~nm}$ is achieved at a wavelength of $488 \mathrm{~nm}$ with a $\times 40$ plan apochromatic objective with a numerical aperture of 1.4 (King, 1992 personal communication).

Although light reflected from the focal plane may be used for image formation, samples are commonly impregnated with a fluorescing dye; in this case rhodamine is used in order to take advantage of the laser's ability to excite fluorescence at a precise wavelength. The images generated by the confocal microscope are in digital form and are directly inputted into an image analysis system.

\section{Results}

Porosity determinations for each sample were made using paired low and high magnification images. Macroporosity (intergranular, moldic, or fracture) is differentiated from microporous regions based on fluorescence intensity. Quantitative determination of fluorescence intensity by image analysis then gives the percentage of each image occupied by macroporosity and microporous regions. Because microporous regions are not entirely porous (i.e., they comprise matrix material as well as microporosity) and because of the highly microporous nature of these samples, high-magnification images are used to delineate and calculate percent microporosity. Specifically, within a particular low magnification area, several high-magnification images are viewed along a traverse, and an average percent microporosity is calculated from these numerous images. Total porosity for the sample, therefore, equals the sum of percent macroporosity determined from the low-magnification images and average microporosity calculated from several high-magnification images.

Worth noting, however, is that even high-magnification images cannot resolve submicron voids within the opaline matrix. As a result microporosity and total porosity values will likely be lower than measured porosity values. Table $2 \mathrm{f} .3$ below summarizes porosity calculations by confocal microscopy and image analysis.

\section{Diagenesis/Reservoir Development}

Reservoir characteristics are directly attributable to the syn- and especially post-depositional processes. Deposition was likely in a deep, low-energy marine environment. Siliceous ooze containing varying amounts of detrital silt, dolomitic grains, microfossils, phosphate, and organic material accumulated as mud on the quiet, basinal floor. Minor carbonate mud may also have been deposited periodically. Following deposition, siliceous biotic grains (particularly diatom tests, sponge spicules and Rely radiolarians) began thermodynamic stabilization, namely mineralogic conversion from original opal-A to opal-CT, and perhaps to quartz in a series of dissolution-reprecipitation stages. Most matrix material is ostensibly in the opal-CT stage at current burial depths and temperature conditions. Early diagenesis also apparently includes the precipitation of very finely crystalline authigenic dolomite within the matrix. 
Most fractures appear to have originally formed early in the diagenetic history. Syndepositional(?), narrow, irregular fractures have been mostly healed, primarily with organic material. Two early fracture sets may be delineated, with some early "fractures" more closely resembling vertical stylolites. Secondary rejuvenation, or reopening of these early fractures occurred later in some cases.

Minor to extensive dissolution occurred in areas of the matrix and along open or partially open fractures. One manifestation of dissolution processes is the presence of enhanced microporosity in the matrix adjacent to fractures. Dissolution may have been associated with mineralogical stabilization, but appears facilitated by fracture-borne fluids and was most extensive at depths with more abundant macroporosity.

With respect to reservoir damage potential, minor amounts of loose siliceous material (microfossil debris) and loosely cemented opaline gouge may migrate as fines through fractures or other macroporous conduits. Large moldic pores, however, appear generally "clean" in thin section. If migration occurs, it will have the greatest impact near the wellbore, as fines tend to migrate toward the borehole during production.

Most of the studied samples are considerably porous (18 - 40\%), and micropores are certainly the dominant pore types and represent the greatest void volume. Furthermore, confocal imaging has revealed the presence of submicron pores in the amorphous, opaline matrix. Extremely small pore-throat size and limited interconnectivity of micropores results in very poor expected matrix permeability (in many cases, $<0.1 \mathrm{md}$ ). Tiny micropores may also bind saline formation water, if present, which will notably affect electric log signatures by decreasing apparent resistivity. Intervals with appreciable moldic macroporosity (e.g., 4002 feet) may also exhibit low permeability in spite of high porosity because of the isolated, poorly connected distribution of these larger pores.

Reservoir quality is clearly dependent on the abundance and distribution of open or rejuvenated, interconnected fractures and microfractures. Fractures are generally more common in stratigraphically higher intervals. In addition, minor amounts of gouge material and/or silica cement have apparently little bearing on fracture effectiveness. However, horizontal permeability barriers may be presented by healed fractures as well as recemented areas within bleed-off zones. Where present, open fractures can not only serve as fluid conduits, but can also permit access to microporous patches and dissolution macroporosity. Whether or not these fractures will produce fluids, however, is dependent on fracture aperture and gravity of oil: narrow-aperture microfractures may allow flow of high-gravity oil but not low-gravity oil, whereas larger fractures will allow both to flow. Microfracture examination in thin section certainly demonstrates that most open or reopened fractures exhibit very narrow apertures, typically $<4-20 \mu \mathrm{m}$. Moreover although narrow-aperture microfractures and microporous voids may decrease oil permeability, they may be viable permeability conduits for adsorbed gas. 


\section{REFERENCES}

Inoue, S., Foundations of confocal scanned imaging in light microscopy, 1990.

Gratton, E., and vandeVen, M. J., Laser sources for confocal microscopy, 1990.

King, E. J., personal communication, 1992.

Table 2f.1. Thin Section Sample Summary.

\begin{tabular}{||c|c|}
\hline $\begin{array}{c}\text { Sample Depth } \\
\text { (feet) }\end{array}$ & Oriented Sample \\
\hline \hline 4002.75 & \\
\hline 4041.65 & $\checkmark$ \\
\hline 4127.95 & \\
\hline 4230.9 & \\
\hline 4333.0 & $\checkmark$ \\
\hline 4370.7 & \\
\hline 4424.1 & \\
\hline 4479.95 & \\
\hline 4538.1 & \\
\hline 4633.6 & \\
\hline 4713.1 & \\
\hline 4763.1 & \\
\hline
\end{tabular}


Table 2f2. Microfracture Characterization.

\begin{tabular}{|c|c|c|c|}
\hline $\begin{array}{l}\text { Sample } \\
\text { Depth (ft) }\end{array}$ & $\begin{array}{l}\text { Microfracture } \\
\text { Orientation }\end{array}$ & Fracture Type & $\begin{array}{l}\text { Approx. } \\
\text { Fracture } \\
\text { Aperture }\end{array}$ \\
\hline 4002.75 & - & $\begin{array}{l}\text { Subparallel, healed and reopened Fractures; organic } \\
\text { fill; some perpendicular hairline cracks also. }\end{array}$ & $<4 \sim 80 \mu \mathrm{m}$ \\
\hline \multirow[t]{2}{*}{4041.65} & $\mathrm{~N} 80^{\circ} \mathrm{E}$ & $\begin{array}{l}\text { Mostly closed, irregular (sinuous) fractures; filled by } \\
\text { organic material and opaline gouge. }\end{array}$ & - \\
\hline & $\mathrm{N} 90^{\circ} \mathrm{E}$ & Reopened, organic-filled fractures. & $4-40 \mu \mathrm{m}$ \\
\hline 4127.95 & - & $\begin{array}{l}\text { Healed and reopened, irregular, organic-filled, } \\
\text { subparallel fractures; *some apertures widened by } \\
\text { sample preparation. }\end{array}$ & $<2-500^{*} \mu \mathrm{m}$ \\
\hline 4230.9 & - & $\begin{array}{l}\text { Sinuous, braided, thin, organic-filled fractures; some } \\
\text { reopened, bleed off porosity common. }\end{array}$ & $<4-25 \mu \mathrm{m}$ \\
\hline \multirow[t]{2}{*}{4333.0} & $\mathrm{~N} 75^{\circ} \mathrm{E}$ & $\begin{array}{l}\text { Reopened linear, organic-filled fractures; minor } \\
\text { discontinuous silica (chalcedony) cement also } \\
\text { present; *some apertures widened by sample } \\
\text { preparation. }\end{array}$ & $\begin{array}{l}2-400^{*} \mu \mathrm{m} \\
\text { mostly } \\
2-8 \mu \mathrm{m}\end{array}$ \\
\hline & $\mathrm{N} 30^{\circ} \mathrm{W}$ & $\begin{array}{l}\text { Closed, irregular, organic-filled fractures; little } \\
\text { porosity visible, extensive cementation, bleed off } \\
\text { porosity, *open perpendicular tension gashes. }\end{array}$ & $<4 \mu \mathrm{m}$ \\
\hline 4370.7 & - & $\begin{array}{l}\text { Sparse organic-filled hairline fractures and incipient } \\
\text { fractures; rare open fractures with bleed off porosity. }\end{array}$ & $5-40 \mu \mathrm{m}$ \\
\hline 4424.1 & - & $\begin{array}{l}\text { Sparse, irregular, very thin, organic-filled fractures; } \\
\text { closed. }\end{array}$ & - \\
\hline \multirow[t]{2}{*}{4538.1} & $\mathrm{~N} 28^{\circ} \mathrm{E}$ & $\begin{array}{l}\text { Mostly closed, linear narrow fractures with organic } \\
\text { and silica (opal) cement; discontinuous patches of } \\
\text { porosity along fracture length. }\end{array}$ & $4 \mu \mathrm{m}$ \\
\hline & $\mathrm{N} 69^{\circ} \mathrm{W}$ & $\begin{array}{l}\text { Open fractures with minor organic material and } \\
\text { opaline cement; tiny perpendicular cracks also } \\
\text { visible. }\end{array}$ & $<2-20 \mu \mathrm{m}$ \\
\hline 4763.1 & - & $\begin{array}{l}\text { Sparse, en echelon, hairline cracks; organic filled } \\
\text { and generally nonporous; }{ }^{*} \text { one thin. open crack with } \\
\text { cement halo. }\end{array}$ & $<2 \mu \mathrm{m}^{*}$ \\
\hline
\end{tabular}


Table 2f.3. Porosity Characterization by Confocal Microscopy.

\begin{tabular}{|c|c|c|c|c|c|c|}
\hline & \multicolumn{3}{|c|}{ Porosity Types and Distribution } & \multicolumn{3}{|c|}{ Average Porosity Derived from Image Analysis } \\
\hline $\begin{array}{c}\text { Sample } \\
\text { Depth (ft) }\end{array}$ & Micropore & Molds & Fractures & $\begin{array}{c}\% \\
\text { Macroporosity }\end{array}$ & $\begin{array}{c}\% \\
\text { Microporosity }\end{array}$ & $\begin{array}{l}\text { \% Total } \\
\text { Porosity }\end{array}$ \\
\hline 4002.75 & $\begin{array}{c}\text { Common, } \\
\text { patchy }\end{array}$ & Abundant & $\begin{array}{l}\text { Open, }-0.3 \mathrm{~cm} \\
\text { spacing }\end{array}$ & 2.5 & 25.5 & 22.6 \\
\hline 4041.65 & $\begin{array}{l}\text { Sparse, } \\
\text { localized } \\
\text { along } \\
\text { fractures }\end{array}$ & Rare & Open & 0.9 & 21.7 & 22.6 \\
\hline 4127.95 & $\begin{array}{c}\text { Common, } \\
\text { patchy }\end{array}$ & Rare & Open & 0.3 & 18.8 & 19.1 \\
\hline 4230.9 & $\begin{array}{c}\text { Sparse, } \\
\text { localized } \\
\text { along }\end{array}$ & Rare & Open & 0.5 & 18.8 & 19.3 \\
\hline 4333.0 & $\begin{array}{l}\text { Common, } \\
\text { patchy }\end{array}$ & Common & Open & 1.1 & 19.2 & 20.3 \\
\hline 4370.7 & Abundant & Rare & Open & 1.0 & 39.0 & 40.0 \\
\hline 4424.1 & $\begin{array}{l}\text { Abundant, } \\
\text { with } \\
\text { nonporous } \\
\text { areas }\end{array}$ & Rare & Closed & 2.2 & 18.0 & 20.2 \\
\hline 4479.95 & $\begin{array}{c}\text { Common, } \\
\text { patchy }\end{array}$ & Rare & None & 0.3 & 32.5 & 32.8 \\
\hline 4538.1 & Abundant & Common & $\begin{array}{c}\text { Open and } \\
\text { partially } \\
\text { healed }\end{array}$ & 2.3 & 15.7 & 18.1 \\
\hline 4633.6 & Abundant & Rare & None & 0.2 & 18.0 & 18.2 \\
\hline 4713.1 & Abundant & Sparse & None & 0.2 & 21.4 & 21.6 \\
\hline 4763.1 & Abundant & Common & Mostly closed & 0.6 & 22.7 & 23.3 \\
\hline
\end{tabular}



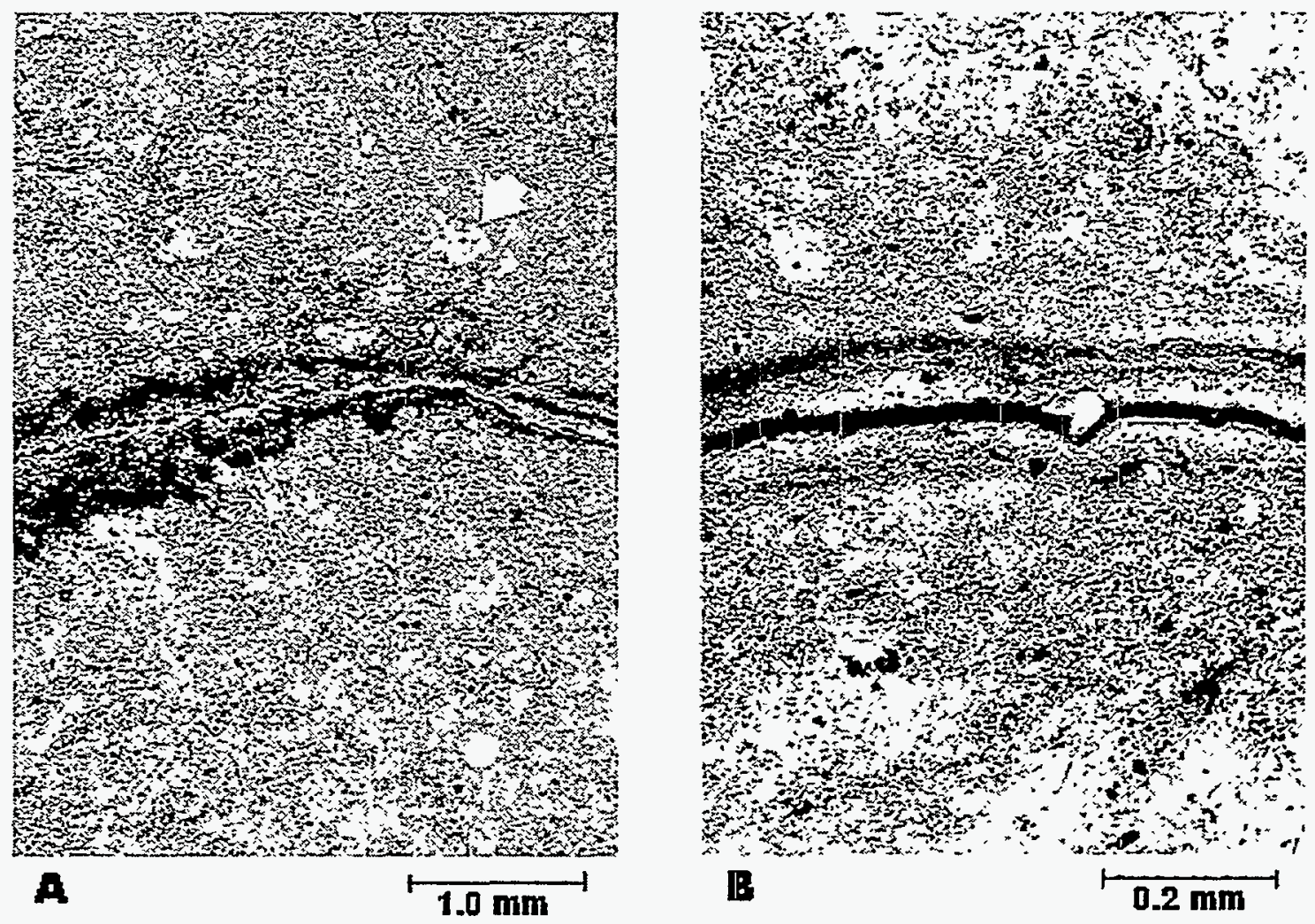

Figure 2f.1. 4041.65 feet Brown Shale: A. Low-magnification overview of tightly cemented mudstone showing an open fracture cross-cutting dense, opaline matrix. Silty, dolomitic matrix contains rare moldic pores as well as fossil remnants, such as the agglutinated foram in the upper right quadrant (arrow). Epoxy (dark banding on either side of fracture) highlights a concentration of microporosity along the open fracture. Planepolarized light $(20 \mathrm{X})$. B. Dense opaline matrix contains isolated very finely crystalline dolomite euhedra, opaque dead organic material, and iron sulfide (pyrite). Interspersed silt is clearly matrix supported, and detrital mineralogy is typically arkosic. Planepolarized light (100X). 


\section{Section $2 \mathrm{~g}$. \\ A Mineral Model and Inorganic Geochemistry \\ of the Brown and Antelope Shales, 653Z-26B Well, Buena Vista Hills \\ Alden B. Carpenter, Angela W. Barker, and Sharon J. Puckett \\ Chevron Petroleum Technology Company}

\section{SUMMARY}

The work described in this report had two major objectives:

1. Determination of the well-logging parameters ("mineral end points') for each of the important minerals in the Brown Shale and upper Antelope Shale members of the Monterey Formation for use in wireline log interpretation.

2. Accurate determination of reservoir mineralogy over selected intervals for testing the accuracy of mineral and lithology determinations from wireline log analysis.

Log parameters ("mineral endpoints") have been determined for opal-CT, K-feldspar, plagioclase, "illite/smectite", dolomite, and non-extractable organic matter in the Brown Shale and upper Antelope Shale members of the Monterey Formation in the 653Z-26B well, Buena Vista (BV) Hills Field. The $d$-spacing of the strongest $\mathrm{x}$-ray diffraction peaks of the opal-CT decreased from $4.085 \AA$ at depths between 3950 to 4250 feet to $4.045 \AA$ between 4640 and 4780 feet. The decrease in the $d$-spacing indicates that there may be a decrease in the water content and/or an increase in the density of the opal-CT with increasing depth in the cored interval. The plagioclase in the cored interval is more calcic and more variable in composition than in most reservoirs. The median composition of plagioclase in very fine-grained samples is $\mathrm{Ab}_{70}$ whereas the median composition of plagioclase in medium-grained sands is $A b_{.85}$. The non-extractable organic matter in the cored interval contains approximately $300 \mathrm{ppm}$ uranium and accounts for over $90 \%$ of the uranium in these rocks. The uranium signal from the spectral gamma ray log should be an excellent indicator of organic carbon content in the Brown Shale and Upper Antelope Shale.

The mineralogical compositions and lithologies of three 80-foot sections of continuously sampled core has been determined by inversion of bulk rock chemical compositions (ESTMIN method).

\section{INTRODUCTION}

Mineral-based formation evaluation is rapidly replacing earlier approaches to formation evaluation. This new approach provides more accurate estimates of porosity and $S_{w}$, provides detection of low resistivity pay zones, and permits recognition of major changes in $R_{w}$ and hydrologic barriers. These gains in formation evaluation are possible because the mineral-based 
approach takes into account the effect of variations in mineral abundances on log responses which in turn allows the optimum use of all sensors on the log tools.

Mineral-based formation evaluation computer programs estimate the hydrocarbon content, brine content, and mineralogy of rocks as a function of depth given several wireline log responses and the relevant well logging parameters ("mineral endpoints") for each phase in the depth interval. The most commonly used parameters include $\mathrm{K}, \mathrm{U}$, and Th content, density, gamma ray signal, apparent thermal neutron porosity $\left(\Phi_{\mathrm{CN}}\right)$, sigma $(\Sigma)$, and photoelectric factor (PEF). Mineral endpoints can be calculated for each mineral given the major element composition and contents of $\mathrm{U}, \mathrm{Th}, \mathrm{B}$, and $\mathrm{Gd}$. The present project provides a particularly good test of the method since the log suite included an Elemental Capture Spectroscopy (ECS) sonde which provided data on the abundances of $\mathrm{Si}, \mathrm{Ti}, \mathrm{Fe}, \mathrm{Ca}, \mathrm{S}$, and $\mathrm{Gd}$.

The potential value of mineral-based formation evaluation is likely to be lost if interpretations are based on "generic" or "default" values of mineral properties. The properties of most common minerals varies widely and there is a high probability that some of the properties of any given mineral in the reservoir will differ significantly from generic values. The first goal of this investigation was to determine the location-specific well-logging parameters ("mineral end points') for each of the important minerals in the Brown Shale and upper Antelope Shale members of the Monterey Formation in the BV Hills field. The second goal of this investigation was to obtain accurate determinations of reservoir mineralogy over selected intervals for testing the accuracy of mineral and lithology determinations from mineral-based wireline log analysis.

\section{METHOD OF STUDY}

\section{Determination of Mineral Endpoints}

The determination of mineral endpoints for mineral-based formation evaluation involves determining the major and trace element composition of all minerals which are likely to have a significant impact on at least one log response. All of the most commonly used log parameters, $\left(\mathrm{K}, \mathrm{U}\right.$, and Th content, density, gamma ray signal, apparent thermal neutron porosity $\left(\Phi_{\mathrm{CN}}\right)$, sigma $(\Sigma)$, and photoelectric factor (PEF) can be calculated from this information. The significant phases in the $653 \mathrm{Z}$ were quartz, opal-CT, K-feldspar, plagioclase, kaolinite; smectite, mixed-layer illite/smectite, discrete illite and mica, calcite, dolomite, pyrite, and non-extractable organic matter.

The elemental compositions of the significant minerals were determined by a variety of methods. These included electron microprobe analysis (feldspars), chemical analysis of natural samples which contained an exceptionally large amount of a particular mineral (opal-CT, clays, carbonates), mineral separates (clays), and statistical analysis of chemical analyses of bulk samples.

Mineral properties of individual minerals were calculated from the elemental composition of each mineral. Mineral densities were calculated as shown below: 
Density $=\frac{\sum x_{1} m_{i}}{\sum x_{1} v_{i}}$

where $x_{i}$ is the mole fraction of a mineral component $i$

$m_{i}$ is the molecular weight of a mineral component $i$

$v_{i}$ is the molar volume of a mineral component $i$.

The gamma ray signal ( $\left(\mathrm{GR}_{\mathrm{API}}\right)$ was calculated using the Schlumberger model,

$\mathrm{GR}_{\mathrm{API}}=16(\mathrm{~K})+8(\mathrm{U})+4(\mathrm{Th})$

where $\mathrm{K}$ is in weight percent and $\mathrm{U}$ and $\mathrm{Th}$ are in ppm (Ellis, 1989).

\section{Determination of Reservoir Mineralogy}

A continuous core sampling technique was used to collect samples for the determination of reservoir mineralogy and chemical composition. The goal of this technique was to determine the chemical and mineralogical characteristics of the formation at a continuity and sampling resolution comparable to that of most wireline logs. This technique provides the most realistic core/log comparisons, particularly in thin-bedded intervals. Continuous core samples of were taken by cutting a $0.5 \mathrm{~cm}$ slab from the top surface of the $2 / 3 \mathrm{rds}$ section of a slabbed core. In general, core was sampled to obtain continuous 1-foot samples. A few samples as short as 0.5 feet. or as long as 1.5 feet. were taken in order to obtain samples that began or ended with changes in lithology. The continuous core samples was crushed to $<10$ mesh and divided with a riffle splitter to obtain an approximately $100 \mathrm{~g}$ subsample. The subsample was ground to $<30$ mesh and sampled with a riffle splitter to obtain splits for different kinds of chemical and mineralogical analysis as needed. Splits for chemical and $\mathrm{x}$-ray diffraction analysis were extracted with toluene followed by soxhlet extraction with a solvent consisting of $80 \%$ methylene chloride and $20 \%$ methanol. Slabbing, crushing, and extraction was performed by Core Laboratories, Bakersfield. Samples were analyzed for $\mathrm{Si}, \mathrm{Al}$, $\mathrm{Ti}$, total iron, ferrous iron in silicates and carbonates, $\mathrm{Mn}, \mathrm{Ca}, \mathrm{Mg}, \mathrm{Na}, \mathrm{K}, \mathrm{P}, \mathrm{CO}_{2}, \mathrm{H}_{2} \mathrm{O}^{+}, \mathrm{S}$, organic carbon, $\mathrm{Cl}, \mathrm{Ba}, \mathrm{Sr}, \mathrm{Zr}, \mathrm{U}$, $\mathrm{Th}, \mathrm{Rb}, \mathrm{Y}, \mathrm{Nb}$, and $\mathrm{Cr}$ by XRAL Laboratories, Toronto. X-ray diffraction analyses of selected samples were performed at Chevron Petroleum Technology Co., La Habra.

The continuous core sampling was carried out over three eighty-foot sections of core selected on the basis of variations in $\log$ response. These intervals were $4100-4180$ feet., $4225-4305$ feet., and $4480-4560$ feet.

The mineralogical compositions of the samples were determined by the conversion of chemical analyses of the bulk rock samples to mineral abundances using the Chevron ESTMIN program (Carpenter et al., 1993). The mineralogy of a rock can be determined from its bulk chemical composition and matrix density (after extraction) by a set of linear equations if the kinds and 
compositions of minerals in the rock are known. The Chevron ESTMIN computer program uses a standard non-negative least-squares algorithm to determine the mineralogy of a rock given a chemical analysis and matrix density and a table of mineral compositions and mineral densities for the rock. The precision of mineralogical analyses by the ESTMIN method is generally $\pm 1 \%$ relative. The accuracy of mineral analyses from chemical data is generally \pm 3 weight percent (absolute) for minerals present in abundances greater than 25 weight percent (Calvert et al., 1989).

\section{RESULTS}

\section{Antelope Shale Mineral Model}

The chemical compositions and densities of major minerals in the cored intervals of the Antelope Shale are given in Table 2g.1. Selected properties and well logging parameters for these minerals in the core are given in Table $2 \mathrm{~g} .2$. The compositions and properties of the minerals in the cored intervals of the 653Z-26B well may not apply to the Antelope Shale at other locations or at other depths.

\section{Discussion}

Quartz Quartz was present in all samples analyzed by $\mathrm{x}$-ray diffraction analysis including very thin beds of glassy opal-CT chert.

Opal-CT The $d$-spacing of the strongest x-ray diffraction peaks of the opal were consistently $4.085 \pm .003 \AA$ at depths between 3950 to $4250 \mathrm{ft}$., decreased to $4.075 \pm .003 \AA$ between 4400 and $4500 \mathrm{ft}$., and decreased to $4.045 \AA$ between 4640 and $4780 \mathrm{ft}$. The $2 \Theta$ positions of the diffraction peaks were calibrated using the positions of quartz diffraction peaks which were contributed by naturally-occurring quartz in the samples.

The water content and density of the opal-CT were generally 5 weight percent and $2.25 \mathrm{gm} / \mathrm{cm}^{3}$ respectively. However, the decrease in the $d$-spacing indicates that there may be a decrease in the water content and/or an increase in the density of the opal-CT with increasing depth in the cored interval. Additional work is in progress to resolve this question.

Feldspar The median compositions of $\mathrm{K}$-feldspar and plagioclase was determined by electron microprobe analysis of more than 600 feldspar grains in 9 thin sections made at approximately 100 foot intervals in the core (Figure 1). Analyses with low totals due to rough surfaces, etc. were not included in any figures or in statistical analyses of the data.

The median composition of the K-feldspar was ${ }^{\circ}{ }_{916} \mathrm{Ab}_{.077} \mathrm{An}_{.001} \mathrm{Cs}_{.006}$ based on data for 156 grains. (Cs is the standard symbol for the barium feldspar celsian.) The median barium content of the K-feldspar was $2700 \mathrm{ppm}$ although some grains containing more than $10,000 \mathrm{ppm}$ barium were present. The median barium content of the $\mathrm{K}$-feldspar was taken into account in calculating the photoelectric factor of the K-feldspar. 
The median composition of the plagioclase was $\mathrm{Or}_{.01} \mathrm{Ab}_{.75} \mathrm{An}_{24}$ based on data for 398 grains. The composition of the plagioclase is highly variable as shown in Figure $2 \mathrm{~g} .1$ and there are significant differences in the median composition of plagioclase between some samples (Figure 2g.2). The median composition of plagioclase in very fine-grained samples is $A b_{70}$ whereas the median composition of plagioclase in medium-grained sands is $\mathrm{Ab}_{.85}$ (samples 4432 and 4668).

Clay Minerals The clay mineral and mica fraction of the rocks was a complex mixture of discrete smectite, discrete illite and mica (biotite and muscovite), mixed-layer illite/smectite including ordered mixed-layer illite/smectite, kaolinite, and trace amounts of chlorite.

Kaolinite The major element composition and density of the kaolinite were assumed to be the same as for pure well-crystallized kaolinite. The thorium and uranium contents of the kaolinite were estimated from least squares analysis of the relationship between thorium contents of bulk samples and the abundances of major minerals likely to contain significant thorium and uranium.

"Illite/Smectite" The remaining clay minerals were estimated as ferrian illite/smectite and ferroan illite/smectite. Chemical analyses of clay rich samples showed that the magnesium and total iron content of the "illite/smectite" fraction was approximately constant and that there was a reciprocal relationship between the ferric and ferrous iron contents. The "illite/smectite" fraction was estimated to contain approximately 10 weight percent $\mathrm{H}_{2} \mathrm{O}^{+}$("bound water, i.e., $\mathrm{H}_{2} \mathrm{O}$ retained by a sample after drying at $110^{\circ} \mathrm{C}$ for one hour). This is more than the 8.5 weight percent $\mathrm{H}_{2} \mathrm{O}^{+}$ commonly associated with end member illite but less than the amount of $\mathrm{H}_{2} \mathrm{O}^{+}$likely to be associated with discrete smectite. The density of the "wet" illite/smectites (including all bound water) was estimated from the mole fractions, molecular weights, and molar volumes of clay and mica components assuming that all non-hydroxyl water has a density of $1.0 \mathrm{gm} / \mathrm{cm}^{3}$. The density of the "dry" "illite/smectites" was calculated the same way but excluding all $\mathrm{H}_{2} \mathrm{O}^{+}$not present as hydroxyl in the octahedral sheets. The thorium and uranium contents of the "illite/smectites" were estimated from least squares analysis of the relationship between thorium contents of bulk samples and the abundances of major minerals likely to contain significant thorium and uranium.

Carbonate Minerals The core contains dolomite, calcite, and siderite. The dolomite is a calcic ferroan dolomite with the approximate composition $\mathrm{Ca}_{.55} \mathrm{Mg}_{35} \mathrm{Fe}_{.10} \mathrm{CO}_{3}$.

There are systematic differences in the kinds and amounts of carbonate in the core with increasing depth. The median carbonate content of the upper continuously sampled interval (4100-4180 feet.) is 0.4 weight percent all of which appears to be siderite. Siderite is a common alteration product of detrital biotite. The median carbonate content of the intermediate continuously sampled interval (4225-4305 feet.) is 1.8 weight percent dolomite. This interval also has a two-foot thick dolomite bed containing 63 weight percent dolomite. The median carbonate content of the lower continuously sampled interval (4480-4560 feet.) is 3.5 weight percent calcite. This interval has small amounts of disseminated dolomite and two thin beds containing $70-85 \%$ dolomite. 
Non-Extractable Organic Matter The $\mathrm{C}, \mathrm{O}, \mathrm{H}, \mathrm{S}$, and $\mathrm{N}$ content of the non-extractable organic matter was estimated from unpublished data. The organic matter contains approximately 300 ppm uranium and accounts for over $90 \%$ of the uranium in these rocks. The uranium content of the organic matter was estimated from least squares analysis of the relationship between the uranium contents of bulk samples and the abundances of major minerals likely to contain significant uranium. There was poor agreement between observed and predicted values of total uranium when uranium was partitioned between the clay minerals by statistical analysis (Figure $2 \mathrm{~g} .3 \mathrm{a}$ ). The agreement between observed and predicted uranium was improved by partitioning uranium between the clay minerals and the organic matter although there were some conspicuous outliers in the results (Figure $2 \mathrm{~g} .3 \mathrm{~b}$ ). These outliers did not correspond to any geochemical anomalies such as zirconium or phosphorous that might indicate the presence of uranium-bearing heavy minerals.

A large difference in the occurrence of thorium and uranium is shown clearly by the data for the continuous core samples. There is no statistically significant difference in the thorium content between the three sets of continuous samples. The mean uranium content of the upper continuous core samples is $12.9 \mathrm{ppm}$ (SD 3.0) whereas the mean uranium content of the lower samples is $6.7 \mathrm{ppm}$ (SD 1.3). This corresponds very closely to the change between the mean non-extractable organic carbon content of the same rocks; 3.34 weight percent organic carbon (SD 0.6) in the upper interval and 1.83 weight percent organic carbon (SD 0.4) in the lower interval.

\section{Mineralogy of the Antelope Shale, 653Z-26B Core}

Results Abundances of selected minerals vs depth for a 20 foot interval of continuous core samples are shown in Table $2 \mathrm{~g} .3$ and in Figure $2 \mathrm{~g} .4$ to illustrate the kind of data which has been collected for the project. Mineral abundances are displayed in Figure 2g.4 as vertical "bars" since the mineralogical composition and matrix densities are truly representative of each vertical increment of depth. Mineral abundances, matrix densities, and calculated log parameters can be smoothed by appropriate functions for comparison with wireline log signals.

Discussion A classification of siliceous shale lithologies in the 653Z-26B core is shown in Figure 2g.5. This classification is based on mineralogy for rocks containing less than $20 \%$ carbonate in which opal-CT plus diagenetic quartz is greater than opal-A. For this diagram, biogenic silica is equal to the sum of all forms of opal plus diagenetic quartz; clay plus mica is equal to the sum of all clay minerals plus non-extractable organic matter. Non-extractable organic matter is included with total clay and mica because both kinds of material are very plastic and inhibit the development of fractures and because both have a relatively hydrogen content and affect some logs in a similar manner. 
The lithologies of the continuously sampled intervals are shown in Figures 2g.6-8. Porcelanite is most abundant in the upper continuously sampled interval. Thin-bedded sands are most abundant in the lower continuously sampled interval.

\section{CONCLUSIONS}

1. Log parameters ("mineral endpoints") have been determined for opal-CT, K-feldspar, plagioclase, "illite/smectite", dolomite, and non-extractable organic matter in the Brown Shale and upper Antelope Shale members of the Monterey Formation in the 653Z-26B well, BV Hills Field.

2. The $d$-spacing of the strongest $\mathrm{x}$-ray diffraction peaks of the opal-CT decreased from $4.085 \AA$ at depths between 3950 to $4250 \mathrm{ft}$ to $4.045 \AA$ between 4640 and $4780 \mathrm{ft}$. The decrease in the $d$ spacing indicates that there may be a decrease in the water content and/or an increase in the density of the opal-CT with increasing depth in the cored interval.

3. The plagioclase in the cored interval is more calcic and more variable in composition than in most reservoirs. The median composition of plagioclase in very fine-grained samples is $A b_{.70}$ whereas the median composition of plagioclase in medium-grained sands is $A b_{.85}$.

4. The non-extractable organic matter in the cored interval contains approximately $300 \mathrm{ppm}$ uranium and accounts for over $90 \%$ of the uranium in these rocks. The uranium signal from the spectral gamma ray log should be an excellent indicator of organic carbon content in the Brown Shale and upper Antelope Shale.

5. The mineralogical compositions and lithologies of three 80 -foot sections of continuously sampled core has been determined by inversion of bulk rock chemical compositions (ESTMIN method).

\section{ACKNOWLEDGMENTS}

We thank Eric Daniels for interpreting the $\mathrm{x}$-ray diffraction patterns from oriented clay mounts and for his suggestions for improvement of this report.

\section{REFERENCES}

Calvert, C. S., Palkowsky, D. A., and Pevear, D. R., 1989, A combined x-ray powder diffraction and chemical method for the quantitative mineral analysis of geological samples: In Pevear, D. R. and Mumpton, F. A., editors, Quantitative Mineral Analysis of Clays, CMS Workshop Lectures Vol. 1, The Clay Minerals Society, Evergreen CO, pp. 154-166.

Carpenter, A. B., Barker, A. W., and Hoffmaster, R. L., 1993, Introduction to Mineralogical Analysis by the ESTMIN Procedure, CPTC Technical Memorandum TM93000707, 16p. 
Table 2g.1. Chemical Compositions of Significant Minerals in Continuously Sampled Intervals, 653Z-26B Well, BV Hills Ficld.

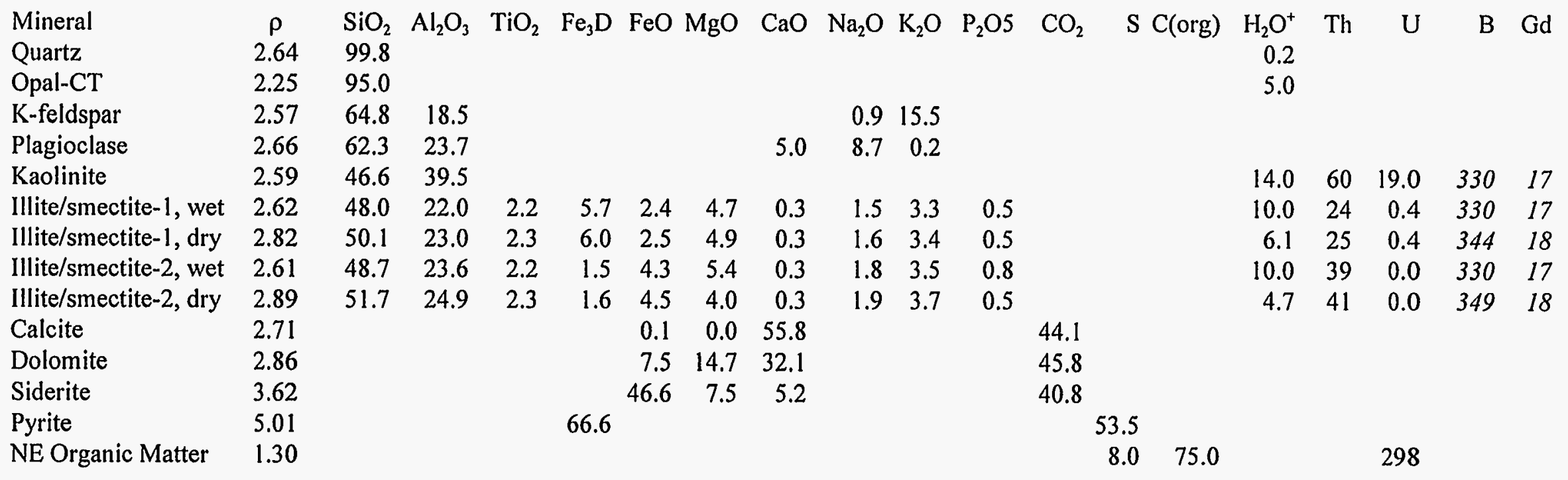

\section{Remarks:}

Compositions are in weight percent except for Th, U, B, Gd which are parts per million.

$\mathrm{B}$ and $\mathrm{Gd}$ contents for the clay minerals are suggested values based on results for the Lost Hills Field.

$\mathrm{Fe}_{3} \mathrm{D}$, "Ferric iron by difference". Total iron excluding ferrous iron in silicates and carbonates expressed as $\mathrm{Fe}_{2} \mathrm{O}_{3}$.

K-feldspar, $\mathrm{Or}_{.916} \mathrm{Ab}_{.077} \mathrm{An}_{.001} \mathrm{Cs}_{.006}$

Plagioclase, $\mathrm{Or}_{01} \mathrm{Ab}_{75} \mathrm{An}_{24}$

Illite/smectite- 1 wet, Ferric-iron-rich clay fraction containing 10 weight percent bound water.

Illite/smectite-1, dry, Ferric-iron-rich clay fraction excluding all water not present as hydroxide in octahedral sheets.

Illite/smectite-2 wet, Ferroan-iron-rich clay fraction containing 10 weight percent bound water.

Illite/smectite-2, dry, Ferroan-iron-rich clay fraction excluding all water not present as hydroxide in octahedral sheets.

Dolomite, $\mathrm{Ca}_{.55} \mathrm{Mg}_{.35} \mathrm{Fe}_{.10} \mathrm{CO}_{3}$

Siderite, $\mathrm{Fe}_{7} \mathrm{Mg}_{2} \mathrm{Ca}_{1} \mathrm{CO}_{3}$

NE Organic Matter, non-extractable organic matter. 
Table 2g.2. Log Parameters ("Mineral Endpoints") For Significant Minerals In Continuously Sampled Intervals, 653Z-26B Well, BV Hills Field.

\begin{tabular}{|c|c|c|c|c|c|c|c|c|c|c|c|c|}
\hline Mineral & $\rho$ & GR & Sigma & PEF & $\mathrm{HI}$ & $\mathrm{C}$ & $\mathrm{O}$ & $\mathrm{C} / \mathrm{O}$ & K & $\mathrm{U}$ & Th & B \\
\hline Quartz & 2.64 & & 4.3 & 1.80 & .01 & & & & & & & \\
\hline Opal-CT & 2.25 & & 5.9 & 1.73 & .11 & & & & & & & \\
\hline K-feldspar & 2.57 & 206 & 14.9 & 3.86 & .00 & & & & 12.9 & & & \\
\hline Plagioclase & 2.66 & 2.4 & 7.0 & 2.05 & .00 & & & & 0.1 & & & \\
\hline Kaolinite & 2.59 & 392 & 57.2 & 1.49 & .36 & & & & & 19.0 & 60.0 & 330 \\
\hline Illite/smectite ferrian, wet & 2.62 & 143 & 64.5 & 3.53 & .26 & & & & 2.7 & 0.4 & 24.0 & 330 \\
\hline Illite/smectite ferrian, dry & 2.82 & 149 & 69.7 & 3.68 & .17 & & & & 2.9 & 0.4 & 25.0 & 344 \\
\hline Illite/smectite ferroan, wet & 2.61 & 203 & 63.8 & 3.13 & .26 & & & & 2.9 & & 39.0 & 330 \\
\hline Illite/smectite ferroan, dry & 2.89 & 214 & 70.6 & 3.33 & .14 & & & & 3.1 & & 41.0 & 349 \\
\hline Calcite & 2.71 & & 1.5 & 5.09 & & 12.0 & 32.1 & .375 & & & & \\
\hline Dolomite & 2.86 & & 7.4 & 4.90 & & 12.5 & 40.8 & .306 & & & & \\
\hline Siderite & 3.62 & & 37.5 & 11.56 & & 11.1 & 43.0 & .259 & & & & \\
\hline Pyrite & 5.01 & & 64.1 & 16.97 & & & & & & & & \\
\hline NE Organic Matter & 1.30 & 2380 & 0.0 & 0.53 & 1.02 & 75.0 & 8.0 & 9.38 & & 298 & & \\
\hline
\end{tabular}

\section{Remarks}

GR, gamma ray signal, Schlumberger model.

PEF, photoelectric factor.

$\mathrm{HI}$, hydrogen index.

NE Organic Matter, non-extractable organic matter. 
Table 2g.3. ESTMIN Mineralogy Of A Selected Interval In The Antelope Shale, 653Z-26B Well, BV Hills Field (weight percent).

\begin{tabular}{|c|c|c|c|c|c|c|c|c|c|c|c|c|c|c|}
\hline \multicolumn{2}{|c|}{ Depth } & \multicolumn{3}{|c|}{ Opal- } & \multicolumn{3}{|r|}{$\mathrm{I} / \mathrm{S}$} & \multicolumn{2}{|l|}{ I/S } & \multirow[b]{2}{*}{ Dolomite } & \multirow[b]{2}{*}{ Pyrite } & \multirow[b]{2}{*}{ Apatite } & \multirow[b]{2}{*}{ NEOM } & \multirow{2}{*}{$\begin{array}{l}\text { Meas. } \\
\text { Density }\end{array}$} \\
\hline From & To & Qtz & $\mathrm{CT}$ & Kspr & Plag & Kaol & $(\mathrm{Fe} 3)$ & $(\mathrm{Fe} 2)$ & Calcite & & & & & \\
\hline 4497.0 & 4498.0 & 27.5 & 30.7 & 4.0 & 4.7 & 4.1 & 8.1 & 13.1 & 3.2 & 0.0 & 2.1 & 0.6 & 3.0 & 2.41 \\
\hline 4498.0 & 4499.0 & 34.3 & 32.9 & 3.2 & 3.6 & 3.9 & 6.3 & 8.4 & 3.4 & 0.0 & 1.7 & 0.6 & 2.9 & 2.40 \\
\hline 4499.0 & 4500.0 & 41.4 & 8.0 & 13.5 & 17.4 & 3.4 & 1.4 & 10.1 & 1.4 & 0.0 & 1.0 & 0.1 & 0.9 & 2.59 \\
\hline 4500.0 & 4501.0 & 53.3 & 16.2 & 2.4 & 0.0 & 6.1 & 4.0 & 10.7 & 2.8 & 0.0 & 1.4 & 0.6 & 2.4 & 2.52 \\
\hline 4501.0 & 4502.0 & 32.4 & 40.2 & 2.6 & 2.9 & 3.4 & 5.4 & 7.9 & 1.7 & 0.0 & 1.2 & 0.5 & 3.0 & 2.36 \\
\hline 4502.0 & 4503.0 & 42.5 & 25.1 & 3.2 & 1.3 & 5.9 & 9.8 & 5.7 & 2.5 & 0.0 & 1.1 & 0.6 & 2.1 & 2.48 \\
\hline 4503.0 & 4504.0 & 28.2 & 46.1 & 2.6 & 5.4 & 1.8 & 2.2 & 9.2 & 1.5 & 0.0 & 1.1 & 0.3 & 2.7 & 2.33 \\
\hline 4504.0 & 4505.0 & 27.4 & 53.4 & 1.8 & 2.8 & 2.0 & 2.5 & 7.5 & 0.7 & 0.0 & 0.9 & 0.2 & 2.5 & 2.30 \\
\hline 4505.0 & 4506.0 & 26.5 & 47.4 & 2.1 & 1.1 & 4.1 & 6.1 & 8.9 & 0.9 & 0.0 & 0.9 & 0.3 & 2.7 & 2.34 \\
\hline 4506.0 & 4507.0 & 29.8 & 51.3 & 3.1 & 6.4 & 0.5 & 4.2 & 1.3 & 0.0 & 1.5 & 0.8 & 0.2 & 2.4 & 2.30 \\
\hline 4507.0 & 4508.0 & 9.3 & 2.2 & 0.0 & 0.0 & 0.0 & 6.1 & 0.0 & 0.0 & 84.1 & 0.2 & 0.0 & 0.8 & 2.76 \\
\hline 4508.0 & 4509.0 & 18.5 & 6.1 & 0.0 & 0.0 & 0.0 & 9.2 & 0.0 & 0.0 & 67.1 & 0.4 & 0.0 & 1.8 & 2.66 \\
\hline 4509.0 & 4510.0 & 28.5 & 35.8 & 1.9 & 2.1 & 2.6 & 13.2 & 6.6 & 2.8 & 3.4 & 1.0 & 0.2 & 3.1 & 2.38 \\
\hline 4510.0 & 4511.3 & 28.7 & 35.0 & 4.9 & 9.4 & 1.5 & 7.5 & 7.8 & 2.0 & 0.1 & 1.3 & 0.3 & 2.7 & 2.38 \\
\hline 4511.9 & 4513.0 & 33.9 & 12.0 & 11.8 & 16.6 & 2.6 & 7.0 & 10.8 & 2.4 & 0.0 & 1.3 & 0.4 & 1.3 & 2.53 \\
\hline 4513.0 & 4514.0 & 27.9 & 25.3 & 5.6 & 8.8 & 3.8 & 9.3 & 12.1 & 3.4 & 0.0 & 1.9 & 0.6 & 2.5 & 2.44 \\
\hline 4514.0 & 4515.0 & 26.0 & 32.0 & 2.5 & 2.5 & 3.6 & 4.0 & 20.2 & 5.7 & 0.0 & 1.7 & 0.2 & 2.6 & 2.42 \\
\hline 4515.0 & 4516.0 & 28.7 & 25.4 & 4.3 & 8.0 & 1.7 & 6.1 & 16.5 & 6.0 & 0.0 & 1.7 & 0.4 & 2.2 & 2.45 \\
\hline 4516.0 & 4517.0 & 32.7 & 17.9 & 5.8 & 9.7 & 3.7 & 4.9 & 17.8 & 4.4 & 0.0 & 1.4 & 0.6 & 1.7 & 2.50 \\
\hline 4517.0 & 4518.0 & 38.0 & 9.8 & 4.6 & 10.2 & 0.6 & 0.0 & 29.3 & 4.7 & 0.4 & 2.1 & 0.1 & 2.3 & 2.50 \\
\hline 4518.0 & 4519.0 & 39.1 & 0.3 & 8.5 & 15.5 & 3.1 & 0.1 & 28.3 & 2.9 & 0.0 & 1.9 & 0.6 & 1.1 & 2.58 \\
\hline
\end{tabular}

Remarks

I/S (Fe3), Ferrian "illite/smectite". I/S (Fe2), Ferroan "illite/smectite". NEOM, non-extractable organic matter. 


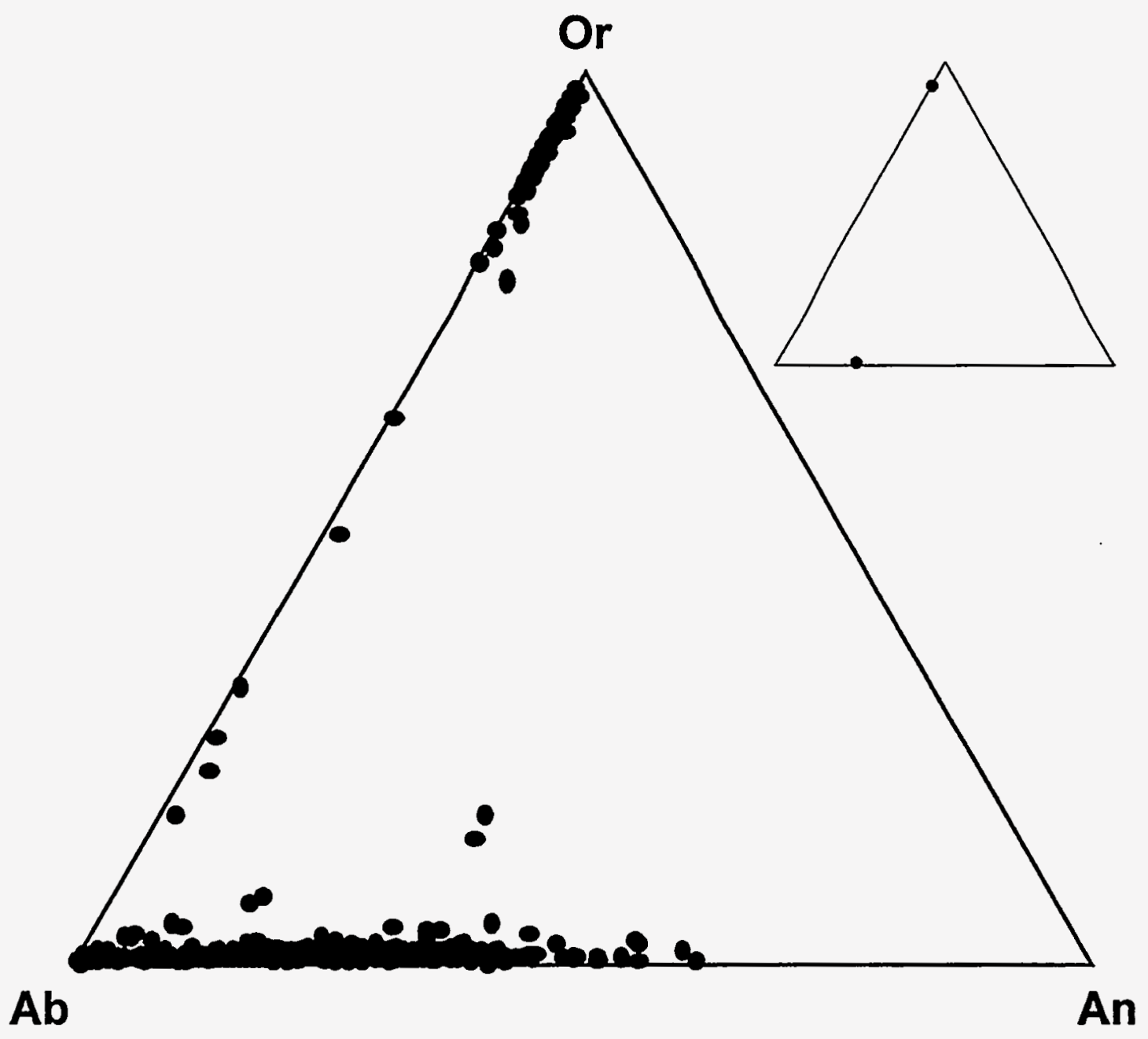

Figure 2g.1. Chemical composition of feldspar grains in the Antelope Shale, 653Z-26B Well, BV Hills field. The median compositions of the $\mathrm{K}$-feldspar and plagioclase are $\mathrm{Or}_{.916} \mathrm{Ab}_{.077} \mathrm{An}_{.001} \mathrm{Cs}_{.006}$ and $\mathrm{Or}_{.01} \mathrm{Ab}_{.75} \mathrm{An}_{.24}$ respectively. The median compositions of the feldspars are shown graphically on the insert at the top right corner of the page. 

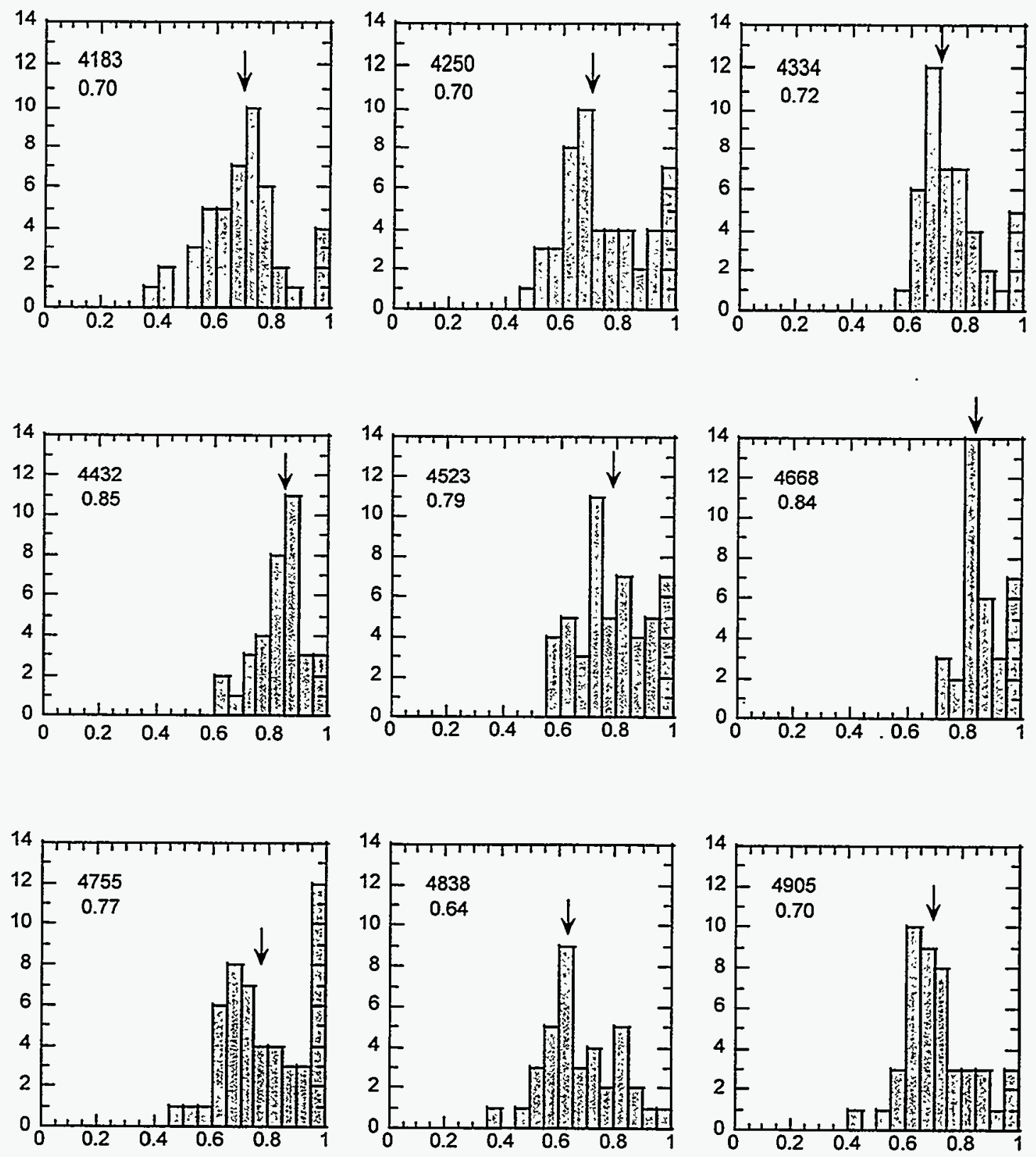

Figure 2g.2. Histograms of plagioclase feldspar compositions at specific depths within the 653Z-26B well. Plagioclase feldspars in the sandier samples (4432 and $4668 \mathrm{ft}$.) are more sodic than the plagioclase feldspars in finer-grained rocks. 

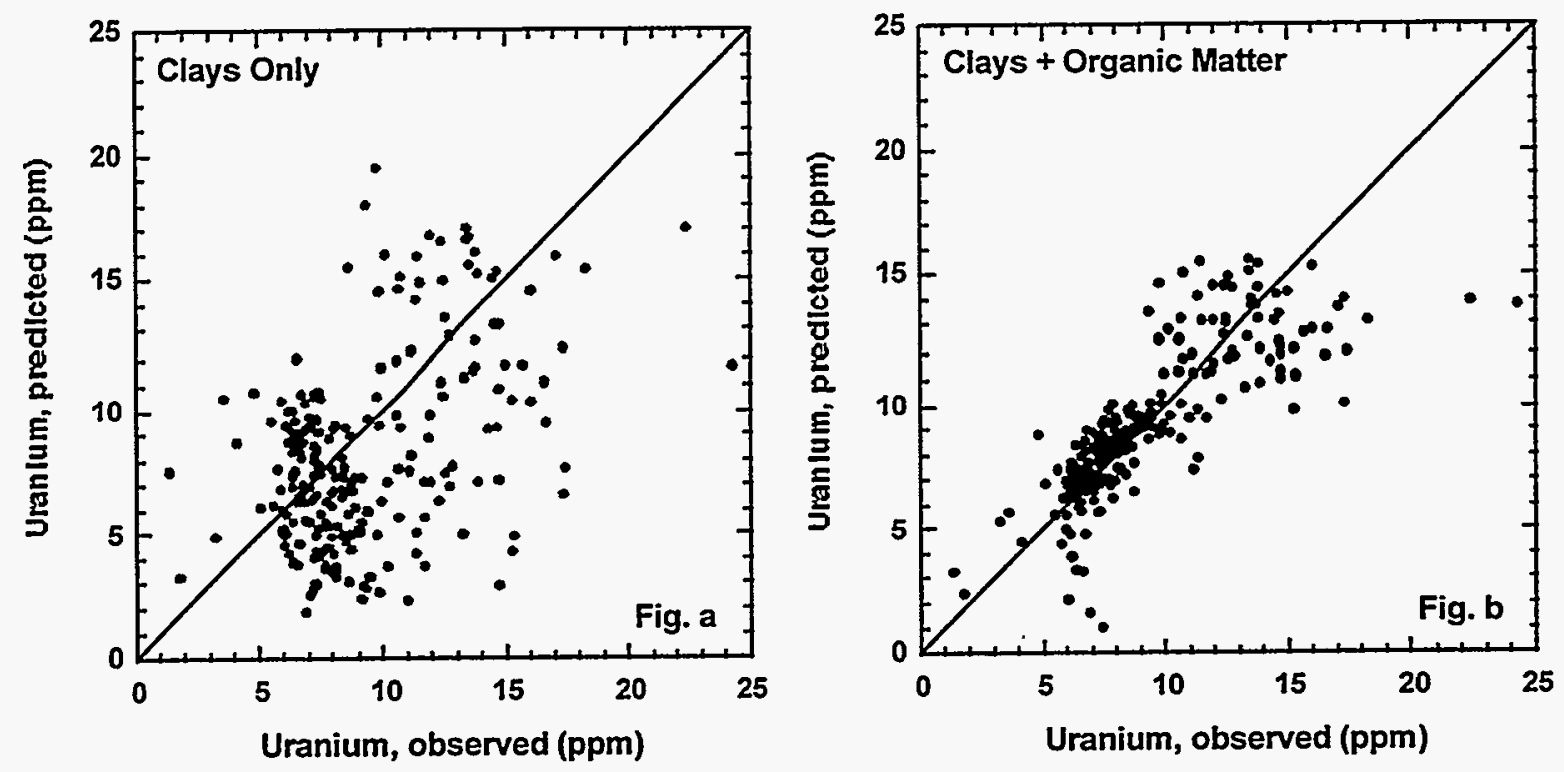

Figure 2g.3. Cross plots of predicted vs observed uranium in the Monterey Formation (653Z-26B well) based on different mineral models. More than 90 percent of the uranium appears to be associated with the nonextractable organic matter. Fig. 3a shows a cross plot of predicted vs observed uranium for the continuous core samples using statistical analysis to partition uranium between the clay minerals. Fig. 3b shows a cross plot of predicted vs observed uranium for the continuous core samples using statistical analysis to partition uranium between the clay minerals and non-extractable organic matter. 


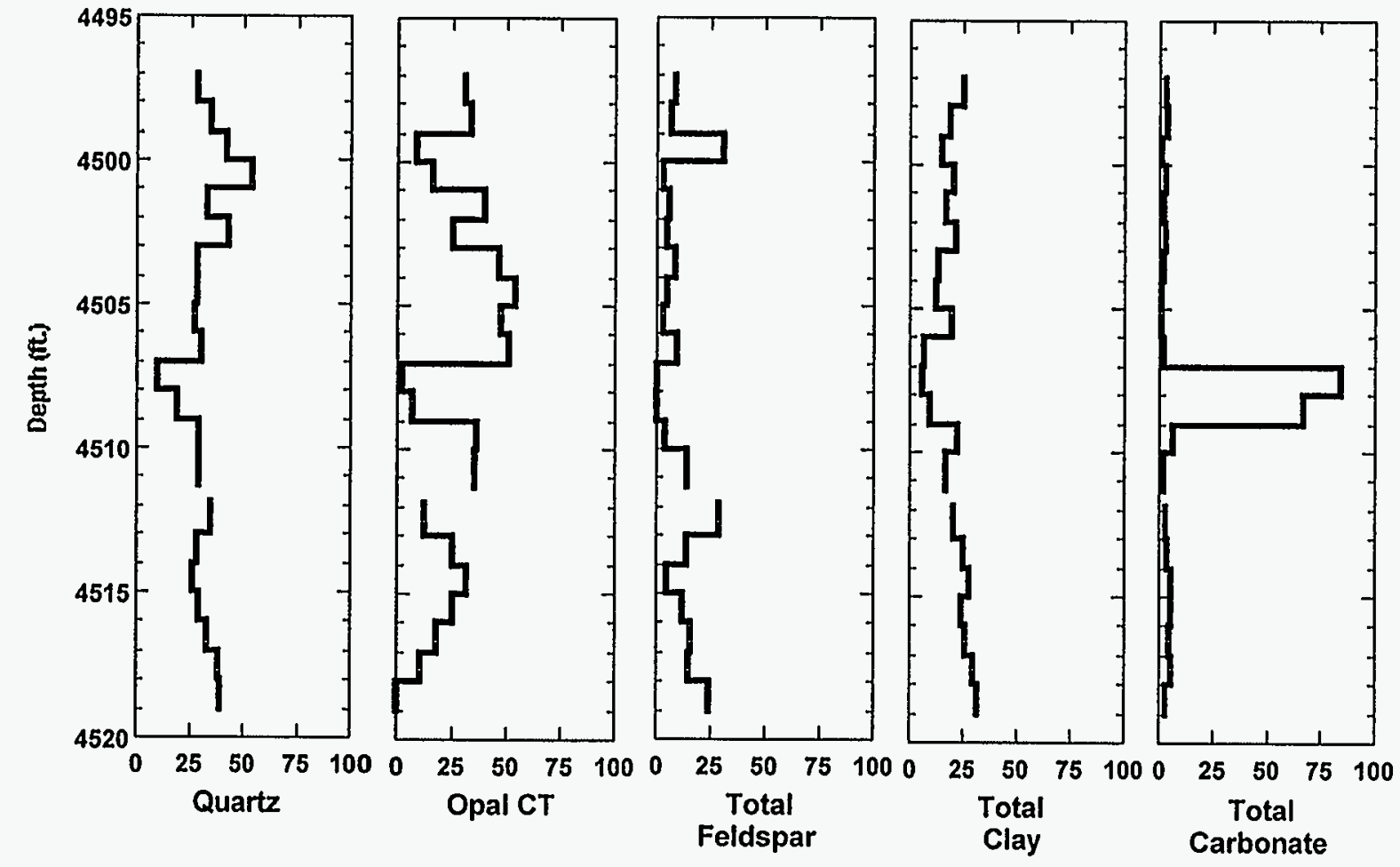

Figure 2g.4. Abundances of selected minerals vs depth for a 20 foot interval of continuous core samples. Mineral abundances are displayed here as vertical "bars" since the mineralogical composition and matrix densities are truly representative of each vertical increment of depth. Mineral abundances, matrix densities, and calculated log parameters can be smoothed by appropriate functions for comparison with wireline log signals. 


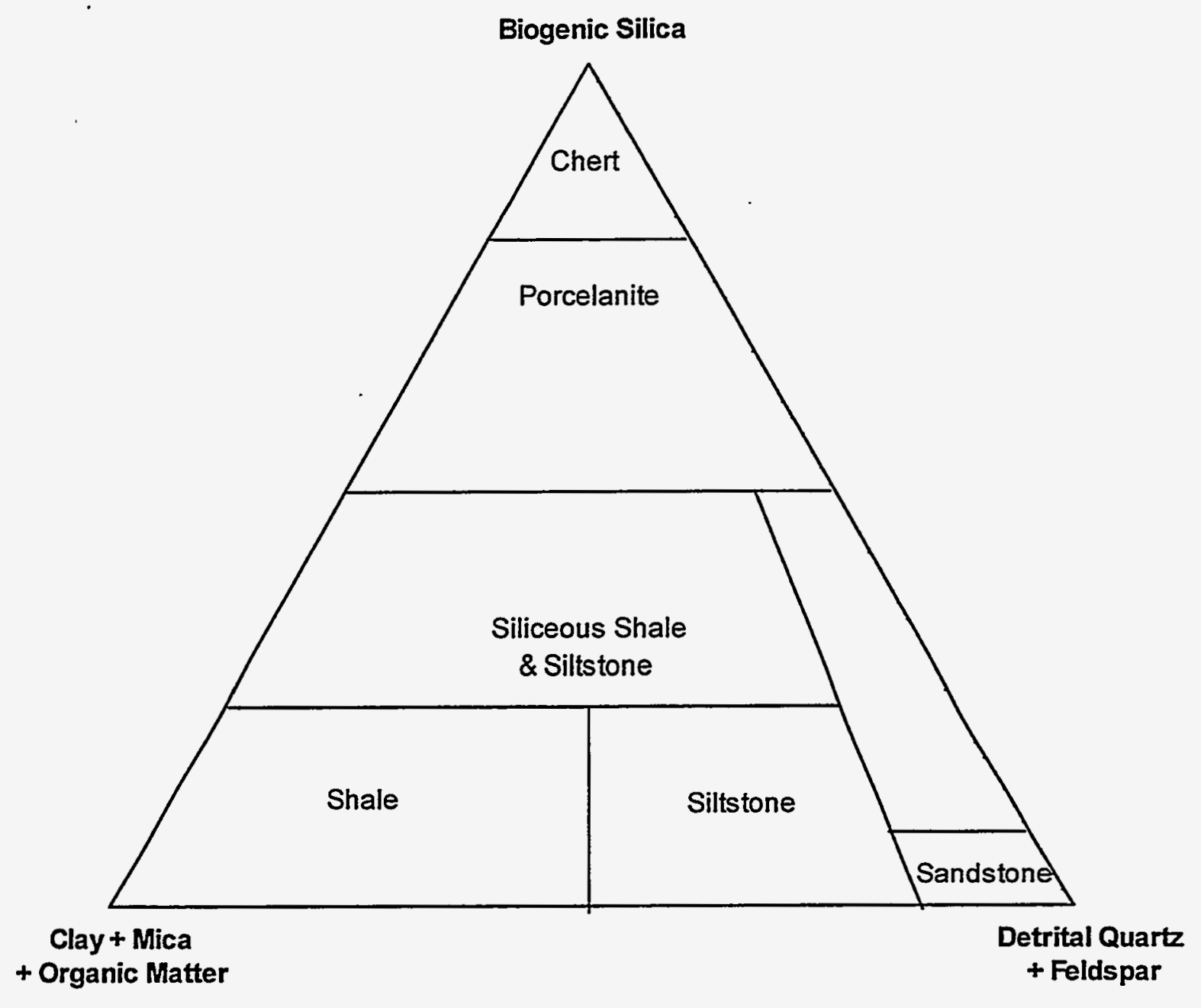

Figure 2g.5. Classification of siliceous shale lithologies based on mineralogy for rocks containing less than $20 \%$ carbonate in which opal-CT plus diagenetic quartz is greater than opal-A. For this diagram as applied to the continuous core samples biogenic silica is equal to the sum of all forms of opal plus diagenetic quartz and clay plus mica is equal to the sum of all clay minerals plus nonextractable organic matter plus pyrite. 


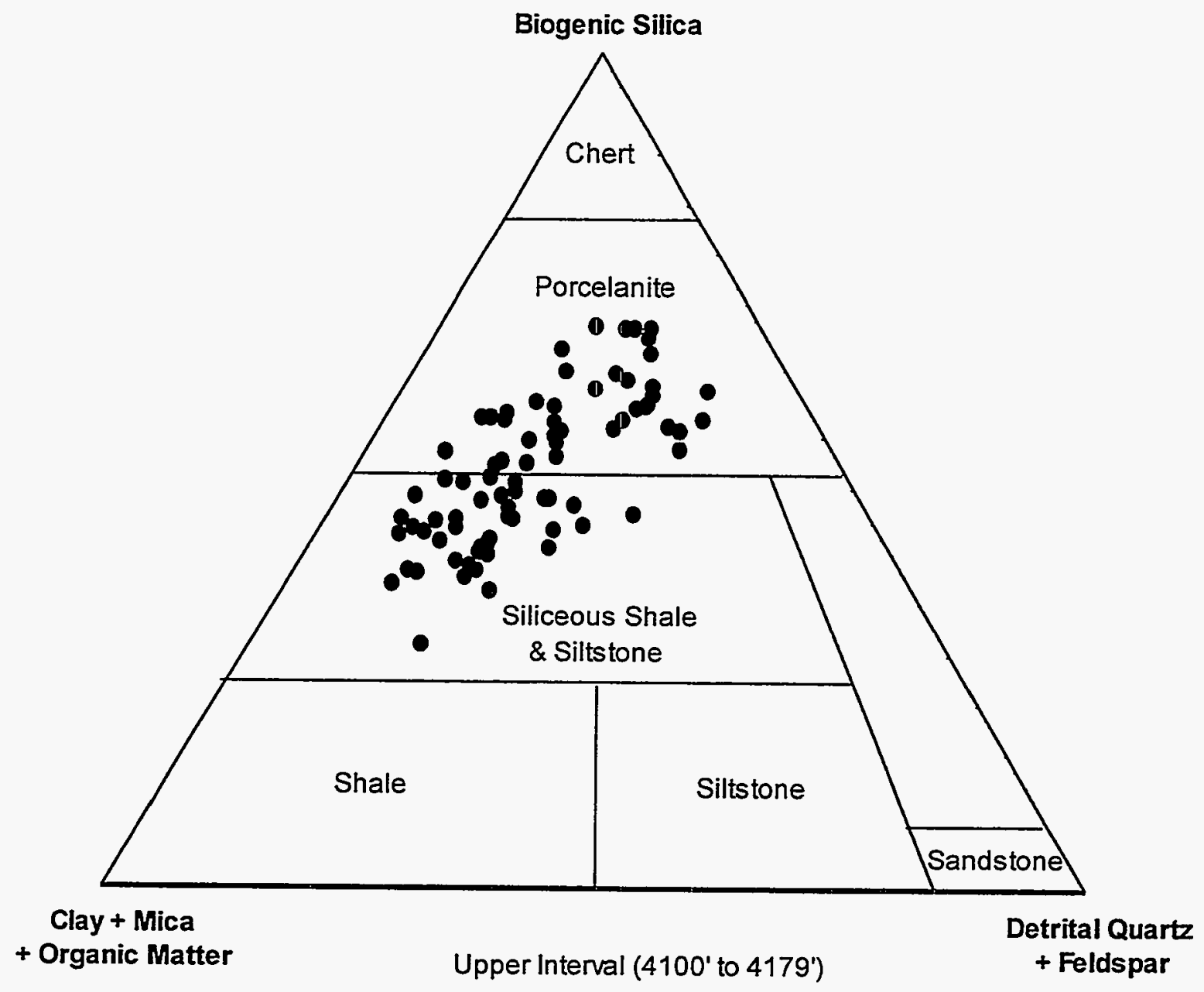

Figure 2g.6. Lithology of siliceous shale samples from the upper continuously sampled core interval $(4100-4180 \mathrm{ft}$.). 


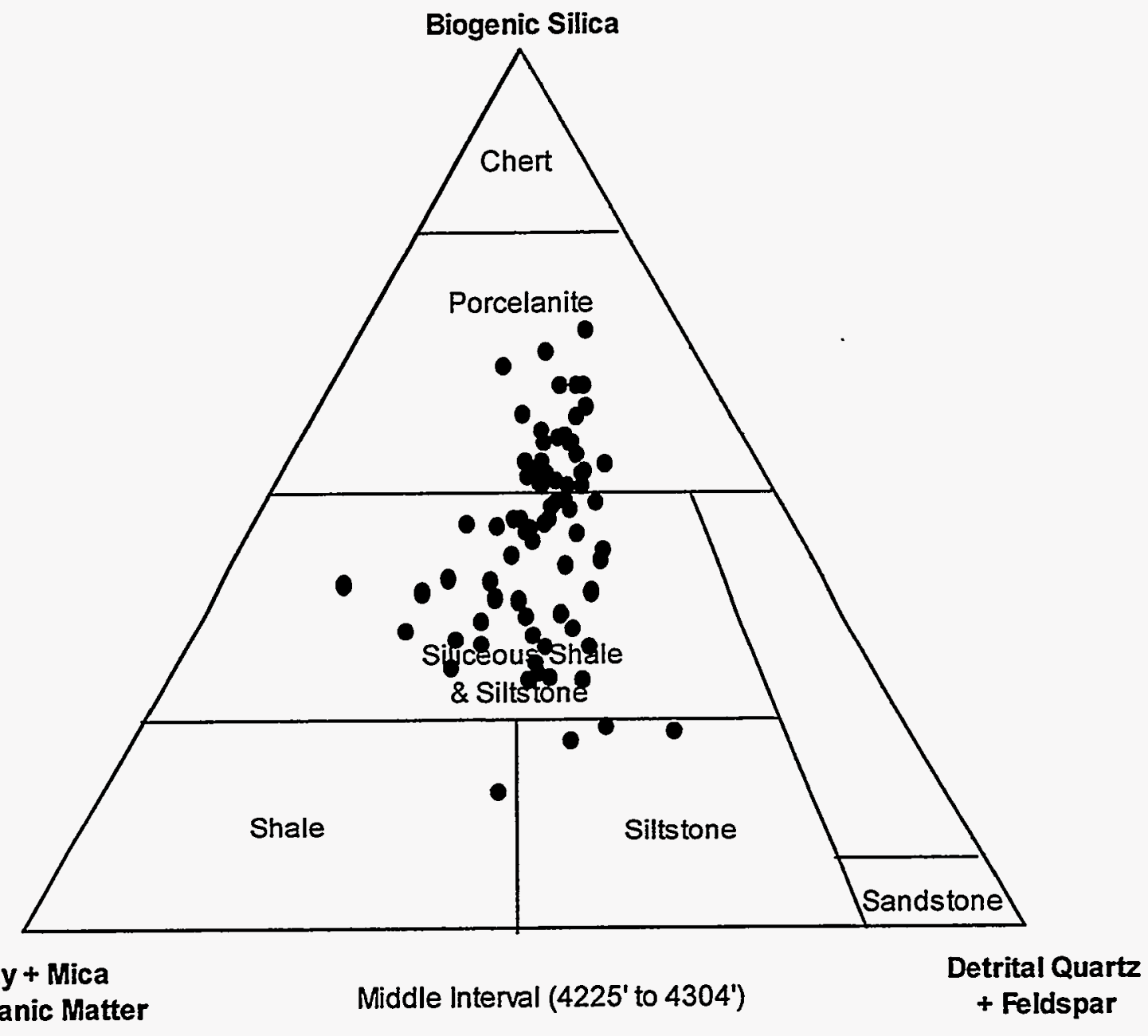

Figure 2g.7. Lithology of siliceous shale samples from the intermediate continuously sampled core interval (4225-4305 ft.). 


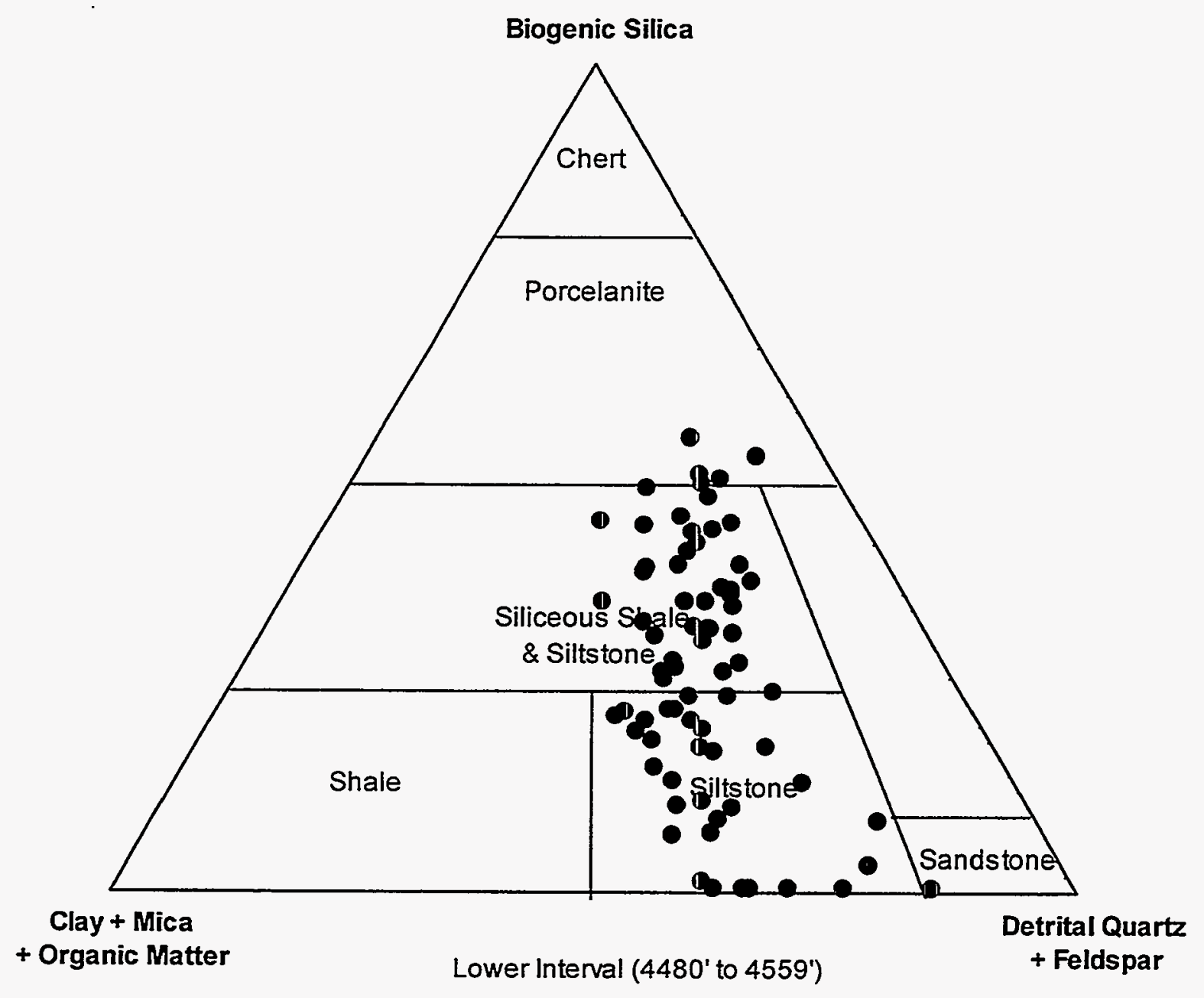

Figure 2g.8. Lithology of siliceous shale samples from the lower continuously sampled core interval (4480-4560 ft.). 


\section{Section $2 \mathrm{~h}$. \\ Complex Lithologic Analysis \\ Tom Zalan \\ Chevron USA Production Company \\ Stan Denoo \\ Schlumberger Wireline Services}

Effective reservoir characterization using a mineral-based formation evaluation strategy requires special types of mineralogical analysis. The approach requires accurate knowledge of the average compositions and related properties of individual minerals within the reservoir. The approach also requires that the validity of mineral models be verified by comparing mineralogical estimates from logs with accurate mineralogical analyses of corresponding core (see preceding section on Mineral Modeling and Inorganic Geochemistry).

Stan Denoo of Schlumberger Wireline Services, Denver has created three mineral models from logging suite combinations: model 1) Platform Express triple combo / Combinable Magnetic Resonance (CMR) / Elemental Capture Sonde (ECS); model 2) Platform Express triple combo / Combinable Magnetic Resonance, and model 3) Platform Express triple combo only. Each suite gives the same outputs, but more and more local constraints are applied as the logging suite gets smaller. This makes model 1 almost universally applicable but model 3 primarily locally defined.

The models consist primarily of five mineral components: clay, potassium feldspar, detrital quartz, carbonate, and opal-CT phase biogenic silica.

The volume of clay is equal to the ECS clay volume taken directly from the log. When the ECS is not in the suite, the clay volume can be computed from the $t 2$ logarithmic mean of the CMR or from the photoelectric factor of the Platform Express.

The volume of potassium feldspar is from the Natural Gamma Tool potassium channel as a linear function. When the Natural Gamma Tool is absent from the logging suite, the feldspar volume is estimated as twenty-five percent of the clay volume.

The volume of detrital quartz is defined as a linear percentage of the clay and feldspar.

The volumes of limestone and dolomite are computed based on an estimated formation grain density. The grain density of the formation is computed from the bulk density and the porosity. When the CMR is part of the logging program, the CMR total porosity may be used to compute the grain density rhogr $=($ rhob - phi) $/(1-p h i)$. If the CMR is not present, the initial porosity is the average of the neutron and density porosity. The grain density computed by a neutron-density average porosity was found to be high by 0.19 $\mathrm{gm} / \mathrm{cc}$. The corrected matrix value is then used to compute the new porosity 
phi $=($ rhogr - rhob) $/($ rhogr -1$)$. Grain densities between $2.66 \mathrm{gm} / \mathrm{cc}$ and $2.73 \mathrm{gm} / \mathrm{cc}$ are defined as limestones, and greater than $2.73 \mathrm{gm} / \mathrm{cc}$ are dolomites.

The volume of opal-CT biogenic silica is determined by clay correcting end point grain densities for pure opal-CT $(2.10 \mathrm{gm} / \mathrm{cc})$ and pure detrital quartz $(2.65 \mathrm{gm} / \mathrm{cc})$, and then dividing the computed total quartz volume into detrital and biogenic parts.

Mineral model 2 using the Platform Express triple combo and Combinable Magnetic Resonance agrees best with mineralogical analyses of core. In wireline log track 3 of Figure 2h.1, volume fractions of mineral components from bulk foot core mineralogical analyses (solid lines) are plotted against mineral model results (dash lines). From the right limit of $\log$ track 3 to the right set of solid and dash lines is the volume of quartz+feldspar. From the right set of solid and dash lines to the left set of solid and dash lines is the volume of clay+pyrite+organic matter. From the left set of solid and dash lines to the left limit of $\log$ track 3 is the volume of opal-CT. Figures $2 \mathrm{~h} .2-4$ are crossplots for the interval 4220 - 4300 feet of the mineral model and core volume fractions of, respectively, quartz+feldspar, clay+pyrite+organic matter, and opal-CT. It is evident from these plots that the mineral model fairly accurately represents the actual (core) mineralogy.

Mineral model 3 using the Platform Express triple combo agrees second best. Mineral model 1, including the Elemental Capture Sonde, agrees worst. We believe adding the Elemental Capture Sonde to the mix degrades the agreement to core because it contributes mineralogical information that conflicts with either the Platform Express triple combo and/or the Combinable Magnetic Resonance. These differences in the model results are still being investigated.

Another byproduct of the Schlumberger modeling effort was the derivation of a permeability from the shallow resistivity log, Rxo. Track 4 of Figure $2 \mathrm{~h} .1$ shows Rxobased permeability agrees in character and magnitude with core permeabilities, as opposed to Combinable Magnetic Resonance-derived permeabilities, which are off from core by one to two orders of magnitude. 

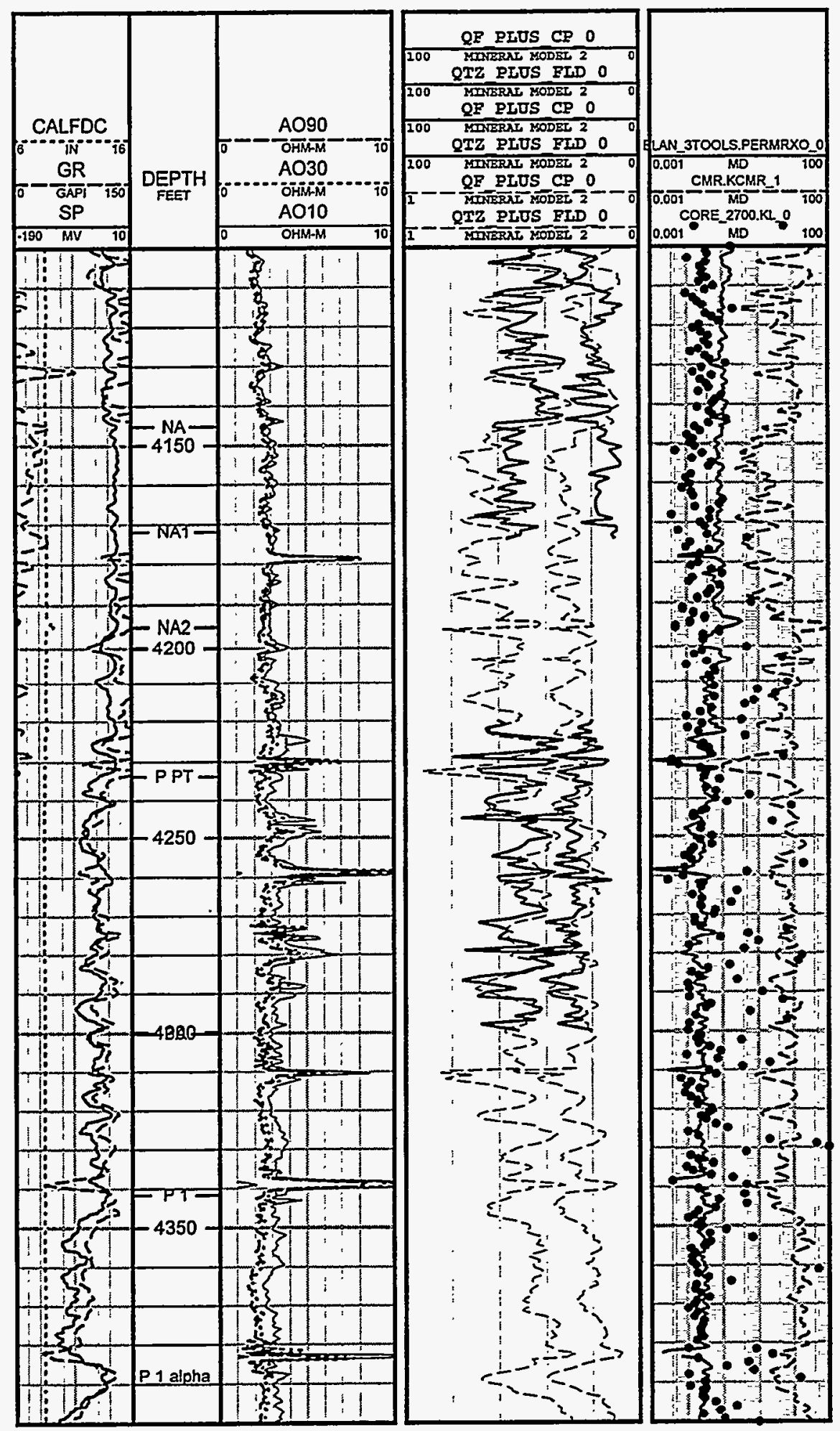

Figure 2h.1. Schlumberger ELAN mineral model from logs (dashed lines in wireline log track 3) agrees with Chevron core ESTMIN mineralogy (solid lines in track 3). Permeability from shallow resistivity log agrees with core permeability (track 4). 


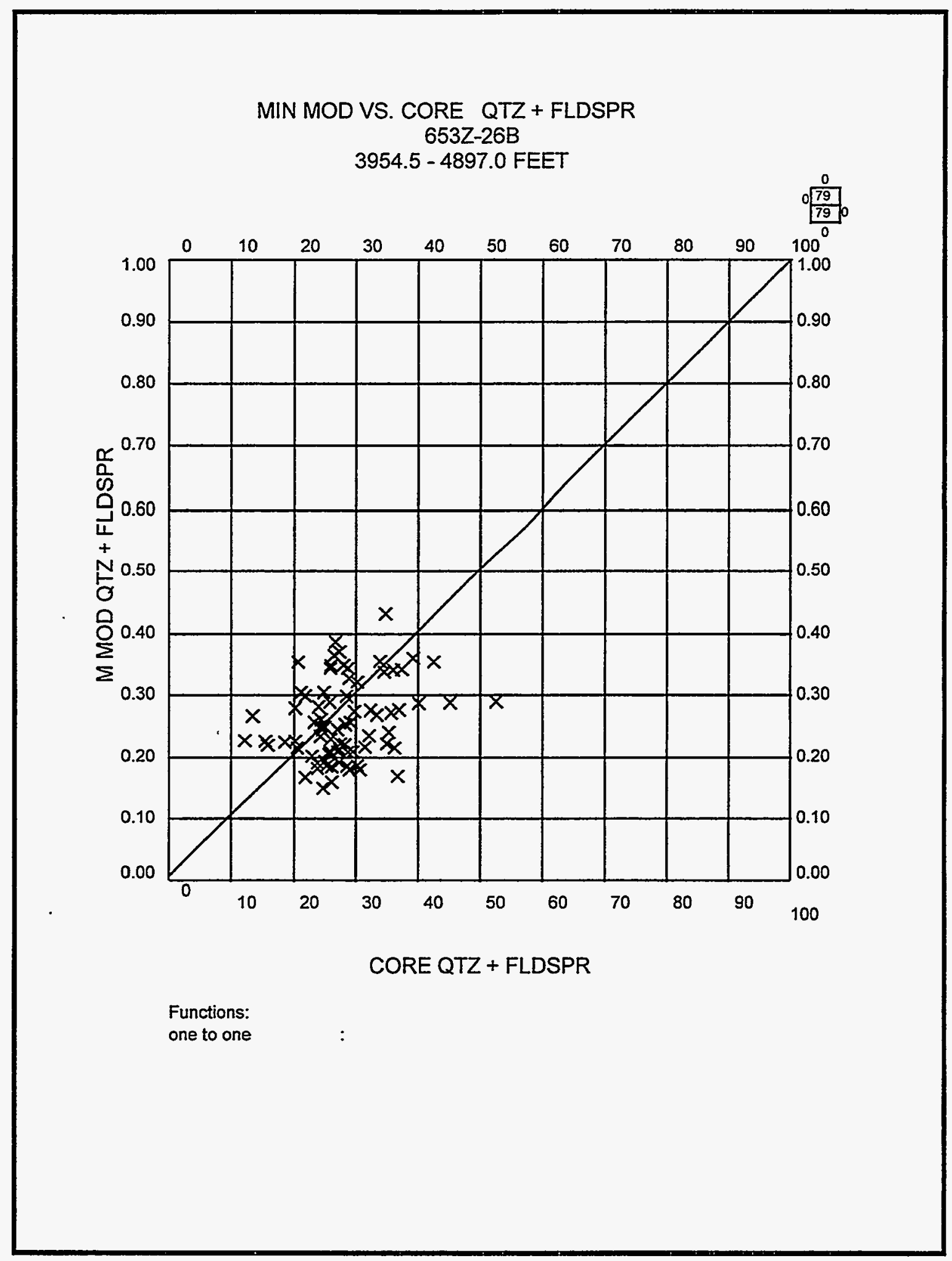

Figure 2h.2. Cross plot of volume of QUARTZ+FELDSPAR - Schlumberger ELAN mineral model versus Chevron core ESTMIN. 
MIN MOD VS. CORE CLAY + PYRITE + ORGANIC MATTER 653Z-26B

3954.5 - 4897.0 FEET

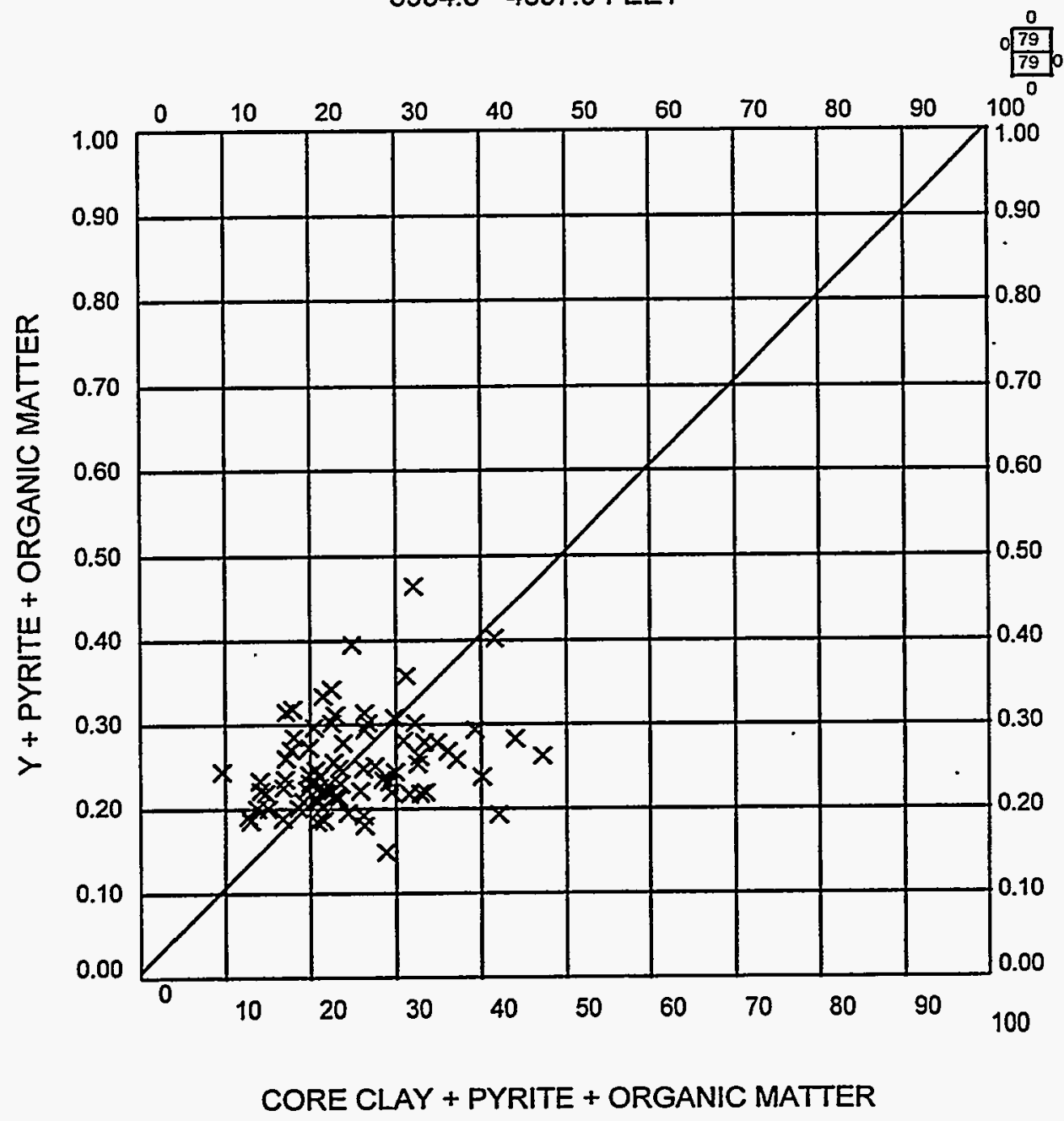

Functions:

one to one

Figure 2h.3. Cross plot of volume of CLAY+PYRITE+ORGANIC MATTER Schlumberger ELAN mineral model versus Chevron core ESTMIN. 


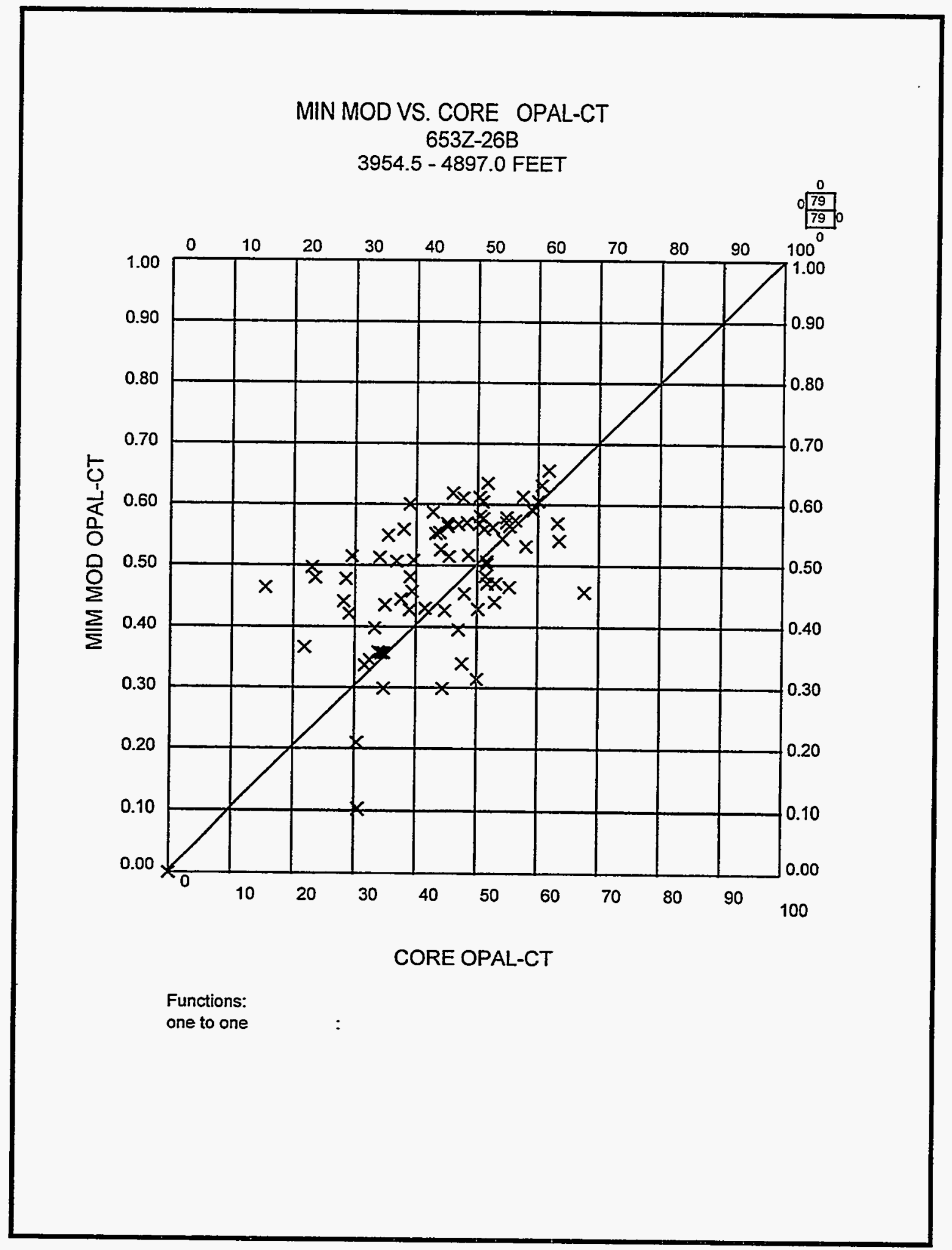

Figure 2h.4. Cross plot of volume of OPAL-CT - Schlumberger ELAN mineral model versus Chevron core ESTMIN. 


\section{Section 2i. \\ 3D Earth Model \\ Dale Julander and Tom Zalan \\ Chevron USA Production Company \\ Dale Beeson, Julian Thorne and Ed Dezabala \\ Chevron Petroleum Technology Company}

There are essentially four main reservoir properties that are being modeled at BV Hills: 1) Porosity, 2) Permeability, 3) Oil Saturation, and 4) Lithofacies (sandiness). During the early part of the year, a large effort was directed at cleaning, modifying, and quality checking the borehole data to prepare them for use in deriving the four reservoir properties. More than $95 \%$ of the wells in the Buena Vista Hills Field have limited openhole log data ((usually 1950's - 1960's vintage electric logs with spontaneous potential (SP) only)). Accordingly, most of our modeling efforts focused on establishing a relationship between these logs - - particularly SP - - and reservoir properties. After considerable effort, reasonable transforms for these properties were derived for wells having SP curve data.

Porosity

The method for deriving porosity curves for each of the wells at BV Hills involved using a transform from the Spontaneous Potential (SP) log to Vshale (Vsh_SP) and subsequently from Vsh_SP to porosity (correlation coefficient $R=0.649$ ). The best-fit transform (Figure 2i.1 )is a third-order polynomial that relates porosity to Vsh_SP as follows:

$$
\text { POROSITY }=-0.3602 V s h-S^{3}+0.5412 V s h \_S^{2}-0.3136 V s h \_S P+0.365
$$

This relationship establishes upper and lower porosity bounds of $37 \%$ and $23 \%$, respectively, which captures the majority of the measured values in the field.

This transform was applied to all of the BV Hills wells during the third quarter of 1997. Subsequently, quality control methods were used to detect anomalous data that required additional attention. Several wells were identified as having anomalously high porosities compared to surrounding wells. Further review indicated that most of these wells required reprocessing due to a variety of reasons (e.g., correction of SP data due to baseline drift and fine-tuning of estimated shale baseline or clean sand SP values) and one well was eliminated because of an overly complicated drilling and logging history. New porosity curves were generated for the problematic wells.

\section{Permeability}

We were unsuccessful in our attempts to derive a direct correlation between core permeability and SP. However, a permeability transform was generated following a lengthy process which included an evaluation of old drill stem test (DST) data from the field. Chuck Magnani of CPTC reviewed DST data from the field to determine its utility 
for estimating permeability in the Brown Shale and Antelope Shale. The data set consisted of more than 400 DSTs, though it was determined early on that the majority were of too short a duration to provide useful information about formation permeability. As a result, Chuck Magnani considered fifty-five DSTs useable and judged eleven to contain some formation permeability information. Seven of those eleven DSTs were determined to have adequate duration to allow estimation of formation permeabilities. Estimates for these seven tests (labeled "valid" tests for discussion purposes) ranged from 0.01 - 1.8 millidarcies (md). The remaining four DSTs were short enough duration to have been somewhat influenced by borehole storage and transition effects but long enough duration to also allow formation permeabilities to be estimated. Estimates for these four tests (labeled "transition \& storage" tests for discussion purposes) ranged from $0.023-5.0$ md.

After trying to establish a correlation between DST permeability and Vsh_SP in many ways (e.g., valid DSTs only, valid DSTs + transition \& storage tests, first/second/third order polynomials, logarithmic, exponential), a best-fit match (Figure 2i.2) was obtained for the exponential case for valid DSTs only (correlation coefficient $R=0.841$ ):

$$
\text { PERMEABILITY }=4.0827 * \mathrm{e}^{* *}(-2.5084 * \text { Vsh_SP })
$$

where permeability is in millidarcies. The actual data used to derive this relationship covered a permeability range from $0: 34$ to $1.8 \mathrm{md}$ and a Vsh_SP range from 0.274 to 0.839. However, the predicted endpoint values of $\mathrm{K}=4.08 \mathrm{md}$ for Vsh_SP $=0$ (coarsest grained case) and $\mathrm{K}=0.33 \mathrm{md}$ for Vsh_SP $=1$ (finest grained case) did not adequately capture the full range of permeabilities known to exist within the reservoir based on modern core data from well 653Z. A modification of the DST-based permeability transform was, therefore, made to more accurately capture low (shale) and high (sandstone) permeability endpoints. The transform, above, was used for Vsh_SP values that fell between 0.274 and 0.839 (the valid range of DST data) while linear functions were used to extend the ends of the transform to Vsh_SP values of 0 and 1, respectively. The permeability endpoints for the linear relationships were estimated from a liquid permeability vs. cumulative probability plot (based on core data from the $653 \mathrm{Z}$ well) and represent the $1 \%(0.009 \mathrm{md})$ and $99 \%$ (31.009 $\mathrm{md})$ cumulative probability permeability values. The final transform equations are as follows:

If $\left(V s h \_S P<0.274\right)$, then PERMEABILITY $=31.009-105.679 *$ Vsh_SP

If $(0.274<=$ Vsh_SP $<=0.839)$, then PERMEABILITY $=4.0827 * \mathrm{e}^{* *}(-2.5084 *$ Vsh_SP)

If $($ Vsh_SP $>0.839)$, then PERMEABILITY $=3.046-3.037 *$ Vsh_SP

Permeability curves have subsequently been calculated for each of the wells in the field and have been checked for quality based on consistency comparisons with surrounding 
wells. Curves that appeared unusually high or low throughout the vertical extent of the model were reviewed and reprocessed as needed.

\section{Oil Saturation}

Efforts to derive a best fit log-based relationship between porosity and irreducible water saturation (Swi) based on capillary pressure measurements from the $653 \mathrm{Z}$ well core plugs were completed in early 1998 (Figure 2i.3). These analyses suggest that separate relationships will need to be derived for sandstones versus siliceous shales. (Sandstones have low Swi values while siliceous shales have high Swi values relative to porosity.) Initial oil saturations (Soi) will then be estimated from the Swi estimates via the following relationship: Soi $=1$ - Swi. Equations for determining Soi have been derived by Ed Dezabala of CPTC as follows:

$$
\begin{array}{ll}
\text { FOR SANDSTONES: } & \text { Soi }=0.55+\mathrm{Phi} \quad(\text { for } 0.10<\mathrm{Phi}<0.30) \\
\text { FOR SILCEOUS SHALE: } & \text { Soi }=-0.229+1.3158 * \mathrm{Phi}(\text { for } 0.25<\mathrm{Phi}<0.44)
\end{array}
$$

Successful estimation of oil saturations hinges on being able to successfully determine the predominant lithofacies for each cell in the 3D geologic model so that the proper ratio of sandstone and siliceous shale (and the proper ratio of high and low Soi) can be assigned to the model. Estimation of oil saturations for the full 3D model are expected to be completed in March 1998.

\section{Lithofacies (Sandiness)}

Estimates of lithofacies (sandiness) have recently been completed for each of the wells in the United Anticline using the following methodology. As a starting point, core lithology data were blocked over 2 foot intervals into percent "sandstone/siltstone" and "shale" for the 12 wells in the field that have Brown and Antelope shale core descriptions. With the exception of the $653 \mathrm{Z}$ well, most of the cores used in this analysis date from the 1950's and 1960's and have subsequently been destroyed. Consequently, the only available lithologic information for these cores comes from the written descriptions stored in our well files. The 2 foot core blocking was designed to represent the lithologic data at about the same level of resolution available in most of the field log data. Table 2i.lshows a list of these 12 core wells.

Lithologic variation across the field was modeled using the neural net analysis capabilities in Chevron's proprietary FaciesFinder application and relating the 2 foot blocked core data to log curves. Only those wells (Table $2 \mathrm{i}$.1, wells in parentheses) were ultimately used in the neural net analysis. These wells contained a large enough number of samples to be representative of the two lithology types and did not excessively over-generalize the lithologic variability. The remaining wells were not used in the analysis either because of the lack of detail available in their respective core descriptions or because the cores were too short to be of much use. The former sometimes resulted in intervals that were effectively blocked over sections that were up to several tens of feet thick. 
In the neural net analysis, fifty percent of the core data from the 5 useable wells comprise the "training" set, and the Vsh_SP log curves were used to predict the fraction of sand, or sandiness. (Note: Though other open-hole logs were available to us - - e.g., deep and shallow resistivity - - we decided to use only the normalized raw SP curve to avoid differences associated with multiple vintages of other log types). In order to deal with occasional occurrences of over-generalized core descriptions that led to thicker than 2 foot blocking, we: 1) allowed exclusion of a percentage of the extreme data in the crossplot between predicted and observed sandiness under the assumption that many of these points were the result of the exaggerated blocking, and 2) allowed a minimal depth shift between predicted and observed sandiness to account for depth generalization due to blocking.

After many iterations, a best fit sandiness prediction between core data and Vsh_SP was achieved based on the following parameters and specifications: 1) $90 \%$ of the data were used for the correlation; 2) textural analysis was applied to the SP using a 4 foot sliding "window"; and 3) a $+/-2$ foot shift in observation location was allowed due to blocking generalization.

These basic parameters applied to the five training wells produced a gross average sandiness value of $7.6 \%$ for the Brown Shale and Antelope sections in the United Anticline. With $10 \%$ of the data eliminated as outliers due to the blocking method applied, the correlation coefficient for the best-fit prediction was $R=0.92$. (Figure 2i.4). This method was recently used to derive sandiness estimates for all wells in the United Anticline.

\section{Visualize Reservoir Property Distributions}

Stratamodel will be used to build the 3D stratigraphic framework across the Buena Vista Hills Field. The G2 geostatistical functionality and GOCAD visualization environment will be used simultaneously with Stratamodel where it adds value in a complementary fashion. In addition, FaciesFinder, an advanced facies-based reservoir characterization UNIX application developed at Chevron, is being used to improve reservoir property simulations for visualization in GOCAD and Stratamodel. The FaciesFinder application relates reservoir property data to "facies" based on well log pattern recognition.

Sixteen structure surfaces (TMC down to and including P2) gridded in Z-Map+ by Dale Julander were quality controlled in GOCAD for conformity. These structure surfaces are interpolated between well marker control and provide the boundary constraints for the stratigraphic grid (SGrid) which contains the reservoir volume. Reservoir property data (i.e., porosity, permeability, oil saturation, and sandiness) will be conditionally simulated within the proportionally layered SGrid. The simulated (i.e., characterized) Sgrid volume will then be available for visualization, testing and validation. This process, and the progress to date, is illustrated in (Figure 2i.5).

Lastly, a preliminary, proof-of-concept, 200,000 cell, SGridded volume was created for a portion of the Upper Antelope Shale (P Pt. to P1B interval) on the United Anticline. The volume was populated with porosity derived from SP curves using a previously derived 
SP to porosity transform. This porosity-populated volume, simulated in FaciesFinder and displayed in GOCAD, was a successful test of a work flow for generating faciesconditioned reservoir property realizations. Efforts are now being directed at improving the quality and content of the database to be used as a front end to this process.

Table 2i.1. Buena Vista Hills Field cored wells.

Well Name

(523-9D)

$(653 Z-26 \mathrm{~B})^{\star *}$

(USL522A-2-26B) $^{* *}$

(552-27B)

563-27B

425-36B **

532-1C

524-6D

552-8D

$502-9 D$

533-9D

(555-9D)
\# of 2ft Sample samples

191

451

125

163

29

62

20

6

754

27

30

430 interval

$3632^{\prime}-5248^{\prime}$

$3953^{\prime}-4903^{1 \star \star}$

$4036^{\prime}-5284^{\prime * *}$

$4005^{\prime}-7000^{\prime}$

$5482^{\prime}-5538^{\prime}$

$4096^{\prime}-4498^{\prime}$

$4360^{\prime}-4398^{\prime}$

$4739^{\prime}-4749^{\prime}$

3700 ' $5542^{\prime}$

$3712^{\prime}-4170^{\prime}$

$4680^{\prime}-5629^{\prime}$

$3917^{\prime}-4778^{\prime}$

\section{Location*}

HA

UA

UA

UA

UA

HA

HA

HA

HA

HA

HA

HA

* UA=United Anticline; HA=Honolulu Anticline

*W. Narr fracture analysis

*** Later removed from database due to bad SP log 


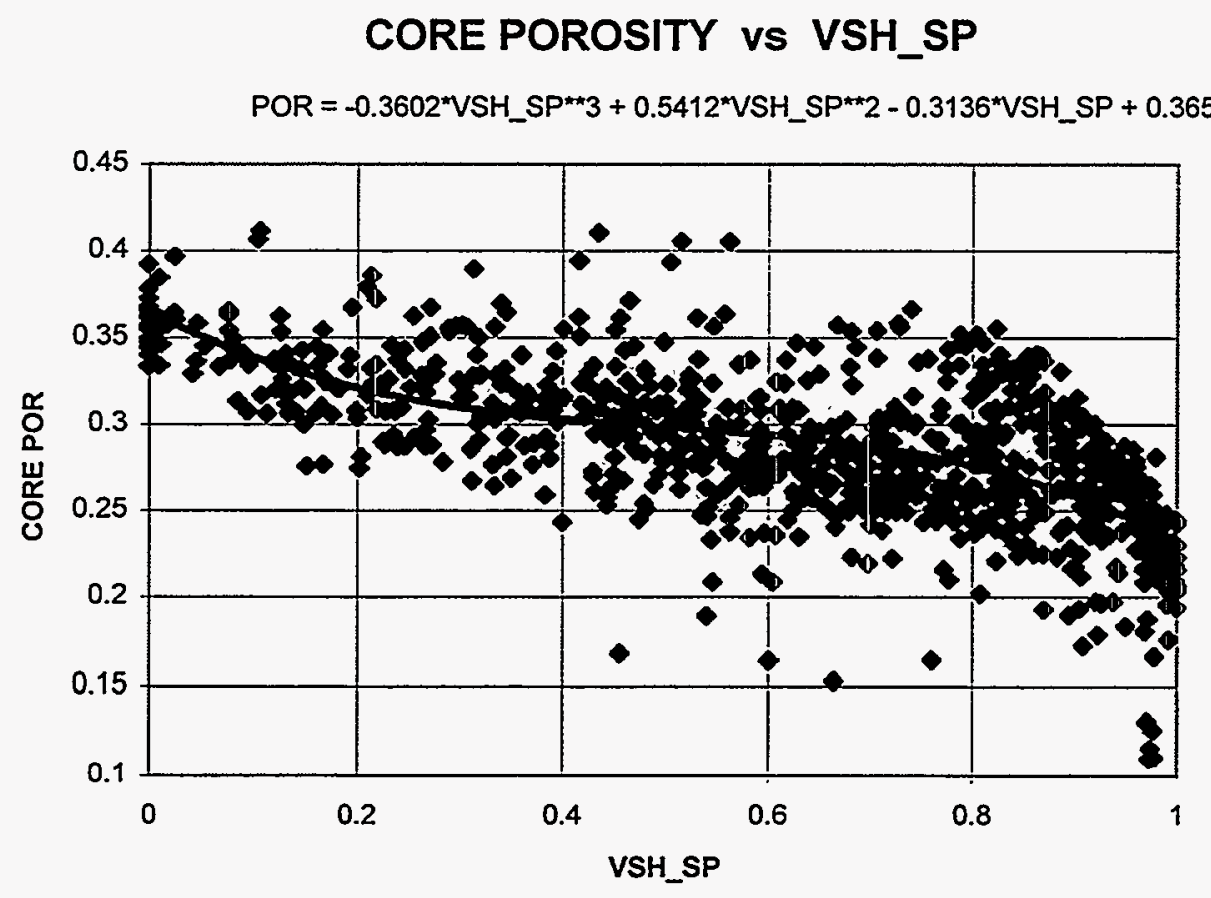

Figure 2i.1. Cross plot of core porosity versus Vshale as calculated using the Spontaneous Potential log (correlation coefficient $=0.649$ ).

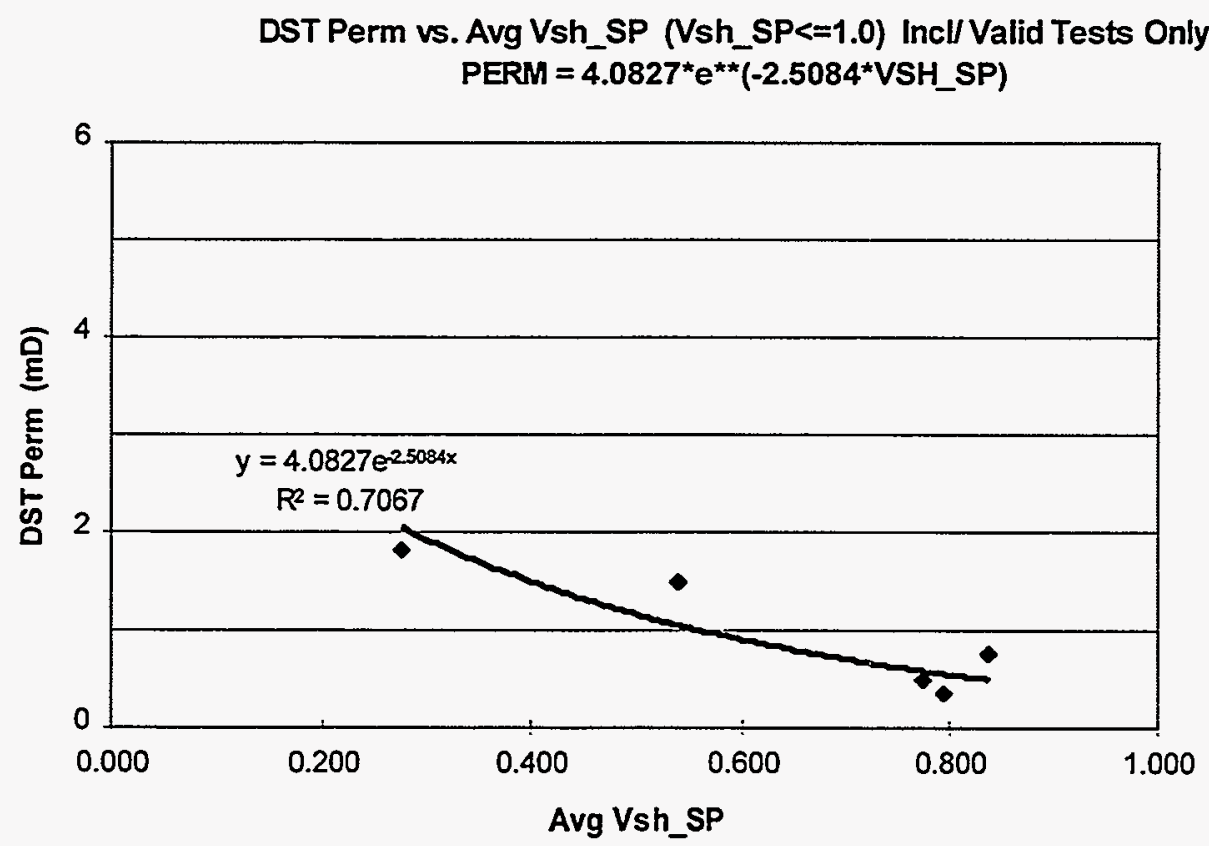

Figure 2i.2. Cross plot of Drill Stem Test permeability versus Vshale as calculated using the Spontaneous Potential $\log$ (correlation coefficient $=0.841$ ). 
Initial Oil Saturation vs. Porosity (from Mercury Intrusion), BV Hills Well 653Z-26B

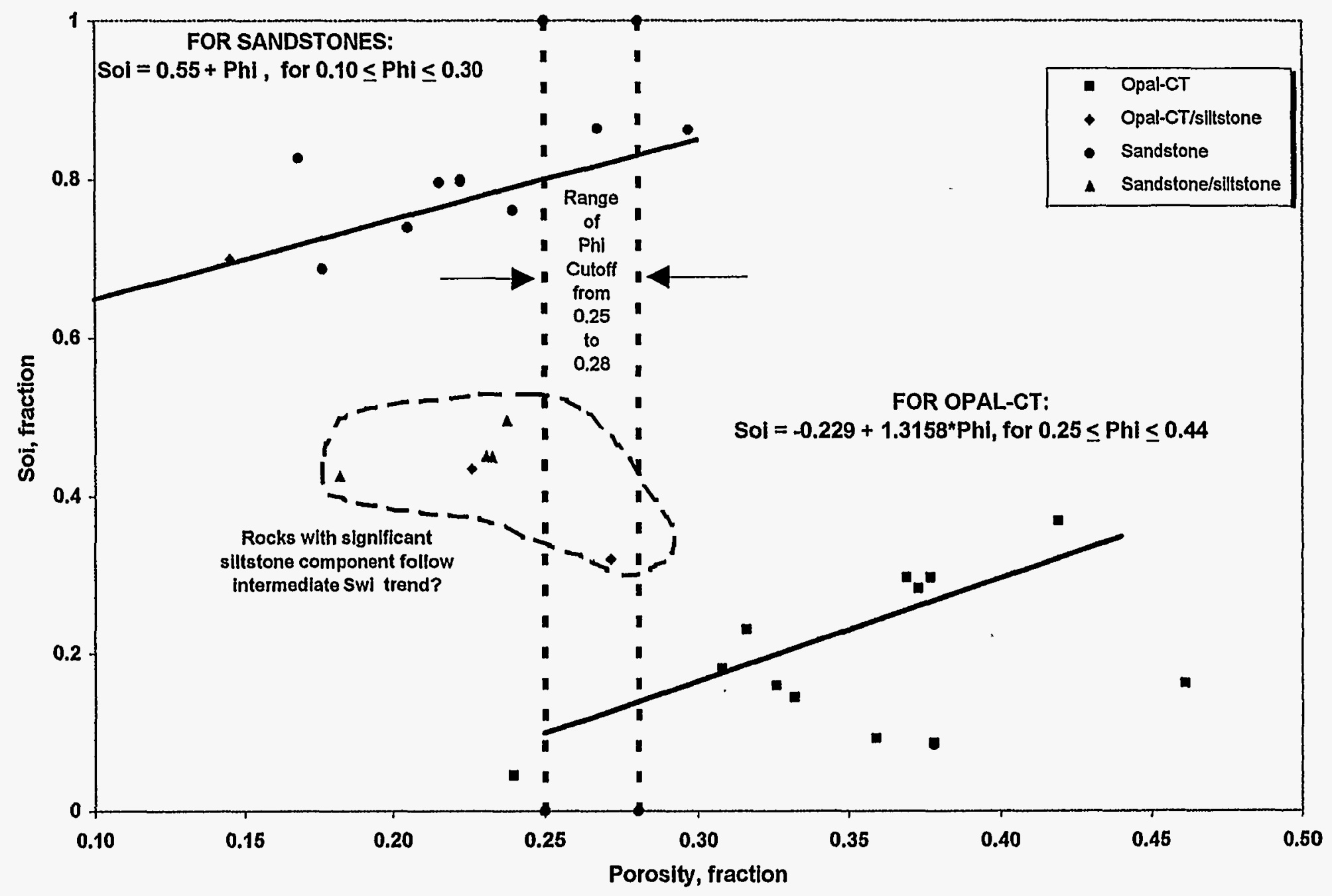

Figure 2i.3. Cross plot of initial oil saturation (as measured by mercury intrusion) versus porosity, calculated using the correlation in Figure 2i.1. 


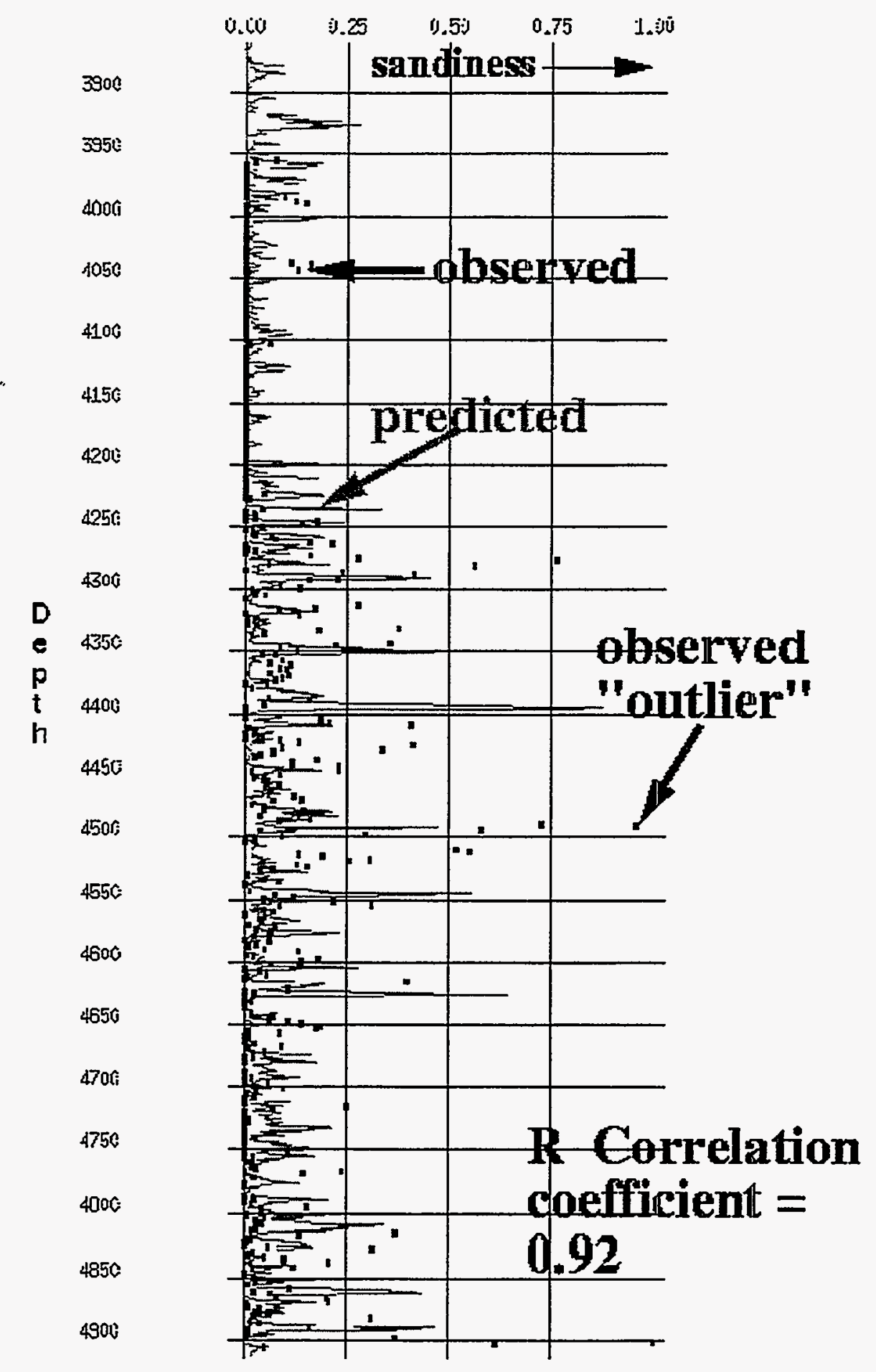

Figure 2i.4. 1D neural net analysis using FaciesFinder. Best fit prediction of sandiness based on matching core descriptions to openhole log data. 


\section{Conventional Geostatistical as well as Facies-based, and Hybrid Workflows for Reservoir Characterization}

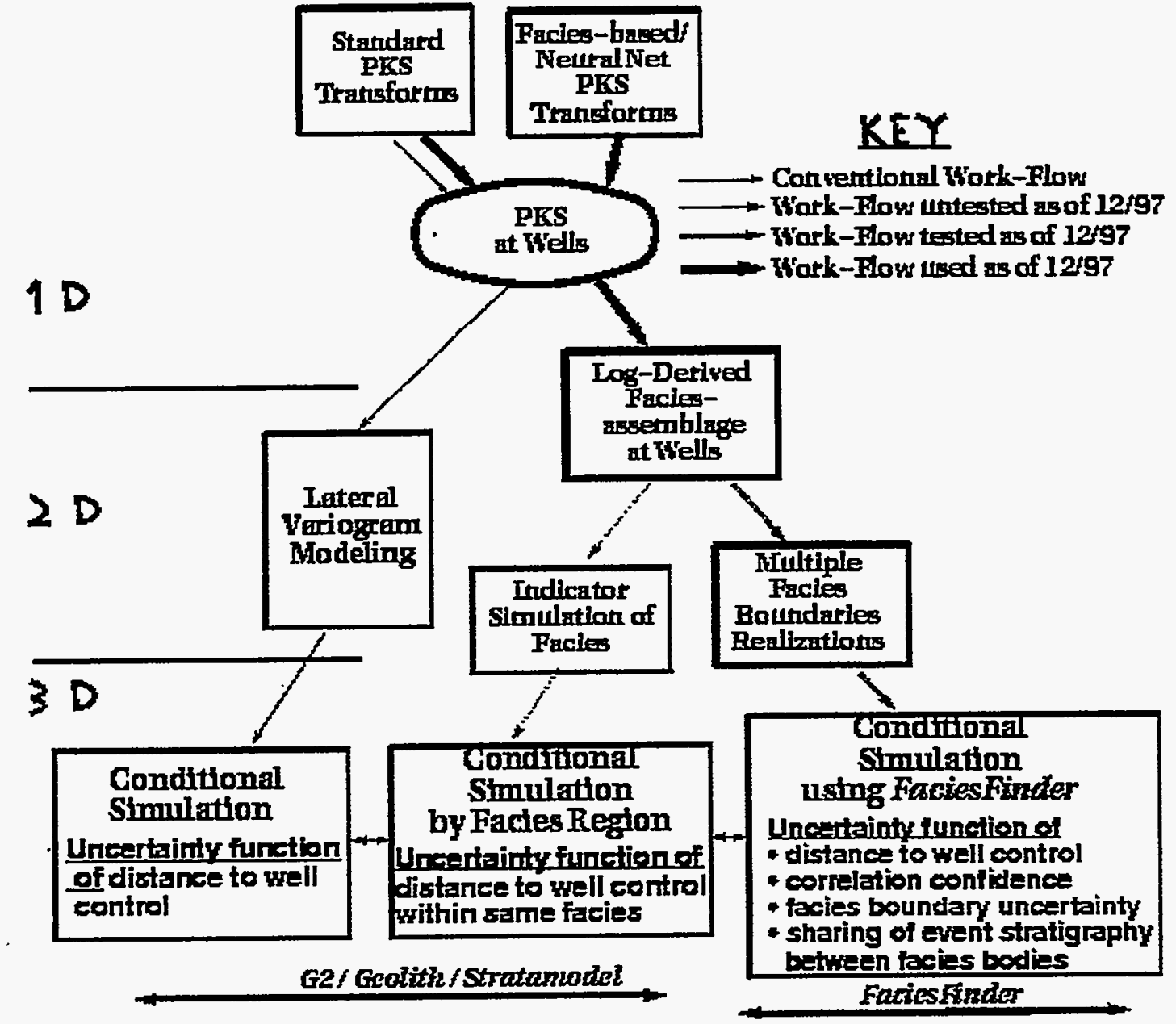

Figure 2i.5. Reservoir characterization workflows. Method applied at Buena Vista Hills shown by dark arrows. Future steps will include Multiple Facies Boundaries Realizations and Conditional Simulation using FaciesFinder. 


\section{Section $2 \mathbf{j}$. \\ CO2 Coreflood Experiments \\ Ray Tang and Dengen Zhou \\ Chevron Petroleum Technology Company}

Laboratory experiments reported in the literature suggest that crossflow driven by diffusion, capillary and gravity forces can recover oil efficiently from heterogeneous reservoirs in a gas injection process. The published experiments were generally conducted on high permeability systems $(>100 \mathrm{md})$. Cores from Buena Vista Hills oil field show mixed lithology, with high permeability sandstone layers and low permeability siliceous shales $(<1 \mathrm{md})$. What we want to determine is whether or not crossflow mechanisms can recover oil from the siliceous shale by injecting $\mathrm{CO} 2$ into the reservoir. In order to do this, laboratory displacement tests were designed to investigate oil recovery potential from control crossflow mechanisms. If results are promising, then the data can be used to design a $\mathrm{CO} 2$ injection project for Buena Vista Hills.

During the $4^{\text {th }}$ quarter, we finished preparing the "mixed lithology" core, which consists of two parts: a sandstone slab and a wholecore siliceous shale slab from the 653Z-26B well. A Viton gasket was used to reduce the flow of gas in the gap between the two slabs and to keep sufficient area for crossflow between the two zones (See.Figure 2j.1). The contact surface of the sandstone and the shale is placed vertically to encourage gravity driven cocurrent crossflow. After the core was placed in the core holder, the core is then saturated with stock tank oil. No water is involved in the experiments to reduce the complexity of the experiments.

The displacement experiment is ongoing. Figure $2 \mathrm{j} .2$ is a schematic of the displacement equipment. The core is situated in an oven at reservoir temperature $(160 \mathrm{~F})$. The core was initially saturated with $\mathrm{BV}$. Hills stock tank oil. $\mathrm{CO} 2$ is then injected at a constant rate of $1.0 \mathrm{cc} / \mathrm{hr}$, which corresponds to a rate of $1 \mathrm{ft} / \mathrm{d}$ if the injected $\mathrm{CO} 2$ flows through the sandstone portion of the core only. In the first phase of the experiment, we kept the core pressure at about 600 psi by using a back pressure regulator connected to the outlet of the core. The produced gas and oil are flashed to room conditions $(68 \mathrm{~F})$, at which the productions of gas and oil are recorded automatically. The system can also automatically monitor the inlet and outlet pressures, from which pressure drop can be calculated. The produced gas is collected into an evacuated gas tank. Cumulative gas production is monitored by pressure change in a 100 liter gas cylinder that was initially evacuated. Figure $2 \mathrm{j} .3$ is the gas tank pressure as a function of time. There are step changes in the pressure data caused by oil slugging through the BPR. When a small slug of oil passes through the BPR, more space is open for gas to flow through. Figure $2 \mathrm{j} .4$ shows the pressure drop across the core during the experiments. The spikes in the pressure drop data correspond to the time when slugs of oil pass through the BPR. Overall, the pressure drop behaves very nicely. 


\section{Recovery Results at 600 psi}

The oil production data at 600 psi suggest only a small contribution from crossflow. Figure 2j.5 shows the oil production from this phase of the experiment. The overall production is low (about 17\% of OOIP). However, it is interesting to note that some additional oil was produced after the $6^{\text {th }}$ day of injection. This small increase in production after two days without oil production indicates the contribution of crossflow from diffusion and/or gravity. More production data are needed before we can assess the significance of crossflow mechanisms. It shall be noted at about $600 \mathrm{psi}, \mathrm{CO} 2$ is not a very efficient solvent to the crude oil. One would expect that crossflow driven by diffusion and gravity increases as system pressure increases, which is being investigated in the second phase of the experiment.

\section{Recovery Results at 2500 psi}

After oil production ceased at $600 \mathrm{psi}$, the system pressure was raised to investigate recovery at $2500 \mathrm{psi}$. At $2500 \mathrm{psi}$, crossflow driven by diffusion and/or gravity has resulted in significant oil production for a long period of time. This stage of the experiment is in its $5^{\text {th }}$ week, and oil recovery continues.

We increased the system pressure to 2500 psi by adjusting the BPR at the out-let of the system. At $2500 \mathrm{psi}$ and $160 \mathrm{~F}, \mathrm{CO} 2$ has a density of about $0.5 \mathrm{~g} / \mathrm{cc}$, however, the pressure is still significantly lower than the minimum miscibility pressure (MMP). Figure $2 \mathrm{j} .6$ shows the oil production as a function of time. The volume of the produced oil is estimated from the weight of the produced oil and the density of the original oil. To date, about eight (8) pore volumes of $\mathrm{CO} 2$ has been recycled at a constant rate of $1 \mathrm{cc} / \mathrm{hr}$, and the oil production rate has been roughly constant (about $1 \mathrm{cc} /$ day). We also observed that the produced oil is significantly lighter than the original oil in the core (stock tank oil). The combination of the constant oil production and the changes in density indicates that crossflow and extraction are the major recovery mechanisms. We are in the process of measuring the densities and the compositions of the produced oils at different times, which can give an indication of the relative contributions of crossflow and extraction to oil production. The measured densities would also give more accurate calculation of the produced oil volume.

Our preliminary calculations suggest that we are producing a significant amount of oil from the shale part of the core. The total pore volume of the sandstone part of the core is estimated to be about $23 \mathrm{cc}$ (more accurate measurement of the porosity will be conducted at the end of the experiment). Up to date, about $36 \mathrm{cc}$ of oil has been recovered, including about $12 \mathrm{cc}$ from the low pressure flood and $24 \mathrm{cc}$ from the high pressure flood. Thus, even if we assume all the oil in the sandstone has been produced, at least half of the oil produced at $2500 \mathrm{psi}$ is from the shale. To scale up the experimental data for field applications, we need to conduct detailed numerical simulations, in which the major recovery mechanisms can be represented. Current finite difference simulators available to the project cannot directly represent physical diffusion. Instead, we will investigate the potential of approximating physical diffusion with numerical diffusion (artifact of finitedifference), for the purposes of field scale predictions. 


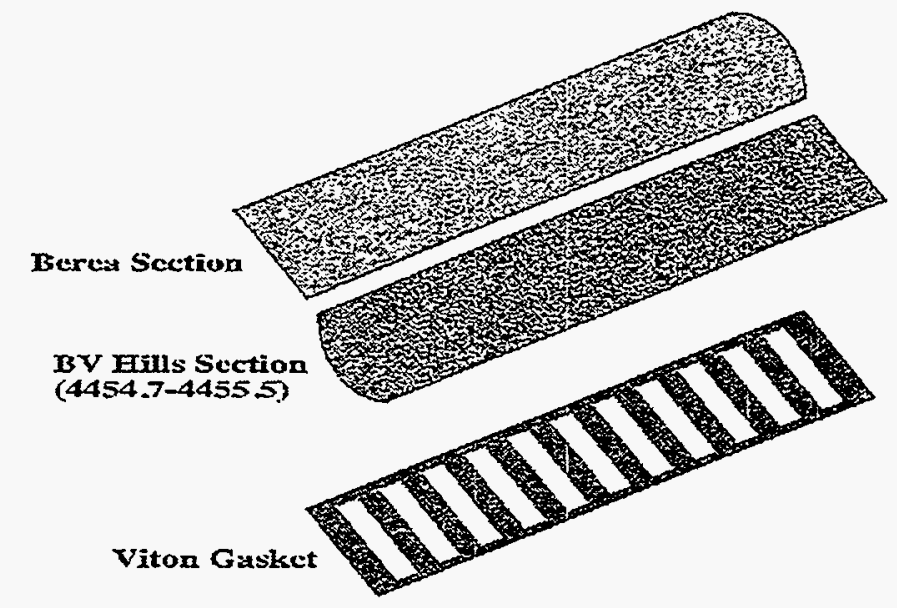

$\begin{array}{ll}\text { Berca Section: } & 825 \text { inches longs } \\ 1 \text { inch beep } & .7414 \mathrm{~K}\end{array}$

BV Gills Sectiun: 8.25 inches long

3 inches Deep

$23763 \mathrm{Kg}$

Figure 2j.1. A schematic of the mixed lithology core elements: slabs of sandstone and BV Hills Shale and a Viton gasket. The gasket is designed to reduce gas flow in the gas between the two slabs in the same time allowing crossflow occur.

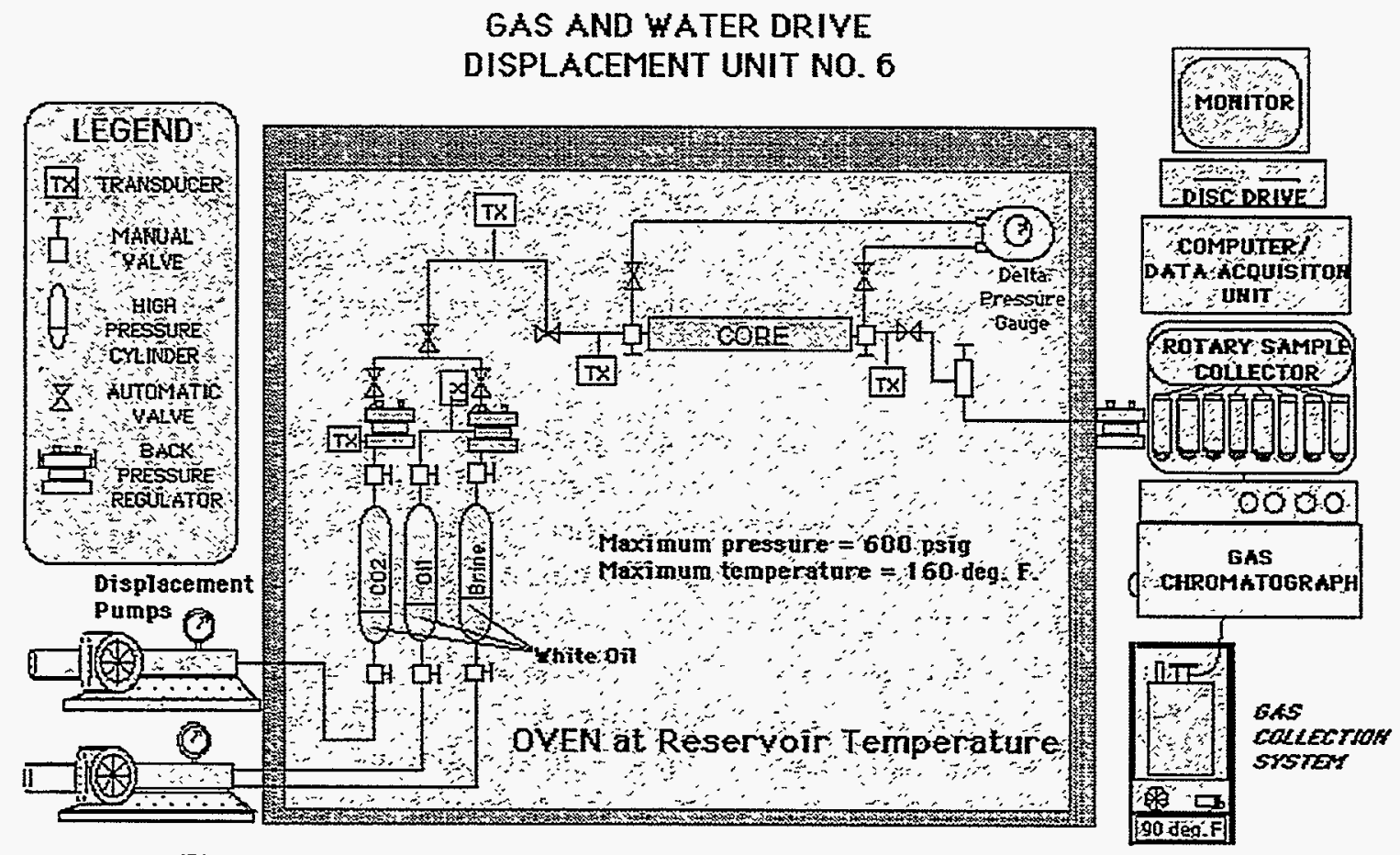

Figure 2j.2. A flow diagram of the displacement rig. The rig is automated to conduct displacements at reservoir temperature and pressure. 


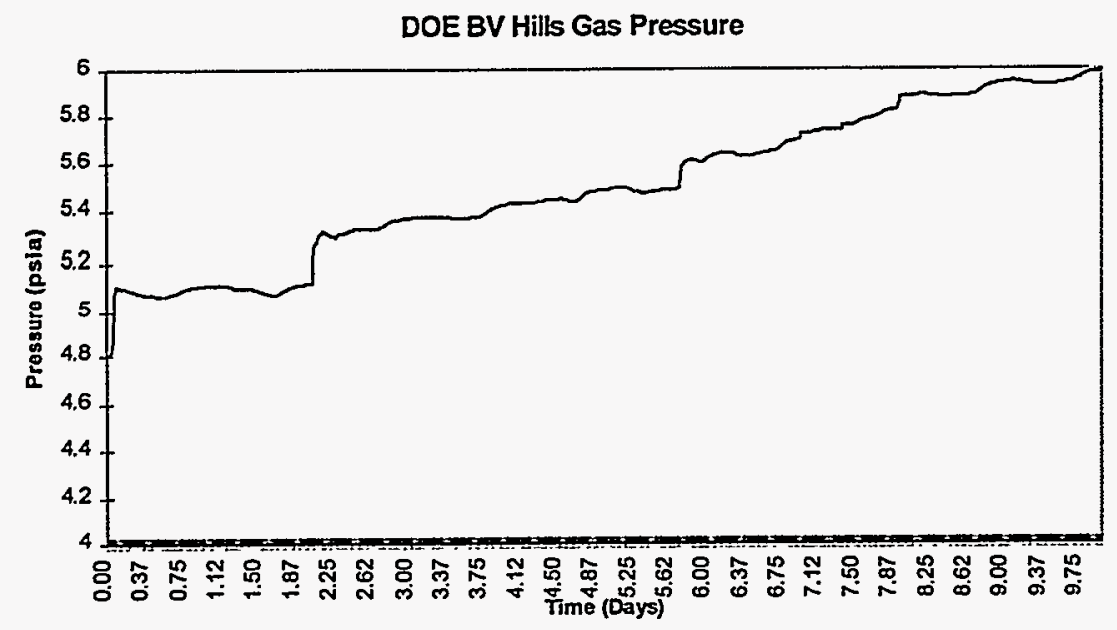

Figure 2j.3. Pressure in the produced gas tank as a function of time.

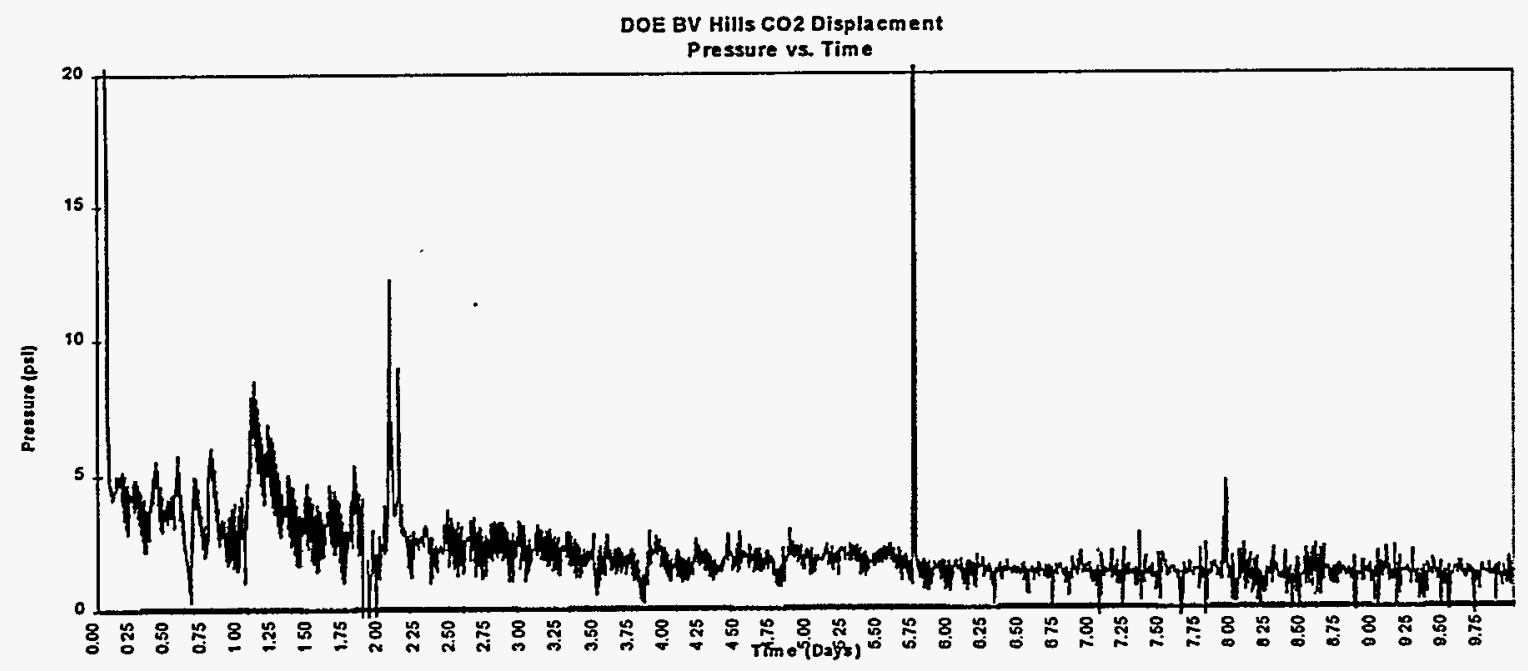

Figure 2j.4. Pressure drop across the mixed lithology core as a function of time. 


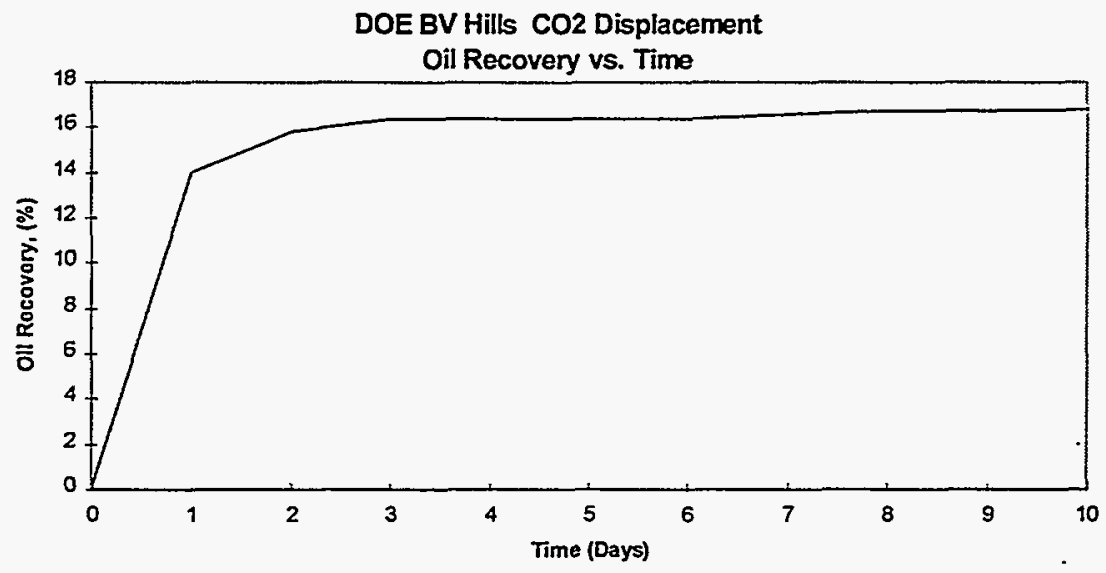

Fig2j.5. Oil Production from $\mathrm{CO} 2$ injection.

DOE BV Hills CO2 Flood - 2500 psi

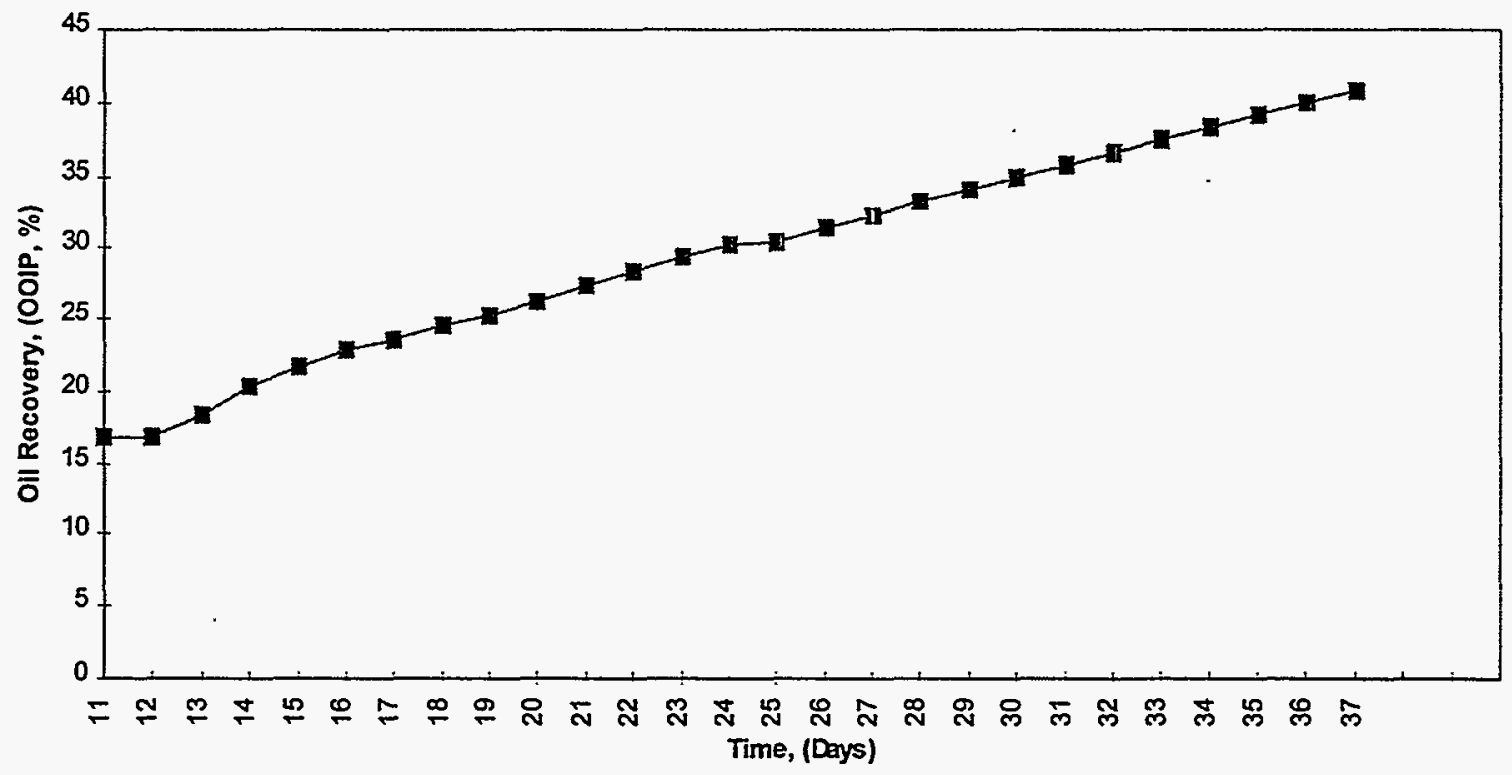

Figure 2j.6. Total oil production from the high pressure (2500 psi) $\mathrm{CO} 2$ flood. The volume of the produced oil is estimated using the density of the stock tank oil, which is higher than that of the produced oil. 


\section{SECTION 3.}

\section{Summary of Technical Progress}

Section 3 gives a summary description of the tasks that were performed during the period covering February 7, 1997 to February 6,1998. A more detailed discussion on some tasks can be found in Section 2 of this report. All core samples or analyses are from the 653Z$26 \mathrm{~B}$ well unless stated otherwise. 


\section{Characterize the Brown Shale and Antelope Shale}

\section{Collect and Analyze Reservoir Data from Existing Wells}

\section{New and Old Tech. Production Logging}

Chuck Magnani of Chevron Petroleum Technology Company (CPTC) independently evaluated the feasibility of using proposed new production logging tools and sensors. The following conclusions were reached.

PANEX Torque-Capacitance Memory Flowmeter: The PANEX torque-capacitance memory flowmeter was evaluated in a controlled field-trial in West Texas. The primary objective of this test was to generally characterize the PANEX flowmeter under controlled single phase conditions to verify instrument performance relative to PANEX specifications. A second goal was to determine the flowmeter's resolution for measuring low flowrates. Key conclusions from this study were: (1) The flowmeter has potential application in single phase, high rate environments such as injection wells; (2) Problems were encountered related to sensor hysteresis, thermal stability, time constants and resolution (PANEX is currently working on these problems); (3) Under controlled conditions, the flowmeter exhibited a linear response when rates exceeded 300 BWPD; however, below 300 BWPD, the instrument was unreliable; (4) The PANEX TorqueCapacitance flowmeter design is not robust and prone to downhole plugging; i.e., the shroud surrounding the spinner acts as a vena contracta causing debris to collect in the spinner metering chamber causing subsequent instrument malfunctions. The flowmeter shows potential; however, additional lab work is required to eliminate observed field problems. At this time the flowmeter is not recommended for multiphase flow evaluation in producing wells at the Buena Vista Field.

Halliburton Gas Holdup Tool (GHT): Chevron conducted the first field trial of Halliburton GHT (Gas-Holdup-Tool) at the East Painter Field on well 13-18A in Wyoming. The GHT was tested in a gas well producing with three phase flow. Although flow rates for East Painter Field well 13-18A were higher than those at the Buena Vista Hills Field, the nature of the flow problem is analogous to producing conditions at Buena Vista Hills. Under controlled field trial conditions, the GHT did not function properly. The GHT identically replicated the response of a backup, center-sample nuclear densitometer. Although both tools utilize nuclear sources, they operate on entirely different nuclear principles. The GHT did not maintain calibration from the beginning to the end of the survey. Halliburton could not explain or reconcile these discrepancies. Since the prototype field test, Halliburton has reported to have improved the GHT sensor performance; however, at this time, the tool has not been characterized under dynamic flow conditions to be credibly integrated in a combinable production logging tool stack to help improve downhole flow rate measurement. Given the overall remaining effort to characterize and reevaluate the GHT, the sensor is not recommended for application at the Buena Vista Hills Field.

Downhole Video Camera (DHV International \& Halliburton): The downhole video camera has been extensively used in the evaluation of producing wells throughout Chevron's worldwide operations. Wells have been logged under static and dynamic 
conditions, some of which have production rates comparable to Buena Vista Hills wells. The downhole video camera has been found to be most effective when wellbore fluid clarity exists, flow rates are not turbulent, water is the continuous phase, gas rates are low, segregated flow exists, and scale is present (scale enhances light reflectivity off casing inner wall). Lastly, the camera must be deployed in such a way as to be able to log under typical producing conditions. Chevron's experience has been positive when using the downhole video camera to view wellbore fluids under shut-in conditions; however, downhole video has limited utility when wells are actually logged under dynamic flowing conditions. Fluid clarity is the key to effective camera application.

Video logs were run in two Buena Vista Hills wells, the 563-26B and 564-26B (Section 26-T31S/R23E) in March 1997. The principal objective of these surveys was to identify gas and oil entry into the wellbore. A secondary objective was to identify possible holes or leaks in the casing that warrant remedial attention.

The 563-26B well was producing $1 / 5 / 20 \mathrm{O} / \mathrm{W} / \mathrm{G}$ prior to shutting in to prepare for video logging. This well held only 10 psi wellhead pressure after having been shut-in for two weeks. The fluid level in the well was at 3052 feet; above the top of the slotted liner at 3938 feet. Gas bubbling was moderate to strong above 4318 feet (in the P interval) and disappeared below 4318 feet. No oil entry was observed in the well. A water shutoff hole or leak was observed in the $85 / 8$ " casing at 1054 feet. Leaks were also observed at the top of the $65 / 8$ " slotted liner at 3897 feet.

The 564-26B well was producing $3 / 60 / 10 \mathrm{O} / \mathrm{W} / \mathrm{G}$ prior to shutting in to prepare for video logging. This well held no wellhead pressure after having been shut-in for two weeks. The fluid level in the well was at 3264 feet; above the top of the slotted liner at 3845 feet. Gas bubbling was observed to be moderate to strong as deep as the video logging tool could be lowered, down to a scale obstruction at 4566 feet (in the P1B interval). Very light oil entry and oil-stained slots were observed at 3986 - 3991 feet (in the $\mathrm{N}$ interval). Four water shutoff holes were observed in the $65 / 8$ " protective string at 3015 feet. A possible hole or crack was observed in the $65 / 8$ " slotted liner at 4555 feet.

\section{Carbon/Oxygen Logging}

A Carbon/Oxygen log was run in the $653 Z$ well in May 1997 for the purpose of measuring oil saturation. Two logging passes of the Schlumberger Reservoir Saturation Tool (RST) were run at a speed of $170 \mathrm{ft} / \mathrm{hr}$ to ensure a repeatability of five saturation units (87\% certainty level). We attempted to run the log to TD (4907 feet MD), but repeatedly encountered an obstruction at 4700 feet $\mathrm{MD}$. Therefore the $\mathrm{C} / \mathrm{O}$ data was acquired from 3700 to 4700 feet.

Schlumberger utilized alpha processing to compute oil saturation. For assisting in choosing a completion interval for the 653Z-26B well, Carbon/Oxygen log results were analyzed to high-grade our choice of interval to complete. RST and core oil saturations are plotted in wireline log track 6 of Figure 3.1. Plotted in wireline log tracks 2 and 3 of Figure 3.1 are, respectively, high core fluorescence and core fluorescence, based on image 
analysis of digital core photography. Relatively high fluorescence is indicative of sandstone/siltstone layering (with minor carbonates), and/or higher oil saturations. Whereas core fluorescence indicates siliceous shales, sandstones and minor carbonates. Based in great part on relatively higher RST oil saturations (20 - 40\%) in select intervals above and below P Point (top Antelope shale), we selected the interval P Point $\pm 100^{\prime}$ (4130 - 4350 feet) to complete. We believe in the six months that lapsed between casing/cementing the well and running the Carbon/Oxygen log, fluids from the undisturbed region in the formation have moved back in the vicinity of the wellbore. Thus, the Carbon/Oxygen log may more accurately reflect actual oil saturations than that measured in core (which is subject to flushing by mud filtrate).

\section{Perform Core Analysis}

\section{Wettability Testing - Laboratory}

Samples from depths of $3989.2,4315.6$ and 4355.95 feet have been miscibly cleaned, saturated with formation brine, and have undergone forced oil, spontaneous water and forced water drainage processes at Core Laboratories, Bakersfield. The remaining samples, 4288.2 and 4414.3 feet, are deemed too tight for analysis.

Combined USBM/Amott wettability measurements were performed on the three above core samples (Table 3.1). The Amott wettability indices indicate that the samples were of mixed wettability (predominantly water-wet). USBM wettability indices indicate that the samples, with the exception of 4315.6 feet, were also water-wet. This particular sample exhibited a wettability index that is slightly oil wet. The above data will be used in the water injection and imbibition studies.

\section{Core Description}

The core has been described and subdivided into seven lithologies by Karen De Louraille, CPTC (Appendix A). Out of 952 feet of continuous core there is only a total of 55 feet of sand ( $5.8 \%$ of cored interval). However there are 748 beds of sand in the core with an average bed thickness of 0.073 feet. Except for a 1 foot sand bed in the Brown Shale, all the sand is from the cored interval of the upper Antelope Shale. In general, the sands are less than an inch thick, poorly sorted, argillaceous, very fine to medium grained, and subangular to subrounded. Lower and upper bed contacts are generally sharp. Some of the thicker sands show normal grading, whereas many of the thinner sand beds show load and injection structures, and are discontinuous across the width of the core face. Figures 3.2-3 show two lithologic examples from the $653 \mathrm{Z}$ core.

\section{Produced and Extracted Oil Geochemical Fingerprinting}

Dave Baskin and Rong Hwang (CPTC) have finished work on the 26 core plug samples for oil extraction, along with produced oil samples from 2 nearby wells (554 and 564) and an oil sample from the $653 \mathrm{Z}$ well. Comparing the extracted oil samples with the produced oils will help identify what zones in the Brown Shale and Antelope Shale are presently contributing to oil production. Although the $653 \mathrm{Z}$ well has not been completed yet, a trace of oil entered the well during a cement squeeze job prior to $\mathrm{C} / \mathrm{O}$ logging (the oil trace did not comprise the log run). In order to run the $\mathrm{C} / \mathrm{O} \log$, the well must first be filled with 
water. It was at this time that an oil sheen was noticed at the top of the water column. We were able to get an oil sample by using the "very high tech" method of lowering a sponge on a string down the well.

The core extract fingerprints, along with the fingerprints of oils from the 653Z, 554 and 564 wells were statistically compared using Chevron's proprietary software, SLIDING WINDOWS. The following conclusions are based on F-SCOT gas chromatography data and weight percent extracts of hydrocarbons in the core samples: 1) the reservoir rocks throughout the Antelope reservoir contain abundant amounts of extractable hydrocarbons which average about $1.2 \%$ by weight or about $3 \%$ by volume; 2 ) the amount of extractable hydrocarbons are distributed unevenly throughout the Antelope reservoir, with the Brown Shale and the Upper Antelope (above P1b marker) averaging about one-third more extractable oil than the Lower Antelope; 3 ) the amount of extractable oil distributed by lithology also varies, with sandstone and porcelanite rocks averaging two to three times more petroleum than the siliceous shales; 4) the low weight percent extractable hydrocarbons are consistent with the presence of moderately high gravity recovered from the Antelope Shale; 5) the hydrocarbon composition of core extracts throughout the Antelope Shale show much variation suggesting the Antelope reservoir is vertically segregated; 6) compared to Lower Antelope extracts, oil composition of core extracts from the Brown and Upper Antelope shales are similar to produced oils, suggesting that most of the present production comes from these two reservoir units. After the $653 \mathrm{Z}$ well is hydraulically fractured and completed, another oil sample will be taken and compared with the oil samples collected to date.

\section{Mineralogical Analysis}

The preliminary work for the Buena Vista Hills siliceous shale mineral-model has been completed. The mineral model was built to determine better estimates of porosity, oil saturation, lithology, permeability, etc. from log data. Three 80 -foot intervals of core were selected for analysis on the basis of log signature and core. A thin continuous slab was cut from each interval and cut into approximately 1 -foot segments. Each core segment was crushed and divided with a riffle splitter to obtain subsamples of the desired weight. A subsample from each segment has been extracted and the matrix density has been measured after extraction. Both Core Laboratories and CPTC have completed their chemical analyses, Mineralog and ESTMIN, respectively. One reason why Mineralog was run in conjunction with ESTMIN was to evaluate the accuracy of Mineralog and calibrate it for use in siliceous shales which are very difficult to analyze due to their fine grain nature and presence of biogenic silica (Opal A, Opal CT, Quartz phase). Mineralog (Table 3.2) is also less expense and a less time consuming analysis than ESTMIN.

Both geochemical techniques show the Brown and Antelope shales to be composed of biogenic silica (Opal-CT), detritus (clay, quartz, feldspar and pyrite) and minor carbonate. The weight percentages of biogenic silica in the Brown Shale at Buena Vista Hills are higher than the typical clay-rich Brown Shale lithology found in other parts of the southern San Joaquin Valley. Results show Mineralog calculates higher amounts of biogenic silica (Opal CT) and lesser amounts of detritus than ESTMIN. See Section 2, "A 
Mineral Model and Inorganic Geochemistry of the Brown and Antelope Shales, 653Z-26B Well, Buena Vista Hills" for a discussion of the ESTMIN analysis.

\section{Mercury Porosimetry}

Mercury porosimetry analysis was performed by Core Laboratories, Bakersfield on 15 core samples in order to determine pore size distribution and help define hydraulic flow units. Siliceous shale samples have pore throat radii less than 0.50 microns while clayey sand samples have radii that can reach into the 2.5 to 10.0 micron range. Mercury saturations at $2000 \mathrm{psi}$ are less than $25 \%$ for siliceous shale, and range from 43 to $87 \%$ for clayey sand. This indicates, that by equating mercury saturation to oil saturation, the siliceous shale at Buena Vista Hills is not capable of having high oil saturations at reservoir conditions, whereas the clayey sand is capable of having high oil saturations. Thus most of, the produced oil in the field may have come from the thin sands and infrequent open fractures in the Brown and Antelope shales. Tables 3.3-5 and Figures 3.4-9 show examples of mercury porosimetry data and pore size histograms for typical Brown and Aintelope shales and sand.

\section{NMR Scan of Core Plugs}

Nuclear magnetic resonance (NMR) measurements were made by Core Laboratories, Houston on fifteen rock plug samples using a Core Spectrometer. NMR measurements were performed before and after fluid extraction from the specific permeability core plugs in order to compare NMR log and core responses.

All fifteen samples were supplied in native state (fresh condition). NMR data were acquired with a $0.5 \mathrm{~ms}$ echo time spacing with delay and train settings to achieve the best possible signal-to-noise $(\mathrm{S} / \mathrm{N})$ ratio.

After NMR measurements on the native state plug samples, the plugs were cleaned, resaturated with synthetic brine, and loaded into the calibrated (using $100 \%$ water samples) Core Spectrometer. The NMR measurements were made with a $0.5 \mathrm{~ms}$ echo time spacing with the delay and train settings to again achieve the best possible $\mathrm{S} / \mathrm{N}$ ratio.

Porosity was calculated from the NMR measurement on each fully brine saturated sample using a multi-exponential fit computer program. Fully saturated and native state NMR measurements are compared in Table 3.6. The median values of the NMR transverse relaxation times, $T 2$, are also compared in Table 3.6. The difference in porosity between the fully brine saturated and native state measurements defines the level of liquid saturation in the rock. The measured porosity and NMR transverse relaxation times are significantly lower in the native state plug samples due to gaseous phase being present.

The geometric mean of the NMR transverse relaxation times, $T_{2}$, match closely with the NMR log, but NMR core plug porosity does not match routine core porosity or NMR log porosity. This porosity discrepancy is not yet understood. 


\section{Rock Mechanics Analysis}

Rock mechanics analyses (compressibility, Poisson's ratio, and Young's modulus) needed for fracture modeling have been completed by Core Laboratories, Dallas (Table 3.7). This data will be used in the modeling and design of hydraulic fractures.

\section{Specific Liquid Permeability}

Analyses have been completed on sand and shale core plugs by Core Laboratories, Bakersfield (Table 3.8). The results show 7 sand core plugs to have liquid permeabilities ranging from 0.004 to 75.2 millidarcies using the hydrostatic test method (cleaned-state samples). For the hydrostatic method: 1) samples were installed in a hydrostatic core holder at a confining stress of $2500 \mathrm{psi}$; 2) the samples were miscibly cleaned using alternating cycles of toluene and methanol using a maximum pressure of $300 \mathrm{psi}$ for all the cleaning (methanol permeability was measured at the end of the cleaning cycle); 3) the last solvent, methanol, was displaced with the test brine at a normal constant rate with backpressure until equilibrium (specific permeability to water was determined at two injection rates).

The 8 siliceous shale core plugs (Table 3.8) show ranges from 1.64 to 6.74 microdarcies using the liquid pulse decay test method (native-state samples). For the liquid pulse decay method: 1) the selected sample was installed in a hydrostatic core holder at a confining stress of $2500 \mathrm{psi}$; 2) the permeameter and core holder were then vacuum saturated with the test brine (pore pressure of 500 psi was slowly applied to the sample while the confining stress was simultaneously increased to $3000 \mathrm{psi}$ and thereby maintaining the net overburden pressure of $2500 \mathrm{psi}) ; 3$ ) a low pressure pulse was applied to the upstream face of the sample (pressure decay was monitored and plotted as a function of time); 4) the sample was then allowed to equilibrate and the process repeated until a stable slope was attained.

\section{Core Imaging}

Core photography (paper prints and digital format) in white and ultraviolet light has been completed using a format of 18 feet per print. The digitized photos also have been used to depth shift the core to wireline logs. In addition, using their Imagelog software, Core Laboratories, Houston converted the ultraviolet images into binary images in order to determine lithology and net pay in the cored interval. This is the first time this technique has been used on siliceous shale. Ultraviolet photographs of the entire 952 feet of core were digitized and computer analyzed for medium to very high fluorescence, and for very high fluorescence only (Figure 3.1). With this data we can quantify the siliceous shale, clay shale, and sand beds found in the core (Table 3.9). Routine core description identified more sand than the Imagelog analysis. This is due in part to complex lithology, the thin and discontinuous nature of some of the sands, and what parameters are used in the Imagelog analysis of each digital image. The core image analysis will be displayed on a well $\log$ montage along with the routine core description and other data. 


\section{Fracture Characterization}

\section{Shear-Wave Birefringence VSP}

A nine-component VSP survey was recorded in well 653Z-26B, Buena Vista Hills Field on Nov. 14-16, 1996, primarily for the purpose of evaluating stress and fracture effects as a function of depth, and help characterize the natural fracture system. This data would then be used to predict the orientation of hydraulic fractures should other wells be fracturestimulated in the future. Analysis of the VSP data was completed in March, 1997 and indicated strong shear-wave (S-wave) birefringence in upper formations but negligible birefringence through a thick zone at the bottom of the well (3330 - 4830 feet) that includes the Brown Shale and the Antelope Shale. The polarization azimuth of the fast shear (S) wave was about N25E in the uppermost anisotropy layer but oscillated about due north in deeper layers. Birefringence in the uppermost layer exceeded 12 percent. It then diminished appreciably but reached 5.1 percent just above the zone of negligible birefringence. Several anisotropy features of the Buena Vista Hills VSP resemble other VSP surveys recorded earlier in the nearby Elk Hills and Railroad Gap Fields.

The negligible birefringence in the Brown and Antelope shales implies that these rocks are isotropic (the fractures are randomly oriented). Thus, the VSP data indicates that there should be no preferred direction for hydraulic fractures to propagate.

\section{Crosswell Seismic}

See Section 2, "Crosswell Imaging in the Buena Vista Hills", for a discussion on this task.

\section{High Resolution Structural Mapping}

During the past year, an OpenWorks database was completed for the Buena Vista Hills Field which contains surface locations, directional surveys, and digital open-hole logs for approximately 250 wells. The database includes all wells that penetrate the Brown Shale and Antelope Shale on the United, Honolulu, and 20B Anticlines. The data from these wells were subsequently used in an effort to correlate formation and marker tops using the StratWorks application. A total of 7 Brown Shale and 15 Antelope Shale marker tops were correlated and a list of observed fault cuts were tabulated.

Structure maps were then generated from the marker data using Z-Map+. In the end, 16 gridded structure surfaces were generated for the Brown Shale and upper Antelope Shale interval. As a final conditioning step, the grids were then exported to Gocad++ where they were forced to tie the marker data in the wells exactly and were tested, and corrected, for any crossover between grids. This crossover occurred occasionally along the flanks where there was little well control. The resulting grids are currently being used to form the framework for the 3D geologic model that will soon be completed.

\section{Core Fracture Analysis}

See Section 2, "Fracture Analysis of the Brown Shale, Buena Vista Hills, 653Z-26B", and "Natural Fractures in the Brown and Antelope Shales, Buena Vista Hills, 653Z-26B", for a discussion of this task. 
Core Microfracture Analysis

See Section 2, "Petrographic and Confocal Analysis, 653Z-26B", for a discussion of this task.

\section{Regional Tectonic Synthesis}

See Section 2, "Regional Tectonic Synthesis", for a discussion of this task.

\section{Acoustic Anisotropy}

Five oriented core samples from the $653 \mathrm{Z}$ well were selected and analyzed for acoustic anisotropy at Core Laboratories, Bakersfield in an attempt to discern the maximum horizontal stress direction as a function of depth in the well bore. Knowledge of the maximum in-situ stress direction is valuable in the design of fracture treatments of wells as well as regional tectonic interpretation.

Acoustic Anisotropy theory is based on the fact that conventional core samples "relax" when they are removed from their in-situ stress state. This relaxation results in the formation of micro fractures oriented perpendicular to the maximum horizontal stress component.

The selected oriented core sample intervals were crosscut from the 2/3-slab section of the conventional core and carefully trimmed to the right partial cylinders. The samples were then oriented north using the down hole survey information provided by Baker Hughes Inteq. Each sample was carefully examined for the presence of microfractures. If micro fractures were present on one end of the right partial cylinder then the opposite end was selected for the acoustic measurements. In no case were both ends found to contain no macro fractures. Azimuth markings at 30 degree increments were marked around the circumference of the selected sample end. Shear wave velocity measurements (using Core Laboratories' proprietary Porosity Sonic Profile equipment) were then made on the selected sample ends.

Acoustic measurements which are made perpendicular to the micro fractures result in slower shear wave transit times than acoustic measurements made parallel to the micro fractures. By plotting the shear wave velocities as a function of azimuth alignment, the maximum horizontal stress direction is found 90 degrees from the maximum shear velocity direction.

The results (Figure 3.10) show that there is a 54 degree clockwise rotation of maximum horizontal stress from N30W at $4565 \mathrm{ft}$ (upper Antelope Shale) to N24E at $4031 \mathrm{ft}$ (Brown Shale). However results from other fracture characterization and orientation tasks in this project show varied results. The formation micro imager log indicated a fracture strike of N45-50E based on limited fractures in the core. The dipole sonic log showed a fast shear wave azimuth of N60W. Anelastic strain recovery showed a maximum principal stress of $\mathrm{N} 40 \mathrm{E}$, the microfracture analysis revealed no repeatable fracture patterns, and the shear 
wave birefringence VSP implied that the rocks are isotropic. In addition, the crosswell seismic, and core fracture studies are not completed at this time. Further analysis of the data will be required to understand the differences in the results of the various methodologies.

\section{Attenuation Imaging}

See Section 2, "Crosswell Imaging in the Buena Vista Hills", for a discussion of this task.

\section{Wireline Log Analysis}

Complex Lithologic Analysis

See Section 2, "Complex Lithologic Analysis", for a discussion of this task.

\section{Characterize Flow Units \\ Define Hydraulic Flow Units}

A hydraulic (flow) unit is a zone that is continuous over a defined volume of reservoir rock and has similar pore geometrical attributes. These pore geometries can be related to depositional and diagenetic changes encountered in a reservoir but need not coincide with facies boundaries. As a result, individual facies can be, and usually are, composed of more than one pore geometry and thus multiple hydraulic units.

In most formations, pore geometries are a function of mineralogy and the way those minerals are arranged, or texture. Various combinations of mineralogy and texture can result in distinct rock units that have similar pore throat attributes. These attributes are strongly correlatable to porosity and permeability through the concept of the Flow Zone Indicator (FZI). FZI is a function of a reservoir's surface area per unit grain volume, tortuosity and pore shape. FZI in turn is strongly correlated with textural characteristics in unconsolidated formations, mineralogy in formations which have gone diagenesis, capillary pressure measurements and end point relative permeability data. As such, FZI values can be used in conjunction with porosity data as a tool for the prediction of petrophysical properties.

A hydraulic unit model has been developed on a foot by foot basis throughout the 952 feet of cored interval. Hydraulic units zonation indicates the existence of nine hydraulic flow units with similar fluid flow characteristics. This data will provide the foundation for integrating log and core information into a flow unit transform.

\section{Develop Flow Unit Transforms}

The overall objective of the study was to develop a model for the Buena Vista Hills Field which may be used to extend the conventional core analysis of the $653 \mathrm{Z}$ well to other wells in the field. This in turn would then help to define an efficient reservoir management/production program for the field.

Deterministic, probabilistic, Neural Networks, and nuclear magnetic resonance (NMR) based probabilistic models were developed by Core Laboratories for the estimation of flow zone indicators (FZI) from wireline log signatures in the $653 \mathrm{Z}$ well. The validity and 
robustness of the models were also checked by comparison with measured data from the $653 Z$ core. Permeability predictions based on the FZI models shows the Neural Networks method (using a combination of deep resistivity, bulk density, and thermal neutron logs) giving the best results of relating predicted permeabilities to core permeabilities, especially the high permeability sands. Unfortunately, there are very few wells in the Buena Vista Hills field that have a combination of deep resistivity, bulk density and thermal neutron log suites. (It was hoped that a correlation with spontaneous potential, SP, could be developed due to the prevalence of these logs in Buena Vista Hills.) Thus although the methodology and transform can not be applied to other wells in Buena Vista Hills, it may be applicable to some other fields where there is more modern data available. We plan to take the Hydraulic Unit and ELAN (complex log analysis) models and apply them to another field in order to see if this technology is transferable to other fields in the San Joaquin Valley.

\section{Develop 3D Earth Model}

Geostatistically Populate Model

See Section 2, "3D Geologic Modeling", for a discussion of this task.

\section{Visualize Reservoir Property Distribution}

See Section 2, "3D Geologic Modeling", for a discussion of this task.

\section{Preliminary Preparation for $\mathrm{CO} 2$ Injection \\ Re-evaluate Pre-1994 Production Performance}

\section{Analyze Recovery, Pressure and Saturation Data}

A Production Analyst (PA)database was created for the Buena Vista Hills Field for all Antelope Shale wells. This PA software program allows historical oil, water, and gas production and injection data to be analyzed to better understand the mechanisms at work in producing this asset. A bubble map of cumulative production and a production rate vs. time plot for every well in the field was generated using this database. This data will also be useful for input into a reservoir simulation model during the history matching phase of the study.

\section{Initiate Fluid Characterization and Lab Displacement Tests Phase Behavior on CO2 - Oil Systems}

While the seven ambient condition relative permeability tests have yielded good results, the reservoir condition tests (two completed) have had problems (Table 3.10). One of the reservoir condition tests yielded the same relative permeability curves as the ambient test of the same plug. Also, the other sample appeared to plug up during the reservoir condition test, possibly due to a problem with the crude oil. Moreover, there are difficulties with closing the material balance using Karl-Fischer titration of the effluent solvents. There is an unknown source of additional water that cannot be accounted for in the solvents. Perhaps it is water in the crude oil. 
Therefore we will not proceed with the reservoir condition tests. Instead some advanced mercury injection tests have been performed. With this data we are able to get a better understanding on initial water saturations (Figure 2i.3).

\section{Perform CO2 Corefloods at Reservoir Conditions}

See Section 2, "CO2 Coreflood Experiment", for a discussion of this task.

\section{Pre-injection Evaluation of the Target Drive Zone}

\section{Perforate and Evaluate Drive Interval}

Work has begun on the completion program for the $653 \mathrm{Z}$ well. The interval between 4150 - 4350 feet (lowermost Brown Shale - uppermost Antelope Shale) will be perforated and hydraulically fractured in February, 1998. This zone was picked based on the Carbon/Oxygen log and geochemical fingerprinting (see Tasks A.1.B., A.1.C. and A.3.G.). Also, the Natural Gamma Ray Spectroscopy (NGT) log shows higher uranium content through this interval which may indicate higher organic matter (= gas prone?). Lastly, the hydraulic unit model that was developed shows this interval to be heterogeneously layered. This heterogeneity may allow this interval to fracture more readily.

\section{Technology Transfer}

\section{Publications:}

Aydin, A., 1997, Fault Control on Hydrocarbon Migration and Fluid Flow in Neogene Basins and Related Reservoirs of Central and Coastal California, USA: An Overview, in, Pollard, D. D. and Aydin, A. eds., Proceedings of the Rock Fracture Project Workshop, Stanford University, Stanford, CA.

Aydin, A., Dholakia, S. K., Antonellini, M., and Lore, J., 1996, Fault Control on Hydrocarbon Migration in Neogene Basins in Central and Coastal California, USA. Faulting, Fault Sealing and Fluid Flow in Hydrocarbon Reservoirs, Conference, University of Leeds.

Bilodeau, B. J. and Smith, S. C., 1997, Session Chairmen for Reservoir Characterization and Improving Recovery in Monterey-type Siliceous Shales, Pacific Section AAPG/SEPM Annual Convention, Bakersfield, CA.

Bilodeau, B. J., Smith, S. C., and Julander, D. R., 1997, Comprehensive Reservoir Characterization Using Open-Hole Wireline Logs, Core, and Downhole Video, Buena Vista Hills Field, California, Pacific Section AAPG/SEPM Annual Convention, Bakersfield, CA.

Britton, A.W., Smith, J. L., and Chapman, D., 1997, Continuous Permeability and Porosity Determinations in the Chevron 653Z-26B Well, Buena Vista Field, Kern County, CA, Pacific Section AAPG/SEPM Annual Convention, Bakersfield, CA. 
Carpenter, A. B., and Moore, T. S., 1997, Origin of Boron-Rich Pore Water in the Monterey Formation, San Joaquin Valley, CA, Pacific Section AAPG/SEPM Annual Convention, Bakersfield, CA.

Decker, D. and Bilodeau, B. J., 1997, Antrim Shale Resource and Reservoir Characterization as an Analog for Diffusion Controlled Gas Production from the Monterey Formation Pacific Section AAPG/SEPM Annual Convention, Bakersfield, CA.

Dholakia, S. K., 1995, An Integrative Study of Fractures and In Situ Stress in the Antelope Shale, Monterey Formation, Stanford Rock Fracture Project, Stanford University, Stanford, CA.

Dholakia, S. K., 1996, Outcrop to Reservoir: Importance of Faulting to Hydrocarbon Migration in the Monterey Formation, CA, Stanford Rock Fracture Project, Stanford University, Stanford, CA.

Dholakia, S. K., Aydin, A. Pollard, D. D., and Zoback, M. D., 1995, Relationship between Hydrocarbon Transport and Shearing Deformation in the Antelope Shale, Monterey Formation, San Joaquin Valley, California, GSA Annual Convention.

Dholakia, S. K., Aydin, A., Pollard, D. D., and Zoback, M. D., 1996, Hydrocarbon Transport and Shearing Processes in the Antelope Shale, Monterey Formation, San Joaquin Valley, California, AAPG Annual Convention San Diego, CA.

Dholakia, S. K., Aydin, A., Pollard, D. D., and Zoback, M. D., in press, Development of Fault-controlled Hydrocarbon Pathways in the Monterey Formation, California, AAPG Bulletin.

Dholakia, S.'K., Aydin, A., Pollard, D. D., Zoback, M. D., and Barton, C., 1996, Integration of Geological and Borehole Image Data for the Interpretation of Conductive Structural Inhomogeneities in the Monterey Formation, California, Geological Application of Borehole Imaging Conference, Houston, TX.

Dholakia, S. K., Aydin, A, Pollard, D. D., Zoback, M. D., Barton, C., and Bilodeau, B. J., 1997, Integration of Surface Geology and Borehole Geophysics for Reservoir Characterization in the Monterey Siliceous Shales for the Purpose of Facilitating Improved Recovery Designs, Pacific Section AAPG/SEPM Annual Convention, Bakersfield, CA.

Dholakia, S. K., Aydin, A., Zoback, M. D., and Pollard, D. D., 1995, Plan for an Integrative Study of Fractures and In Situ Stress in the Antelope Shale, Monterey Formation, Stanford Rock \& Borehole Geophysics Project Annual Report, Stanford University, Stanford, CA. 
Dholakia, S. K., Lore, J., Brankman, C. M., and Roznovsky, T., 1996, Fault Control on Hydrocarbon Migration in the Monterey Formation, CA, Proceedings of the Stanford Rock Fracture Project Field Workshop, Stanford University, Stanford, CA.

Dholakia, S. K., Zoback, M. D., and Aydin, A., 1996, Stress State, Shearing Deformation and Implications for Hydrocarbon Transport in the Monterey Formation, California, Stanford Rock \& Borehole Geophysics Project Annual Report, Stanford University, Stanford, CA.

Dholakia, S. K., Zoback, M. D., Barton, C., Aydin, A. and Pollard, D. D., Active Faults and Hydrocarbon Migration and Production in the Monterey Formation, California, Geophysics (in prep).

Fargo, D., 1997, Advanced Coring and Wellsite Handling Add Pizazz to Buena Vista Hills Core, Pacific Section AAPG/SEPM Annual Convention, Bakersfield, CA.

Fargo, D., 1997, Advanced Coring and Wellsite Case Study of Chevron/DOE Well 653Z26B, Core Technology Meeting, Anchorage, AK.

Fargo, D., 1997, Case Study: Chevron/DOE Buena Vista Field Core Project, Technology Meeting, Aera Energy, Bakersfield, CA.

Jacobs, J. L., 1997, Characterization and Formation of En Echelon Fracture Arrays in the Monterey Formation, California. In, Pollard, D. D. and Aydin, A. eds., Proceedings of the Rock Fracture Project Workshop, Stanford University, Stanford, CA.

Kuuskraa, V., 1997, Incorporating Reservoir Characterization into Optimized Production of Siliceous Shales and Other Gas Bearing Shales, Pacific Section AAPG/SEPM Annual Convention, Bakersfield, CA.

Langan, R. T., July, 1997, Crosswell Reflection Imaging in the San Joaquin Valley: Buena Vista Hills, Society of Exploration Geophysicists, Development and Production Forum, Vail, CO.

Langan, R. T., October, 1997, Crosswell Seismology, Where We've Been and Where We're Going, Producers Executive Committee, Gas Research Institute, Chicago, IL.

Langan, R. T., October, 1997, Crosswell Imaging in West Texas and the San Joaquin Valley, Geosciences Department, Princeton University, Princeton, NJ.

Mamula, N., and Campagna, D. J., 1997, Determination of Reservoir Compartmentalization Using Mesoscopic Scale Fracture Analysis in the Buena Vista Hills Area of the Southern San Joaquin Valley, CA, Pacific Section AAPG/SEPM Annual Convention, Bakersfield, CA. 
Morea, M. F., 1997, Advanced Reservoir Characterization in the Antelope Shale to Establish the Viability of $\mathrm{CO} 2$ Enhanced Oil Recovery in California's Monterey Formation Siliceous Shales, Oil Technology and Gas Environmental Program Review Meeting, Houston, TX.

Morea, M. F., Zalan, T. A., and Jacobs, J. L., 1997, Buena Vista Hills Reservoir Characterization Study, Chevron/DOE Class III Reservoir Project. In, Advances in Reservoir Description Techniques as Applied to California Oil and Gas Fields Workshop, Pacific Section AAPG/SEPM Annual Convention, Bakersfield, CA.

Wang, G. Y., November, 1997, 3-D Attenuation Imaging, SEG Annual Meeting, Dallas, TX.

Zalan, T. A., Morea, M. F., Julander, D. R., and Denoo, S. A., 1998, Applying Integrated Formation Evaluation to Advanced Reservoir Characterization in California's Monterey Formation Siliceous Shales, DOE/ BDM OK/ PTTC Class Project Logging Workshop, Advanced Applications of Wireline Logging for Improved Oil Recovery, Denver, CO.

Zoback, M. D., Barton, C., Finkbeiner, T., and Dholakia, S. K., 1996, Evidence for Fluid Flow along Critically-Stressed Faults in Crystalline and Sedimentary Rock, Faulting, Fault Sealing and Fluid Flow in Hydrocarbon Reservoirs, Abstracts, Conference, University of Leeds.

The following papers have been accepted at the 1998 AAPG Annual Convention, Salt Lake City, UT:

Britton, A. W., and Morea, M. F., Acoustic Anisotropy Measurements in the Siliceous Shale, 653Z-26B Well, Buena Vista Hills Field, California.

Campagna, D. J., Amos, J. F., and Mamula, N., Influence of Structure, Reservoir Compartments, and Natural Fractures on Oil and Gas Production in the Southern San Joaquin Basin, California.

Morea, M. F., Zalan, T. A., Julander, D. R., and Britton, A. W., Advanced Reservoir Characterization of the Siliceous Shale, Buena Vista Hills, California. Part I: Integration of Geological, Geochemical, and Petrophysical Data.

The following paper has been accepted to the 1998 SPE Western Regional Meeting, Gems Session, Bakersfield, CA:

Zalan, T. A., Morea, M. F., Julander, D. R., and Denoo, S. A., Integrated Formation Evaluation in California's Monterey Formation Siliceous Shales, Buena Vista Hills Field, California. 
The following paper has been accepted at the 1998 SPWLA Annual Convention, Keystone, CO:

Zalan, T. A., Morea, M. F., Julander, D. R., and Denoo, S. A., Applying Integrated Formation Evaluation to Advanced Reservoir Characterization in California's Monterey Formation Siliceous Shales.

The following paper has been submitted to the 1998 SPE Archie Conference, Kerrville, $T X$ :

Harris, J. M., Preliminary Results on 3-D Attenuation Imaging for Reservoir Characterization.

A booth has been reserved at the 1998 Pacific Section AAPG Convention, Ventura, CA: Morea, M. F., Julander, D. R., Zalan, T. A., and Beeson, D. C., Advanced Reservoir Characterization of the Siliceous Shale, Buena Vista Hills, California. We plan to have displays reviewing our data and interpretations, and a workstation showing our 3D visualization/geologic modeling.

Data from this project has been given to Southwest Research Institute, San Antonio, TX and included in their project:

Parra, J. O., Characterization of Fracture Reservoirs using Static and Dynamic Data: From Sonic and 3D Seismic to Permeability Distribution, BDM Subcontract No. G4S51-731, and Prime Contract No. DE-AC22-94PC91008. 
Table 3.1. Wettability analyses on $653 \mathrm{Z}$ Well core plugs.

USBM/Amott Method

Sample Condition: Restored

Initial Fluid Imbibed:

Water

Sample Depth, Feet

3989.20

4315.60

4355.95

Basic Parameters of Test Samples

\begin{tabular}{|l|l|l|l|}
\hline Permeability to Air, millidarcy & 0.025 & 0.091 & 3.700 \\
Porosity, fraction & 0.305 & 0.139 & 0.293 \\
Initial Water Saturation, fraction & 0.976 & 0.991 & 0.994 \\
\hline
\end{tabular}

Imbibition of Oil

\begin{tabular}{|l|l|l|l|}
\hline Spontaneous Imbibition, fraction Vp & 0.008 & 0.067 & 0.017 \\
Dynamic Imbibition, fraction Vp & 0.072 & 0.342 & 0.050 \\
Total Imbibed, fraction Vp & 0.080 & 0.409 & 0.067 \\
\hline
\end{tabular}

Imbibition of Water

\begin{tabular}{|l|l|l|l|}
\hline Spontaneous Imbibition, fraction Vp & 0.225 & 0.303 & 0.105 \\
Dynamic Imbibition, fraction Vp & 0.033 & 0.263 & 0.007 \\
Total Imbibed, fraction Vp & 0.258 & 0.566 & 0.112 \\
\hline
\end{tabular}

Wettability Indices

\begin{tabular}{|l|c|c|c|}
\hline Amott Wettability Index to Water & 0.873 & 0.535 & 0.937 \\
Amott Wettability to Oil & 0.098 & 0.164 & 0.255 \\
USBM Wettability Index & 0.328 & -0.084 & 0.903 \\
\hline
\end{tabular}


Table 3.2. Mineralogy determined by Mineralog method.

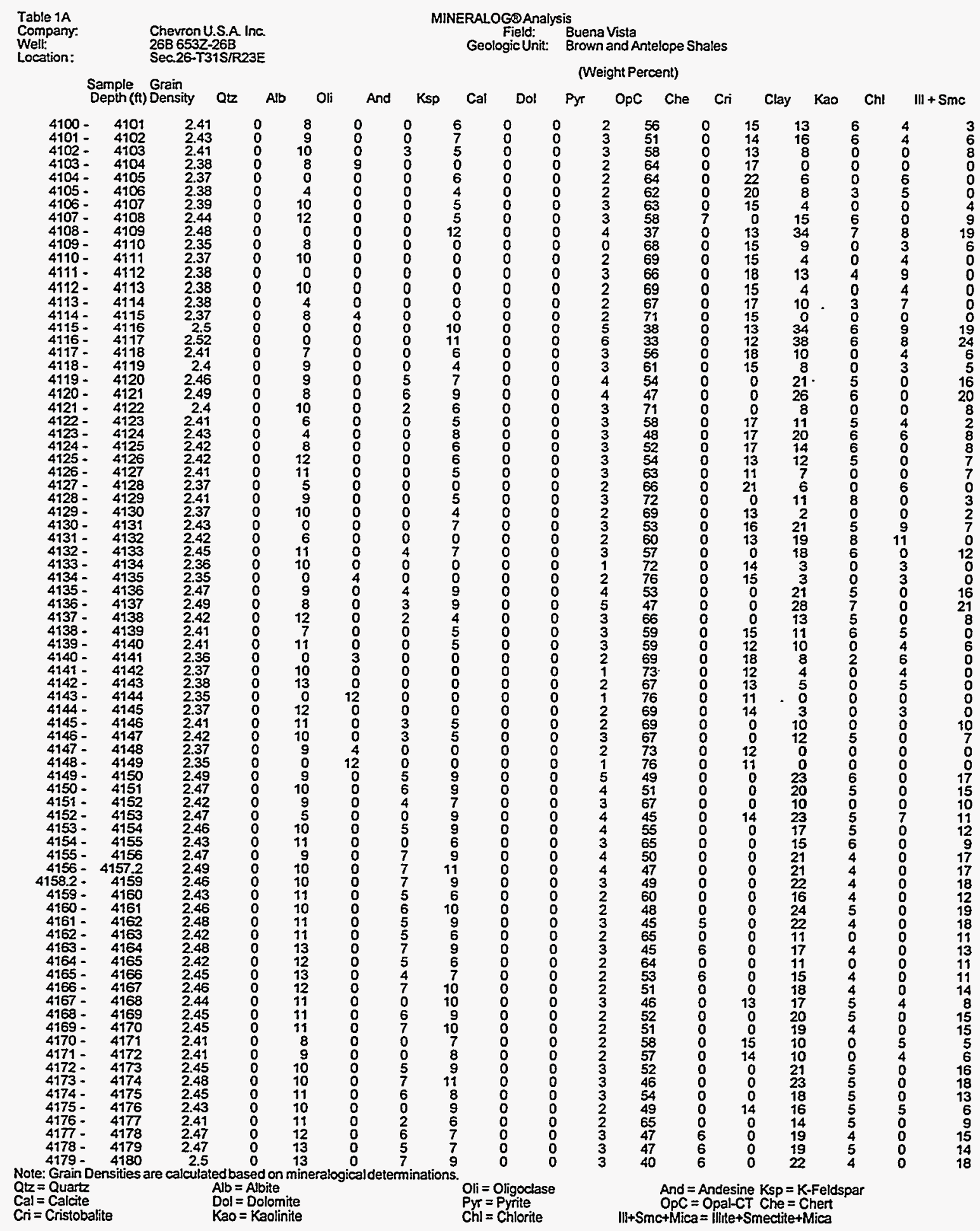


Table 3.2 Continued. Mineralogy determined by Mineralog method.

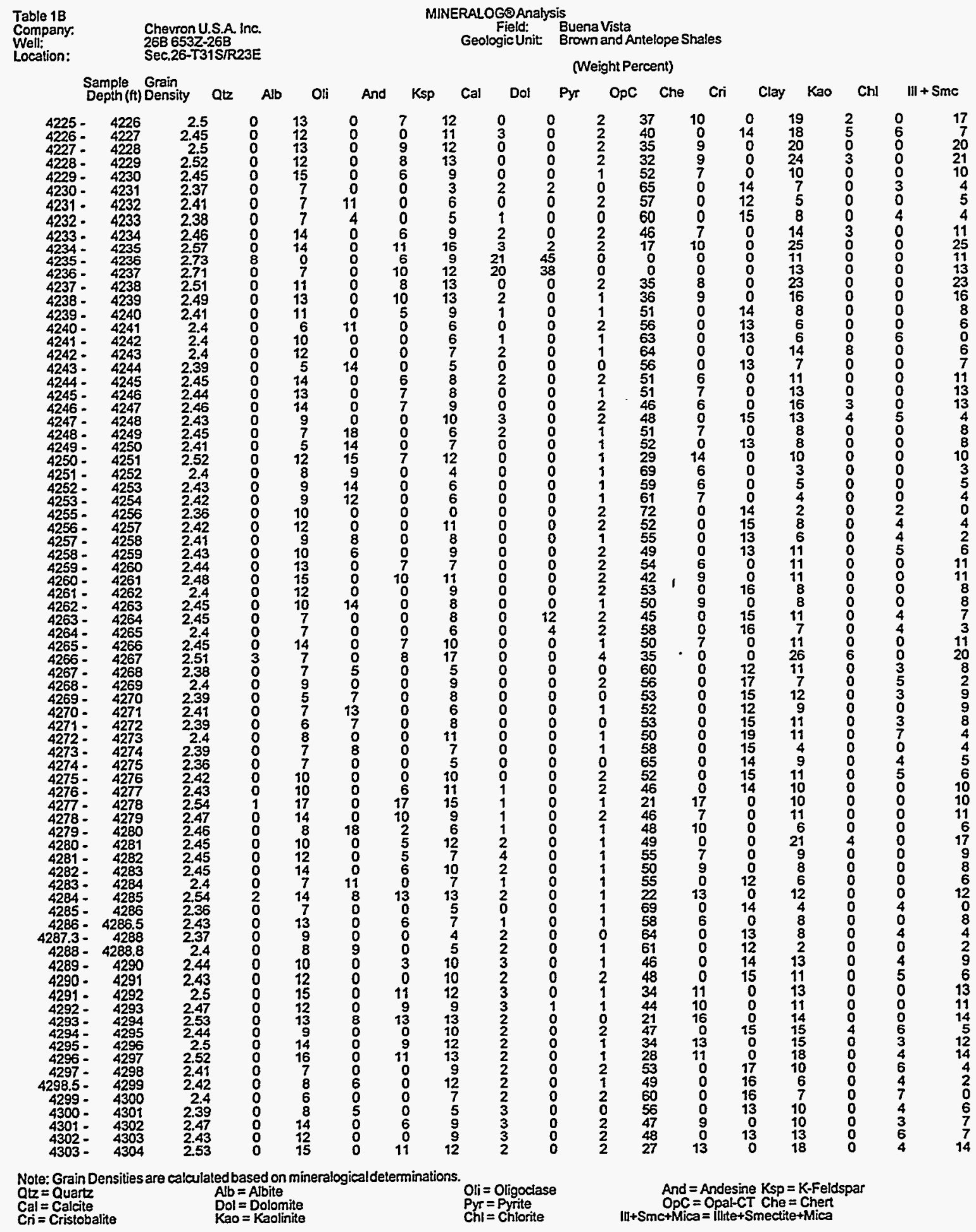


Table 3.2 Continued. Mineralogy determined by Mineralog method.

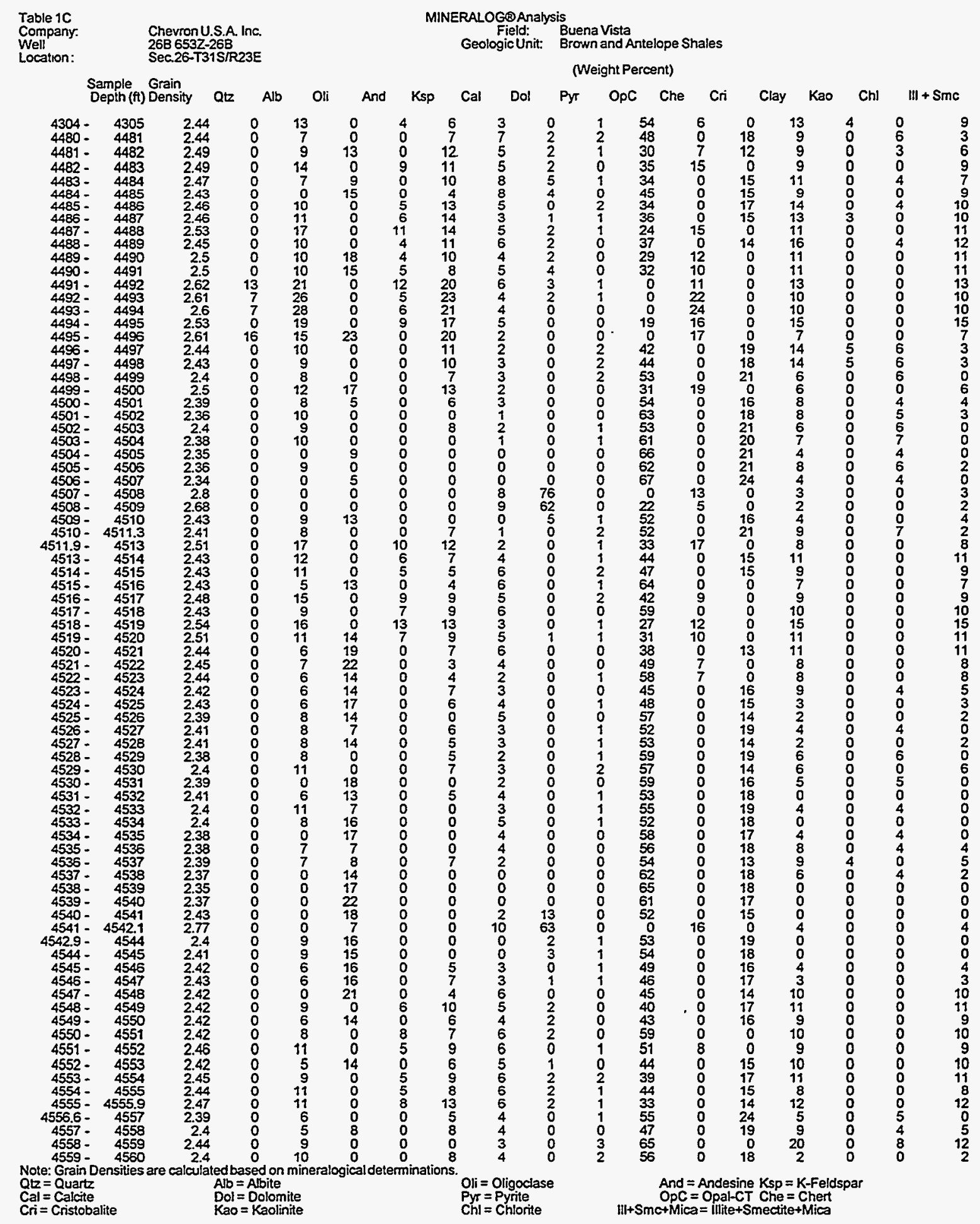


Table 3.3. Mercury injection data summary for a typical siliceous shale from the Brown Shale interval.

\author{
MERCURYINJECTIONDATA SUMMARY
}

653Z-26B Well

Buena Vista Hills Field

Depth, feet:

Klinkenberg Permeability, md:

4200.05

Porosity, fraction:

86.00

0.24

Injection Mercury 1.0-Mercury Pore

Pressure, Saturation, Saturation, Radius, J

Estimated Height

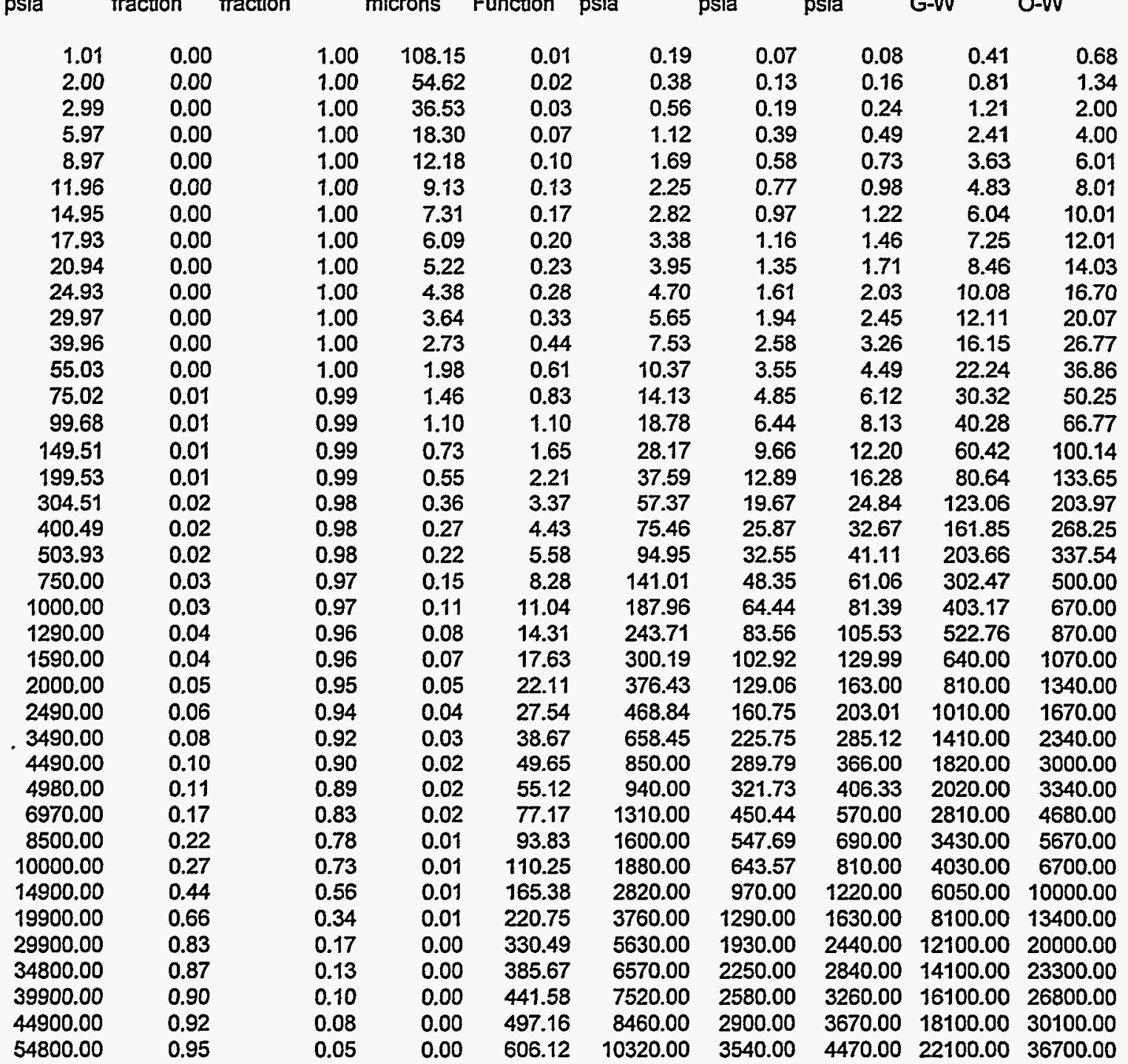


Table 3.4. Mercury injection data summary for a typical siliceous shale from the Antelope Shale interval.

\author{
MERCURY INJECTION DATA SUMMARY \\ 653Z-26B Well \\ Buena Vista Hills Field \\ Depth, feet: \\ 4271.65 \\ Klinkenberg Permeability, md: \\ 0.11 \\ Porosity, fraction: \\ 0.32
}

\begin{tabular}{|c|c|c|c|c|c|c|c|c|c|}
\hline $\begin{array}{l}\text { Injection } \\
\text { Pressure, } \\
\text { psia }\end{array}$ & $\begin{array}{l}\text { Mercury } \\
\text { Saturation, } \\
\text { fraction }\end{array}$ & $\begin{array}{l}\text { 1.0-Mercury } \\
\text { Saturation, } \\
\text { fraction }\end{array}$ & $\begin{array}{l}\text { Pore } \\
\text { Radius, } \\
\text { microns }\end{array}$ & $\begin{array}{l}\mathbf{J} \\
\text { Function }\end{array}$ & $\begin{array}{l}\text { Other Labora } \\
\text { Gas-Water, } \\
\text { psia }\end{array}$ & $\begin{array}{l}\text { atory System } \\
\text { Gas-Oil, } \\
\text { psia }\end{array}$ & $\begin{array}{l}\text { ns } \\
\text { Oil-Water, } \\
\text { psia }\end{array}$ & $\begin{array}{l}\text { Estimated } \mathrm{H} \\
\text { Above Free } \\
\text { G-W }\end{array}$ & $\begin{array}{l}\text { Height } \\
\text { Water, ft } \\
\text { O-W }\end{array}$ \\
\hline 1.02 & 0.00 & 1.00 & 107.09 & 0.00 & 0.19 & 0.07 & 0.08 & 0.41 & 0.68 \\
\hline 2.01 & 0.00 & 1.00 & 54.34 & 0.00 & 0.38 & 0.13 & 0.16 & 0.81 & 1.35 \\
\hline 3.00 & 0.00 & 1.00 & 36.41 & 0.00 & 0.57 & 0.19 & 0.24 & 1.21 & 2.01 \\
\hline 5.98 & 0.00 & 1.00 & 18.27 & 0.00 & 1.13 & 0.39 & 0.49 & 2.42 & 4.01 \\
\hline 8.97 & 0.00 & 1.00 & 12.18 & 0.00 & 1.69 & 0.58 & 0.73 & 3.63 & 6.01 \\
\hline 11.97 & 0.00 & 1.00 & 9.13 & 0.00 & 2.26 & 0.77 & 0.98 & 4.84 & 8.02 \\
\hline 14.95 & 0.00 & 1.00 & 7.31 & 0.01 & 2.82 & 0.97 & 1.22 & 6.04 & 10.01 \\
\hline 17.93 & 0.00 & 1.00 & 6.09 & 0.01 & 3.38 & 1.16 & 1.46 & 7.25 & 12.01 \\
\hline 20.94 & 0.00 & 1.00 & 5.22 & 0.01 & 3.95 & 1.35 & 1.71 & 8.46 & 14.03 \\
\hline 24.93 & 0.00 & 1.00 & 4.38 & 0.01 & 4.70 & 1.61 & 2.03 & 10.08 & 16.70 \\
\hline 29.98 & 0.00 & 1.00 & 3.64 & 0.01 & 5.65 & 1.94 & 2.45 & 12.12 & 20.08 \\
\hline 39.95 & 0.00 & 1.00 & 2.73 & 0.01 & 7.53 & 2.58 & 3.26 & 16.15 & 26.76 \\
\hline 54.76 & 0.00 & 1.00 & 1.99 & 0.02 & 10.32 & 3.54 & 4.47 & 22.13 & 36.68 \\
\hline 74.96 & 0.00 & 1.00 & 1.46 & 0.03 & 14.12 & 4.84 & 6.12 & 30.29 & 50.21 \\
\hline 99.92 & 0.00 & 1.00 & 1.09 & 0.03 & 18.83 & 6.45 & 8.15 & 40.38 & 66.93 \\
\hline 150.19 & 0.00 & 1.00 & 0.73 & 0.05 & 28.30 & 9.70 & 12.25 & 60.70 & 100.60 \\
\hline 199.23 & 0.00 & 1.00 & 0.55 & 0.07 & 37.54 & 12.87 & 16.25 & 80.52 & 133.45 \\
\hline 299.27 & 0.00 & 1.00 & 0.36 & 0.10 & 56.39 & 19.33 & 24.42 & 120.95 & 200.46 \\
\hline 398.93 & 0.01 & 0.99 & 0.27 & 0.14 & 75.16 & 25.77 & 32.55 & 161.22 & 267.21 \\
\hline 502.29 & 0.01 & 0.99 & 0.22 & 0.17 & 94.64 & 32.45 & 40.98 & 202.99 & 336.44 \\
\hline 750.00 & 0.03 & 0.97 & 0.15 & 0.26 & 141.33 & 48.46 & 61.20 & 303.16 & 500.00 \\
\hline 1000.00 & 0.06 & 0.94 & 0.11 & 0.35 & 189.21 & 64.87 & 81.93 & 405.85 & 670.00 \\
\hline 1300.00 & 0.09 & 0.91 & 0.08 & 0.45 & 244.32 & 83.77 & 105.79 & 524.06 & 870.00 \\
\hline 1600.00 & 0.11 & 0.89 & 0.07 & 0.56 & 301.34 & 103.32 & 130.48 & 650.00 & 1070.00 \\
\hline 2000.00 & 0.13 & 0.87 & 0.05 & 0.69 & 376.25 & 129.00 & 162.92 & 810.00 & 1340.00 \\
\hline 2490.00 & 0.16 & 0.84 & 0.04 & 0.87 & 469.65 & 161.02 & 203.36 & 1010.00 & 1670.00 \\
\hline 3490.00 & 0.20 & 0.80 & 0.03 & 1.21 & 656.99 & 225.25 & 284.48 & 1410.00 & 2340.00 \\
\hline 4490.00 & 0.23 & 0.77 & 0.02 & 1.56 & 850.00 & 290.14 & 366.44 & 1820.00 & 3010.00 \\
\hline 4990.00 & 0.25 & 0.75 & 0.02 & 1.73 & 940.00 & 322.46 & 407.26 & 2020.00 & 3340.00 \\
\hline 6970.00 & 0.30 & 0.70 & 0.02 & 2.42 & 1310.00 & 450.56 & 570.00 & 2810.00 & 4680.00 \\
\hline 8500.00 & 0.33 & 0.67 & 0.01 & 2.94 & 1600.00 & 547.32 & 690.00 & 3430.00 & 5670.00 \\
\hline 10000.00 & 0.36 & 0.64 & 0.01 & 3.46 & 1880.00 & 643.71 & 810.00 & 4030.00 & 6700.00 \\
\hline 14900.00 & 0.49 & 0.51 & 0.01 & 5.19 & 2820.00 & 970.00 & 1220.00 & 6050.00 & 10000.00 \\
\hline 19900.00 & 0.69 & 0.31 & 0.01 & 6.92 & 3750.00 & 1290.00 & 1630.00 & 8000.00 & 13400.00 \\
\hline 29900.00 & 0.84 & 0.16 & 0.00 & 10.39 & 5630.00 & 1930.00 & 2440.00 & 12100.00 & 20000.00 \\
\hline 34800.00 & 0.88 & 0.12 & 0.00 & 12.10 & 6560.00 & 2250.00 & 2840.00 & 14100.00 & 23300.00 \\
\hline 39900.00 & 0.91 & 0.09 & 0.00 & 13.85 & 7510.00 & 2570.00 & 3250.00 & 16100.00 & 26700.00 \\
\hline 44800.00 & 0.93 & 0.07 & 0.00 & 15.57 & 8440.00 & 2890.00 & 3660.00 & 18100.00 & 30000.00 \\
\hline 54800.00 & 0.97 & 0.03 & 0.00 & 19.03 & 10320.00 & 3540.00 & 4470.00 & 22100.00 & 36700.00 \\
\hline
\end{tabular}


Table 3.5. Mercury injection data summary for a typical sand from the Antelope Shale interval.

\author{
MERCURY INJECTION DATA \\ 653Z-26B Well \\ Buena Vista Hills Field
}

$\begin{array}{lr}\text { Depth, feet: } & 4432.50 \\ \text { Klinkenberg Permeability, md: } & 202.00 \\ \text { Porosity, fraction: } & 0.30\end{array}$

\begin{tabular}{|c|c|c|c|c|c|c|c|c|c|}
\hline $\begin{array}{l}\text { Injection } \\
\text { Pressure, }\end{array}$ & $\begin{array}{l}\text { Mercury } \\
\text { Saturation, }\end{array}$ & $\begin{array}{l}\text { 1.0-Mercury } \\
\text { Saturation, }\end{array}$ & $\begin{array}{l}\text { Pore } \\
\text { Radius, }\end{array}$ & & $\begin{array}{l}\text { Other Labor } \\
\text { Gas-Water, }\end{array}$ & $\begin{array}{l}\text { atory Systen } \\
\text { Gas-Oil, }\end{array}$ & $\begin{array}{l}\text { ms } \\
\text { Oil-Water, }\end{array}$ & $\begin{array}{l}\text { Estimated } \\
\text { Above Free }\end{array}$ & $\begin{array}{l}\text { Height } \\
\text { Water, ft }\end{array}$ \\
\hline & fraction & fraction & microns & Function & psia & nsia & & G-W & O-W \\
\hline 1.01 & 0.00 & 1.00 & 108.15 & 0.02 & 0.19 & 0.07 & 0.08 & 0.41 & 0.68 \\
\hline 2.00 & 0.00 & 1.00 & 54.62 & 0.03 & 0.38 & 0.13 & 0.16 & 0.81 & 1.34 \\
\hline 2.99 & 0.00 & 1.00 & 36.53 & 0.05 & 0.56 & 0.19 & 0.24 & 1.21 & 2.00 \\
\hline 5.97 & 0.00 & 1.00 & 18.30 & 0.09 & 1.12 & 0.39 & 0.49 & 2.41 & 4.00 \\
\hline 8.97 & 0.00 & 1.00 & 12.18 & 0.14 & 1.69 & 0.58 & 0.73 & 3.63 & 6.01 \\
\hline 11.96 & 0.01 & 0.99 & 9.13 & 0.18 & 2.25 & 0.77 & 0.98 & 4.83 & 8.01 \\
\hline 14.95 & 0.05 & 0.95 & 7.31 & 0.23 & 2.82 & 0.97 & 1.22 & 6.04 & 10.01 \\
\hline 17.93 & 0.27 & 0.73 & 6.09 & 0.27 & 3.38 & 1.16 & 1.46 & 7.25 & 12.01 \\
\hline 20.94 & 0.39 & 0.61 & 5.22 & 0.32 & 3.95 & 1.35 & 1.71 & 8.46 & 14.03 \\
\hline 24.93 & 0.48 & 0.52 & 4.38 & 0.38 & 4.70 & 1.61 & 2.03 & 10.08 & 16.70 \\
\hline 28.11 & 0.52 & 0.48 & 3.89 & 0.43 & 5.30 & 1.82 & 2.29 & 11.36 & 18.83 \\
\hline 37.91 & 0.59 & 0.41 & 2.88 & 0.58 & 7.14 & 2.45 & 3.09 & 15.32 & 25.39 \\
\hline 52.82 & 0.64 & 0.36 & 2.07 & 0.80 & 9.95 & 3.41 & 4.31 & 21.35 & 35.38 \\
\hline 72.65 & 0.67 & 0.33 & 1.50 & 1.11 & 13.69 & 4.69 & 5.93 & 29.36 & 48.66 \\
\hline 97.24 & 0.70 & 0.30 & 1.12 & 1.48 & 18.32 & 6.28 & 7.93 & 39.30 & 65.13 \\
\hline 146.93 & 0.74 & 0.26 & 0.74 & 2.24 & 27.68 & 9.49 & 11.99 & 59.38 & 98.42 \\
\hline 196.86 & 0.76 & 0.24 & 0.55 & 3.00 & 37.09 & 12.72 & 16.06 & 79.56 & 131.86 \\
\hline 301.73 & 0.79 & 0.21 & 0.36 & 4.60 & 56.85 & 19.49 & 24.62 & 121.94 & 202.10 \\
\hline 397.66 & 0.81 & 0.19 & 0.27 & 6.06 & 74.92 & 25.69 & 32.44 & 160.71 & 266.36 \\
\hline 501.22 & 0.82 & 0.18 & 0.22 & 7.63 & 94.43 & 32.38 & 40.89 & 202.56 & 335.73 \\
\hline 750.00 & 0.84 & 0.16 & 0.15 & 11.35 & 140.43 & 48.15 & 60.81 & 301.23 & 500.00 \\
\hline 990.00 & 0.85 & 0.15 & 0.11 & 15.15 & 187.40 & 64.25 & 81.15 & 401.98 & 670.00 \\
\hline 1290.00 & 0.86 & 0.14 & 0.08 & 19.65 & 243.15 & 83.37 & 105.29 & 521.56 & 860.00 \\
\hline 1590.00 & 0.86 & 0.14 & 0.07 & 24.22 & 299.63 & 102.73 & 129.74 & 640.00 & 1070.00 \\
\hline 1990.00 & 0.87 & 0.13 & 0.05 & 30.38 & 375.85 & 128.86 & 162.75 & 810.00 & 1340.00 \\
\hline 2490.00 & 0.87 & 0.13 & 0.04 & 37.85 & 468.32 & 160.57 & 202.79 & 1000.00 & 1660.00 \\
\hline 3490.00 & 0.88 & 0.12 & 0.03 & 53.18 & 657.85 & 225.55 & 284.86 & 1410.00 & 2340.00 \\
\hline 4480.00 & 0.89 & 0.11 & 0.02 & 68.28 & 840.00 & 289.61 & 365.76 & 1800.00 & 3000.00 \\
\hline 4980.00 & .0 .89 & 0.11 & 0.02 & 75.81 & 940.00 & 321.58 & 406.14 & 20.00 & 3330.00 \\
\hline 6970.00 & 0.90 & 0.10 & 0.02 & 106.15 & 1310.00 & 450.26 & 570.00 & 2810.00 & 4680.00 \\
\hline 8500.00 & 0.91 & 0.09 & 0.01 & 129.08 & 1600.00 & 547.52 & 690.00 & 3430.00 & 5670.00 \\
\hline 10000.00 & 0.93 & 0.07 & 0.01 & 151.72 & 1880.00 & 643.54 & 810.00 & 4030.00 & 6700.00 \\
\hline 14900,00 & 0.94 & 0.06 & 0.01 & 227.56 & 2820.00 & 970.00 & 1220.00 & 6050.00 & 10000.00 \\
\hline 19900.00 & 0.95 & 0.05 & 0.01 & 303.78 & 3760.00 & 1290.00 & 1630.00 & 8100.00 & 13400.00 \\
\hline 29900.00 & 0.97 & 0.03 & 0.00 & 454.81 & 5630.00 & 1930.00 & 2440.00 & 12100.00 & 20000.00 \\
\hline 34800.00 & 0.97 & 0.03 & 0.00 & 530.73 & 6570.00 & 2250.00 & 2840.00 & 14100.00 & 23300.00 \\
\hline 39900.00 & 0.98 & 0.02 & 0.00 & 607.63 & 7520.00 & 2580.00 & 3260.00 & 16100.00 & 26800.00 \\
\hline 44900.00 & 0.98 & 0.02 & 0.00 & 684.17 & 8460.00 & 2900.00 & 3670.00 & 18100.00 & 30100.00 \\
\hline 54800.00 & 0.99 & 0.01 & 0.00 & 834.09 & 10320.00 & 3540.00 & 4470.00 & 22100.00 & 36700.00 \\
\hline
\end{tabular}


Table 3.6. Results of NMR core plug analyses.

\begin{tabular}{|c|c|c|c|c|c|}
\hline & & \multicolumn{2}{|c|}{ Fully Saturated State } & \multicolumn{2}{c|}{ Native State } \\
\hline Lithology & Sample Depth, Ft. & Porosity (\%) & $\mathrm{T}_{\mathbf{2}}(\mathrm{ms})^{*}$ & Porosity (\%) & $\mathrm{T}_{\mathbf{2}}(\mathrm{ms})^{*}$ \\
\hline Sand & 4432.50 & 19.11 & 119.11 & 10.76 & 23.08 \\
Sand & 4640.10 & 10.59 & 19.85 & 10.02 & 9.99 \\
Sand & 4668.85 & 16.58 & 125.33 & 9.26 & 12.46 \\
Sand & 4836.90 & 12.02 & 59.64 & 11.38 & 37.48 \\
Sand & 4838.85 & 4.53 & 7.60 & 4.08 & 2.42 \\
Sand & 4866.00 & 8.99 & 25.64 & 6.90 & 6.14 \\
Sand & 4869.30 & 9.40 & 30.06 & 9.16 & 15.45 \\
\hline Siliceous Shale & 4369.80 & 35.52 & 7.66 & 30.79 & 7.26 \\
Siliceous Shale & 4370.00 & 32.42 & 7.38 & 30.67 & 8.59 \\
Siliceous Shale & 4271.65 & 27.00 & 6.08 & 26.39 & 4.61 \\
Siliceous Shale & 4744.25 & 31.44 & 6.86 & 29.11 & 5.65 \\
Siliceous Shale & 4200.05 & 21.83 & 1.46 & 19.44 & 1.28 \\
Siliceous Shale & 4747.95 & 38.76 & 9.81 & 38.66 & 9.75 \\
Siliceous Shale & 3958.05 & 34.79 & 6.08 & 32.44 & 5.33 \\
Siliceous Shale & 3959.00 & 34.59 & 6.17 & 33.87 & 5.30 \\
\hline
\end{tabular}

$*-\mathrm{T}_{2}$ is the median value (50 percentile).

Table 3.7. Ultrasonic Velocity and Dynamic Moduli Summary

Chevron USA 653Z-26B Well

Sample Type:

1.5 in. diameter plug

Buena Vista Hills Field

\begin{tabular}{|c|c|c|c|c|c|c|c|c|}
\hline \multirow{2}{*}{$\begin{array}{c}\text { Sample } \\
\text { Depth. } \\
\text { feet }\end{array}$} & \multirow{2}{*}{$\begin{array}{c}\text { Net } \\
\text { Stress. } \\
\text { psi }\end{array}$} & \multirow{2}{*}{$\begin{array}{c}\text { Bulk } \\
\text { Density. } \\
\text { gm/cc }\end{array}$} & \multicolumn{2}{|c|}{ Velocity } & \multirow{2}{*}{$\begin{array}{c}\text { Bulk } \\
\text { Modulus, } \\
\text { 1e+06 psi }\end{array}$} & \multirow{2}{*}{$\begin{array}{l}\text { Young's } \\
\text { Modulus, } \\
\text { te+06 psi }\end{array}$} & \multirow{2}{*}{$\begin{array}{c}\text { Shear } \\
\text { Modulus. } \\
1 \mathrm{e}+06 \mathrm{psi}\end{array}$} & \multirow[b]{2}{*}{$\begin{array}{c}\text { Poisson's } \\
\text { Ratio }\end{array}$} \\
\hline & & & $\begin{array}{l}\text { Comp, } \\
\mathrm{ft} / \mathrm{sec}\end{array}$ & $\begin{array}{l}\text { Shear, } \\
\text { ft'sec }\end{array}$ & & & & \\
\hline 4191.00 & 1400 & 1.84 & 9690 & 6440 & 0.954 & 2.258 & 1.022 & 0.104 \\
\hline 4325.30 & 2100 & 2.00 & 10230 & 6730 & 1.189 & 2.724 & 1.218 & 0.118 \\
\hline 4372.15 & 2100 & 1.78 & 8730 & 5580 & 0.825 & 1.712 & 0.741 & 0.155 \\
\hline 4459.80 & 2200 & 1.94 & 9580 & 6470 & 0.931 & 2.348 & 1.086 & 0.081 \\
\hline 4568.95 & 2200 & 1.98 & 9530 & 6120 & 1.088 & 2.289 & 0.996 & 0.149 \\
\hline 4671.10 & 2200 & 1.76 & 7860 & 5290 & 0.574 & 1.432 & 0.659 & 0.086 \\
\hline 4799.30 & 2200 & 1.73 & 7420 & 4640 & 0.609 & 1.172 & 0.497 & 0.179 \\
\hline
\end{tabular}


Table 3.8. Summary of Specific Liquid Permeability, 653Z-26B well.

\begin{tabular}{|c|c|c|c|c|}
\hline $\begin{array}{c}\text { Sample Depth, } \\
\text { feet }\end{array}$ & $\begin{array}{c}\text { Sample } \\
\text { Lithology }\end{array}$ & $\begin{array}{c}\text { Stress } \\
\text { psi }\end{array}$ & $\begin{array}{c}\text { Method } \\
\text { of Testing }\end{array}$ & Liquid Perm. \\
\hline 4432.50 & Sand & 2500 & Hydrostatic & 75.2 millidarcies \\
\hline 4640.10 & Sand & 2500 & Hydrostatic & 1.3 millidarcies \\
\hline 4668.85 & Sand & 2500 & Hydrostatic & 70.5 millidarcies \\
\hline 4836.90 & Sand & 2500 & Hydrostatic & 33.5 millidarcies \\
\hline 4838.85 & Sand & 2500 & Hydrostatic & 0.004 millidarcies \\
\hline 4866.00 & Sand & 2500 & Hydrostatic & 1.6 millidarcies \\
\hline 4869.30 & Sand & 2500 & Hydrostatic & 2.5 millidarcies \\
\hline 4369.80 & Siliceous Shale & 2500 & Liq. Pulse Decay & 9.58 microdarcies \\
\hline 4370.00 & Siliceous Shale & 2500 & Liq. Pulse Decay & 5.03 microdarcies \\
\hline 4271.65 & Siliceous Shale & 2500 & Liq. Pulse Decay & 7.95 microdarcies \\
\hline 4744.25 & Siliceous Shale & 2500 & Liq. Pulse Decay & 6.85 microdarcies \\
\hline 4200.05 & Siliceous Shale & 2500 & Liq. Pulse Decay & 0.061 microdarcies \\
\hline 4747.95 & Siliceous Shale & 2500 & Liq. Pulse Decay & 25.1 microdarcies \\
\hline 3958.05 & Siliceous Shale & 2500 & Liq. Pulse Decay & 6.90 microdarcies \\
\hline 3959.00 & Siliceous Shale & 2500 & Liq. Pulse Decay & 25.5 microdarcies \\
\hline
\end{tabular}


Table 3.9. Lithology Determinations from Imagelog Analysis.

\begin{tabular}{|c|c|c|c|c|c|c|}
\hline Fluorescence & & & & Low - None & Medium & High \\
\hline Lithology & & & & Clay Shales & $\begin{array}{c}\text { Siliceous } \\
\text { Shales }\end{array}$ & $\begin{array}{c}\begin{array}{c}\text { Sands and } \\
\text { Minor Calc. } \\
\text { Beds* }\end{array} \\
\end{array}$ \\
\hline Core Number & Top Core (ft.) & Base Core (ft.) & Gross Footage & & & \\
\hline 1 & 3955.0 & 3984.0 & 29.0 & 14.3 & 14.7 & 0.0 \\
\hline 2 & 3984.0 & 4015.0 & 31.0 & 27.6 & 3.4 & 0.0 \\
\hline 3 & 4015.0 & 4045.0 & 30.0 & 16.1 & 13.9 & 0.0 \\
\hline 4 & 4045.0 & 4073.7 & 28.7 & 15.9 & 12.8 & 0.0 \\
\hline 5 & 4073.7 & 4105.0 & 31.3 & 20.1 & 11.2 & 0.0 \\
\hline 6 & 4105.0 & 4135.0 & 30.0 & 16.1 & 13.9 & 0.0 \\
\hline 7 & 4135.0 & 4165.0 & 30.0 & 22.6 & 7.4 & 0.0 \\
\hline 8 & 4165.0 & 4196.1 & 31.1 & 22.2 & 8.9 & 0.0 \\
\hline 9 & 4196.1 & 4227.0 & 30.9 & 21.0 & 9.9 & 0.0 \\
\hline 10 & 4227.0 & 4258.0 & 31.0 & 19.6 & 10.2 & 1.2 \\
\hline 11 & 4258.0 & 4289.0 & 31.0 & 21.1 & 6.6 & 3.3 \\
\hline 12 & 4289.0 & 4320.0 & 31.0 & 20.1 & 9.6 & 1.3 \\
\hline 13 & 4320.0 & 4350.4 & 30.4 & 21.1 & 7.1 & 2.2 \\
\hline 14 & 4350.4 & 4381.3 & 30.9 & 17.2 & 12.7 & 1.0 \\
\hline 15 & 4381.3 & 4411.5 & 30.2 & 16.9 & 12.4 & 0.9 \\
\hline 16 & 4411.5 & 4441.8 & 30.3 & 19.4 & 8.6 & 2.3 \\
\hline 17 & 4441.8 & 4471.9 & 30.1 & 20.8 & 7.0 & 2.3 \\
\hline 18 & 4471.9 & 4502.0 & 30.1 & 17.1 & 8.2 & 4.8 \\
\hline 19 & 4502.0 & 4532.0 & 30.0 & 14.3 & 12.4 & 3.3 \\
\hline 20 & 4532.0 & $456 \varphi 1.8$ & 29.8 & 16.0 & 10.4 & 3.4 \\
\hline 21 & 4561.8 & 4592.5 & 30.7 & 18.6 & 11.1 & 1.0 \\
\hline 22 & 4592.5 & 4622.6 & 30.1 & 15.7 & 13.7 & 0.7 \\
\hline 23 & 4622.6 & 4652.0 & 29.4 & 13.6 & 15.2 & 0.6 \\
\hline 24 & 4652.0 & 4682.0 & 30.0 & 20.2 & 8.8 & 1.0 \\
\hline 25 & 4682.0 & 4712.0 & 30.0 & 14.4 & 15.1 & 0.5 \\
\hline 26 & 4712.0 & 4741.8 & 29.8 & 19.0 & 10.3 & 0.5 \\
\hline 27 & 4741.8 & 4772.0 & 30.2 & 16.1 & 13.6 & 0.5 \\
\hline 28 & 4772.0 & 4786.6 & 14.6 & 8.6 & 5.6 & 0.4 \\
\hline 29 & 4786.6 & 4817.0 & 30.4 & 13.7 & 16.1 & 0.6 \\
\hline 30 & 4817.0 & 4847.3 & 30.3 & 19.3 & 10.2 & 0.8 \\
\hline 31 & 4847.3 & 4877.0 & 29.7 & 21.2 & 7.4 & 1.1 \\
\hline 32 & 4877.0 & 4907.3 & 30.3 & 21.2 & 8.3 & 0.8 \\
\hline Total & & & 952.3 & 581.1 & 336.7 & 34.5 \\
\hline
\end{tabular}

* See core description for breakout of calcareous beds 
Table 3.10. Results of the relative permeability tests on $653 \mathrm{Z}$ core plugs.

\author{
GAS-OIL RELATIVE PERMEABILITY \\ Unsteady-State Cleaned-State Samples \\ Temperature: Ambient
}

\begin{tabular}{|c|c|c|c|c|c|c|c|c|c|}
\hline \multirow[b]{2}{*}{$\begin{array}{l}\text { Depth, } \\
\text { feet }\end{array}$} & \multirow[b]{2}{*}{$\begin{array}{l}\text { Permeability } \\
\text { to Air, } \\
\text { millidarcies }\end{array}$} & \multirow[b]{2}{*}{$\begin{array}{l}\text { Porosity, } \\
\text { fraction }\end{array}$} & \multicolumn{2}{|c|}{ Initial Conditions } & \multicolumn{3}{|c|}{ Terminal Conditions } & \multicolumn{2}{|c|}{ Oil Recovery, } \\
\hline & & & $\begin{array}{c}\text { Water } \\
\text { Saturation, } \\
\text { fraction } V_{p}\end{array}$ & $\begin{array}{l}\text { Effective } \\
\text { Permeability } \\
\text { to Oil, } \\
\text { millidarcies }\end{array}$ & $\begin{array}{c}\text { Oil } \\
\text { Saturation, } \\
\text { fraction } V p\end{array}$ & $\begin{array}{c}\text { Effective } \\
\text { Permeability } \\
\text { to Gas, } \\
\text { millidarcies }\end{array}$ & $\begin{array}{l}\text { Relative } \\
\text { Permeability } \\
\text { to Gas*, } \\
\text { fraction }\end{array}$ & fraction $\mathrm{Vp}$ & $\begin{array}{l}\text { fraction } \\
\text { OIP }\end{array}$ \\
\hline 4490.85 & 13.30 & 0.200 & 0.313 & 8.23 & 0.329 & 7.3 & 0.881 & 0.358 & 0.521106 \\
\hline 4432.65 & 168.00 & 0.241 & 0.223 & 166.00 & 0.239 & 80.8 & 0.487 & 0.538 & 0.692407 \\
\hline 4491.05 & 2.57 & 0.203 & 0.543 & 1.23 & 0.068 & 0.7 & 0.537 & 0.389 & 0.850831 \\
\hline 4493.20 & 3.13 & 0.201 & 0.520 & 1.80 & 0.112 & 0.9 & 0.48 & 0.368 & 0.766188 \\
\hline 4499.55 & 62.48 & 0.169 & 0.405 & 53.90 & 0.165 & 31.1 & 0.577 & 0.431 & 0.723762 \\
\hline $\begin{array}{l}4512.35 \\
4518.55\end{array}$ & $\begin{array}{l}0.28 \\
0.33\end{array}$ & $\begin{array}{l}0.212 \\
0.213\end{array}$ & $\begin{array}{l}0.561 \\
0.469\end{array}$ & $\begin{array}{l}0.02 \\
0.11\end{array}$ & $\begin{array}{l}0.305 \\
0.318\end{array}$ & $\begin{array}{l}0.0 \\
0.1\end{array}$ & $\begin{array}{l}0.523 \\
0.683\end{array}$ & $\begin{array}{l}0.134 \\
0.213\end{array}$ & $\begin{array}{l}0.305239 \\
0.401206\end{array}$ \\
\hline 4291.30 & 0.90 & 0.202 & 0.663 & 0.24 & 0.111 & 0.1 & 0.59 & 0.226 & 0.670424 \\
\hline
\end{tabular}

- Relative to the effective permeability to oil at initial water saturation

\title{
WATER-OIL RELATIVE PERMEABILITY \\ Unsteady-State Cleaned-State Samples \\ Temperature: Ambient
}

\begin{tabular}{|c|c|c|c|c|c|c|c|c|c|}
\hline \multirow[b]{2}{*}{$\begin{array}{c}\text { Depth, } \\
\text { feet }\end{array}$} & \multirow[b]{2}{*}{$\begin{array}{c}\text { Permeability } \\
\text { to Air, } \\
\text { millidarcies }\end{array}$} & \multirow[b]{2}{*}{$\begin{array}{l}\text { Porosity, } \\
\text { fraction }\end{array}$} & \multicolumn{2}{|c|}{ Initial Conditions } & \multicolumn{3}{|c|}{ Terminal Conditions } & \multicolumn{2}{|c|}{ Oil Recovery, } \\
\hline & & & $\begin{array}{c}\text { Water } \\
\text { Saturation, } \\
\text { fraction } V p\end{array}$ & $\begin{array}{c}\text { Effective } \\
\text { Permeability } \\
\text { to Oil, } \\
\text { millidarcies }\end{array}$ & $\begin{array}{c}\text { Oil } \\
\text { Saturation, } \\
\text { fraction } V_{p}\end{array}$ & $\begin{array}{l}\text { Effective } \\
\text { Permeability } \\
\text { to Water, } \\
\text { millidarcies }\end{array}$ & $\begin{array}{l}\text { Relative } \\
\text { Permeability } \\
\text { to Water", } \\
\text { fraction }\end{array}$ & fraction VP & $\begin{array}{c}\text { fraction } \\
\text { OIP }\end{array}$ \\
\hline 4490.85 & 13.30 & 0.200 & 0.313 & 8.20 & 0.239 & 4.5 & 0.545 & 0.448 & 0.652 \\
\hline 4432.65 & 168.00 & 0.241 & 0.223 & 166.00 & 0.311 & 14.3 & 0.086 & 0.466 & 0.600 \\
\hline 4491.05 & 2.60 & 0.203 & 0.543 & 1.20 & 0.037 & 0.4 & 0.347 & 0.420 & 0.919 \\
\hline 4493.20 & 3.10 & 0.201 & 0.520 & 1.80 & 0.063 & 0.7 & 0.362 & 0.417 & 0.869 \\
\hline 4499.55 & 62.50 & 0.169 & 0.405 & 53.90 & 0.301 & 4.4 & 0.081 & 0.294 & 0.494 \\
\hline 4518.55 & 0.33 & 0.213 & 0.469 & 0.11 & 0.180 & 0.0 & 0.217 & 0.351 & 0.661 \\
\hline 4291.30 & 0.90 & 0.202 & 0.663 & 0.24 & 0.046 & 0.1 & 0.549 & 0.291 & 0.864 \\
\hline
\end{tabular}

- Relative to the effective permeability to oil at initial water saturation

\section{WATER-OIL RELATIVE PERMEABILITY \\ Unsteady-State Cleaned-State Samples \\ Temperature: $160 \mathrm{~F}$}

\begin{tabular}{|c|c|c|c|c|c|c|c|c|c|}
\hline \multirow[b]{2}{*}{$\begin{array}{l}\text { Depth, } \\
\text { feet }\end{array}$} & \multirow[b]{2}{*}{$\begin{array}{c}\text { Permeability } \\
\text { to Air. } \\
\text { millidarcies }\end{array}$} & \multirow[b]{2}{*}{$\begin{array}{c}\text { Porosity, } \\
\text { fraction }\end{array}$} & \multicolumn{2}{|c|}{ Initial Conditions } & \multicolumn{3}{|c|}{ Terminal Conditions } & \multicolumn{2}{|c|}{ Oil Recovery. } \\
\hline & & & $\begin{array}{c}\text { Water } \\
\text { Saturation, } \\
\text { fraction Vp }\end{array}$ & $\begin{array}{c}\text { Effective } \\
\text { Permeability } \\
\text { to Oil, } \\
\text { millidarcies }\end{array}$ & $\begin{array}{c}\text { Oil } \\
\text { Saturation, } \\
\text { fraction } V_{p}\end{array}$ & $\begin{array}{l}\text { Effective } \\
\text { Permeability } \\
\text { to Water, } \\
\text { millidarcies }\end{array}$ & $\begin{array}{c}\text { Relative } \\
\text { Permeability } \\
\text { to Water*, } \\
\text { fraction }\end{array}$ & fraction $V_{p}$ & $\begin{array}{c}\text { fraction } \\
\text { OIP }\end{array}$ \\
\hline 4490.85 & 13.30 & 0.200 & 0.217 & 5.40 & 0.323 & 1.4 & 0.257 & 0.460 & 0.587 \\
\hline 4432.65 & 168.00 & 0.241 & 0.182 & 104.00 & 0.473 & 6.3 & 0.061 & 0.345 & 0.422 \\
\hline
\end{tabular}




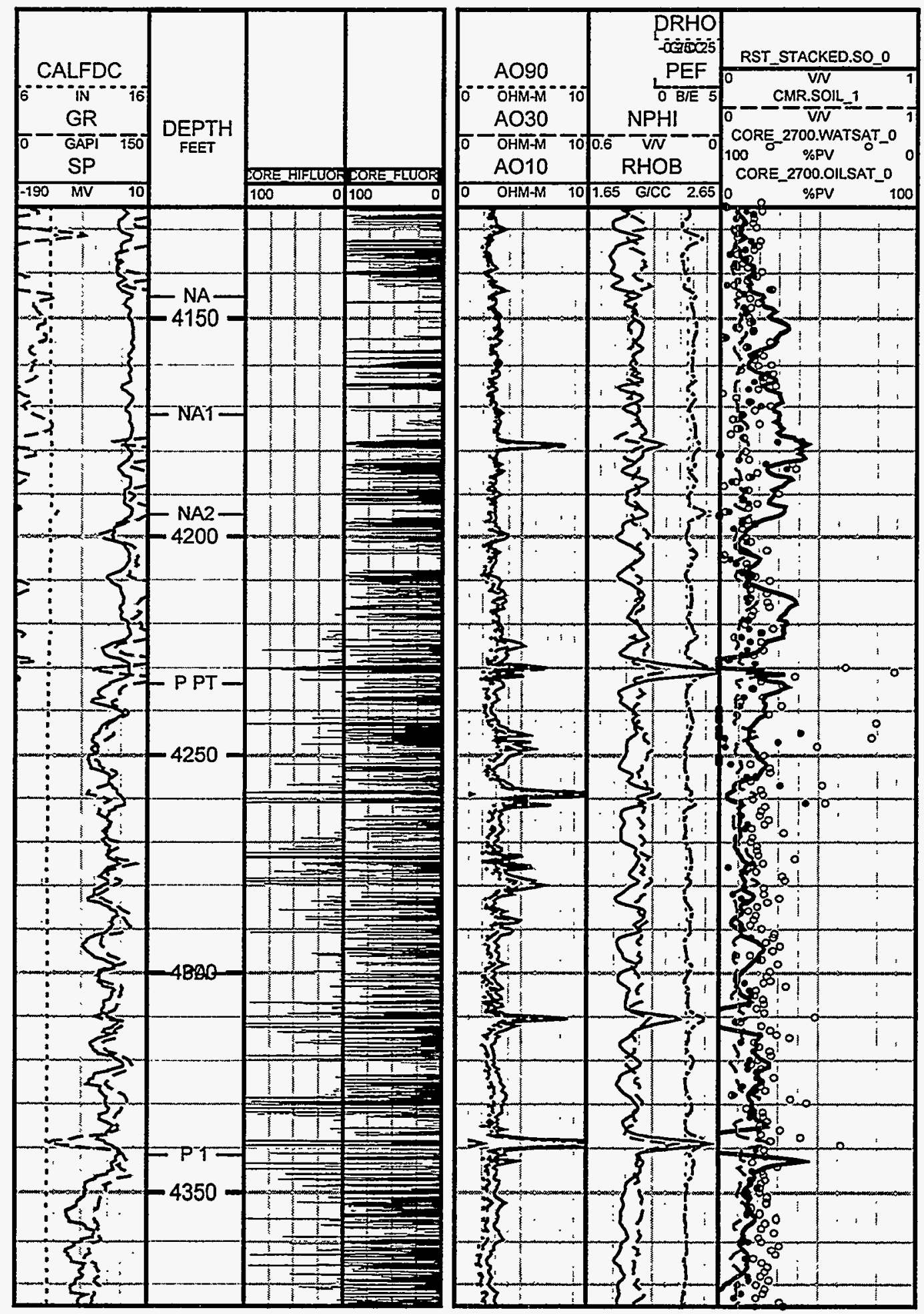

Figure 3.1. Carbon/Oxygen log (wireline log track on the right), shows higher oil saturations than core in the interval 4140 - 4260 feet. 


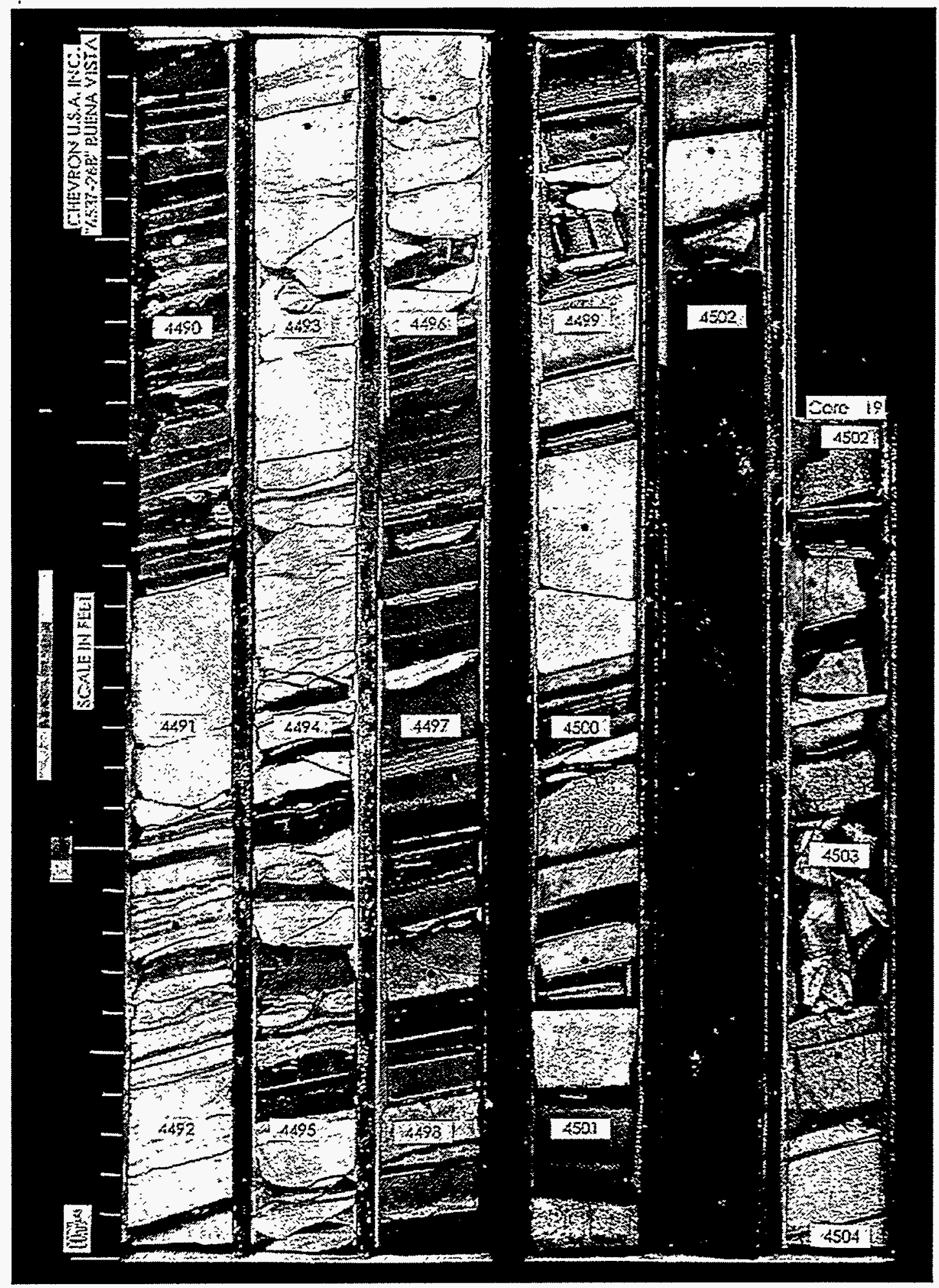

Figure 3.2. Antelope Shale core from 653Z-26B showing sands (light gray), siliceous shales (medium gray), and clay shales (dark gray to black). Note discontinuous nature in thin sands. Core depth $4489.3-4504$ feet. Scale on left (tenths of a foot). 


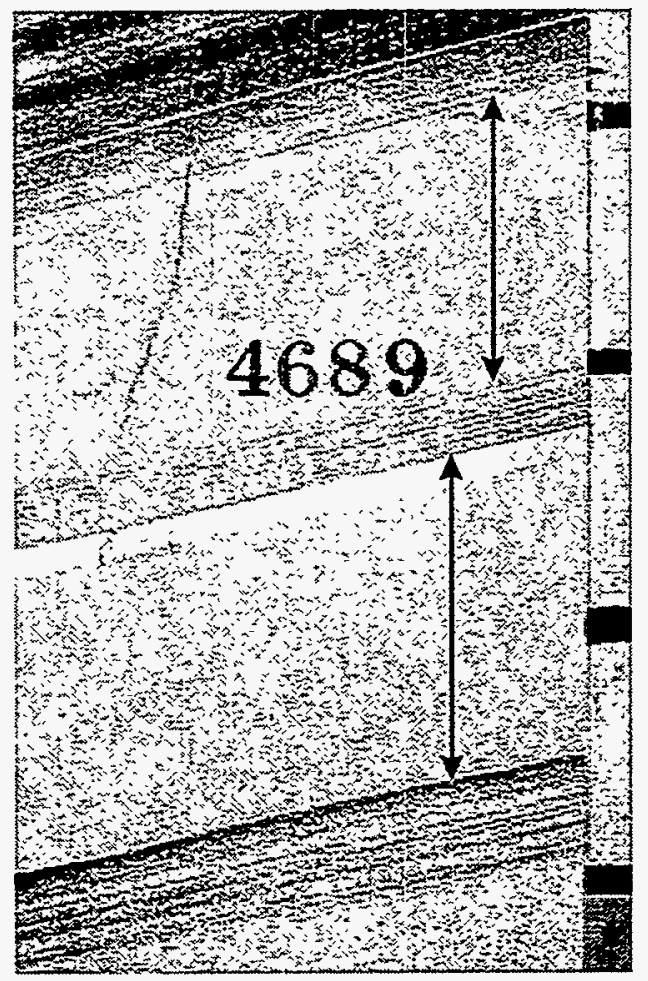

Figure 3.3. Antelope Shale core from 4689 feet, 653Z-26B. Two typical siliceous shale graded beds (silty siliceous shale grading to porcelanite) interbedded with finely laminated silty clay shale. Scale on right (tenths of a foot). 


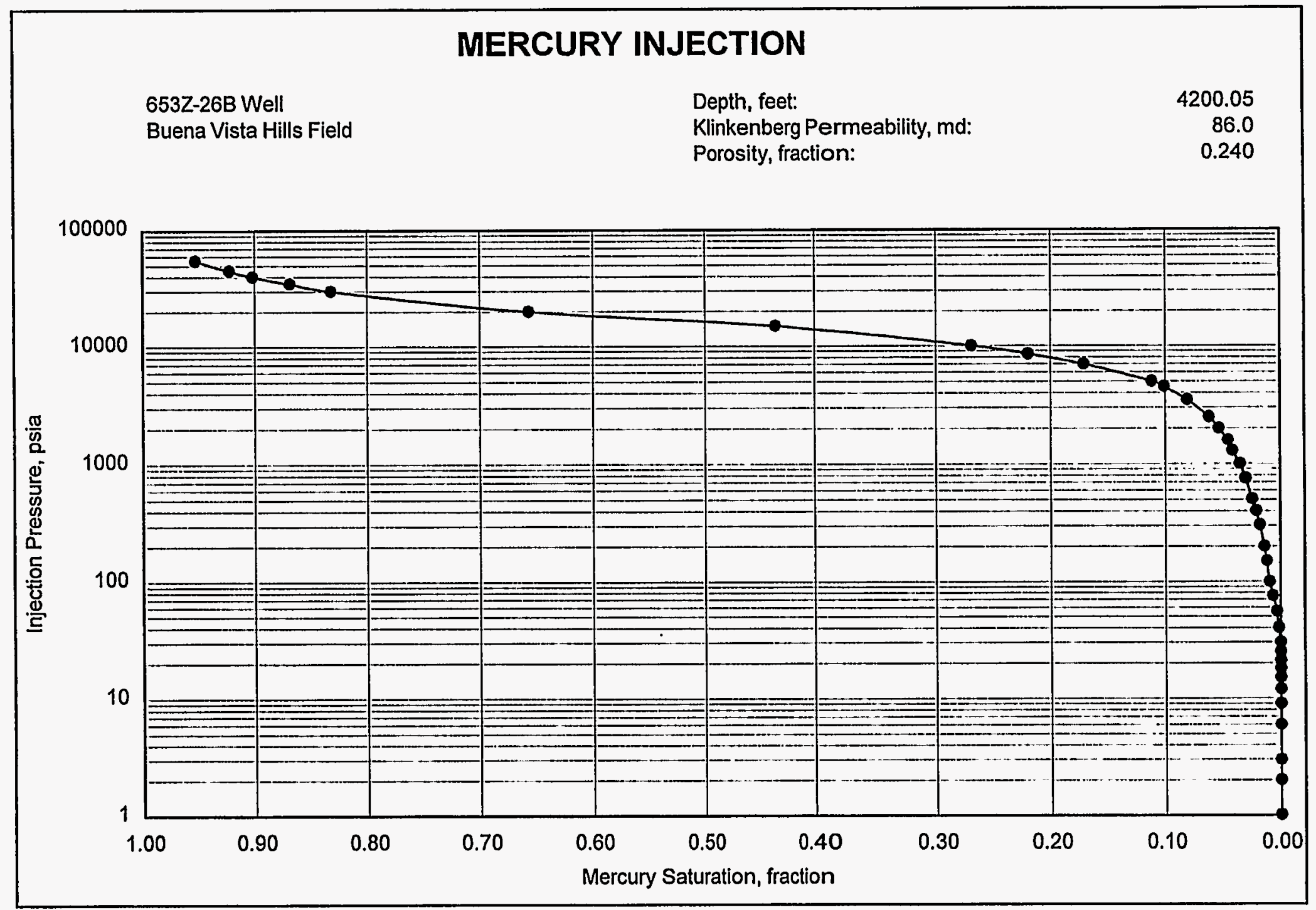

Figure3.4. Graph showing injection curve data from a typical siliceous shale from the Brown Shale interval. 


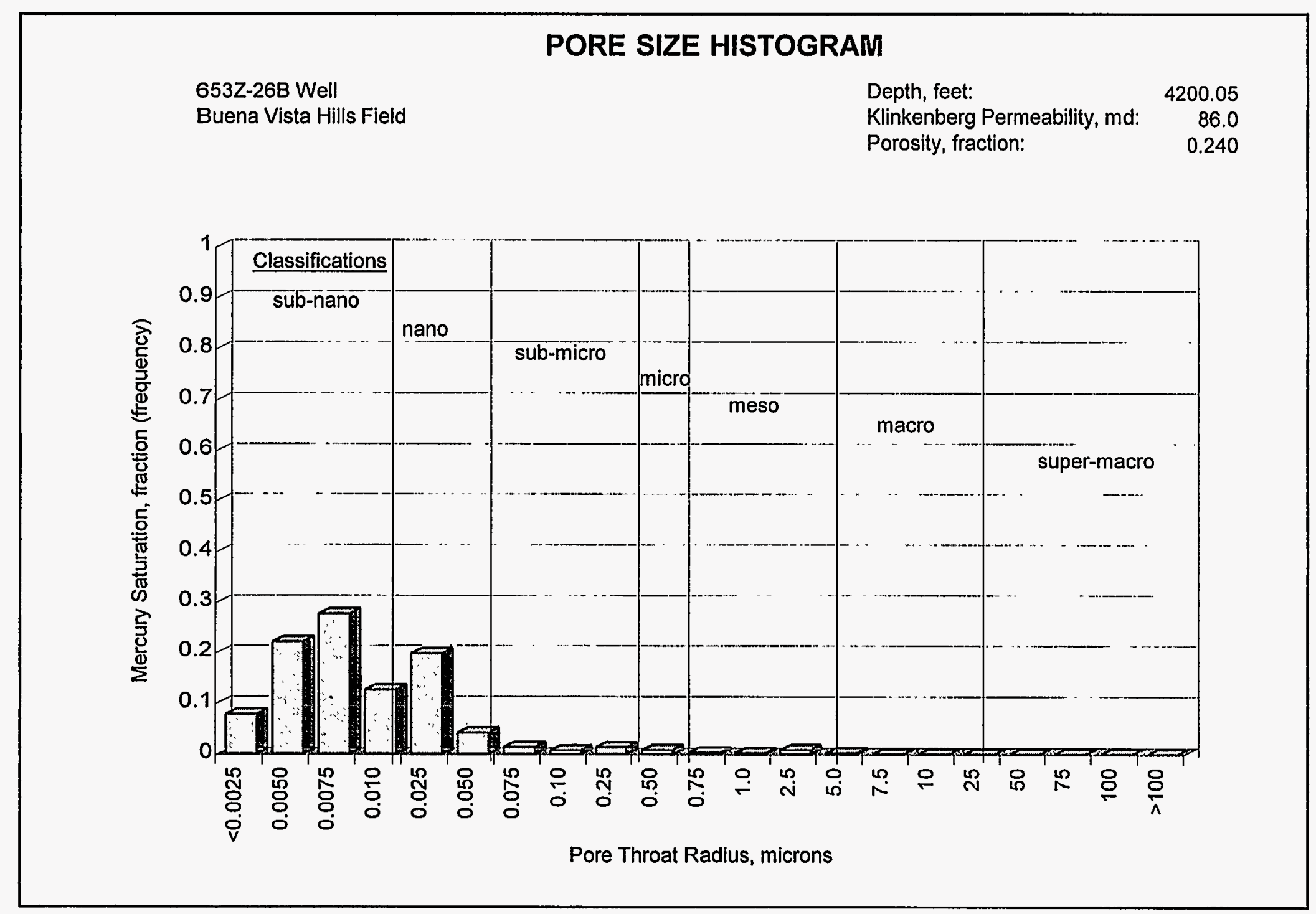

Figure 3.5. Pore size histogram of a typical siliceous from the Brown Shale interval. 


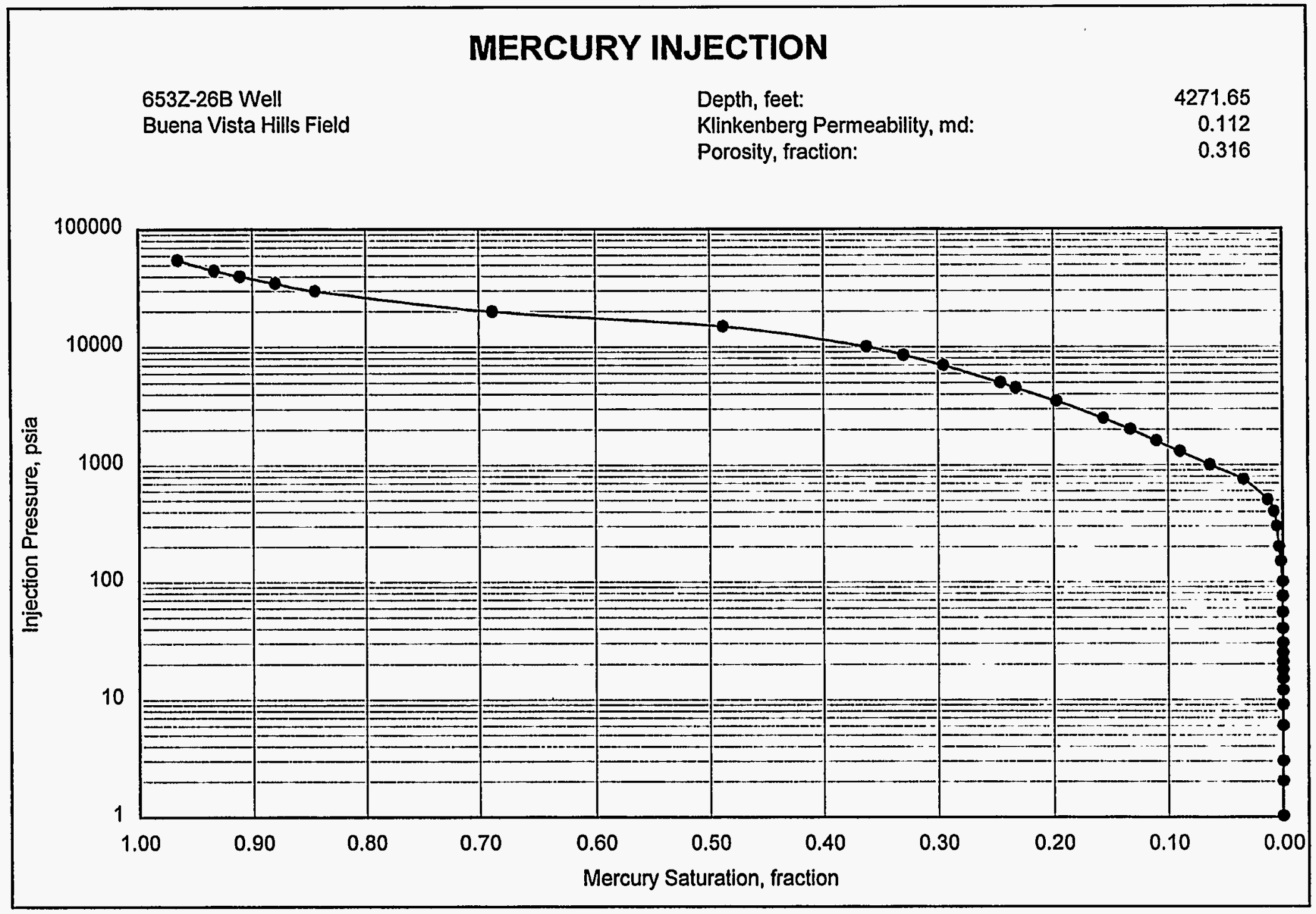

Figure 3.6. Graph showing injection curve data from a typical siliceous shale from the Antelope Shale interval. 


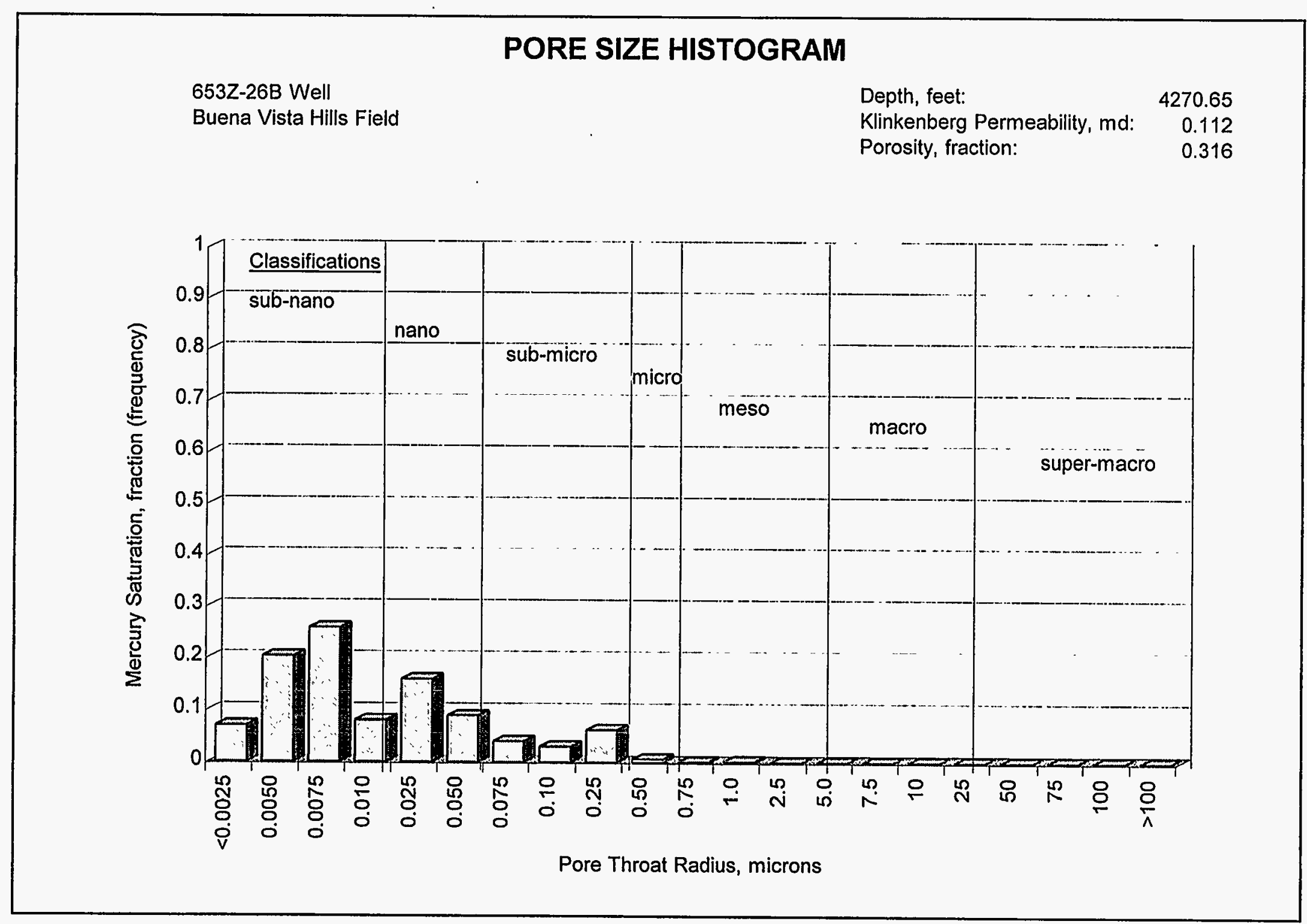

Figure 3.7. Pore size histogram of a typical siliceous from the Antelope Shale interval. 


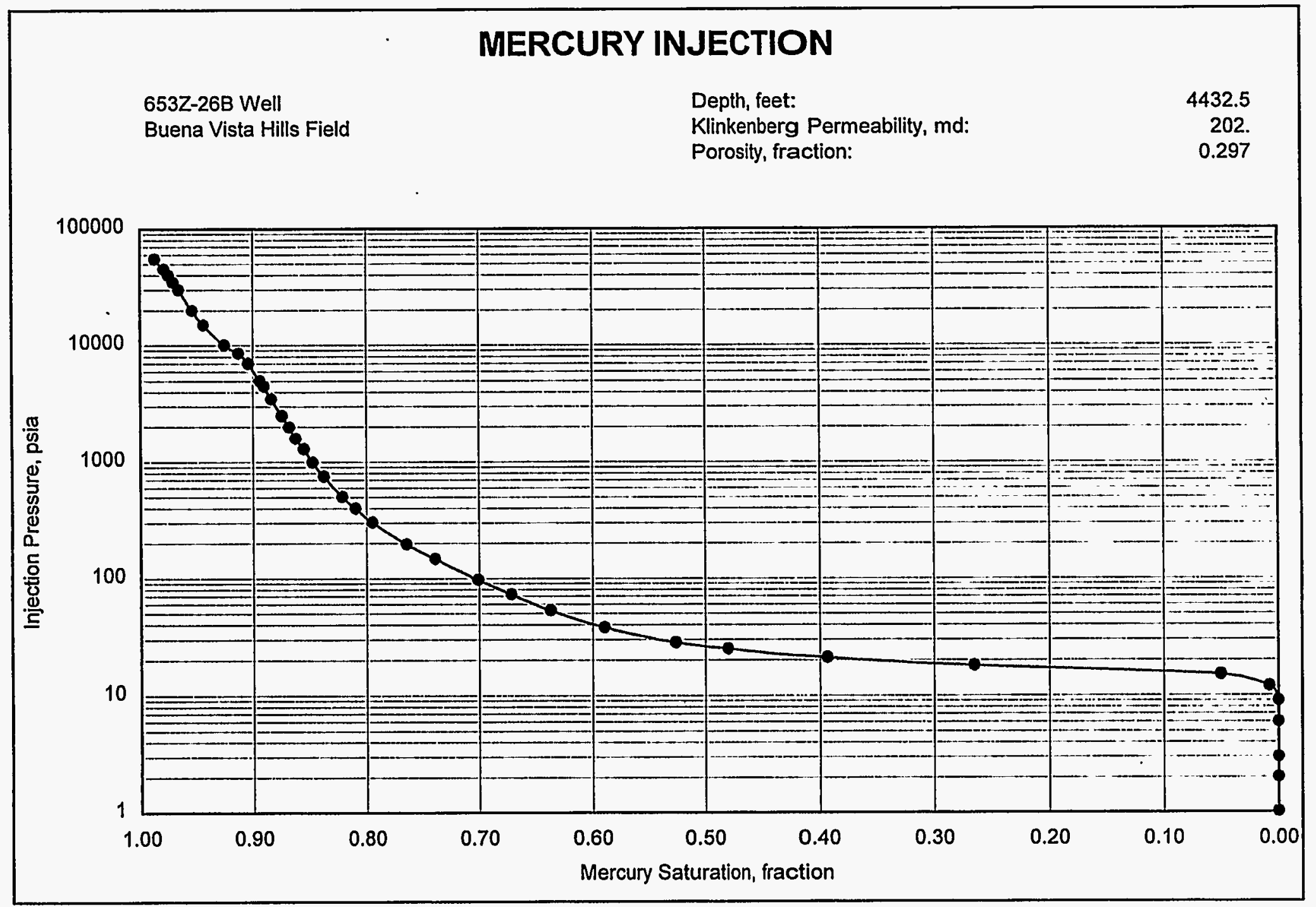

Figure 3.8. Graph showing injection curve data from a typical sand from the Antelope Shale interval. 


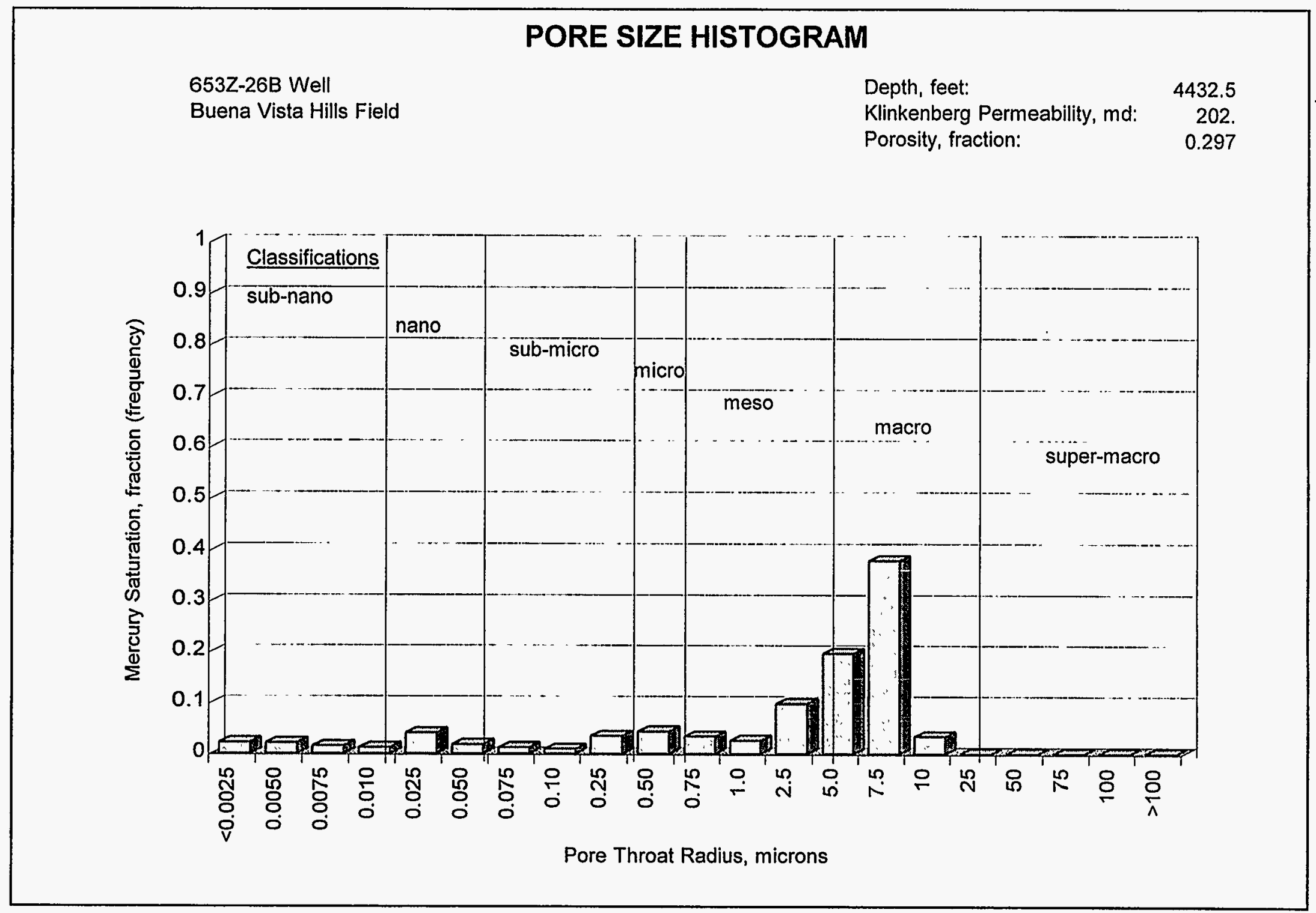

Figure 3.9. Pore size histogram of a typical sand from the Antelope Shale interval. 


\section{Acoustic Anisotropy - 4031.6'}

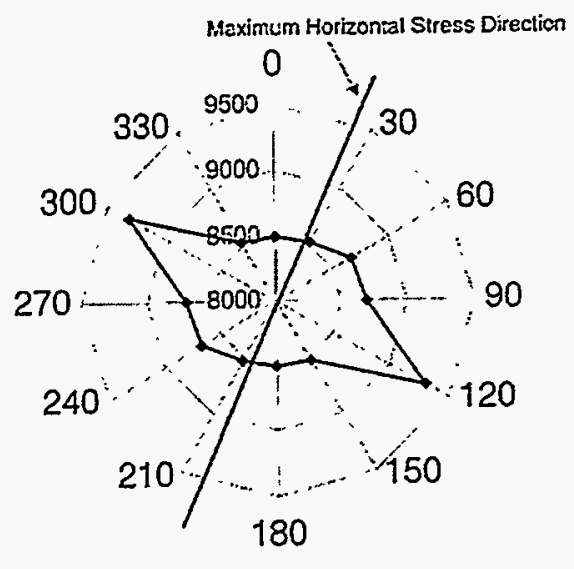

\section{Acoustic Anisotropy - 4095.2'}

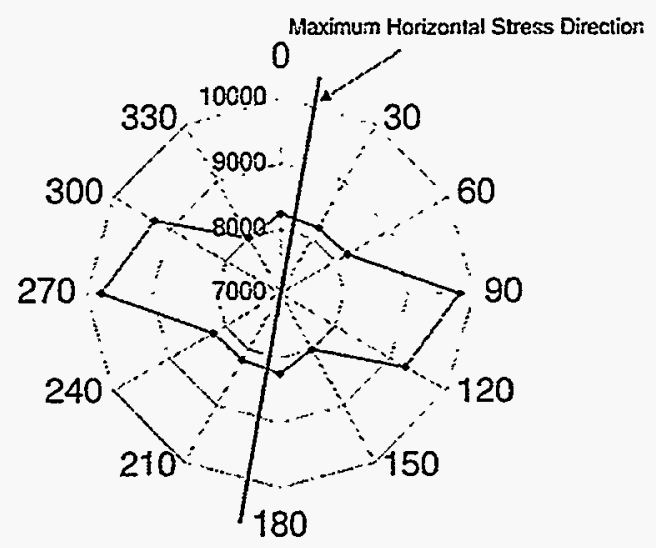

Acoustic Anisotropy - 4259.4

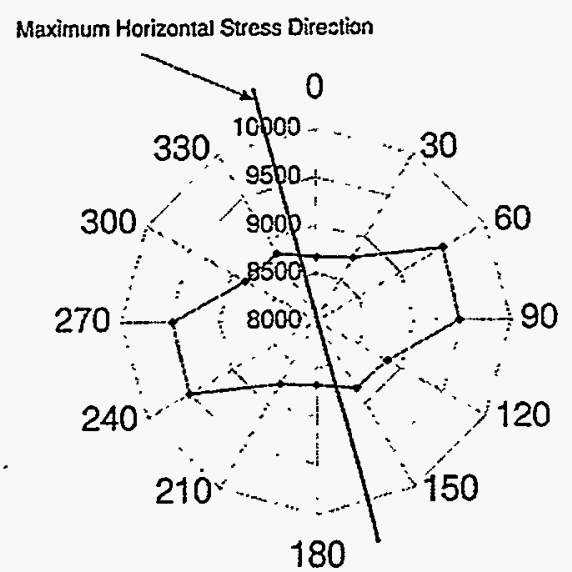

Acoustic Anisotropy - 4294.0'

Acoustic Anisotropy - 4565.7
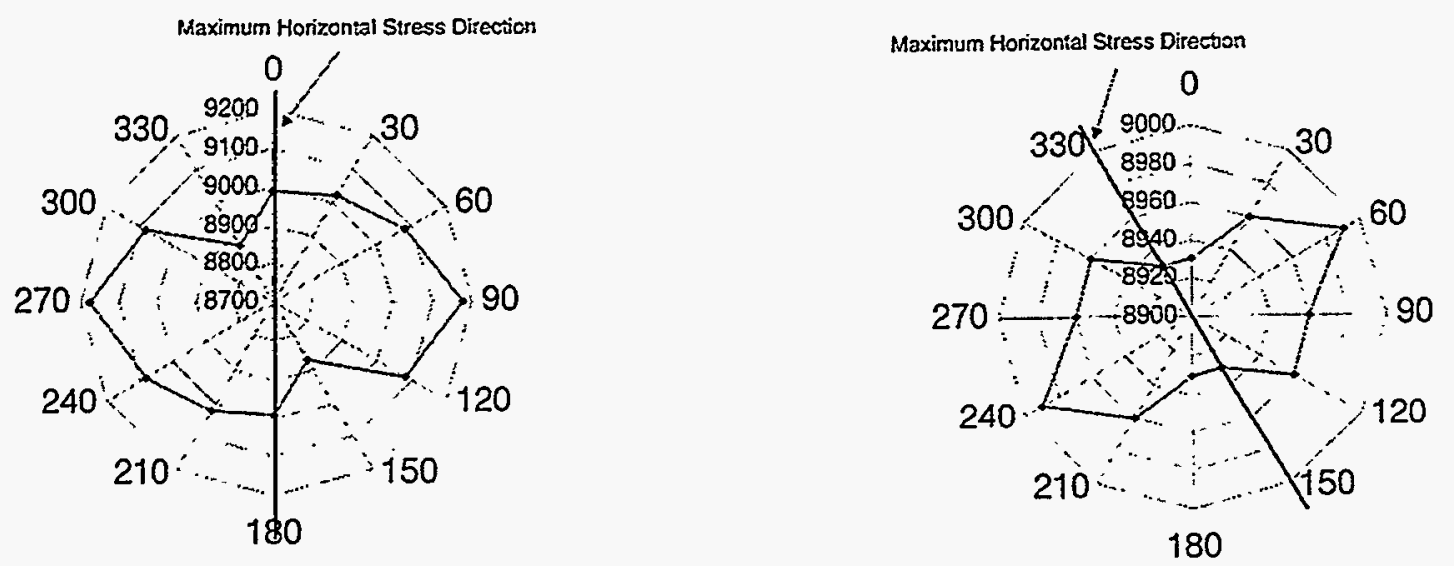

Figure 3.10. Results of the acoustic anisotropy measurements showing the maximum horizontal stress direction for each $653 \mathrm{Z}$ core sample. 


\begin{abstract}
Appendix A
Graphical Core Description, 653Z-26B

Buena Vista Hills

Karen De Louraille

Chevron Production Technology Company
\end{abstract}


CORE 1

B. V. HILLS 653Z-26B

\section{LEGEND}

$\because \because$ Sandstone

Ss (cemented)

SS/SH laminae $<0.2^{\prime \prime}$

$E=$ Shale

Dolomite

Dolomite rubble

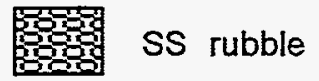

$\triangle$ No core

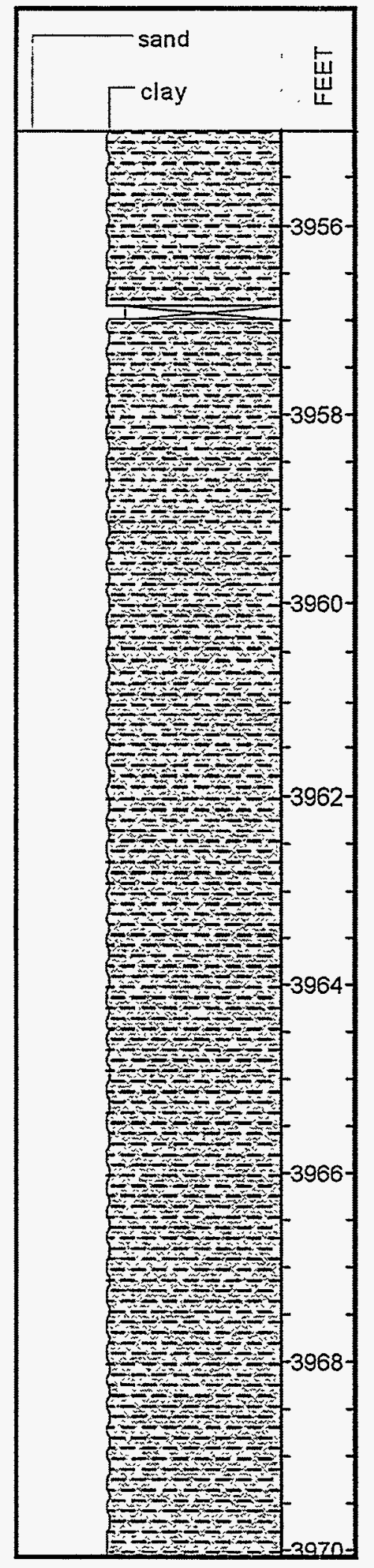


CORE 2

B. V. HILLS 653Z-26B

\section{LEGEND}

$\because \because$ Sandstone

SS (cemented)

SS/SH laminae $<0.2^{\prime \prime}$

Shale

Dolomite

Dolomite rubble

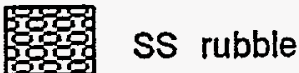

$\searrow$ No core

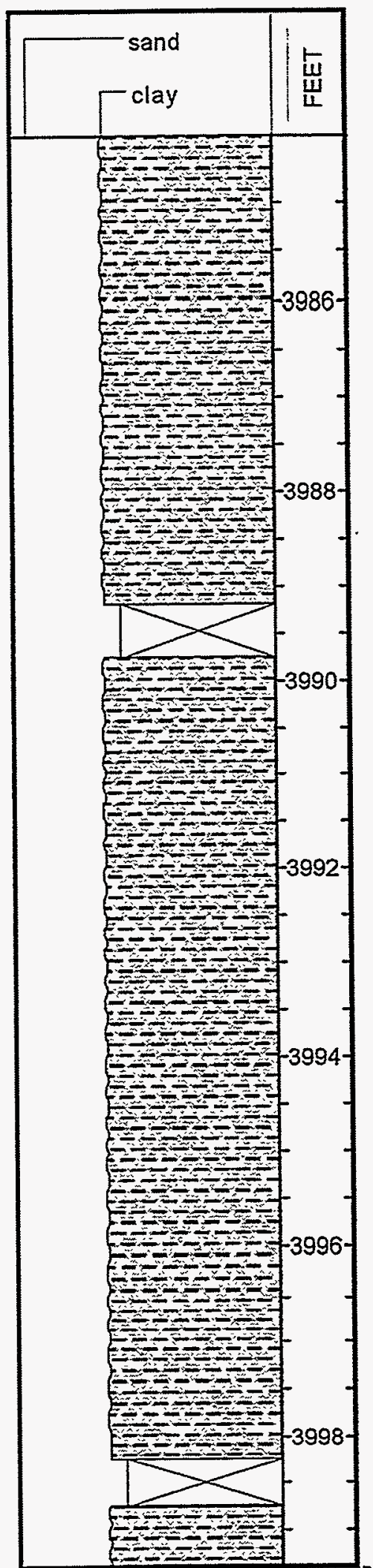

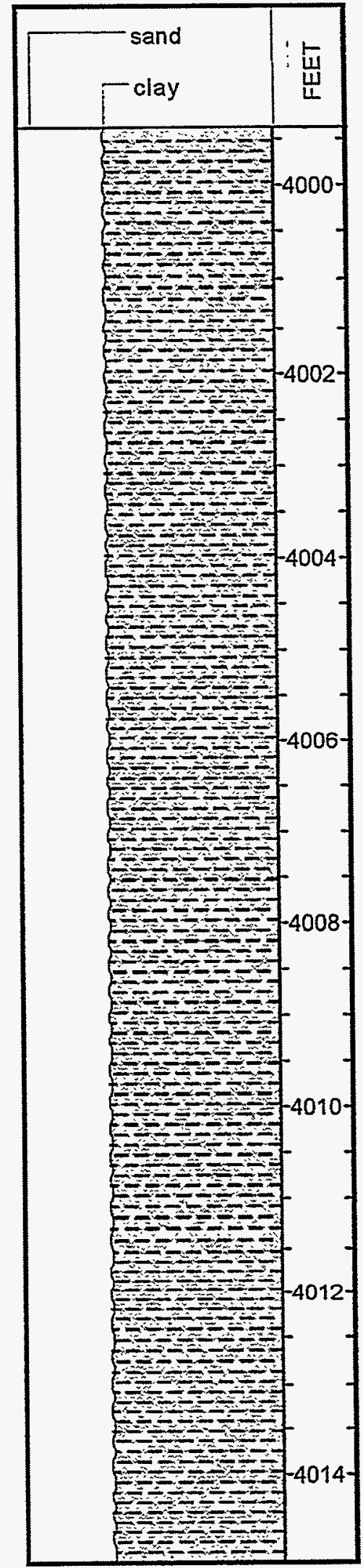


CORE 3

B. V. HILLS 653Z-26B

\section{LEGEND}

\section{$\because \because \quad$ Sandstone}

Ss (cemented)

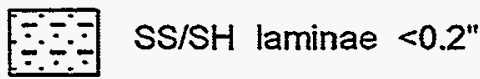

Shale
Dolomite

85: Dolomite rubble

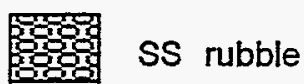

$\triangle$ No core
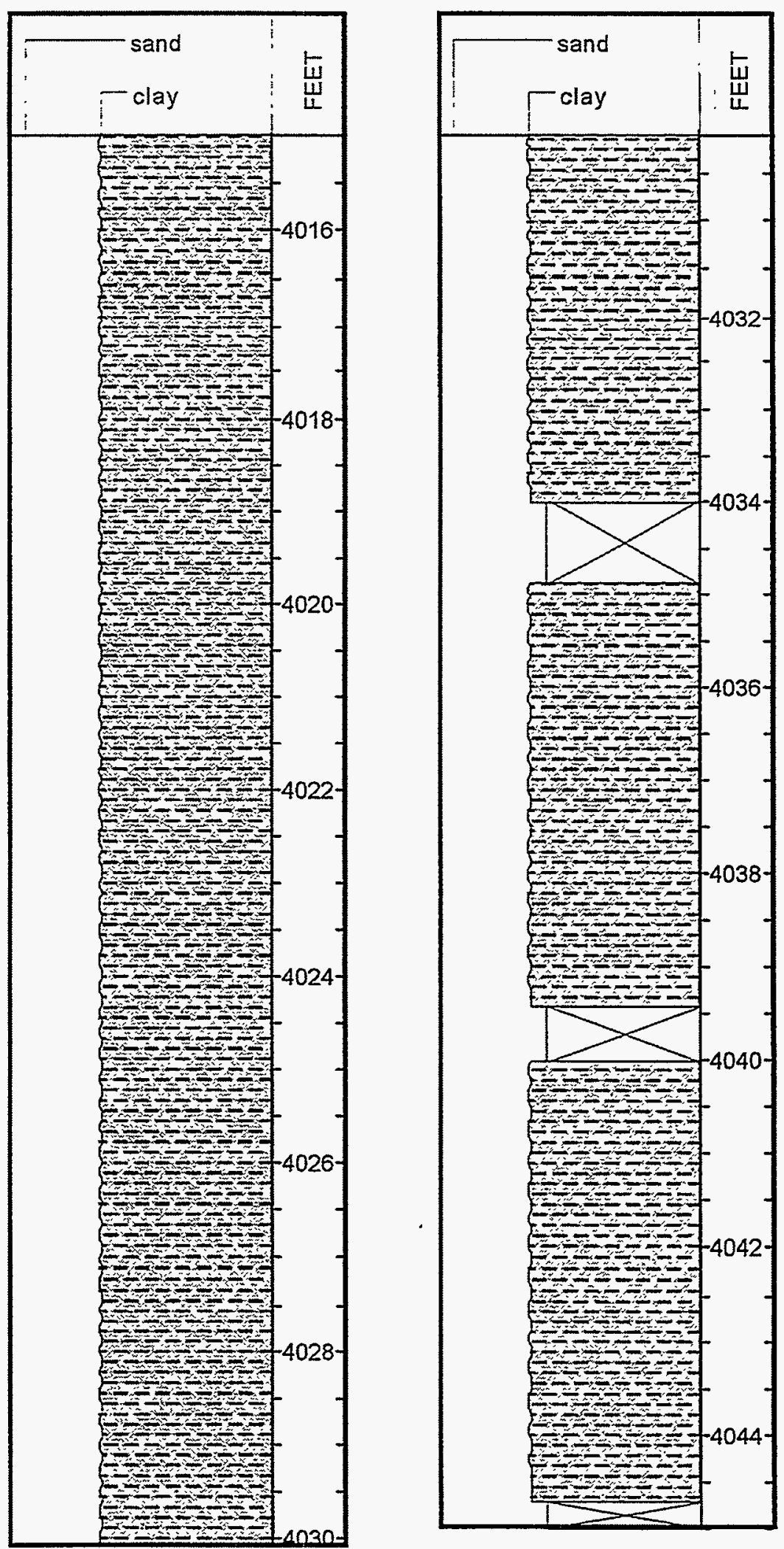
CORE 4

B. V. HILLS $653 Z-26 B$

\section{LEGEND}

$\because \because$ Sandstone

SS (cemented)

SS/SH laminae $<0.2$

$=-3$ Shale

Dolomite

69:0 Dolomite rubble

SS rubble

$\triangle$ No core

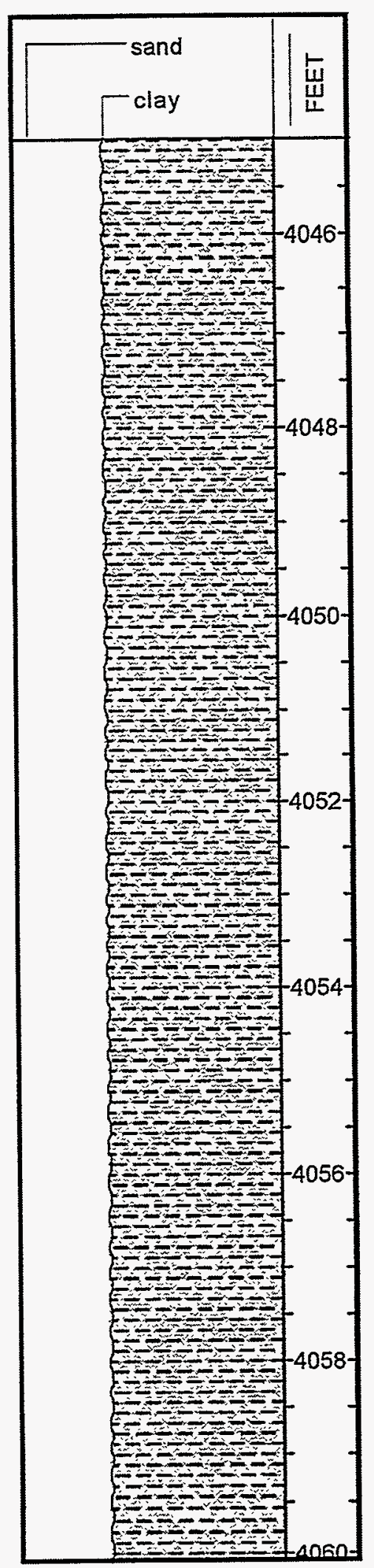

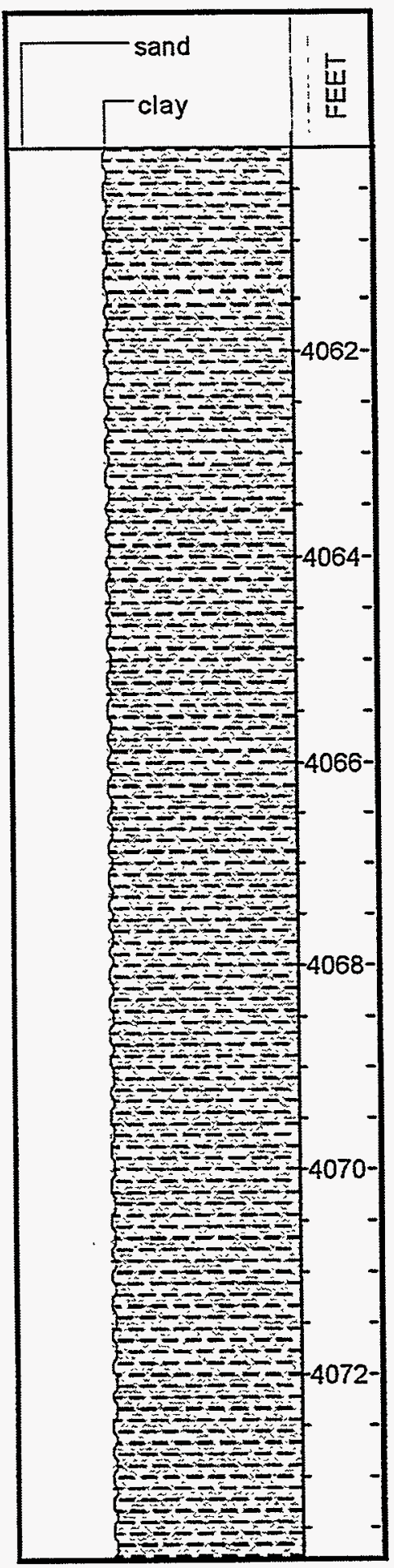


CORE 5

\section{B. V. HILLS $6532-26 B$}

\section{LEGEND}

$\because \because$ Sandstone
$\therefore$ SS (cemented)

SS/SH laminae $<0.2^{n}$

03 Shale

Dolomite

80.0 Domite rubble

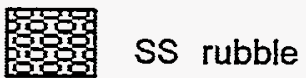

$\searrow$ No core

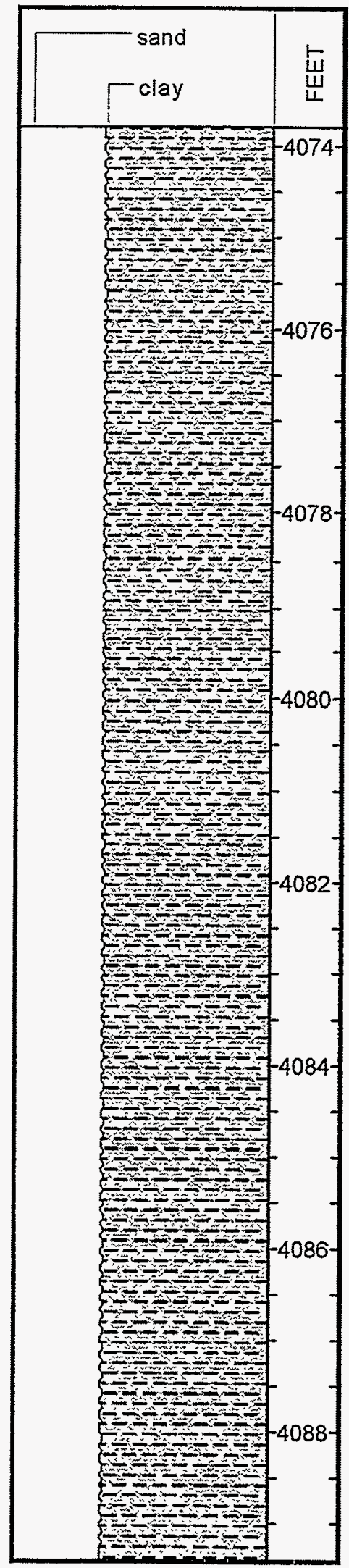


CORE 6

B. V. HILLS $653 Z-26 B$

\section{LEGEND}

$\because \because$ Sandstone

SS (cemented)

SS/SH laminae <0.2"

$E=-$ Shale

Dolomite

Dolomite rubble

ros rubble

$>$ No core

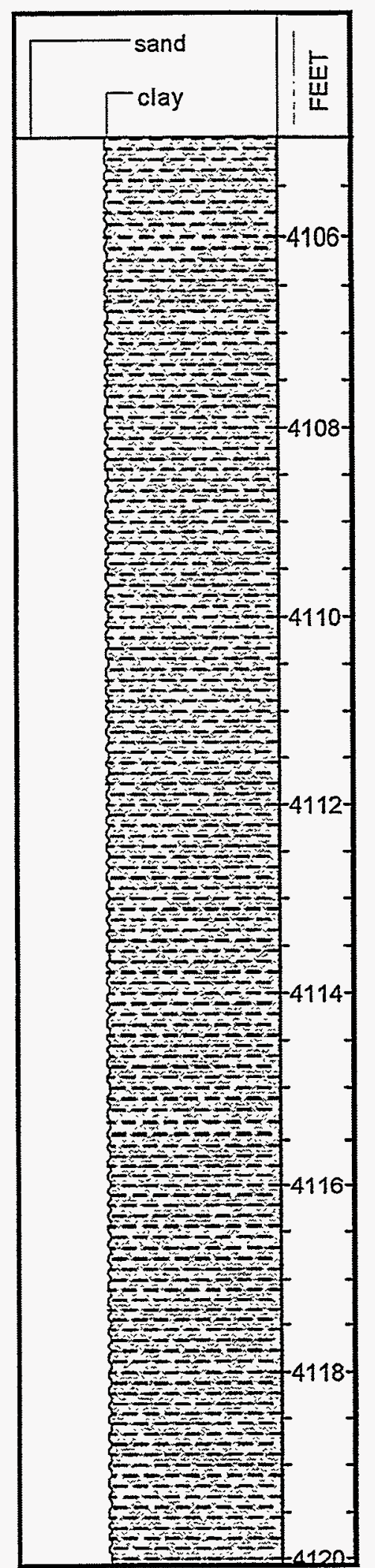


CORE 7

B. V. HILLS 653Z-26B

\section{LEGEND}

$\because \because$ Sandstone

$\therefore$ ss (cemented)

:- $\mathrm{SS} / \mathrm{SH}$ laminae $<0.2$

Shale

Dolomite

Dolomite rubble

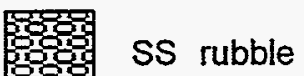

$\searrow$ No core
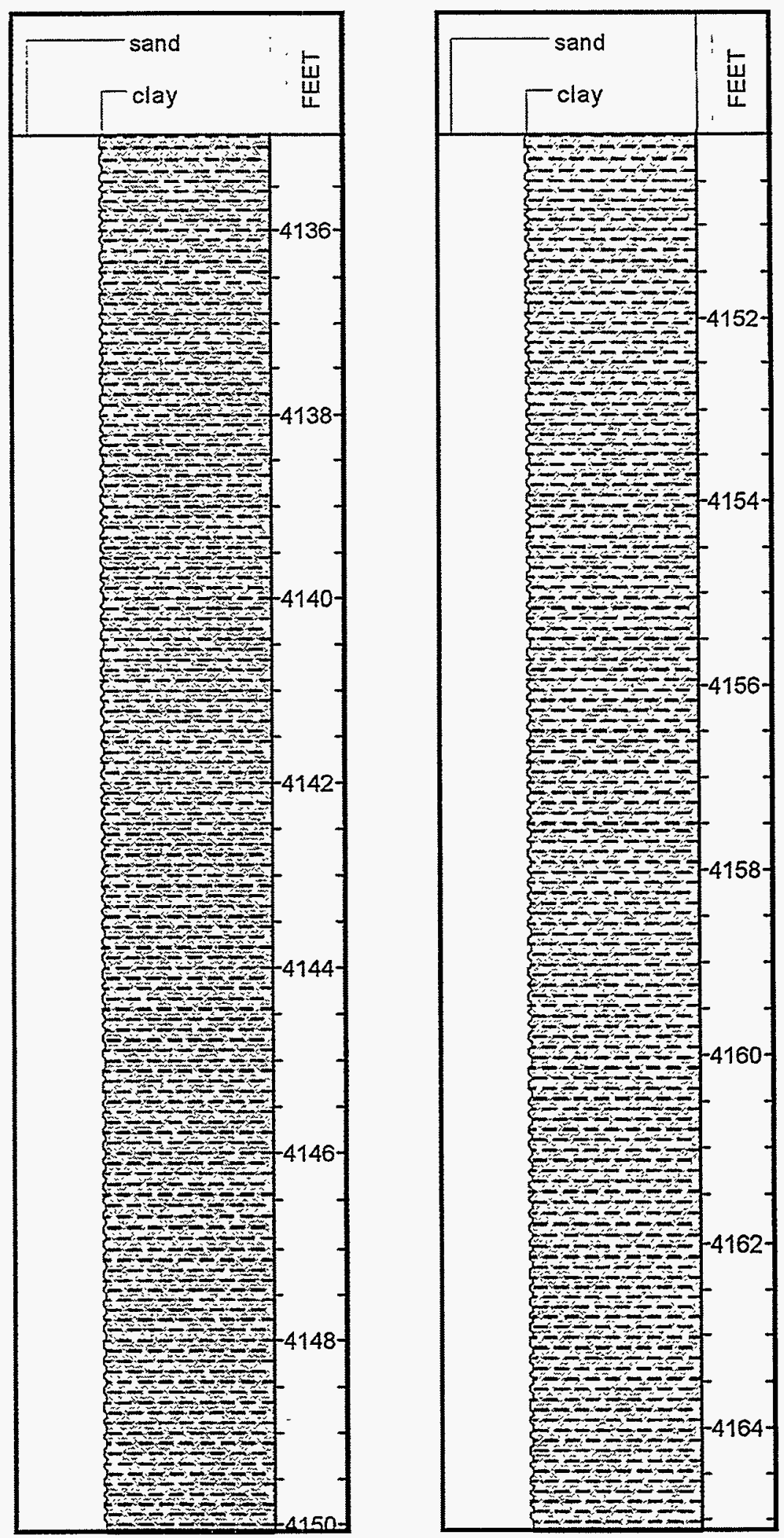
CORE 8

B. V. HILLS 653Z-26B

\section{LEGEND}

$\because \because$ Sandstone

Ss (cemented)

SS/SH laminae $<0.2^{n}$

Shale

Dolomite

60: Dolomite rubble

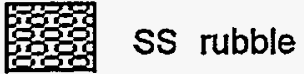

$\searrow$ No core

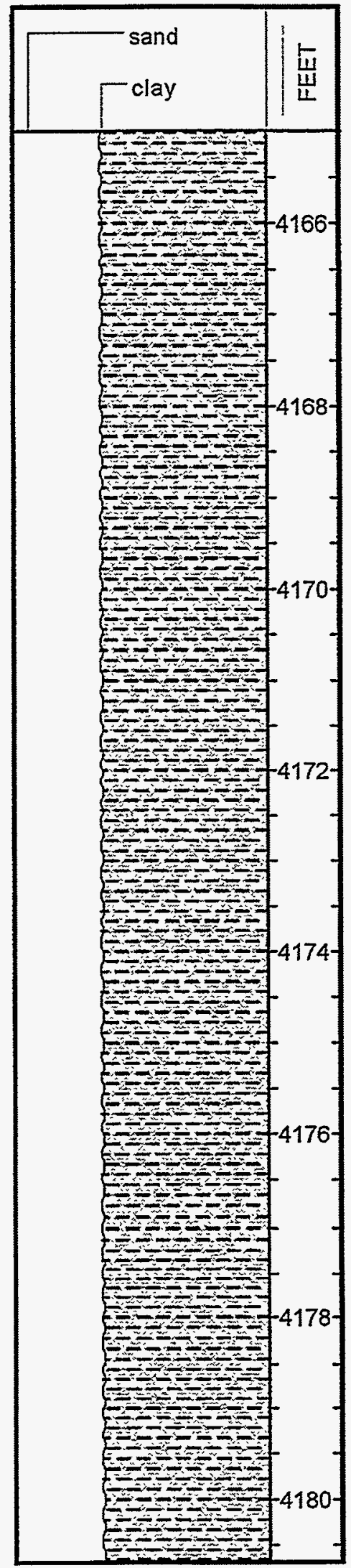


CORE 9

\section{B. V. HILLS 653Z-26B}

\section{LEGEND}

$\because \because$ Sandstone

: ss (cemented)

SS/SH laminae $<0.2^{n}$

Shale
Dolomite

89: Dolomite rubble

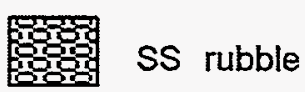

$\triangle$ No core

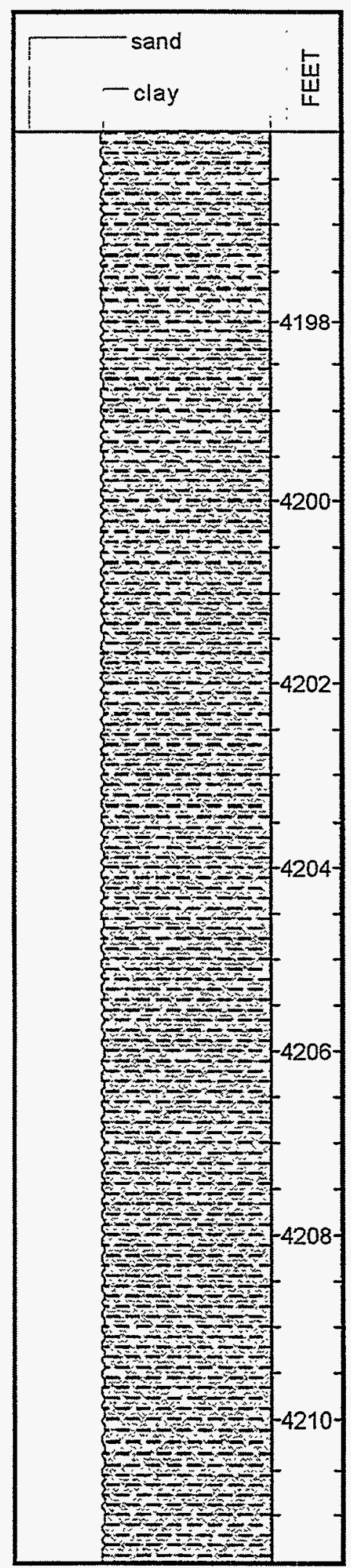


CORE 10

B. V. HILLS 653Z-26B

\section{LEGEND}

$\because \because$ Sandstone

ss (cemented)

SS/SH laminae $<0.2^{\prime \prime}$

$E=$

Dolomite

60: Dolomite rubble

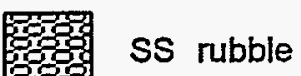

$\triangle$ No core

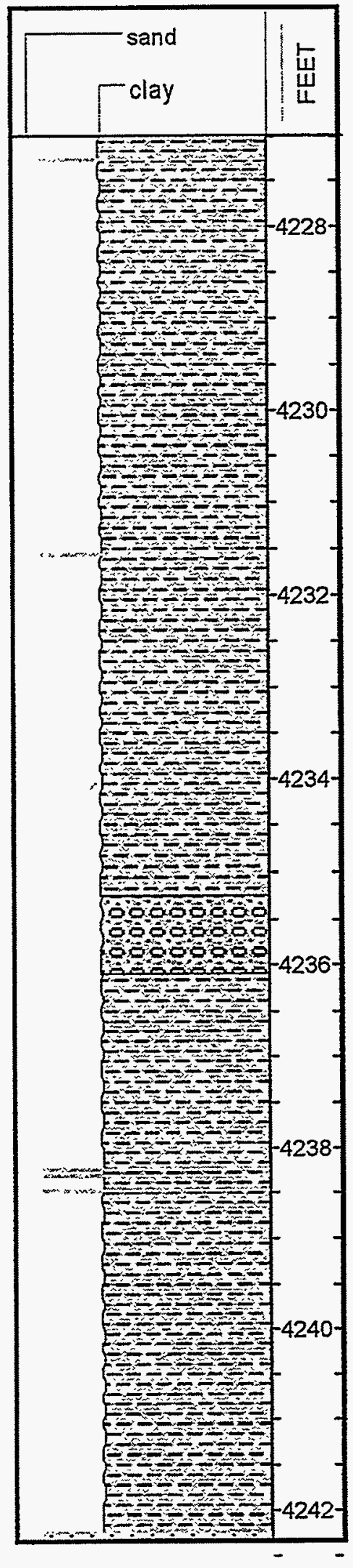

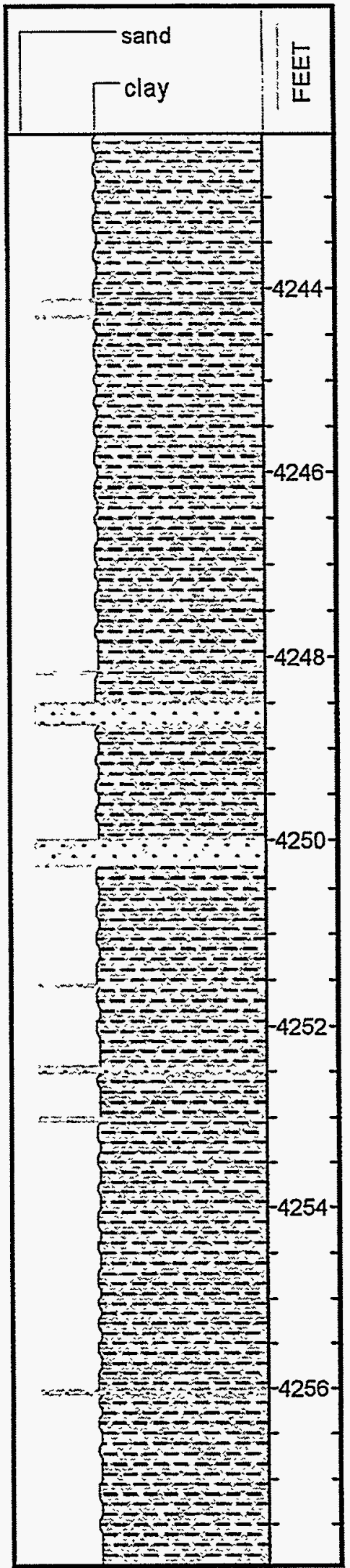


CORE 11

B. V. HILLS $653 Z-26 B$

LEGEND

$\because \because$ Sandstone

$\because \because$ SS (cemented)

SS/SH laminae $<0.2^{\prime \prime}$

$=$ Shale

Dolomite

S0: Dolomite rubble

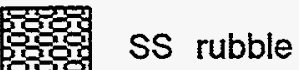

$\triangle$ No core

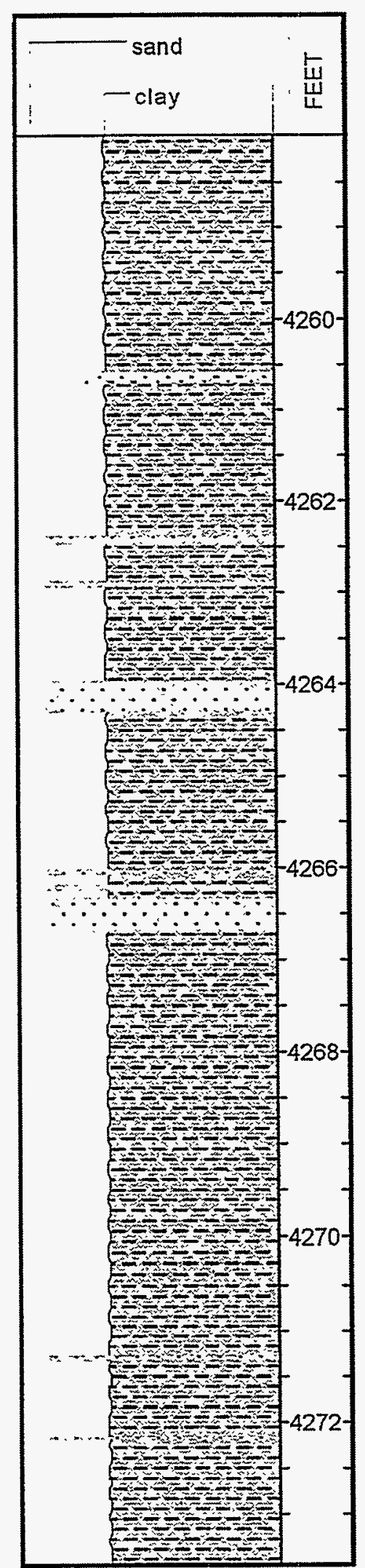


CORE 12

B. V. HILLS 653Z-26B

\section{LEGEND}

$\because \because$ Sandstone

SS (cemented)

SS/SH laminae $<0.2^{\prime \prime}$

$E=$ Shale

Dolomite

Dolomite rubble

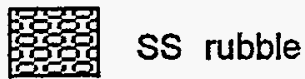

$\triangle$ No core

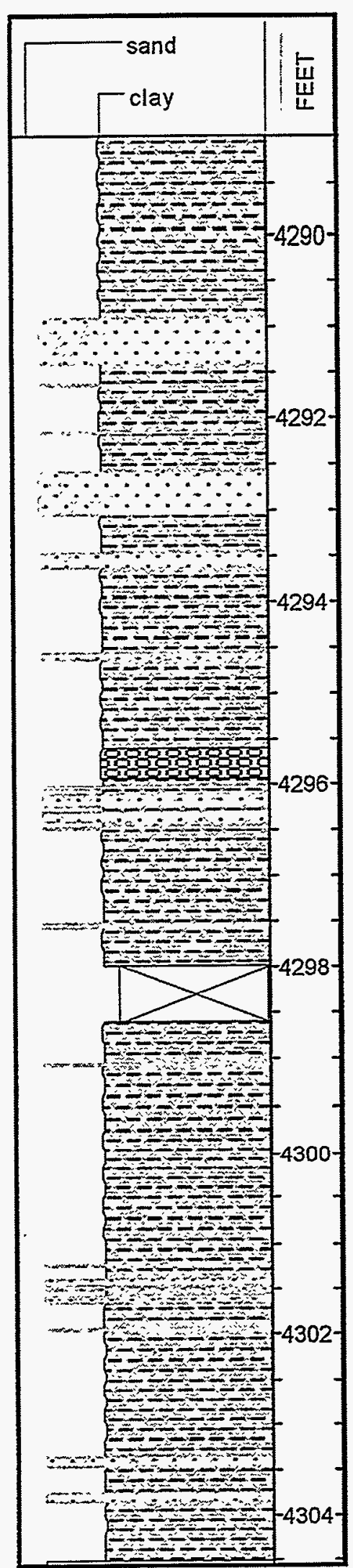


CORE 13

B. V. HILLS $653 Z-26 B$

LEGEND

$\therefore \quad$ Sandstone

Ss (cemented)

SS/SH laminae $<0.2^{\prime \prime}$

$E=3$ Shale

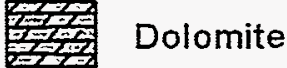

809 Dolomite rubble

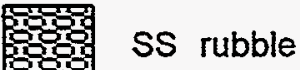

$\triangle$ No core

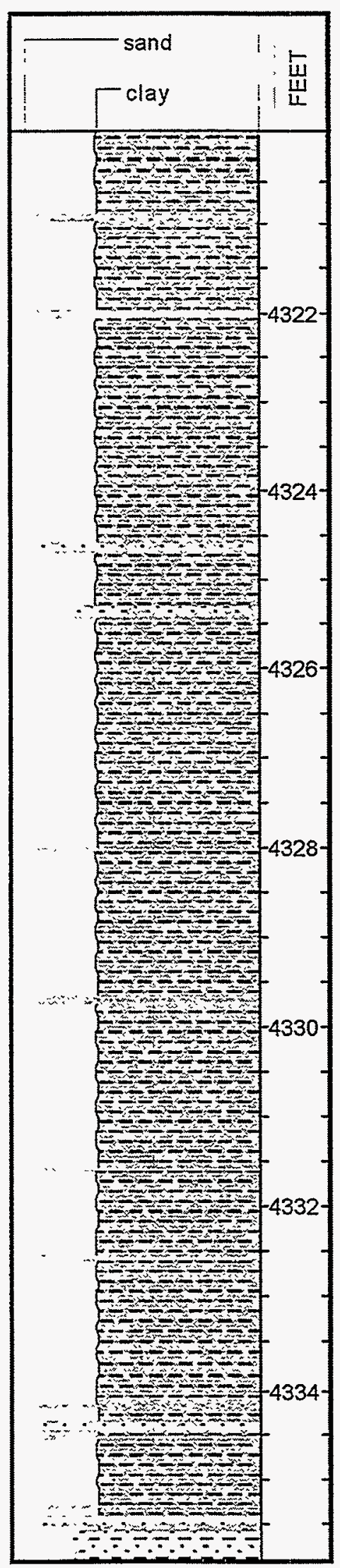


CORE 14

B. V. HILLS $653 Z-26 B$

LEGEND

$\because \because \because$ Sandstone
$\therefore \because$ SS (cemented)

SS/SH laminae $<0.2^{\prime \prime}$

$E=$ shale

Dolomite

Dolomite rubble

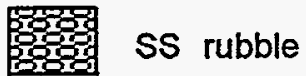

$>$ No core
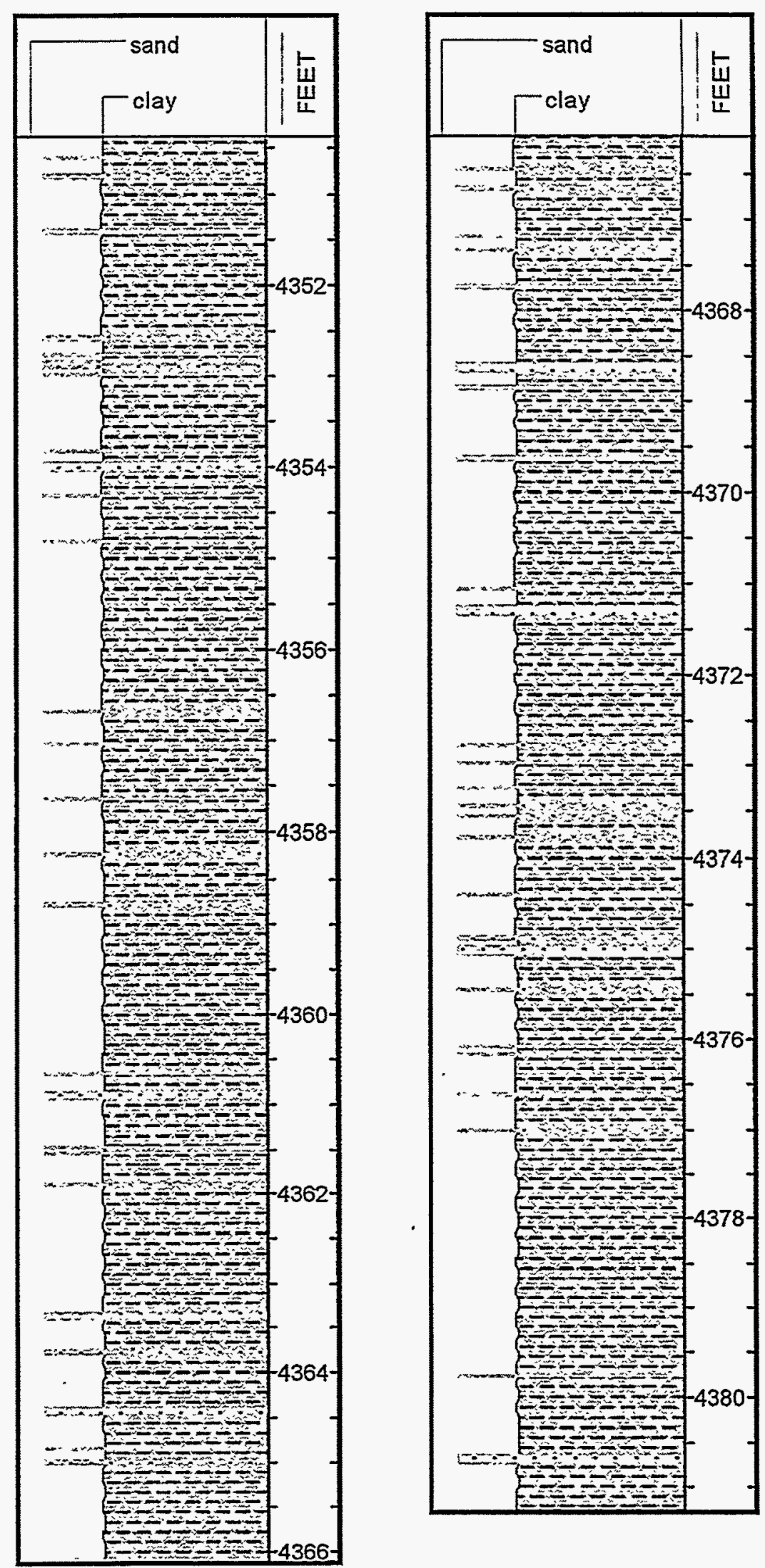
CORE 15

B. V. HILLS $653 Z-26 B$

LEGEND

$\because \because$ Sandstone

Ss (cemented)

$\left[\begin{array}{ll}0 \\ 0\end{array}\right.$

Shale

Dolomite

85: Dolomite rubble

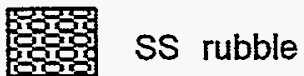

$\searrow$ No core

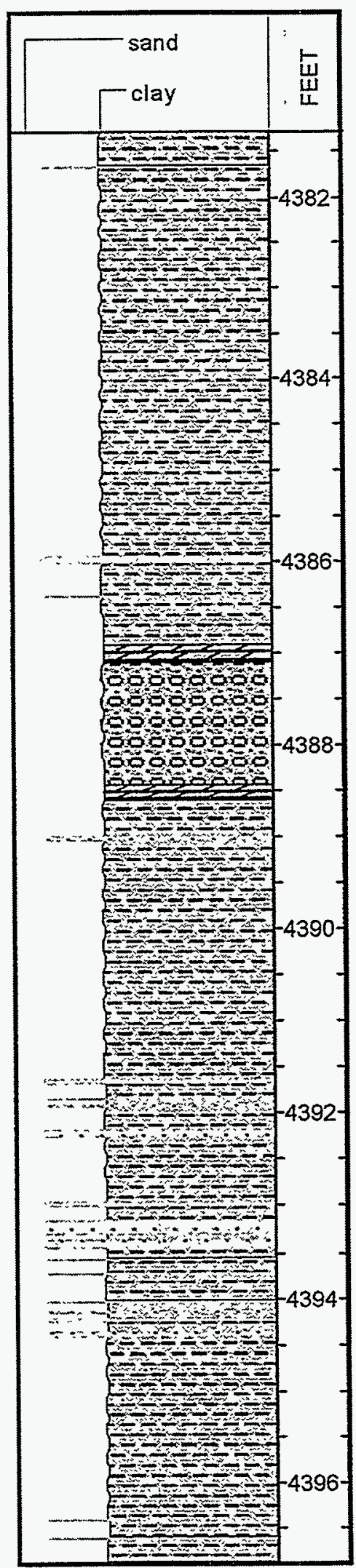

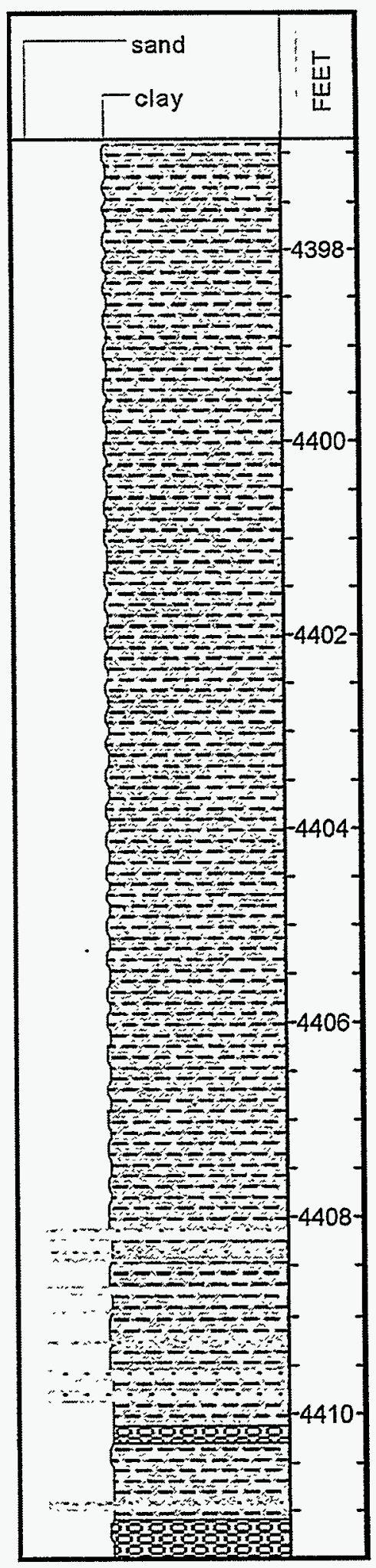


CORE 16

B. V. HILLS 653Z-26B

\section{LEGEND}

\section{$\because \because$ Sandstone}

Ss (cemented)

$\mathrm{SS} / \mathrm{SH}$ laminae $<0.2^{\prime \prime}$

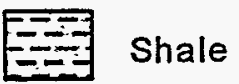

Dolomite

Dolomite rubble

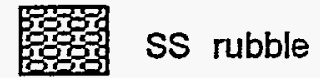

$\triangle$ No core
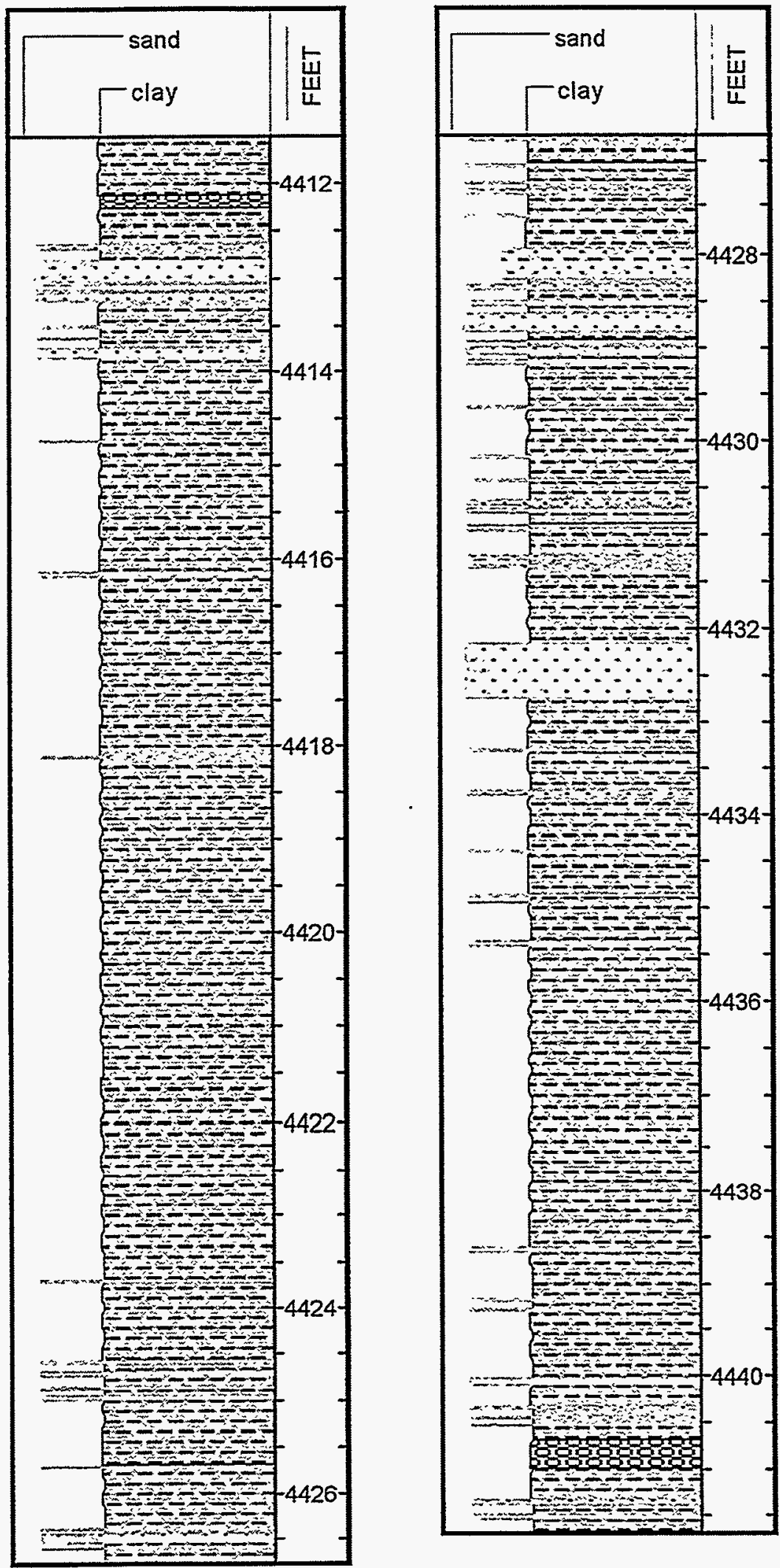
CORE 17

B. V. HILLS $653 Z-26 B$

LEGEND

$\because \because \quad$ Sandstone

$\because \quad$ SS (cemented)

SS/SH laminae $<0.2$

Shale

Dolomite

5olomite rubble

SS rubble

$\triangle$ No core

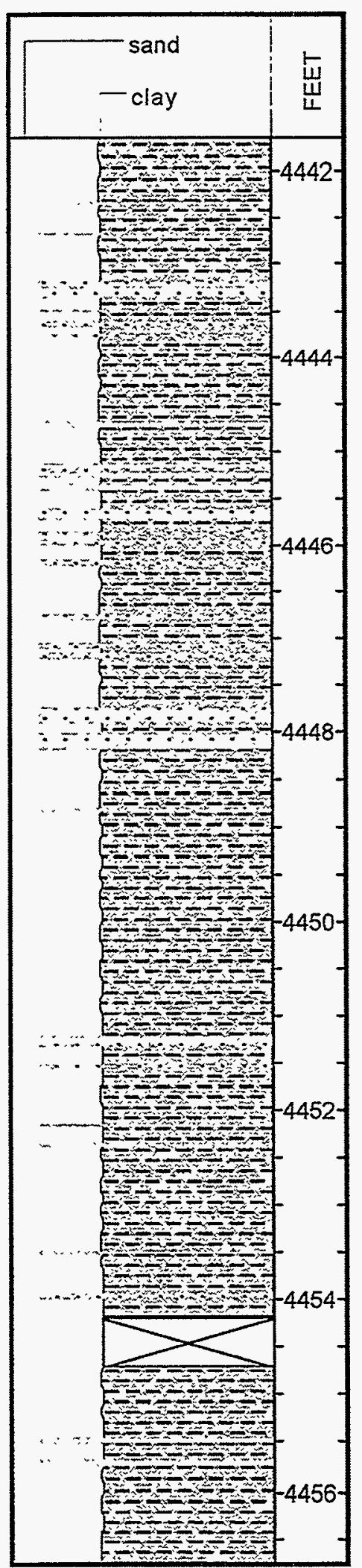


CORE 18

B. V. HILLS 653Z-26B

\section{LEGEND}

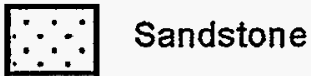

SS (cemented)

SS/SH laminae $<0.2$

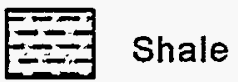

Dolomite

Dolomite rubble

庭得

$\triangle$ No core

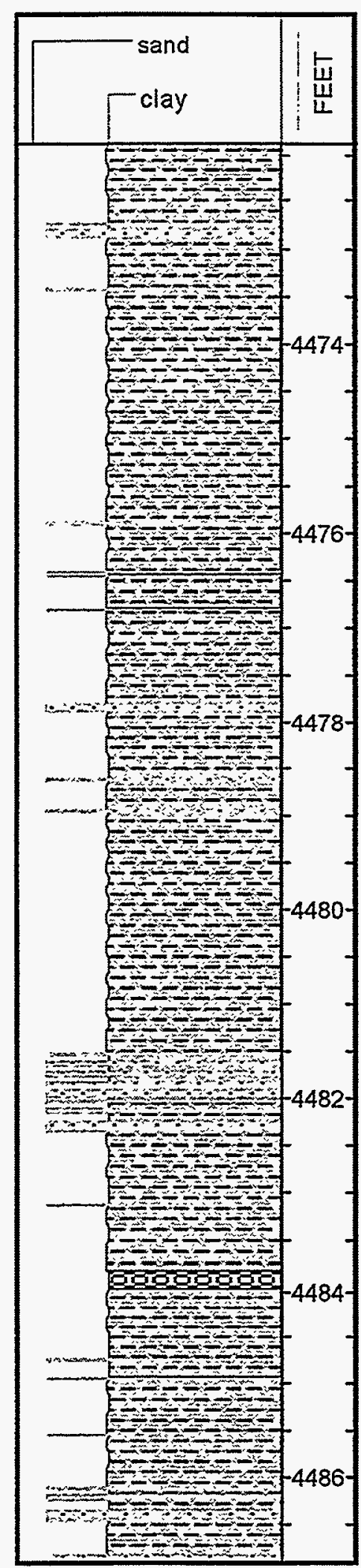


CORE 19

B. V. HILLS 653Z-26B

LEGEND

$\because \because \quad$ Sandstone

$\because$ SS (cemented)

SSISH laminae $<0.2^{\prime \prime}$

Shale

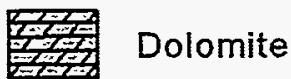

80: Dolomite rubble

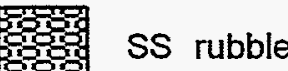

$\triangle$ No core

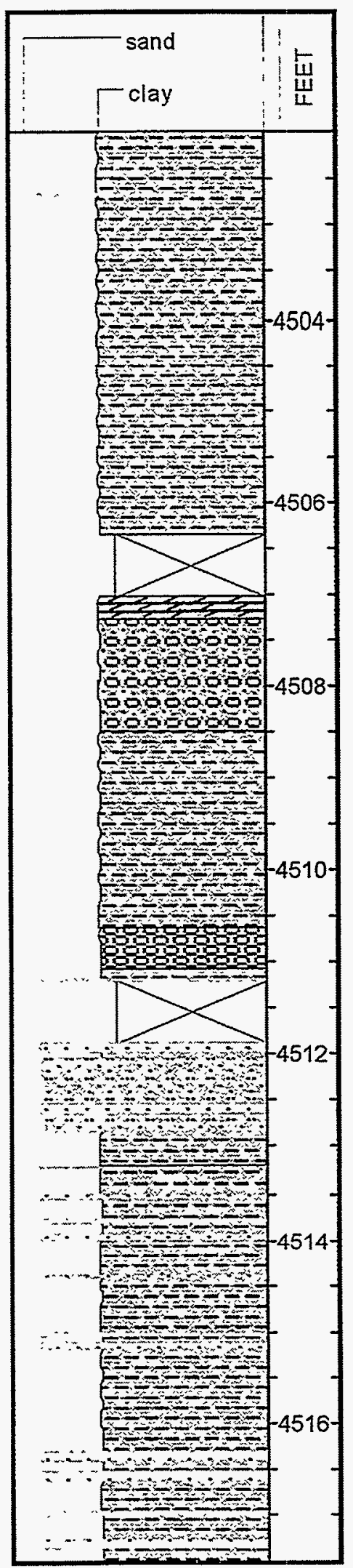


CORE 20

B. V. HILLS 653Z-26B

\section{LEGEND}

$\therefore \because$ Sandstone

ss (cemented)

SS/SH laminae $<0.2^{\prime \prime}$

$E=-$ shale

Dolomite

영영 Dolomite rubble

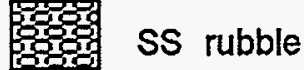

$\triangle$ No core

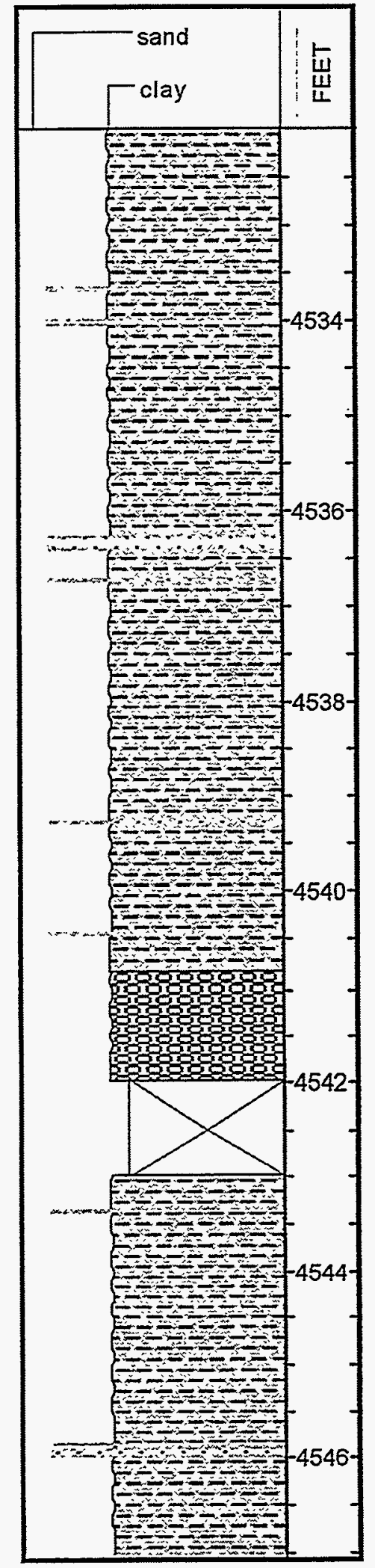

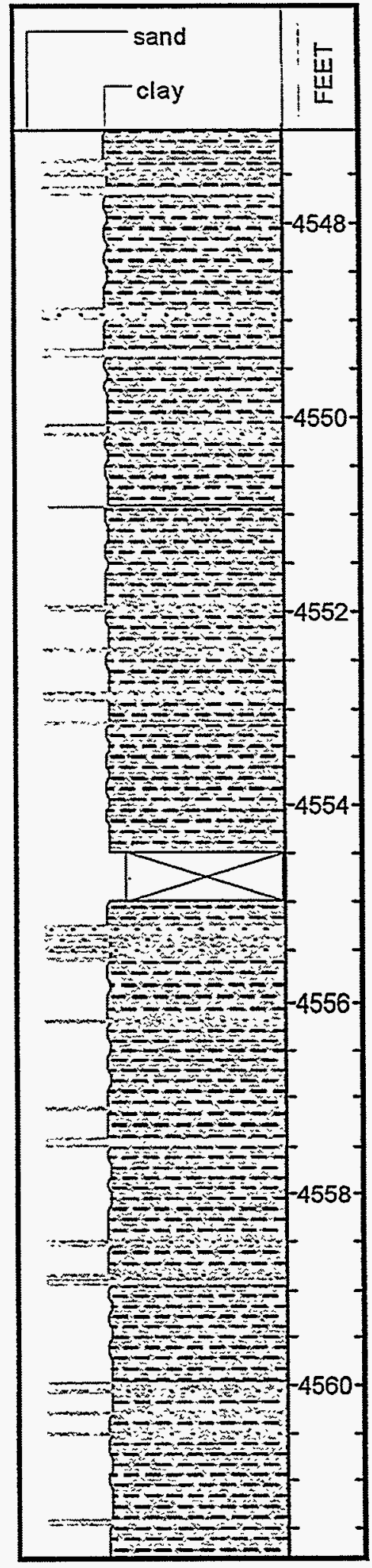


CORE 21

B. V. HILLS $653 Z-26 B$

\section{LEGEND}

$\because \because$ Sandstone

$\therefore$ ss (cemented)

SS/SH laminae $<0.2^{\prime \prime}$

Shale

Dolomite

80: Dolomite rubble

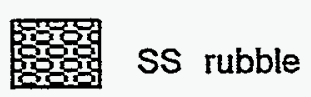

$\triangle$ No core

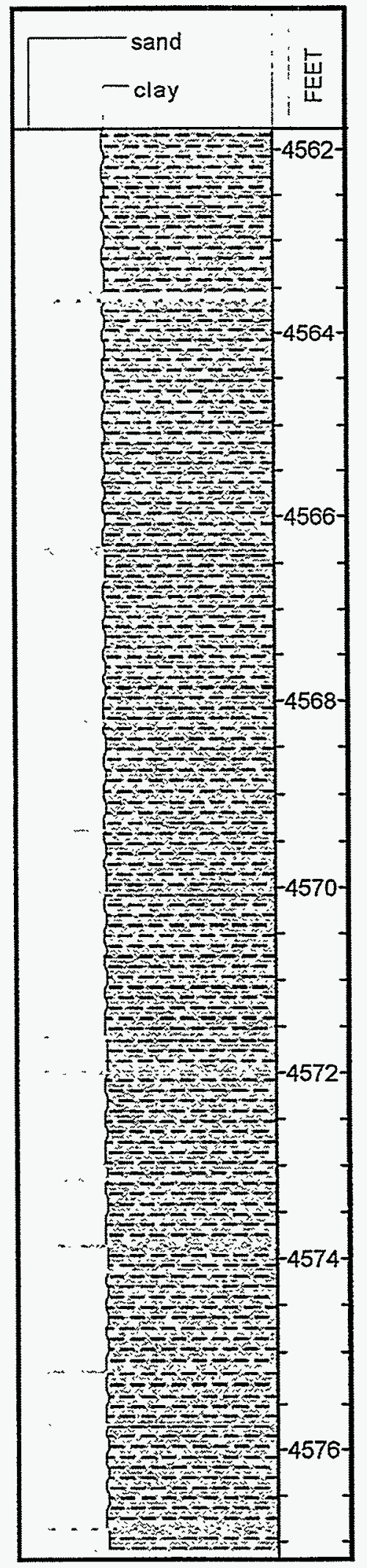


CORE 22

B. V. HILLS $653 Z-26 B$

\section{LEGEND}

$\because \because \quad$ Sandstone

SS (cemented)

$\therefore$ SS/SH laminae $<0.2^{\prime \prime}$

E= Shale

Dolomite

80.0mite rubble

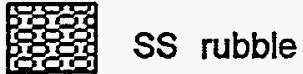

$\searrow$ No core

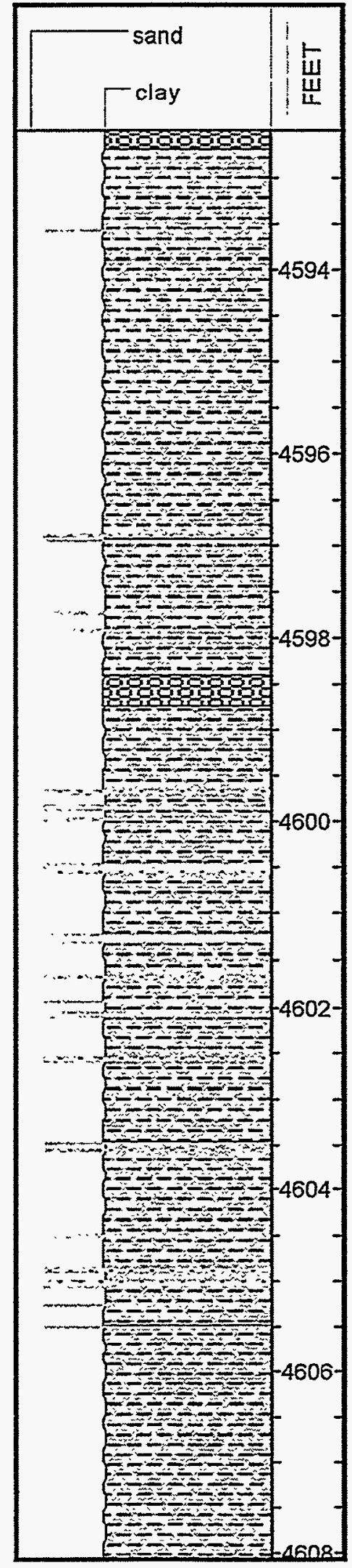

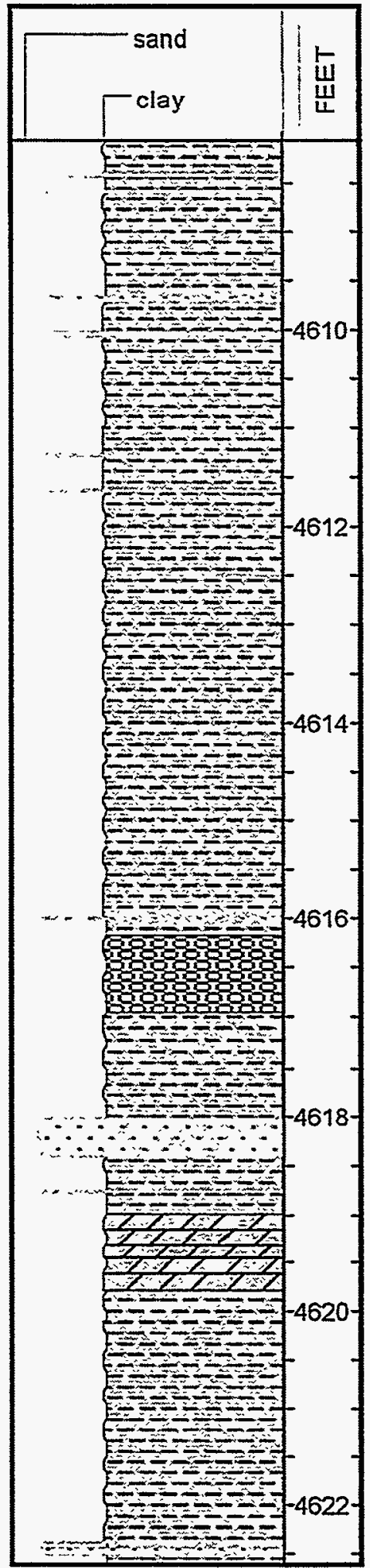




\section{CORE 23}

\section{B. V. HILLS 653Z-26B}

\section{LEGEND}

$\because \because$ Sandstone

$\because \because$ Ss (cemented)

SS/SH laminae $<0.2^{\prime \prime}$

$=3$ Shale

济 Dolomite

89: Dolomite rubble

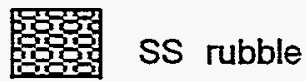

$\triangle$ No core

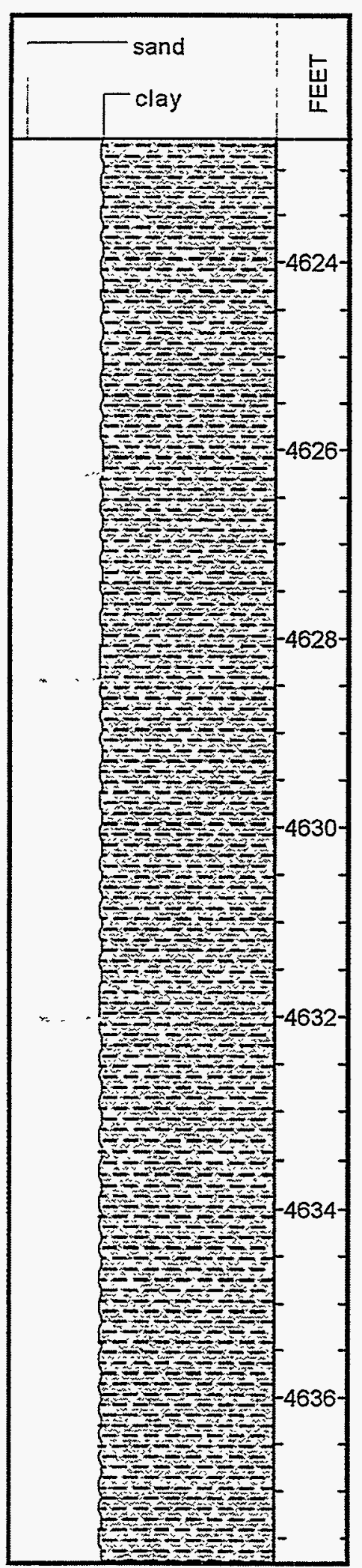


CORE 24

B. V. HILLS 653Z-26B

\section{LEGEND}

$\because \because$ Sandstone

SS (cemented)

SS/SH laminae $<0.2^{\prime \prime}$

$=-3$ Shale

Dolomite

Dolomite rubble

Prof SS rubble

$\triangle$ No core

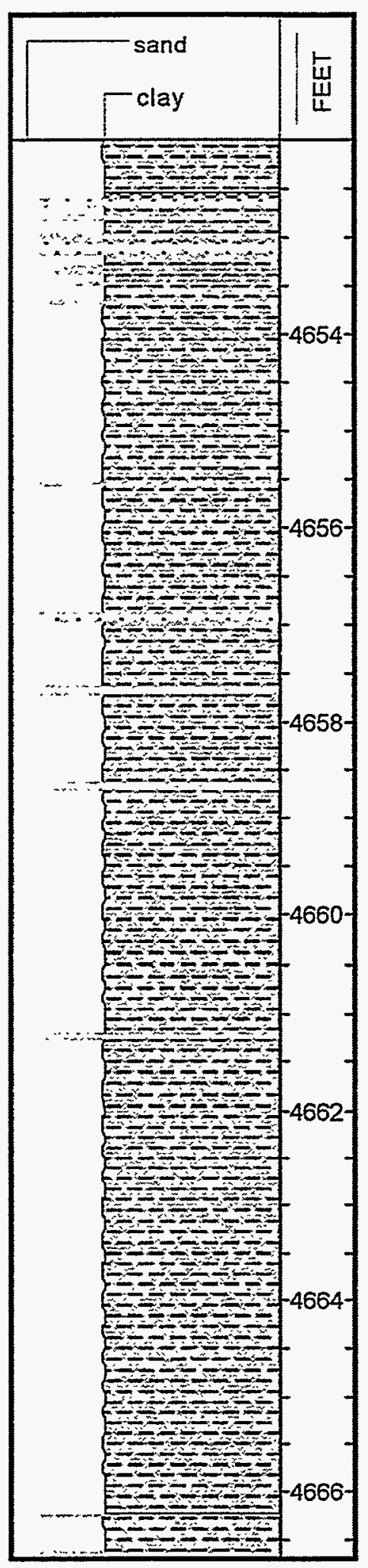

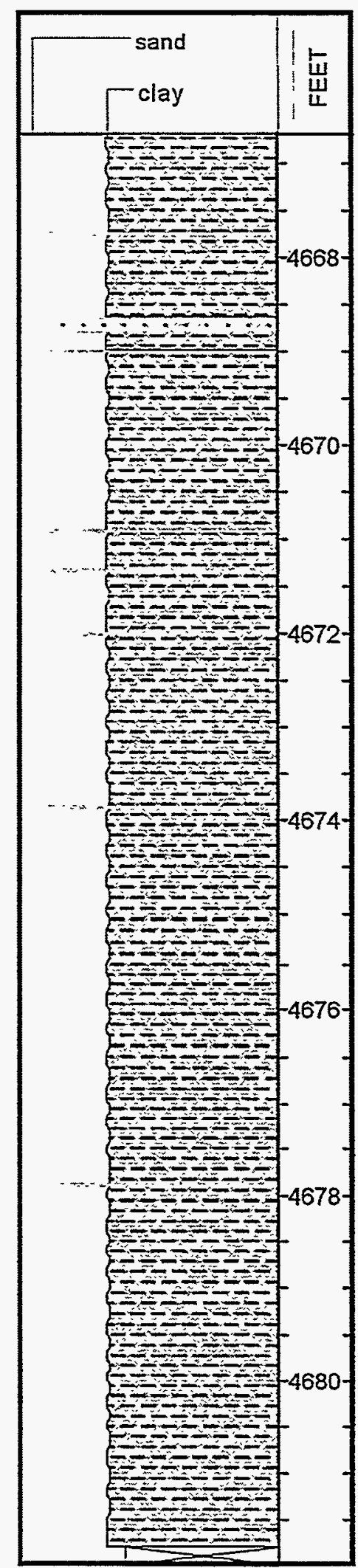


CORE 25

B. V. HILLS $653 Z-26 B$

LEGEND

$\because \because$ Sandstone

$\because \because$ SS (cemented)

SS/SH laminae $<0.2$

Shale

焉窗

Fo: Dolomite rubble

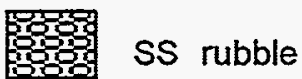

$\triangle$ No core

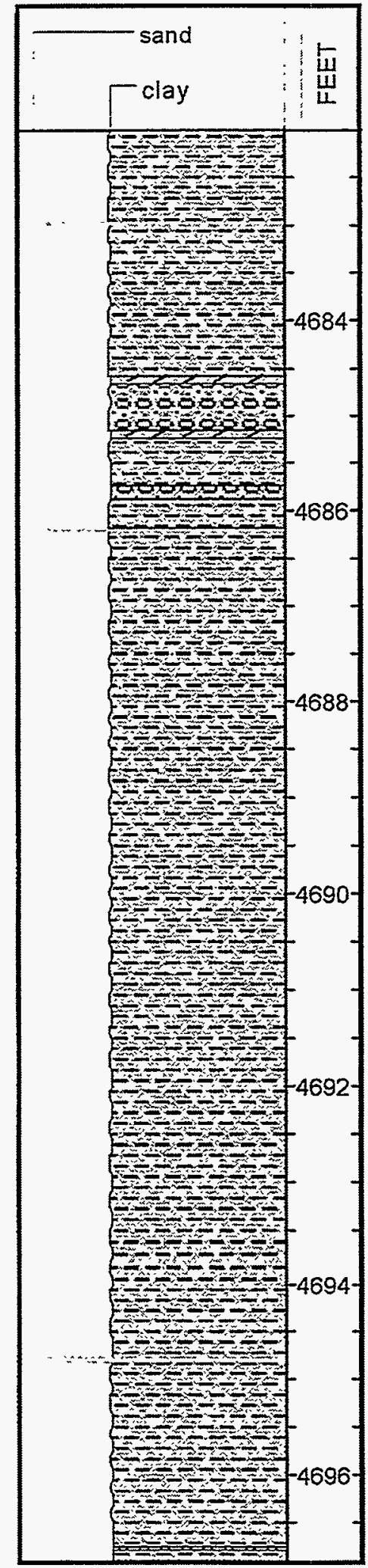


CORE 26

B. V. HILLS 653Z-26B

\section{LEGEND}

$\because \therefore$ Sandstone

SS (cemented)

SS/SH laminae $<0.2$

$E=-9$ Shale

Dolomite

Dolomite rubble

SS rubble

$\searrow$ No core

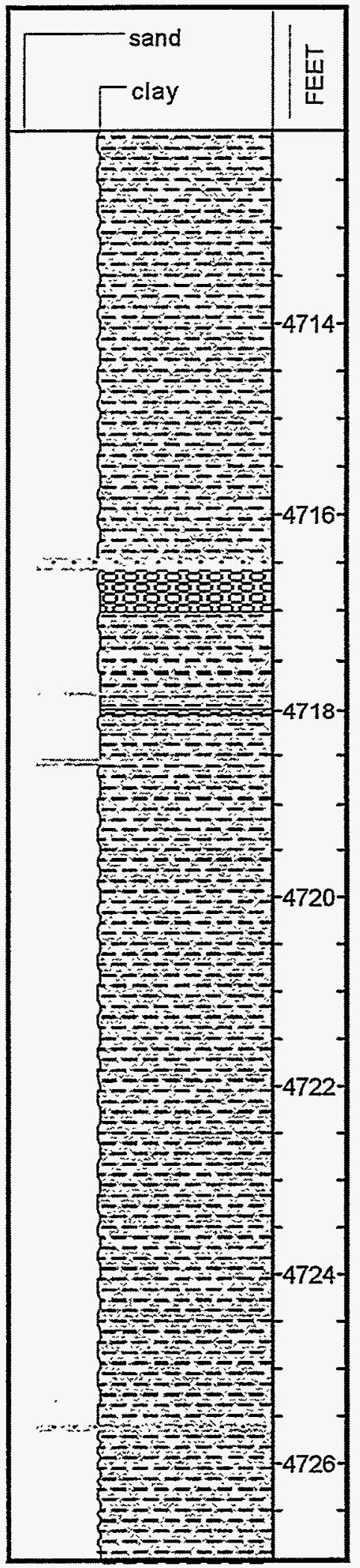


CORE 27

B. V. HILLS $653 Z-26 B$

LEGEND

$\because \because$ Sandstone

ss (cemented)

SS/SH laminae $<0.2^{\prime \prime}$

Shale

Dolomite

50: Dolomite rubble

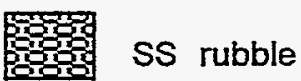

$\triangle$ No core
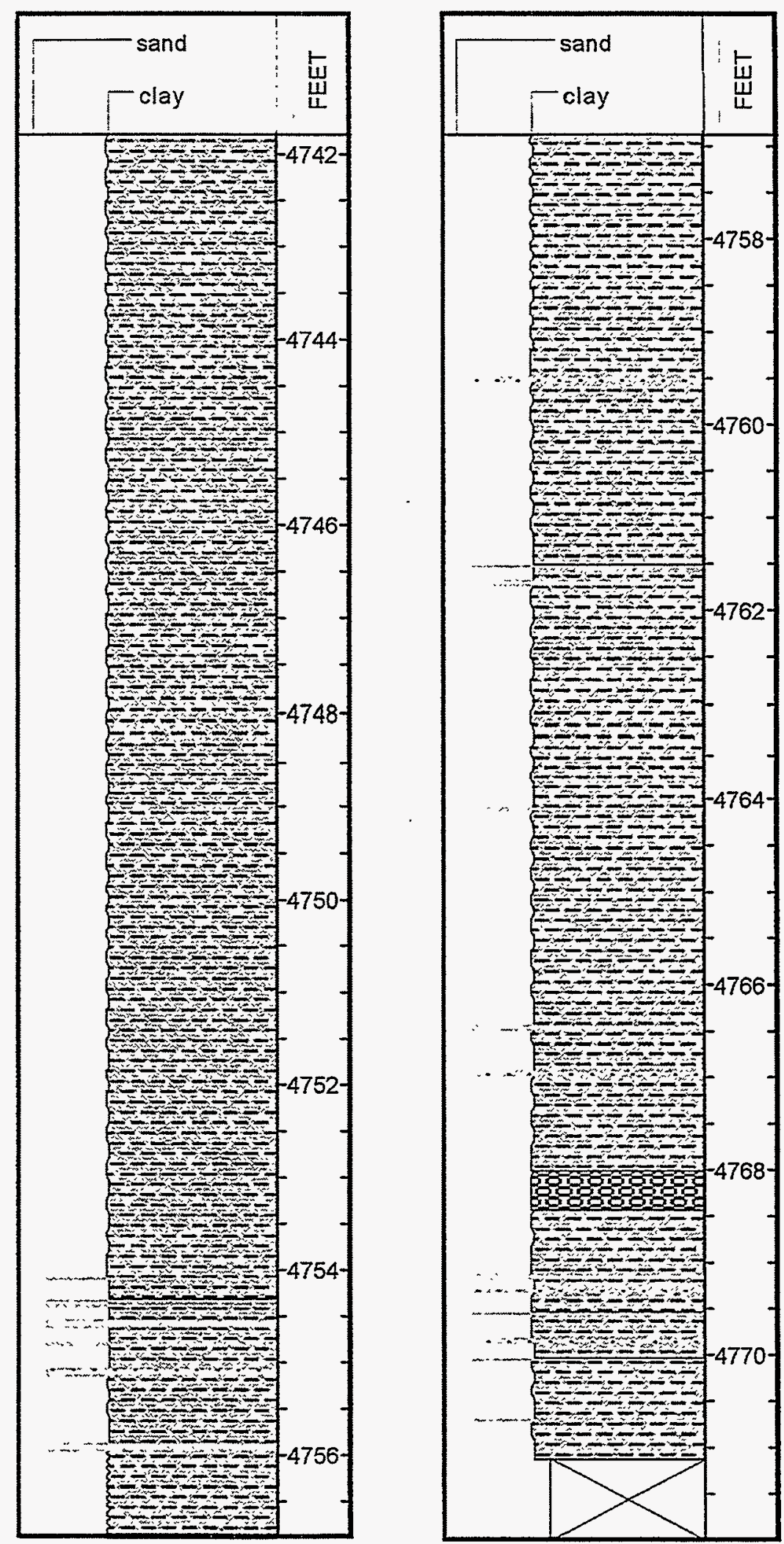
CORE 28

B. V. HILLS $653 Z-26 B$

LEGEND

$\because \because$ Sandstone

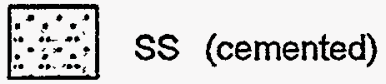

SS/SH laminae <0.2"

$E=-3$ Shale

Dolomite

\%g Dolomite rubble

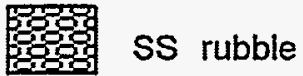

$\triangle$ No core

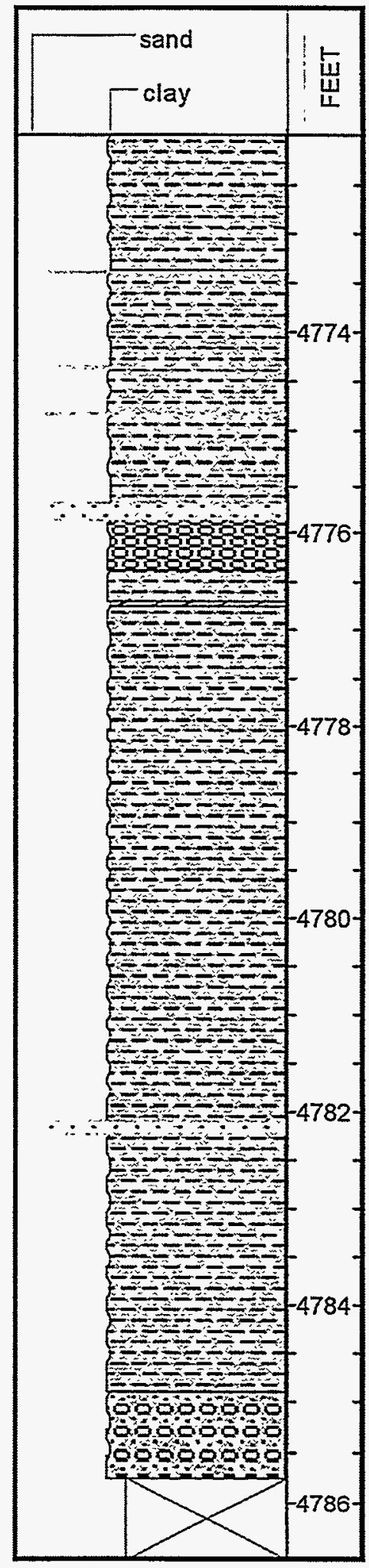


CORE 29

B. V. HILLS $653 Z-26 B$

\section{LEGEND}

$\because \because$ Sandstone

$\because \because$ Ss (cemented)

SS/SH laminae $<0.2^{\prime \prime}$

Shale

Dolomite

5olomite rubble

Fo영 ss rubble

$\triangle$ No core

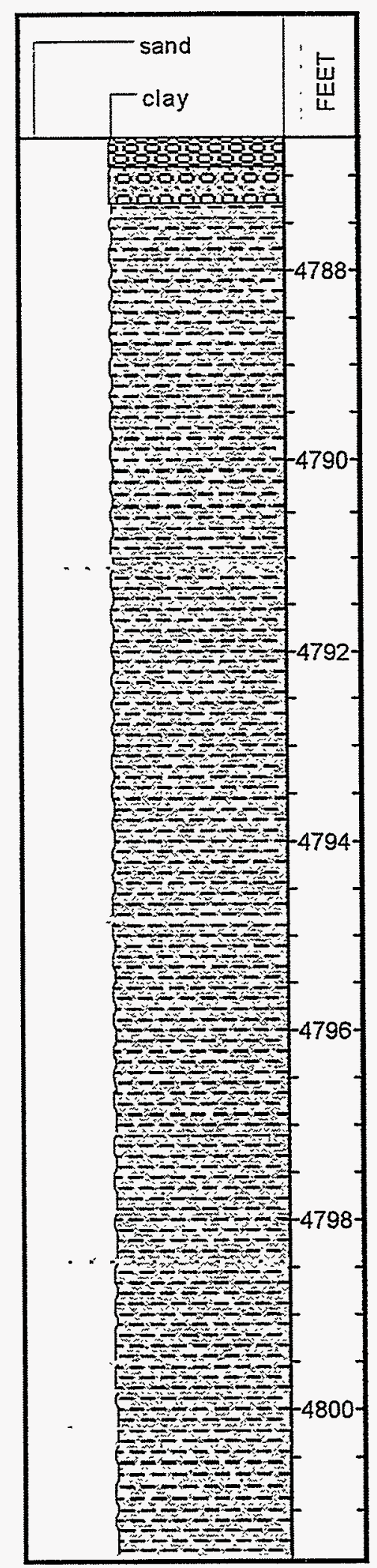

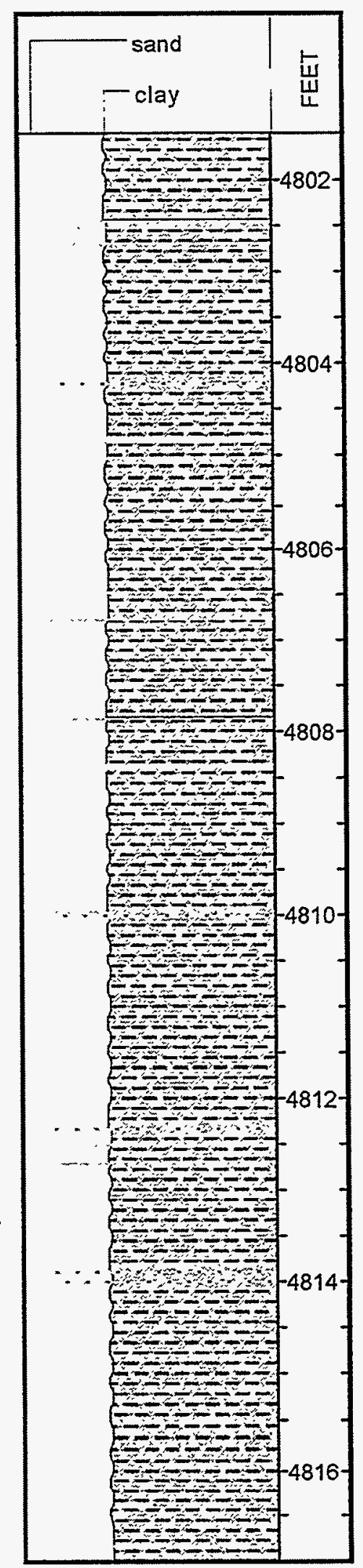


CORE 30

\section{B. V. HILLS 653Z-26B}

\section{LEGEND}

$\because \because$ Sandstone

Ss (cemented)

SS/SH laminae $<0.2^{\prime \prime}$

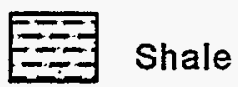

Dolomite

Dolomite rubble

履得圈 Ss rubble

$\triangle$ No core
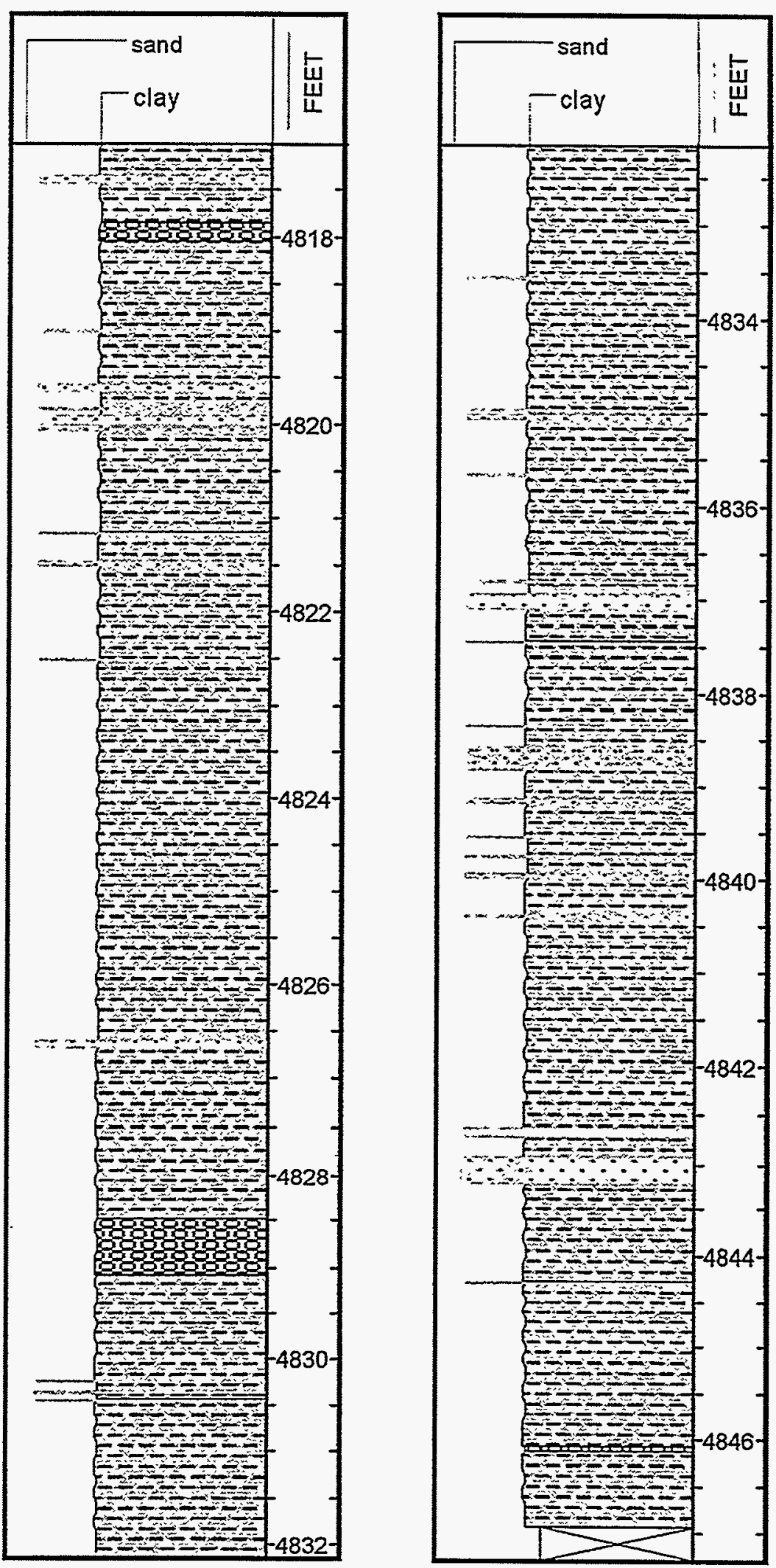
CORE 31

B. V. HILLS $653 Z-26 B$

\section{LEGEND}

$\because \because$ Sandstone

Ss (cemented)

SS/SH laminae $<0.2^{\prime \prime}$

Shale

Dolomite

80: Dolomite rubble

Fs rubble

$\triangle$ No core

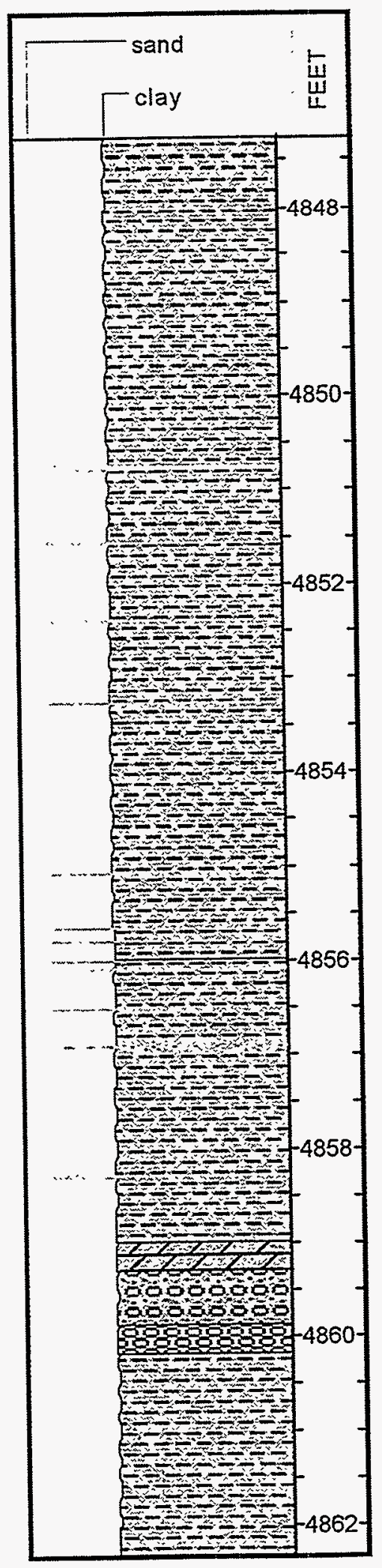


CORE 32

B. V. HILLS 653Z-26B

\section{LEGEND}

$\therefore \because$ Sandstone

SS (cemented)

SS/SH laminae $<0.2^{\prime \prime}$

$E=$ Shale

Dolomite

60:3 Dolomite rubble

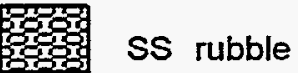

$\triangle$ No core

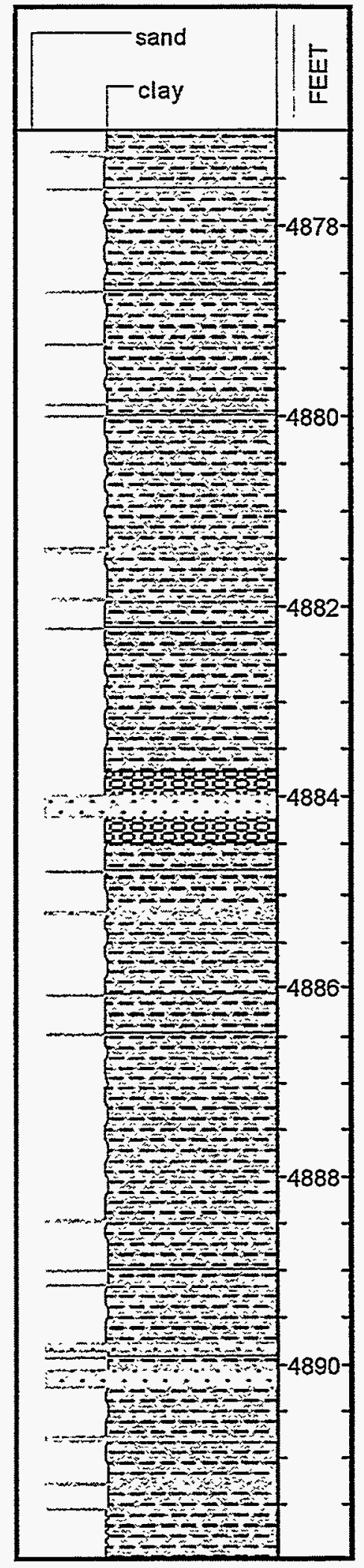

